UNIVERSIDADE DE SÃO PAULO

ESCOLA DE ENFERMAGEM

IRENE MARI PEREIRA

CARGA DE TRABALHO DOS PROFISSIONAIS DE SAÚDE: INSTRUMENTOS DE MEDIDA SEGUNDO A CLASSIFICAÇÃO DAS INTERVENÇÕES DE ENFERMAGEM

SÃO PAULO

2017 


\section{CARGA DE TRABALHO DOS PROFISSIONAIS DE SAÚDE: INSTRUMENTOS DE MEDIDA SEGUNDO A CLASSIFICAÇÃO DAS INTERVENÇÕES DE ENFERMAGEM}

Tese apresentada ao Programa de PósGraduação em Gerenciamento em Enfermagem da Escola de Enfermagem da Universidade de São Paulo para obtenção do título de Doutor em Ciências

Área de Concentração: Fundamentos e Práticas de Gerenciamento em Enfermagem e em Saúde

Orientadora:

Prof. ${ }^{a}$. Dra. Raquel Rapone Gaidzinski

Co-orientadora:

Prof. ${ }^{a}$ Dr. ${ }^{a}$ Heloísa Helena Ciqueto Peres

\section{VERSÃO CORRIGIDA}

A versão original encontra-se disponível na Biblioteca da Escola de Enfermagem da Universidade de São Paulo e na Biblioteca Digital de Teses e Dissertações da Universidade de São Paulo.

\section{SÃO PAULO}


AUTORIZO A REPRODUÇÃO E DIVULGAÇÃO TOTAL OU PARCIAL DESTE TRABALHO, POR QUALQUER MEIO CONVENCIONAL OU ELETRÔNICO, PARA FINS DE ESTUDO E PESQUISA, DESDE QUE CITADA A FONTE.

Assinatura:

Data:

\section{Pereira, Irene Mari}

Carga de trabalho dos profissionais de saúde: instrumentos de medida segundo a Classificação das Intervenções de Enfermagem/ Irene Mari Pereira. São Paulo, 2017. $207 \mathrm{p}$.

Tese (Doutorado) - Escola de Enfermagem da Universidade de São Paulo.

Orientadora: Prof. ${ }^{a}$ Dr. ${ }^{a}$ Raquel Rapone Gaidzinski

Área de concentração: Fundamentos e Práticas de Gerenciamento em Enfermagem e em Saúde

1. Administração de recursos humanos. 2. Carga de trabalho. 3. Intervenção da enfermagem. I. Título. 
Nome: Irene Mari Pereira

Título: Carga de trabalho dos profissionais de saúde: instrumentos de medida segundo a classificação das intervenções de enfermagem

Tese apresentada ao Programa de Pós-Graduação em Gerenciamento em Enfermagem da Escola de Enfermagem da Universidade de São Paulo para obtenção do título de Doutora em Ciências

Aprovado em:

\section{Banca Examinadora}

Orientador: Prof. Dr.

Instituição: Assinatura:

Prof. Dr.:

Instituição:

Julgamento: Assinatura:

Prof. Dr.: Instituição:

Julgamento: Assinatura:

Prof. Dr.: Instituição:

Julgamento: Assinatura:

Prof. Dr.: Instituição: Julgamento: Assinatura:

Prof. Dr.: Instituição: Julgamento: Assinatura: 


\section{AGRADECIMENTOS}

Agradeço imensamente a DEUS e a todos os meus amigos espirituais;

À Prof.a Raquel Rapone Gaidzinski, minha querida orientadora, por ser tão generosa, acolhedora, motivadora, carinhosa;

Às Prof.as Fernanda Maria Togeiro Fugulin e Heloísa Helena Ciqueto Peres pela amizade e sugestões;

$\mathcal{A}$ todos os colegas e amigos do Departamento ENO pelo incentivo, apoio, compreensão, ajuda e sugestões; Aos colegas e amigos do Hospital Universitário - USP;

Aos colegas do grupo de pesquisa pelas discussóes, apontamentos e estudos que realizaram;

Aos funcionários do serviço de Pós-Graduação pela dedicação delicadeza e prontidão no atendimento;

Aos funcionários do serviço da biblioteca e de reprografia pela atenção e dedicação;

Aos colegas que conheci nas disciplinas pela troca, apoio, ajuda e preocupação nessa trajetória;

Minha eterna gratidão. 
Pereira IM. Carga de trabalho dos profissionais de saúde: instrumentos de medida segundo a Classificação das Intervenções de Enfermagem [tese]. São Paulo: Escola de Enfermagem, Universidade de São Paulo; 2017.

\section{RESUMO}

Introdução: Conhecer e medir a carga de trabalho dos profissionais de saúde pode contribuir para a gestão eficiente e eficaz das organizações de saúde, a carga de trabalho excessiva é a principal causa de estresse e insatisfação. Objetivo: Levantar e analisar as dissertações e teses referentes à distribuição da carga de trabalho dos profissionais de saúde, fundamentadas na Classificação das Intervenções de Enfermagem, desenvolvidas por participantes do grupo de pesquisa "Gerenciamento de recursos humanos: conceitos, instrumentos e indicadores do processo de dimensionamento de pessoal", cadastrado no diretório do Conselho Nacional de Desenvolvimento Científico e Tecnológico (CNPq). Método: Estudo secundário tipo documental para identificar os instrumentos produzidos para medir a carga de trabalho, as intervenções/atividades realizadas, bem como a probabilidade de ocorrência e o percentual do tempo produtivo na jornada de trabalhadores profissionais de saúde. As fontes de dados foram dissertações e teses desenvolvidas pelos participantes do grupo de pesquisa disponíveis no banco de TESES-USP e DEDALUS. Resultados: Foram selecionados dezessete estudos nos quais foram construídos dezessete instrumentos de medida da carga de trabalho para profissionais de saúde sendo: $11,7 \%$ enfermeiros, $76,5 \%$ enfermeiros e técnicos/auxiliares de enfermagem, $5,9 \%$ assistente técnico administrativo e $5,9 \%$ nutricionista clínico. Os instrumentos foram aplicados nas unidades de alojamento conjunto, ambulatório de especialidades de oncologia e hematologia, centro cirúrgico de oncologia, centro de diagnóstico por imagem, clínica cirúrgica, clínica médica, emergência, serviço de nutrição, sala de recuperação pós-anestésica, unidade de internação pediátrica, unidades de terapias intensivas: adulto, pediátrica e neonatal; unidade de saúde da família. Os instrumentos apresentaram 192 intervenções de cuidado direto, 75 com frequência $\geq 1 \%$ e 80 intervenções de cuidado indireto, 39 com frequência $\geq 1 \%$. As intervenções com maior frequência, no conjunto das unidades, foram Documentação, Administração de medicamentos, Passagem de plantão. $\mathrm{O}$ tempo produtivo dos profissionais na jornada ficou distribuído entre intervenções de cuidado direto e indireto e atividades associadas ao trabalho. Conclusões: Os instrumentos elaborados e aplicados evidenciaram as intervenções/atividades essenciais em cada unidade estudada e por categoria profissional que mais contribuem na medida da carga de trabalho e no tempo produtivo, mostrando ser importante estratégia gerencial para reorganizar os processos de trabalho.

Palavras chave: Administração de Recursos Humanos, Recursos Humanos em Saúde, Carga de Trabalho - Instrumentos, Intervenções de Enfermagem. 
Pereira IM. Health professionals workload: measurement instruments according to the Nursing Interventions Classification [thesis]. São Paulo: USP Nursing School; 2017.

\section{ABSTRACT}

Introduction: Knowing and measuring the workload of health professionals can contribute to the efficient and effective management of health organizations; excessive workload is the main cause of stress and dissatisfaction. Objectives: Analyze the dissertations and theses related to the distribution of the workload of health professionals, based on the Classification of Nursing Interventions, developed by participants of the research group "Human resources management: concepts, instruments and indicators of the nursing staff process" registered in the directory of the National Council of Scientific and Technological Development (CNPq). Methods: Documentary study secondary type to identify the instruments produced to measure the workload, was performed, the interventions / activities performed, the interventions / activities performed, as well as the probability of occurrence and the percentage of productive time in the workday of health professionals. The data sources were dissertations and theses, developed by the research group participants available at the thesis base USP and DEDALUS. Results: Were selected seventeen studies were carried out in which 17 workload measurement instruments were constructed for health professionals: $11.7 \%$ nurses, $76.5 \%$ nurses and technicians/Nursing assistants, $5.9 \%$ administrative assistant and 5, 9\% clinical nutritionist. They were applied in pediatric areas, medical clinic, surgical clinic, emergency, rooming-in, surgical center, units of intensive therapies: adult, pediatric and neonatal, oncology and hematology outpatient clinic, diagnostic imaging center; family health unit and nutrition service. The instruments presented 192 direct care interventions, 75 with $\geq 1 \%$ frequency and 80 indirect care interventions, 39 with frequency $\geq 1 \%$. The most frequent interventions, in the units as a whole, were Documentation, Medication Administration, Shift work. The productive time of the professionals on the journey was distributed between direct and indirect care interventions and work-related activities. Conclusions: The instruments elaborated and applied showed the essential interventions / activities in each unit studied and by professional category that contribute the most to the work load and productive time, showing that it is an important managerial strategy to reorganize work processes.

Key Words: Human Resources Administration, Human Resources in Health, Workload- Instruments, Nursing Interventions. 


\section{LISTA DE FIGURAS}

Figura 1 - Fluxograma de seleção das teses e dissertações que trataram da construção de instrumentos de medida da carga de trabalho. São Paulo, 2017. ........................................................... 70

Figura 2 - Estudos concluídos que contemplaram os critérios de inclusão. São Paulo, 2017. 73

Figura 3 - Etapas para a construção dos instrumentos de medida da carga de trabalho dos profissionais de saúde. São Paulo,

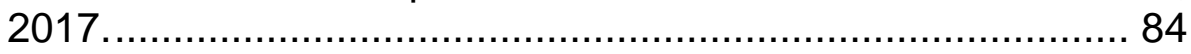

Figura 4 - Representação das categorias de análise do tempo produtivo dos profissionais de saúde, segundo o referencial das intervenções/atividades. São Paulo, 2017. 


\section{LISTA DE QUADROS}

Quadro 1 - Distribuição da produção de dissertações e teses do grupo de pesquisa Gerenciamento de recursos humanos: conceitos, instrumentos e indicadores do processo de dimensionamento de pessoal. São Paulo, 2017. 69

Quadro 2 - Identificação das dissertações e teses concluídas pelos integrantes do grupo de pesquisa gerenciamento de recursos humanos: conceitos, instrumentos e indicadores do processo de dimensionamento de pessoal. São Paulo 2017. 71

Quadro 3 - Identificação das dissertações e teses selecionadas que utilizaram a taxonomia NIC, segundo autor, nome do instrumento, tipo de unidade, tipo de serviço e número de unidades/serviços. São Paulo, 2017...................................... 74

Quadro 4 - Identificação dos estudos por tipo de unidade/serviço. São Paulo, 2017.............................................................. 77

Quadro 5 - Apresentação da estrutura dos instrumentos quanto à categorização de intervenções/atividades. São Paulo, 2017.. 78

Quadro 6 - Apresentação das intervenções presentes nos instrumentos, em domínios NIC. São Paulo, 2017. 80

Quadro 7 - Distribuição do número de amostras de observações dos profissionais de saúde, nas unidades estudadas. São Paulo, $2017 .$. 88

Quadro 8 - Intervenções de cuidado direto e indireto identificadas nos instrumentos dos estudos selecionados. São Paulo, 2017. 92

Quadro 9 - Demonstrativo das Intervenções de cuidado direto, com frequência $\geq 1 \%$, presentes nos instrumentos estudados. São Paulo, 2017. 98

Quadro 10 - Demonstrativo das Intervenções de cuidado indireto, com frequência $\geq 1 \%$, presentes nos instrumentos estudados. São Paulo, 2017. 103

Quadro 11 - Demonstrativo das intervenções presentes nos instrumentos estudados, com frequência $\geq 1 \%$, atualizadas segundo NIC, 2016. São Paulo, 2017. 107

Quadro 12 - Intervenções de cuidado direto com frequência $\geq 1 \%$ que foram observadas em três ou mais unidades por categoria profissional. São Paulo, 2017. 
Quadro 13 - Intervenções de cuidado direto com frequência $\geq 1 \%$ que foram observadas em duas unidades por categoria profissional. São Paulo, 2017... 125

Quadro 14 - Intervenções de Cuidado Direto com frequência $\geq 1 \%$ que foram observadas em uma unidade, por categoria profissional. São Paulo, 2017 128

Quadro 15 - Intervenções de cuidado indireto com frequência $\geq 1 \%$ que foram observadas em três ou mais unidades por categoria profissional. São Paulo, 2017. 135

Quadro 16-Intervenções de Cuidado Indireto com frequência $\geq 1 \%$ observadas em até duas unidades por categoria profissional. São Paulo, 2017. 151

Quadro 17 - Intervenções de Cuidado Indireto com frequência $\geq 1 \%$, observadas em uma unidade, por categoria profissional. São Paulo, 2017 152

Quadro 18 - Elenco das 43 intervenções mais frequentes no conjunto dos 16 estudos analisados. São Paulo, 2017 183 


\section{LISTA DE TABELAS}

Tabela 1 - Distribuição do total das intervenções, constantes nos instrumentos, nos domínios e classes, segundo o referencial da NIC. São Paulo, 2017............................................... 83

Tabela 2 - Distribuição das intervenções identificadas nos instrumentos, segundo frequência de observação. São Paulo, 2017 110

Tabela 3 - Distribuição das intervenções de cuidado direto que foram observados em uma unidade, com frequência $\geq 1 \%$ a $\leq 2 \%$, segundo categoria profissional. São Paulo, 2017

Tabela 4 - Distribuição das intervenções de cuidado direto que foram observados em uma unidade, com frequência $>2 \%$ a $\leq 10 \%$, segundo categoria profissional. São Paulo, 2017. 132 


\section{LISTA DE GRÁFICOS}

Gráfico 1 - Instrumentos construídos, segundo categoria profissional. São Paulo, 2017.............................................................. 76

Gráfico 2 - Produção dos instrumentos de medida da carga de trabalho, segundo a NIC, período de 2006 a 2016. São Paulo, 2017.... 77

Gráfico 3 - Distribuição das intervenções presentes nos instrumentos, em domínios NIC. São Paulo, 2017.

Gráfico 4 - Número de intervenções de cuidado direto e indireto presentes nos instrumentos, número de intervenções observadas com frequência $\geq 1 \%$ e menor que 1\%. São Paulo, 2017. 109

Gráfico 5 - Distribuição das intervenções de cuidado direto com frequência $\geq 1 \%$, segundo o número de unidades em que foram observadas. São Paulo, 2017. 111

Gráfico 6 - Demonstrativo da intervenção Administração de medicamentos, com frequência $\geq 1 \%$, nas unidades de saúde estudadas por categoria profissional. São Paulo, 2017 112

Gráfico 7 - Demonstrativo da intervenção Alimentação, com frequência $\geq$ $1 \%$, nas unidades de saúde estudadas por categoria profissional. São Paulo, 2017 113

Gráfico 8 - Demonstrativo da intervenção Assistência em exames, com frequência $\geq 1 \%$, nas unidades de saúde estudadas por categoria profissional. São Paulo, 2017.............................. 114

Gráfico 9 - Demonstrativo da intervenção Banho, com frequência $\geq 1 \%$, nas unidades de saúde estudadas por categoria profissional. São Paulo, 2017. 115

Gráfico 10 - Demonstrativo da intervenção Controle de dispositivos para acesso venoso, com frequência $\geq 1 \%$, nas unidades de saúde estudadas, por categoria profissional. São Paulo, 2017....... 116

Gráfico 11 -Demonstrativo da intervenção Punção endovenosa, com frequência $\geq 1 \%$, com frequência $\geq 1 \%$, nas unidades de saúde estudadas, por categoria profissional. São Paulo, 2017....... 117

Gráfico 12 - Demonstrativo da intervenção Controle de imunização/vacina, com frequência $\geq 1 \%$, nas unidades de saúde estudadas, por categoria profissional. São Paulo, 2017. 118 
Gráfico 13 - Demonstrativo da intervenção Controle do ambiente: conforto, com frequência $\geq 1 \%$, nas unidades de saúde estudadas, por categoria profissional. São Paulo, 2017....... 119

Gráfico 14 - Demonstrativo da intervenção Cuidados na admissão, com frequência $\geq 1 \%$, nas unidades de saúde estudadas, por categoria profissional. São Paulo, 2017 119

Gráfico 15 - Demonstrativo da intervenção Ensino: processo de doença, com frequência $\geq 1 \%$, nas unidades de saúde estudadas, por categoria profissional. São Paulo, 2017 120

Gráfico 16 - Demonstrativo da intervenção Plano de alta, com frequência $\geq$ $1 \%$, nas unidades de saúde estudadas, por categoria profissional. São Paulo, 2017 120

Gráfico 17 - Demonstrativo da intervenção Escuta ativa, com frequência $\geq$ $1 \%$, nas unidades de saúde estudadas, por categoria profissional. São Paulo, 2017. 121

Gráfico 18 - Demonstrativo da intervenção Monitoração de sinais vitais, com frequência $\geq 1 \%$, nas unidades de saúde estudadas, por categoria profissional. São Paulo, 2017. 122

Gráfico 19 - Demonstrativo da intervenção Supervisão, com frequência $\geq$ $1 \%$, nas unidades de saúde estudadas, por categoria profissional. São Paulo, 2017. 123

Gráfico 20 - Demonstrativo da intervenção Transporte: intra-hospitalar, com frequência $\geq 1 \%$, nas unidades de saúde estudadas, por categoria profissional. São Paulo, 2017. 124

Gráfico 21 - Demonstrativo das Intervenções de Cuidado Direto observadas em até duas unidades com frequência $\geq 1 \% a \leq 2 \%$, por categoria profissional. São Paulo, 2017. 126

Gráfico 22 - Demonstrativo das Intervenções de Cuidado Direto observadas em até duas unidades com frequência $>2 \%$, por categoria profissional. São Paulo, 2017. 127

Gráfico 23 - Demonstrativo das Intervenções de Cuidado Direto com frequência > 10, observadas em uma unidade de saúde, segundo categoria profissional. São Paulo,2017.................. 133

Gráfico 24 - Distribuição das Intervenções de cuidado indireto com frequência $\geq 1 \%$ nas unidades observadas. São Paulo, 2017 134

Gráfico 25 - Demonstrativo da intervenção Apoio ao médico, com frequência $\geq 1 \%$, nas unidades de saúde estudadas, por categoria profissional. São Paulo, 2017. 136 
Gráfico 26 - Demonstrativo da intervenção Controle de infecção, com frequência $\geq 1 \%$, nas unidades de saúde estudadas, por categoria profissional. São Paulo, 2017.

Gráfico 27 - Demonstrativo da intervenção Proteção contra infecção, com frequência $\geq 1 \%$, nas unidades de saúde estudadas, por categoria profissional. São Paulo, 2017 137

Gráfico 28 - Demonstrativo da intervenção Controle de suprimentos, com frequência $\geq 1 \%$, nas unidades de saúde estudadas, por categoria profissional. São Paulo, 2017 138

Gráfico 29 - Demonstrativo da intervenção Controle do ambiente, nas unidades de saúde estudadas, por categoria profissional. São Paulo, 2017 139

Gráfico 30 - Demonstrativo da intervenção Delegação, com frequência $\geq 1 \%$, nas unidades de saúde estudadas, por categoria profissional. São Paulo, 2017. 140

Gráfico 31 - Demonstrativo da intervenção Desenvolvimento de funcionários, com frequência $\geq 1 \%$, nas unidades de saúde estudadas, por categoria profissional. São Paulo, 2017. 141

Gráfico 32 - Demonstrativo da intervenção Documentação, com frequência $\geq 1 \%$, nas unidades de saúde estudadas, por categoria profissional. São Paulo, 2017. 142

Gráfico 33 - Demonstrativo da intervenção Gerenciamento de caso, com frequência $\geq 1 \%$, nas unidades de saúde estudadas, por categoria profissional. São Paulo, 2017 143

Gráfico 34 - Demonstrativo da intervenção Interpretação de dados laboratoriais, com frequência $\geq 1 \%$, nas unidades de saúde estudadas, por categoria profissional. São Paulo, 2017....... 144

Gráfico 35 - Demonstrativo da intervenção Passagem de plantão, com frequência $\geq 1 \%$, nas unidades de saúde estudadas, por categoria profissional. São Paulo, 2017 145

Gráfico 36 - Demonstrativo da intervenção Preceptor: estudante, com frequência $\geq 1 \%$, nas unidades de saúde estudadas, por categoria profissional. São Paulo, 2017 146

Gráfico 37 - Demonstrativo da intervenção Reunião para avaliação dos cuidados multidisciplinares, com frequência $\geq 1 \%$, nas unidades de saúde estudadas, por categoria profissional. São Paulo, 2017 147 
Gráfico 38 - Demonstrativo da intervenção Supervisão de funcionários, com frequência $\geq 1 \%$, nas unidades de saúde estudadas, por categoria profissional. São Paulo, 2017.

Gráfico 39 - Demonstrativo da intervenção Transcrição de prescrições, com frequência $\geq 1 \%$, nas unidades de saúde estudadas, por categoria profissional. São Paulo, 2017. 149

Gráfico 40 - Demonstrativo da intervenção Troca de informação sobre cuidados de saúde, com frequência $\geq 1 \%$, nas unidades de saúde estudadas, por categoria profissional. São Paulo, 2017. 150

Gráfico 41 - Demonstrativo das Intervenções de Cuidado Indireto com frequência $\geq 1 \%$ observadas em até duas unidades por categoria profissional. São Paulo, 2017. 151

Gráfico 42 - Demonstrativo das Intervenções de Cuidado Indireto com frequência $\geq 1 \%$, observadas em uma unidade por categoria profissional. São Paulo, 2017. 153

Gráfico 43 - Distribuição percentual de tempo produtivo dos enfermeiros nas unidades de saúde estudadas. São Paulo, 2017. 155

Gráfico 44 - Produtividade (\%) dos téc./aux. de enfermagem nas unidades de saúde estudas. São Paulo, 2017. 156

Gráfico 45 - Produtividade dos nutricionistas nos três hospitais estudados. São Paulo, 2017. 157

Gráfico 46 - Produtividade dos ATA em unidade de saúde da família. São Paulo, 2017. 157

Gráfico 47 - Produtividade dos profissionais de saúde das unidades de emergência, clínica médico-cirúrgica, clínica médica, clínica cirúrgica e UTIP. São Paulo, 2017 159

Gráfico 48 - Produtividade dos profissionais de saúde das unidades de pediatria, UTIP-NEO e AC. São Paulo, 2017. 160

Gráfico 49 - Produtividade dos profissionais de saúde das unidades de SRPA e CCO. São Paulo, 2017. 160

Gráfico 50 - Produtividade dos profissionais de saúde das unidades de CDI e AEOH. São Paulo, 2017. 161

Gráfico 51 - Produtividade dos profissionais de saúde das USF. São Paulo, 2017. 161 
Gráfico 52 - Distribuição das cinco intervenções mais frequentes observadas, realizadas por enfermeiros na unidade de AC. São Paulo, 2017. 163

Gráfico 53 - Distribuição das cinco intervenções mais frequentes observadas, realizadas por téc./aux. de enfermagem na unidade de AC. São Paulo, 2017. 163

Gráfico 54 - Distribuição das cinco intervenções mais frequentes observadas, realizadas por enfermeiros nas PED1 e PED2. São Paulo, 2017. 164

Gráfico 55 - Distribuição das cinco intervenções mais frequentes observadas, realizadas por téc./aux. de enfermagem nas PED1 e PED 2. São Paulo, 2017. 165

Gráfico 56 - Distribuição das cinco intervenções mais frequentes observadas, realizadas por enfermeiros na UTIP-NEO São Paulo, 2017 166

Gráfico 57 - Distribuição das cinco intervenções mais frequentes observadas, realizadas por téc./aux. de enfermagem na UTIPNEO. São Paulo, 2017. 166

Gráfico 58 - Distribuição das cinco intervenções mais frequentes observadas, realizadas por enfermeiros na CC. São Paulo, 2017. 167

Gráfico 59 - Distribuição das cinco intervenções mais frequentes observadas, realizadas por téc./aux. de enfermagem na CC. São Paulo, 2017. 168

Gráfico 60 - Distribuição das cinco intervenções mais frequentes observadas, realizadas por enfermeiros na CM. São Paulo, 2017 169

Gráfico 61 - Distribuição das cinco intervenções mais frequentes observadas, realizadas por técnico/auxiliar de enfermagem na CM. São Paulo, 2017. 169

Gráfico 62 - Distribuição das cinco intervenções mais frequentes observadas, realizadas por enfermeiros na CM-CC. São Paulo, 2017 170

Gráfico 63 - Distribuição das cinco intervenções mais frequentes observadas, realizadas por enfermeiros na EMER. São Paulo, 2017 171

Gráfico 64 - Distribuição das cinco intervenções mais frequentes observadas, realizadas por enfermeiros na UTI-A. São Paulo, 2017 172 
Gráfico 65 - Distribuição das cinco intervenções mais frequentes observadas, realizadas por téc./aux.de enfermagem na UTI-A. São Paulo, 2017.

Gráfico 66 - Distribuição das cinco intervenções mais frequentes observadas, realizadas por enfermeiros no CCO. São Paulo, 2017 173

Gráfico 67 - Distribuição das cinco intervenções mais frequentes observadas, realizadas por téc./aux.de enfermagem no CCO. São Paulo, 2017.

Gráfico 68 - Distribuição das cinco intervenções mais frequentes observadas, realizadas por enfermeiros na SRPA. São Paulo, 2017 175

Gráfico 69 - Distribuição das cinco intervenções mais frequentes observadas, realizadas por téc./aux.de enfermagem na SRPA. São Paulo, 2017. 175

Gráfico 70 - Distribuição das cinco intervenções mais frequentes observadas, realizadas por enfermeiros no AEOH. São Paulo, 2017 176

Gráfico 71 - Distribuição das cinco intervenções mais frequentes observadas, realizadas por téc./aux. de enfermagem no AEOH. São Paulo, 2017. 177

Gráfico 72 - Distribuição das cinco intervenções mais frequentes observadas, realizadas por enfermeiros no CDI. São Paulo, 2017. 178

Gráfico 73 - Distribuição das cinco intervenções mais frequentes observadas, realizadas por téc./aux. de enfermagem no CDI. São Paulo, 2017. 178

Gráfico 74 - Distribuição das cinco intervenções mais frequentes observadas, realizadas por enfermeiros na USF. São Paulo, 2017 179

Gráfico 75 - Distribuição das cinco intervenções mais frequentes observadas, realizadas por téc./aux. de enfermagem na USF. São Paulo, 2017. 180

Gráfico 76 - Distribuição das cinco intervenções mais frequentes observadas, realizadas pelo ATA na USF. São Paulo, 2017.181

Gráfico 77 - Distribuição das cinco intervenções mais frequentes observadas, realizadas por nutricionistas clínicos nas unidades hospitalares. São Paulo, 2017. 182 


\section{LISTA DE ABREVIATURAS E SIGLAS}

AC

$\mathrm{AEOH}$

ATA

CC

$\mathrm{CCO}$

CDI

$\mathrm{CM}$

$\mathrm{CM}-\mathrm{CC}$

$\mathrm{CNPq}$

DEDALUS

EMER

GP

NIC

PED

PPGEn

SN

SRPA

TESES-USP

UBS

USF

UTI-A

UTIP-NEO
Alojamento Conjunto

Ambulatório de Especialidades Oncologia e Hematologia

Assistente Técnico Administrativo

Clínica Cirúrgica

Centro Cirúrgico de Oncologia

Centro de Diagnóstico por Imagem

Clínica Médica

Clínica Médica e Clínica Cirúrgica

Conselho Nacional de Desenvolvimento Científico e Tecnológico

Catálogo coletivo das Bibliotecas da USP

Emergência

Grupo de Pesquisa

Classificação das Intervenções de Enfermagem; Nursing Interventions Classification

Unidade de Internação Pediátrica

Programa de Pós-Graduação em Gerenciamento de Enfermagem

Serviço de Nutrição

Sala de Recuperação Pós-Anestésica

Biblioteca digital de teses e dissertações da USP

Unidade Básica de Saúde

Unidade de Saúde da Família

Unidade de Terapia Intensiva Adulto

Unidade de Terapia Intensiva Pediátrica e Neonatal 


\section{SUMÁRIO}

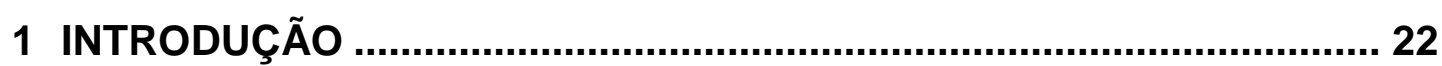

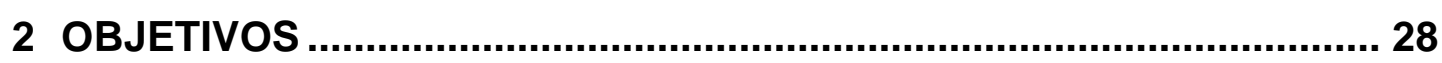

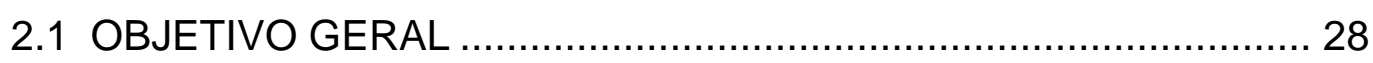

2.2 OBJETIVOS ESPECÍ́FICOS .................................................... 28

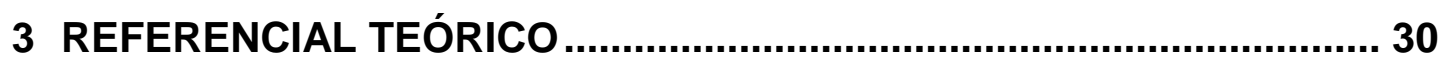

3.1 IMPORTÂNCIA DOS INSTRUMENTOS PARA A GESTÃO ............ 30

3.2 INSTRUMENTOS NO PROCESSO DE TRABALHO ....................... 31

3.3 CARGA DE TRABALHO: FUNDAMENTAL PARA O DIMENSIONAMENTO DE PROFISSIONAIS DE SAÚDE............... 35

3.4 INSTRUMENTOS PARA MEDIR A CARGA DE TRABALHO .......... 41

3.5 A IMPORTÂNCIA DA CONSTRUÇÃO DE INSTRUMENTOS PARA SUBSIDIAR O DIMENSIONAMENTO DE PESSOAL ........... 54

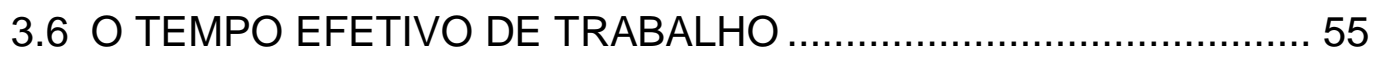

3.7 MÉTODOS DE ESTUDO DE TEMPO E MOVIMENTO ................... 57

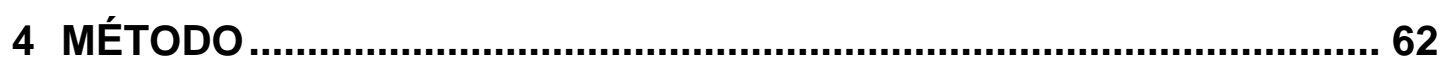

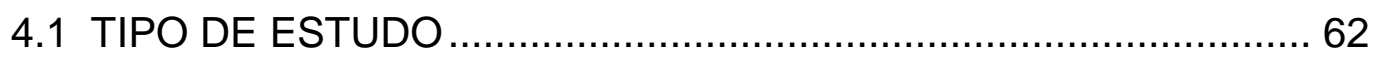

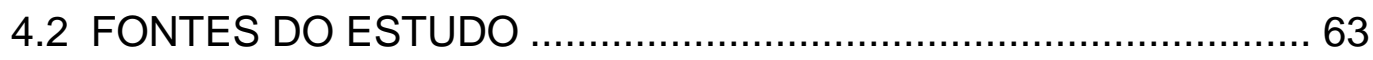

4.3 PROCEDIMENTOS METOdOLÓGICOS........................................ 64

4.3.1 Levantamento das dissertações e teses.............................. 64

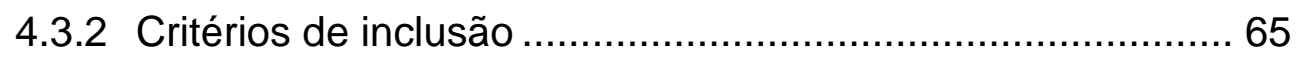

4.3.3 Definição das informações a serem extraídas dos estudos 66

4.3.4 Tratamento, análise e interpretação dos dados encontrados

4.3.5 Apresentação e discussão dos resultados 
5.1 APRESENTAÇÃO DOS ESTUDOS SELECIONADOS.

5.2 IDENTIFICAÇÃO E APRESENTAÇÃO DOS INSTRUMENTOS

DE MEDIDA DE CARGA DE TRABALHO

5.3 MÉTODO PARA A CONSTRUÇÃO DOS INSTRUMENTOS DE MEDIDA DE CARGA DE TRABALHO

5.3.1 Identificação das atividades realizadas pelos profissionais de saúde....

5.3.2 Mapeamento das atividades identificadas em intervenções

5.3.3 Validação das atividades em intervenções. 86

5.3.4 Mensuração do tempo despendido nas intervenções/atividades

5.3.5 Amostras do número de observações dos profissionais de saúde

5.4 INTERVENÇÕES DE CUIDADO DIRETO E CUIDADO INDIRETO

5.5 IDENTIFICAÇÃO DAS INTERVENÇÕES QUE CONTRIBUEM COM A CARGA DE TRABALHO COM FREQUÊNCIA $\geq 1 \%$

5.6 INTERVENÇÕES DE CUIDADO DIRETO E INDIRETO QUE CONTRIBUEM PARA A CARGA DE TRABALHO DOS PROFISSIONAIS DE SAÚDE

5.6.1 Intervenções de Cuidado Direto

5.6.2 Intervenções de Cuidado Indireto

5.7 TEMPO PRODUTIVO DOS PROFISSIONAIS DE SAÚDE

5.8 AS CINCO INTERVENÇÕES MAIS FREQUENTES OBSERVADAS NAS UNIDADES.

6 CONCLUSÕES

REFERÊNCIAS 


\section{INTRODUÇÃO}

As últimas décadas foram marcadas por importantes transformações no sistema de saúde de muitos países, evidenciando o processo de reforma na estrutura dos sistemas de serviços de saúde o qual acomete a prestação dos serviços, 0 financiamento e as atribuições do Estado (Nogueira, Santana, 2000; Rigoli, Rocha, Foster, 2006; Atun et al., 2014).

O ambiente de trabalho em saúde também mudou consideravelmente e tornouse mais complexo, desafiador e estressante diante da reestruturação dos serviços, das medidas de contenção de custos que afetam o quadro de pessoal e do aumento da expectativa de atendimento dos usuários (Duffield, Roche, Merrick; 2006).

No Brasil, este processo de reforma teve início com iniciativas de reformular o sistema de saúde, amparado pela Constituição Federal de 1988 que garante o direto à saúde de todos os indivíduos em território nacional nos seus artigos 196 a 200 e no decreto da Lei Federal $n^{\circ} .8 .080$ de 1990, que dispõe sobre as condições para a promoção, proteção e recuperação da saúde, a organização e o funcionamento dos serviços de saúde que constituem o Sistema Único de Saúde (SUS) (Brasil, 1988, 1990; Nogueira, Santana, 2000).

O processo de consolidação do SUS necessitou de propostas e estratégias de viabilização das políticas de recursos humanos para garantir ações e serviços que definem a qualidade, efetividade, oportunidade e acesso da população aos serviços de saúde (Seixas, 2002).

Esse processo de reforma apresentou novo estilo de administração pública com necessidade de diminuir o tamanho do aparato de Estado e o combate à burocracia (Nogueira, Santana, 2000).

Sem a transformação do comportamento e aprimoramento das competências dos trabalhadores de saúde não seria possível gerar os resultados esperados com as reformas ocorridas no sistema de serviços de saúde (Rigoli, Rocha, Foster, 2006).

A discussão sobre um novo paradigma do trabalho nas sociedades pósindustriais, com reestruturação produtiva, recoloca a centralidade do trabalhador no processo produtivo, ampliando a discussão sobre a gestão do trabalho, sobre os processos de planejamento e qualificação do trabalho e do trabalhador, colocando assim nova agenda para os gestores da saúde (Brasil, 2006). 
Sendo então necessário que as políticas de recursos humanos representem ações e procedimentos definidos que estejam relacionadas com a produção e distribuição no que tange a formação e preparação para o trabalho e a regulação relacionada à gestão do trabalho (Seixas, 2002).

As bases legais que legitimam essas ações estão expressas no artigo 200, inciso III da Constituição Federal que estabelece, como uma das atribuições do SUS, a ordenação da formação de recursos humanos; a articulação entre as esferas de governo para formalizar a execução da política de recursos humanos, por sua vez, está expressa na Lei n ${ }^{8080 / 90 ~(S e i x a s, ~ 2002) . ~}$

Há compreensão de que é preciso adequar a força de trabalho às necessidades de saúde da população, porém ainda é uma ação complexa, pois é necessário considerar a diversidade dos serviços e a singularidade das ações a serem desenvolvidas (Mandelli, Rigoli; 2015).

A gestão dos recursos humanos em saúde é considerada uma área estratégica e fundamental para aprimorar a gestão em saúde, pois interfere na qualidade dos serviços prestados e no grau de satisfação dos usuários, além de envolver as dimensões relacionadas à composição e distribuição da força de trabalho, formação e qualificação profissional, mercado de trabalho, organização do trabalho, regulação do exercício profissional, relações de trabalho e a clássica administração de pessoal (Nogueira, 2002; Vieira, 2008). Esse cenário apresenta uma rede com dimensões complexas de atuação para o gestor.

As atribuições dos gestores passaram a ser mais complexas, pois foram incorporadas as ações ligadas às políticas de formação, desenvolvimento, planejamento e gestão da força de trabalho com foco nas diretrizes de regulação da mobilidade profissional, valorização da força de trabalho, geração de satisfação com o trabalho, compreensão do processo de trabalho, implementação da educação permanente e do processo de avaliação de desempenho (Vieira, 2008).

Nesse contexto, os gestores dos serviços de saúde encontram inúmeros desafios a serem superados para atingir a gestão adequada dos recursos humanos na saúde; dentre eles, está em distribuir adequadamente o número de trabalhadores para proporcionar a prestação de serviços de forma adequada, garantir a qualidade e o desempenho das equipes (Pierantoni, Varella, França, 2004).

Diante da necessidade de serem desenvolvidas metodologias para determinar parâmetros para estimar o quadro de pessoal, a Organização Mundial da Saúde 
(OMS) produziu e vem aprimorando o método denominado Workload Indicators Staffing Need (WISN) (Indicadores de Carga de Trabalho para Necessidades de Pessoal) (Ozcan, Hornby, 1999) que utiliza as cargas de trabalho observadas nos serviços de saúde para definir as necessidades de pessoal por meio do levantamento das atividades desenvolvidas, considerando a complexidade dos cuidados prestados (Shipp, 1998; WHO, 2010).

Os recursos humanos dos serviços de saúde são constituídos por categorias profissionais, das quais boa parcela pertence à equipe de enfermagem, cujas ações estão relacionadas com a organização do trabalho, a assistência à saúde, o ensino e a pesquisa (Pereira, 2011).

O Conselho Federal de Enfermagem (Cofen), em parceria com a Fundação Osvaldo Cruz (Fiocruz), realizou uma pesquisa sobre o perfil da enfermagem que apresentou o diagnóstico detalhado da situação dos enfermeiros, técnicos e auxiliares de enfermagem no Brasil. Esta pesquisa mostrou que a enfermagem é a maior categoria profissional no campo da saúde, pois está presente em todos os municípios e diretamente inserida no SUS, com campos de atuação bastante amplos nos setores público, privado, filantrópico e de ensino (Cofen, 2016).

A distribuição de recursos humanos para o serviço de enfermagem tem sido questão preocupante para os enfermeiros que ocupam cargos de gerência de enfermagem e para os administradores dos serviços de saúde. A alocação desses recursos interfere diretamente na eficácia, na qualidade e no custo da assistência à saúde (Gaidzinski, 1998; Fugulin, Gaidzinski, Lima, 2016).

Os gerentes de enfermagem declaram que a inadequação de recursos materiais, físicos e humanos pode gerar diversidade de processos de desgastes no trabalhador que podem prejudicar a capacidade laboral de forma temporária ou permanente (Baptista, 2014).

Ao enfermeiro cabe o papel de coordenar a equipe de enfermagem e, quando gerente da unidade de saúde, coordenar a equipe de saúde do serviço. Para o sucesso do seu trabalho necessita trabalhar em equipe, supervisionar as atividades realizadas, diagnosticar a situação do serviço, conhecer as atividades desenvolvidas pela enfermagem e implantar o planejamento da assistência de enfermagem (Pereira, 2011).

A previsão do quantitativo de pessoal de enfermagem é um processo que depende do conhecimento da carga de trabalho existente. A operacionalização do 
processo de dimensionamento de pessoal de enfermagem requer a aplicação de um método capaz de sistematizar o inter-relacionamento e a mensuração das variáveis que interferem na carga de trabalho da equipe de enfermagem, que, por sua vez, depende das necessidades de cuidados dos usuários e do padrão de assistência pretendido (Gaidzinski, 1998).

Para Gaidzinski (1998), o método de dimensionamento de pessoal de enfermagem é a aplicação de um processo sistemático para determinar o número e a categoria profissional requerida para prover os cuidados de enfermagem, que garantam a qualidade, previamente estabelecida, a um grupo de pacientes. Fugulin, Gaidzinski, Lima (2016) definem o dimensionamento de pessoal de enfermagem como:

Processo sistemático que fundamenta o planejamento e avaliação do quantitativo e qualitativo de pessoal, necessário para prover a assistência, de acordo com a singularidade dos serviços de saúde, que garantam a segurança dos usuários/cliente e dos profissionais.

Para a realização dos cuidados de enfermagem com segurança, qualidade, eficácia e eficiência são necessários o planejamento quantitativo e qualitativo dos profissionais de enfermagem, fundamentado em um método de dimensionamento de pessoal de enfermagem (Fugulin, Gaidzinski, Lima 2016).

A concepção e a produção deste conhecimento têm contribuído para aplicação do método no cotidiano das atividades gerenciais dos enfermeiros, porém, apesar da geração e da evolução do método, ainda não é efetiva sua aplicação na prática para dimensionar outras categorias dos profissionais de saúde dos serviços de saúde.

O Cofen tem intensificado as discussões, proporcionado capacitações dos trabalhadores e fiscalizando os serviços de enfermagem para que sejam realizados o dimensionamento e a distribuição adequada dos profissionais de enfermagem, porém os demais conselhos que integram o campo da saúde ainda têm medidas incipientes para resolver a questão.

A aplicação do método Gaidzinski (1998) gerou análises de cenários, principalmente em unidades hospitalares de clínica médica, clínica cirúrgica, unidade de terapia intensiva adulto, unidade de terapia intensiva pediátrica e neonatal, unidade neonatal, alojamento conjunto, ambulatório de oncologia, centro cirúrgico, pronto socorro, centro de diagnóstico por imagem, unidades de atenção primária à saúde e serviço de nutrição. Esta análise possibilitou a construção de instrumentos para medir 
o tempo das intervenções/atividades despendido no cuidado, calcular a carga de trabalho a ser utilizado como instrumento gerencial pelos enfermeiros e gestores de serviços de saúde.

Em síntese, os instrumentos de medida de carga de trabalho têm a finalidade de:

$\checkmark \quad$ Identificar o elenco das intervenções/atividades necessárias para 0 atendimento das necessidades de cuidado dos usuários, familiares e comunidade nas unidades de saúde;

$\checkmark$ Possibilitar, pela observação direta e sistematizada, a mensuração da probabilidade de ocorrência e do tempo médio das intervenções/atividades despendido pela equipe de enfermagem e de saúde em sua jornada de trabalho;

$\checkmark \quad$ Calcular a carga média de trabalho de uma unidade;

$\checkmark \quad$ Estabelecer parâmetros específicos para planejar e avaliar o quadro de profissionais necessários para garantir a qualidade da assistência prestada e a saúde dos profissionais;

$\checkmark \quad$ Compreender e analisar as práticas de saúde.

Considerando a quantidade de instrumentos gerados e a importância de estudar a distribuição dos tempos efetivos de trabalho, variável fundamental para medir a carga de trabalho, este estudo teve como questões:

1) Quais instrumentos, fundamentados na Classificação das Intervenções de Enfermagem - NIC - foram construídos para realizar a medida do tempo de trabalho para os profissionais de enfermagem e de saúde?

2) Quais as intervenções que mais despendem o tempo dos profissionais de enfermagem e de saúde nas diferentes unidades?

3) Quais as intervenções que caracterizam o trabalho dos profissionais de enfermagem e de saúde em cada tipo de unidade?

4) Existe a possibilidade de elaborar um instrumento único que possibilite apreender o trabalho dos profissionais de enfermagem e de saúde em diferentes unidades, a partir da análise das convergências dos diferentes instrumentos de medida de carga de trabalho desenvolvidos? 
2 OBJETIVOS 


\section{OBJETIVOS}

\subsection{OBJETIVO GERAL}

Analisar as dissertações e teses referentes à distribuição da carga de trabalho dos profissionais de saúde, fundamentadas na Classificação das Intervenções de Enfermagem, desenvolvidas por participantes do grupo de pesquisa "Gerenciamento de recursos humanos: conceitos, instrumentos e indicadores do processo de dimensionamento de pessoal", cadastrado no diretório do Conselho Nacional de Desenvolvimento Científico e Tecnológico (CNPq).

\subsection{OBJETIVOS ESPECÍFICOS}

Em cada estudo selecionado nesta investigação:

1- Identificar a estrutura dos instrumentos de medida de carga de trabalho desenvolvidos;

2- Verificar as técnicas para obtenção do tempo de trabalho;

3- Levantar a distribuição do tempo durante a jornada de trabalho em: intervenções de cuidado direto e indireto, atividades associadas e pessoais;

4- Reconhecer as intervenções diretas e indiretas que mais contribuem para carga de trabalho;

5- Analisar e comparar as frequências de uma mesma intervenção de cuidado, que ocorrem nos diferentes cenários de assistência;

6- Analisar o tempo de trabalho produtivo dos profissionais. 


\section{REFERENCIAL TEÓRICO}




\section{REFERENCIAL TEÓRICO}

\subsection{IMPORTÂNCIA DOS INSTRUMENTOS PARA A GESTÃO}

As políticas e as práticas relacionadas à gestão de pessoas, na realidade brasileira, têm sido apenas um conjunto de normas burocráticas que visam controlar o gestor e suas ações (Dutra, 2012, p. 18).

Essa visão tem causado distorções na análise e interpretação da realidade organizacional, gerando instrumentos, processos e metodologias inadequadas para a gestão de pessoas, de difícil compreensão e utilização pelos gestores e pelos próprios profissionais especializados (Dutra, 2012, p.19).

Diante dessa dinâmica complexa, o setor saúde é um expressivo espaço de inovação e de concentração de capital, que origina condições para novas oportunidades de investimento, renda e emprego e representa um impacto no setor de serviços, pois imprime mudanças nas práticas assistenciais o que gera tensões entre a lógica da indústria, dos serviços de saúde e dos usuários (Gadelha, 2003).

A busca da qualidade do trabalho realizado nos serviços de saúde tornou-se incontestável e exigência da sociedade, o que torna fundamental a criação de normas e mecanismos de avaliação e controle da qualidade assistencial (Brasil, 2007).

O modelo de gestão dos serviços de saúde e a forma de organizar a produção de bens estão em transformações e necessitam desenvolver metas alternativas de desempenho com vistas à produção, qualidade, custos e compromisso com a demanda de necessidades de saúde da população (Gadelha, 2003).

Os gestores dos serviços de saúde têm realizado ações com o objetivo de aperfeiçoar o desenvolvimento das atividades dos trabalhadores, assegurar a prestação de serviço de qualidade, reduzir custos e garantir a acessibilidade e a satisfação dos usuários.

Nessa lógica, os serviços de saúde necessitam encontrar métodos e utilizar instrumentos adequados e eficazes para gerenciar a dinâmica do trabalho que é determinada pela complexidade dos serviços prestados e pelas 
necessidades dos usuários com a intenção de maior produtividade e racionalização do trabalho (Leopardi, 1999, p.77).

"Os instrumentos são recursos empregados para se alcançar um objetivo ou conseguir um resultado" (Cianciarullo, 1996 p.1).

Segundo Marx (1994, p.202), o instrumento é:

"Um dos elementos do processo de trabalho; é uma coisa ou um complexo de coisas que o trabalhador insere entre si mesmo e o objeto de trabalho e lhe serve para dirigir sua atividade sobre esse objeto; serve para medir o desenvolvimento da força humana de trabalho; indica as condições sociais que possibilite a realização do trabalho".

\subsection{INSTRUMENTOS NO PROCESSO DE TRABALHO}

No contexto da organização do trabalho em saúde, "os instrumentos são aqueles capazes de aplicar na prática a teoria, ou seja, os instrumentos são criados de acordo com a necessidade de realizarem na prática a transformação, para isto, utilizam as áreas de conhecimentos terapêuticos, farmacológicos e técnicos" (Gonçalves, 1992, p.36).

A busca de instrumentos adequados para a realização do trabalho na saúde começa com a compreensão da necessidade que mobiliza e gera um processo de trabalho, de modo que seja realizado aquilo que possa satisfazer tal necessidade (Leopardi,1999, p.73).

Os produtos materiais e os saberes, colocados no sistema produtivo e nos serviços de saúde, são originários de pesquisa científica e da reflexão teórica, que são entendidos como objetivação da própria ciência, transformada em tecnologias, que ao serem incorporadas, irão desencadear novos processos de trabalho (Leopardi, 1999, p.73).

O conhecimento é um poderoso instrumento utilizado pelo trabalhador, pois demonstra o seu empenho e capacitação para a execução de atividades necessárias (Merhy, 1997; Leopardi, 1999, p.71).

O conhecimento não tem existência por si só, é necessário aplicá-lo em algo concreto, na forma de estratégia de trabalho ou na operacionalização de 
uma técnica, aplicados na forma de instrumentos que serão inseridos como elementos fundamentais da prática (Leopardi, 1999, p.73).

Nas instituições de saúde, o processo de trabalho é executado pelos trabalhadores de saúde que utilizam instrumentos para a realização de procedimentos com os indivíduos, para procedimentos administrativos que organizam o espaço e os trabalhadores e para procedimentos informacionais que permitem articulações entre as diferentes parcelas do trabalho com os indivíduos (Leopardi, 1999, p.74).

Castelhanos et al. (1989) apresentaram alguns instrumentos de trabalho utilizados para a ação de cuidar: a observação, o levantamento de dados, o planejamento, a evolução, a avaliação dos pacientes, os sistemas de assistência, os procedimentos técnicos e de comunicação e interação entre pacientes e enfermagem e entre os diversos profissionais.

Para a ação administrar, Castelhanos et al. (1989) apontam que são utilizados os instrumentos modelos e métodos de administração, normas e rotinas, a força de trabalho em enfermagem e os equipamentos e materiais permanentes.

Historicamente, o trabalho da enfermagem tem envolvido dois campos de atividades: a dos cuidados diretos e procedimentos assistenciais, e o da administração da assistência de enfermagem e do espaço assistencial (Leopardi, 1999, p.39).

Ao analisar os processos de trabalho na saúde, em realidades concretas, podem-se apreender as contradições e a dinâmica da prática e contribuir com estratégias de mudança da realidade (Almeida, Rocha, 1997).

Leopardi (1999, p.80) descreve três tipos de instrumentos: os instrumentos materiais (camas especiais, medicamentos, equipamentos, termômetros, seringas, bisturis) que constituem em elementos de precisão e rapidez na realização do cuidado; os instrumentos metodológicos (abordagens interativas, organização da tarefa, método de avaliação clínica) que promovem uma forma de realizar o trabalho; e os instrumentos locais (hospital, posto de saúde, ambulatório, centro cirúrgico) que implicam em uma finalidade e em uma dada organização do processo de trabalho. 
Já para Felli, Peduzzi (2016 p.24), o processo de trabalho do enfermeiro é constituído de duas perspectivas: a assistencial e a gerencial. Para o trabalho assistencial, o objeto é a necessidade de cuidado de enfermagem em que é utilizada a Sistematização da Assistência de Enfermagem como instrumento que qualifica o cuidado. Para o trabalho gerencial, os objetos são a organização do trabalho e os recursos humanos de enfermagem e, para realizar este trabalho, são utilizados os instrumentos de planejamento, dimensionamento de pessoal, o recrutamento e a seleção, a educação continuada e/ou permanente, a supervisão, a avaliação de desempenho e de serviços, os saberes administrativos, de gestão e gerência local e outros instrumentos como a força de trabalho e a saúde do trabalhador, os materiais, os equipamentos e as instalações.

A articulação destes componentes do processo de trabalho tem a finalidade de criar condições apropriadas para a realização do cuidado aos usuários e promover o desempenho adequado dos trabalhadores (Felli, Peduzzi, 2016 p.28).

No estudo de Hausmann, Peduzzi (2009) foi observada a articulação entre $\mathrm{o}$ trabalho gerencial e assistencial do enfermeiro, pois as atividades das duas dimensões foram apresentadas de forma sequencial e interligadas, isto é, ações que permitem intervenções de cuidado e de gerenciamento simultaneamente.

Com esta organização no processo de trabalho, a utilização de instrumentos adequados pode conferir mudança significativa na qualidade da assistência prestada, pois pode estabelecer mediação entre o instrumento e o objeto, sendo possível ao trabalhador identificar suas atividades e os resultados alcançados. Por outro lado, o uso de instrumentos pode dar a conotação de controle ao trabalho para se alcançar o resultado almejado.

Decidir por um ou outro instrumento pode apontar para resultados positivos e desejados ou para resultados negativos e indesejados. A percepção destas possibilidades pode necessitar de mais esforços dos trabalhadores no momento da apreensão do conhecimento que os trabalhadores precisam ter para utilizar o instrumento de forma adequada. 
Para amenizar esta questão, Leopardi (1999 p. 77) considera que a qualificação profissional possibilita o entendimento técnico sobre certos instrumentos de trabalho para que o trabalho seja realizado com credibilidade científica e autonomia, porém ainda não permite que esse entendimento seja praticado sobre todo o processo de assistência à saúde.

A criação, o uso e a atualização de instrumentos de trabalho, pelo enfermeiro, estão garantidos na Resolução CNE/CES 3/2001 do Conselho Nacional de Educação/Câmara de Educação Superior que recomendam, no seu Artigo $5^{\circ}$, "que dentre as habilidades e competências esperadas dos egressos dos cursos de graduação em enfermagem, o profissional enfermeiro deverá gerenciar o processo de trabalho em enfermagem utilizando instrumentos que garantam a qualidade do cuidado e da assistência à saúde" (Brasil, 2001).

Definir os instrumentos de trabalho a serem utilizados nos serviços de saúde, para um recém-formado, é realmente tarefa ambiciosa, pois requer deste profundo conhecimento do processo de trabalho da unidade, porém é uma etapa importante e o conhecimento envolvido nesse processo se dará ao longo do tempo.

Os instrumentos utilizados podem ter objetivos diferentes para a realização do processo de trabalho e a articulação destes possibilita a identificação da teoria e da prática que sustenta o processo de trabalho do serviço de saúde que está expresso na missão, visão, valores e na estrutura organizacional da instituição.

A construção e o uso de instrumentos têm facilitado o entendimento da realidade por serem elementos que constituem o processo de trabalho e por imprimirem a busca de melhorias nos serviços de saúde.

Os instrumentos de gestão são ferramentas de trabalho e não um fim em si mesmo, porque são dinâmicos e flexíveis e devem conter informações claras, a fim de permitir a compreensão de seu conteúdo, possibilitar a compreensão dos principais problemas de saúde, as estratégias implantadas e os resultados alcançados, além de orientar a tomada de decisão em saúde (Brasil, 2002, p.5). 
Para os gestores, é importante elaborar instrumentos que retratem a realidade e seja feita discussão abrangente para a implantação destes, em que haja o reconhecimento de suas potencialidades e fragilidades, além de empregar ações em busca de melhorias contínuas ao longo do tempo e que possam garantir e aperfeiçoar o funcionamento e a qualidade nos serviços de saúde (Brasil, 2002, p.5; Tronchin, 2011, p.25).

Ainda é complexa a discussão sobre a criação, implantação e manutenção dos instrumentos para organizar e potencializar o processo de trabalho e imprimir mais qualidade aos serviços de saúde prestados à população.

\subsection{CARGA DE TRABALHO: FUNDAMENTAL PARA O DIMENSIONAMENTO DE PROFISSIONAIS DE SAÚDE}

Desde os primórdios da enfermagem moderna, Florence Nightingale demonstrou que os cuidados de enfermagem de qualidade estão associados ao melhor resultado para os pacientes. As agências de avaliação dos serviços de saúde do Canadá têm reconhecido os cuidados de enfermagem pela eficácia e eficiência e por considerarem que os enfermeiros são elementos centrais para o atendimento e melhoria na saúde dos pacientes (O’Brien Pallas, 2012).

Conhecer e medir a carga de trabalho da enfermagem pode contribuir para a gestão eficiente e eficaz dos hospitais e unidades de saúde - a carga de trabalho excessiva é a principal causa de estresse e insatisfação da força de trabalho de enfermagem (Duffield, Roche, Merrick, 2006).

Há uma definição comum para o termo carga de trabalho indexada pelo Descritor em Ciências da Saúde (DeCS) que o descreve como "a quantidade total de trabalho a ser desenvolvido por um indivíduo, um departamento, ou outro grupo de trabalhadores em um período de tempo" (BVS, 2016).

Conhecer a carga de trabalho e mensurar as variáveis que interferem na mesma é passo necessário para operacionalizar o processo de dimensionamento de pessoal de enfermagem (Gaidzinski, 1998). 
A carga de trabalho pode ser representada pelo tempo médio necessário para a realização da assistência de enfermagem no atendimento às necessidades de cuidado requerido pelos pacientes (Gaidzinski, 1998; Canadian Nurses Association, 2003).

Nessa perspectiva, Morris et al. (2007) realizou uma revisão da literatura em que foram encontrados diferentes conceitos e medidas sobre a carga de trabalho, sendo importante compreender tais diferenças. A partir dessa constatação, foi proposto um modelo preliminar que estabelece relações entre a enfermagem e os conceitos de carga de trabalho, a fim de que esta seja mais bem compreendida e se torne mais visível e reconhecida e, assim, tenha impacto positivo sobre a gestão da carga de trabalho da enfermagem e sobre a prestação da assistência ao paciente.

$\mathrm{Na}$ literatura, podemos encontrar a utilização do termo Carga de trabalho em diferentes contextos e sua análise é realizada nas perspectivas dos custos, da saúde do trabalhador, do cuidado e da organização da unidade e do planejamento da força de trabalho. A carga de trabalho é uma variável que pode ser estudada em diferentes perspectivas gerando diferentes desdobramentos.

$\mathrm{Na}$ perspectiva dos custos, foram realizados os primeiros estudos sobre a análise da carga de trabalho em meados de 1930 e publicados por Pfefferkorn e Roveta em 1940. Nessa ocasião, os pesquisadores tinham o objetivo de realizar o melhor controle dos custos hospitalares e apresentaram as horas médias de assistência de enfermagem despendidas no cuidado a pacientes de unidades de internação, nas 24 horas do dia, em hospitais que apresentavam as melhores realidades com o melhor padrão de assistência de enfermagem (Gaidzinski, 1998).

As organizações de saúde têm enfrentado problemas relacionados à alocação de recursos, condições de acesso, ineficiência dos serviços e custos crescentes. Considerando que a equipe de enfermagem representa, quantitativamente, o percentual e o orçamento mais significativo e por ser considerada a equipe que permanece a maior parte do tempo à beira do leito realizando cuidados de enfermagem, passa a ser a equipe mais visada 
quando se trata de redução de custos (Gaidzinski, 1998; Gonçalves, 2011; Cofen, 2016).

A literatura apresenta estudos que evidenciaram a associação entre o reduzido quadro de pessoal de enfermagem e o excesso de carga de trabalho com a diminuição da eficácia dos cuidados prestados, prejudicando a qualidade da assistência, aumentando o tempo de hospitalização e, consequentemente, o acréscimo do custo do tratamento do paciente (Miranda, 1999; Aiken et al., 2002; Yang, 2003; Cho et al., 2003).

Os melhores modelos de dotação de enfermeiros e os elevados níveis educacionais geram melhores resultados para os enfermeiros e para os pacientes, porém é reconhecido que as decisões na área da saúde nem sempre são movidas pela evidência, mas pelas políticas de custeio dos serviços de saúde (O’Brien Pallas, 2012).

Na perspectiva da saúde do trabalhador, a carga de trabalho é definida como um conjunto de componentes do processo de trabalho que atuam entre si e com o corpo do trabalhador e geram alterações que se manifestam como desgastes que originam a perda da capacidade corporal e psíquica que podem se manifestar em diferentes níveis (Laurell, Noriega, 1989).

A natureza do trabalho em enfermagem e as condições em que este é realizado têm evidenciado processos de desgastes dos trabalhadores que são expressos na ocorrência de acidentes e de doenças relacionadas ao trabalho, os quais se manifestam na qualidade de vida do trabalhador e na qualidade da assistência prestada aos usuários (Laurell, Noriega, 1989; Gutierrez, Ciampone, 2007; Sancinetti et al., 2009).

Nesse contexto, os gerentes de enfermagem reconhecem e se preocupam com o adoecimento dos trabalhadores, mas também precisam garantir e se responsabilizar pela produtividade e pelo serviço de enfermagem prestado, o que estabelece interface entre a saúde do trabalhador e a segurança do paciente (Baptista et al., 2015).

A sobrecarga de trabalho tem sido identificada como um fator importante que desencadeia as ocorrências relacionadas às licenças médicas, a acidentes de trabalho com ou sem afastamentos, além de estar 
associada ao número reduzido de profissionais, baixos salários e jornadas de trabalho extensas (Bernardes et al., 2014).

Na perspectiva da assistência e segurança do paciente, a intensidade dos cuidados de enfermagem está relacionada ao cuidado de enfermagem específico e individualizado para cada paciente, considerando os conceitos de dependência, gravidade da doença, complexidade dos cuidados e tempo necessário para realizar o atendimento ao paciente, sendo que a intensidade dos cuidados de enfermagem depende da necessidade de cuidados de enfermagem do paciente (Morris et al.,2007).

As ações de racionalização dos custos empregadas no desenvolvimento de ações de atendimento à saúde têm colocado em risco a qualidade da assistência e a segurança do paciente (Aiken et al., 2002). A associação entre a carga de trabalho e a presença de eventos adversos durante a prestação de assistência tem sido objeto de estudo.

Cho et al. (2013) analisaram os efeitos da dotação adequada de enfermeiros e a presença dos eventos adversos: úlcera de pressão, administração errada de medicamentos, pneumonia, infecção urinária, infecção de ferida cirúrgica e sepse. Encontraram nesta análise que o aumento de uma hora de trabalho por enfermeiros por dia por paciente estava associado à diminuição de $8,9 \%$ na probabilidade de pneumonia. O maior número de horas de enfermagem por dia por paciente estava associado à menor probabilidade de úlceras de pressão. A ocorrência do evento adverso foi associada ao prolongado tempo de permanência dos pacientes e carga de trabalho do enfermeiro.

A análise do cuidado realizado pela enfermagem é essencial para a compreensão da relação entre pessoal de enfermagem e os resultados da assistência prestada aos pacientes (Cho et al., 2013).

Na perspectiva da força do trabalho em saúde, é observada a inclusão de novos modelos de prestação de cuidados que tem ameaçado a qualidade de assistência ao paciente, sendo que, para modificar esse quadro, é necessário incluir capacitações em recursos humanos da saúde com foco no planejamento, construção de modelos assistenciais baseados em equipes e reorganização da prática do cuidado, sendo que os enfermeiros têm liderado 
as investigações no que tange o planejamento dos recursos de enfermagem, a fim de que as evidências encontradas possam contribuir no desenvolvimento das decisões para melhorar os cuidados de saúde (O'Brien Pallas, 2012).

O estudo relacionado à força de trabalho da enfermagem tem contribuído para tratar as questões que afetam o atendimento ao paciente, como, por exemplo, investigar as iniciativas para melhorar os ambientes insalubres de trabalho da enfermagem e torná-los melhores para os enfermeiros e para os pacientes (O'Brien Pallas, 2012).

A carga de trabalho de enfermagem continua sendo um ponto crítico para o planejamento da força de trabalho, pois novos processos são incorporados à gestão das unidades, por um lado aumentando o volume de atividades gerenciais, por outro, os enfermeiros têm a necessidade de realizar com rapidez o cuidado, o que tem impactado negativamente no atendimento ao paciente (O'Brien Pallas, 2012).

As evidências disponíveis devem ser usadas para orientar as inovações de prestação de cuidados e comprometer-se a avaliar essas inovações na prática, a fim de estabilizar a força de trabalho de enfermagem e garantir a qualidade do cuidado às necessidades de políticas do sistema de saúde e práticas baseadas em evidências, proporcionando melhores ambientes de trabalho e participação dos enfermeiros em pesquisas em todos os níveis seja assistencial, gerencial ou ensino (O'Brien Pallas, 2012).

Na perspectiva do planejamento e organização os serviços de saúde, há escassez na contratação de enfermeiros ao mesmo tempo em que as condições de trabalho na enfermagem estão se deteriorando. Os líderes institucionais precisam conhecer a situação financeira, avaliar o desfecho dos cuidados realizados aos pacientes, analisar como o estresse ambiental está afetando os trabalhadores para desenvolver e aplicar medidas para identificar e melhorar as situações insalubres (Jennings, 2008).

Analisar as dimensões da carga de trabalho tornou-se imprescindível diante dos desfechos apresentados. Carayon e Gurses (2005) descreveram as principais dimensões que merecem análise dos gerentes: a carga de 
trabalho física, a carga de trabalho cognitiva, a pressão do tempo, a carga de trabalho emocional, a quantidade e qualidade da carga de trabalho.

A carga de trabalho vivenciada pelos enfermeiros pode levar a vários resultados como impacto na saúde, na qualidade de vida no trabalho com insatisfação no trabalho, estresse, exaustão e rotatividade e na segurança do paciente (Carayon, Alvarado, 2007).

Estes autores defendem que a avaliação da carga de trabalho deve ser sistêmica para que sejam avaliadas as diferentes dimensões da carga de trabalho a que os enfermeiros estão submetidos, sendo necessário identificar os fatores do trabalho e as diferentes dimensões que estão contribuindo para aumentá-la (Carayon, Alvarado, 2007).

A carga de trabalho sofre influência não só pela quantidade de profissionais de enfermagem, mas também pela organização da unidade e pelo apoio de equipes administrativas, sendo estudada nas dimensões da unidade de trabalho, na especialidade do enfermeiro e na complexidade do paciente (Mello, 2011, p.143).

As perspectivas apresentadas expressam pontos de convergência que são demonstrados no conceito desenvolvido por Gaidzinski (1998) em que a inadequação de profissionais de saúde gera situações de risco para o usuário, para a equipe de enfermagem e para a instituição de saúde, pois favorece a ocorrência de falhas pela sobrecarga de trabalho e deficiência da qualidade de assistência prestada.

Os profissionais de saúde nas organizações têm vivenciado necessidades de saúde cada vez mais complexas o que gera sobrecarga de trabalho e interfere na qualidade da assistência pretendida, sendo necessário assegurar que as equipes e os profissionais de saúde possam atender aos problemas e às necessidades de saúde da população (Fugulin, 2002; Fugulin, Gaidzinski, Lima, 2016).

A análise da carga de trabalho dos profissionais de saúde pretende assegurar um conjunto de intervenções essenciais com maior eficácia e eficiência ao atendimento prestado aos pacientes delimitado por um campo de conhecimento. 
Os profissionais de saúde são responsáveis pela realização das intervenções captadas a partir dos problemas e das necessidades de saúde apresentadas para melhorar as condições de saúde da população (Campos, Domitti, 2007).

\subsection{INSTRUMENTOS PARA MEDIR A CARGA DE TRABALHO}

Avaliar a carga de trabalho é ação relevante devido ao seu impacto na qualidade e na segurança da assistência prestada. Aplicar instrumentos que identifiquem as condições clínicas e a necessidade de cuidados dos pacientes tornou-se medida importante, pois pode prever períodos de internação prolongados, aumento no custo dos tratamentos e exposição dos pacientes e da equipe de saúde a riscos (Queijo, Padilha, 2009; Queijo et al., 2013; Oliveira, Garcia, Nogueira, 2016).

Carayon e Gurses (2005), em revisão da literatura sobre unidades de terapia intensiva, demonstraram que a carga de trabalho de enfermagem é uma variável que contribui para a segurança do paciente.

Morris et al. (2007) realizaram revisão sobre a carga de trabalho dos enfermeiros, a qual dizia que a questão em torno da medição da carga de trabalho tem recebido menos atenção, no entanto duas abordagens diferentes para medi-la têm sido encontradas na literatura: uma abordagem baseada na gravidade do paciente e proporção de enfermeiro/paciente e outra abordagem que leva em conta a experiência e a competência do enfermeiro.

A primeira abordagem é utilizada para descrever as atividades relacionadas ao pessoal de enfermagem, como organizar as diferentes atividades de acordo com a gravidade do paciente e de acordo com as atividades relacionadas à gestão do cuidado. A segunda abordagem é utilizada para atividades de investigação para determinar a quantidade de esforço de enfermagem e para analisar os resultados de cada atividade realizada (Hoonakker et al., 2011).

A avaliação da carga de trabalho dos profissionais de saúde despertou interesse na década de 1970, quando foi necessário determinar a efetividade 
dos cuidados e o custo envolvido na assistência prestada, principalmente sobre as atividades realizadas pela enfermagem (Guccione et al., 2004).

Os serviços de saúde vivenciam, desde então, um contexto complexo em que os gestores devem buscar novos conhecimentos e investir em novos instrumentos capazes de auxiliar o planejamento e a tomada de decisão.

Para medir e avaliar a carga de trabalho, em diferentes unidades hospitalares, foram desenvolvidos instrumentos com a proposta de identificar a necessidade e a demanda de trabalho da equipe de saúde e, assim, identificar as intervenções terapêuticas demandadas pelos pacientes, mensurar a gravidade dos pacientes, classificar os pacientes em níveis de cuidados e calcular a carga de trabalho da equipe de enfermagem.

Os principais instrumentos encontrados na literatura para identificar a carga de trabalho:

SCP, 1960 - Sistema de Classificação de Pacientes;

TISS, 1974 a 1996 - Therapeutic Intervention Scoring System (TISS57, TISS-76, TISS-28);

PRN, 1980 - Project of Research of Nursing;

MATRIX, 1980 - Sistema de Classificação de Pacientes;

APACHE II, 1981 - Acute Physiology and Chronic Health Evaluation;

SAPS II, 1981 - Simplified Acute Physiology Score;

OMEGA, 1986 - Sistema de Índice de Gravidade Simplificado;

TOSS, 1991 - Time Oriented Score System;

LODS, 1993 - Logistic Organ Dysfunction System;

NEMS, 1996 - Nine Equivalents of Nursing Manpower Use Score;

NAS, 2001 - Nursing Activities Score;

VACTE, 2007 - Valoracion de Cargas de Trabajo y Tempos de Enfermeria.

Uma das categorias de instrumentos que podem ser utilizadas para a medida de carga de trabalho corresponde ao Sistema de Classificação de 
Pacientes (SCP), definido como um processo em que os pacientes são categorizados em níveis de complexidade assistencial de acordo com os cuidados requeridos, o que assegura distribuição equitativa da assistência, aumenta a produtividade e a eficiência do serviço de saúde (Ribeiro, 1972; Perroca, 2000).

O Sistema de Classificação de Pacientes (SCP) foi inicialmente desenvolvido em 1960, aplicado e validado em diferentes realidades. É um instrumento muito utilizado por subsidiar a reorganização das unidades, definir as categorias de pacientes por complexidade assistencial, identificar o perfil dos pacientes, redistribuir os leitos, podendo ainda interferir na adequação da planta física e na realocação de recursos humanos de acordo com a complexidade assistencial do paciente, sendo ainda possível, avaliar a qualidade, a efetividade da assistência prestada e a produtividade da unidade (Fugulin, 2002).

O SCP utiliza o número médio de horas despendidas pela equipe de enfermagem de acordo com cada categoria de cuidado (Tanos, Massarollo, Gaidzinski, 2000).

Fugulin (2002) realizou revisão sobre a implantação dos SCP em diversos contextos no Brasil (Ribeiro, 1972; Alcalá et al., 1982; Campedelli et al., 1987; Alves et al., 1988; Santos, 1992; Romero et al. 1994; Dias et al.,1996; Ayoub, Alves, Silva, 2000; Martins,1997; Martins, Haddad, 2000; Ramos et al., 1996; Ueti et al., 1991; Dalben, 2000), sendo que o SCP proposto por Fugulin (1994) é formado por cinco categorias de cuidados, cujas implantação e avaliação evidenciaram a contribuição para a qualidade da assistência prestada, o que garantiu efetividade e produtividade da equipe de enfermagem. Além disso, contribuiu para 0 fortalecimento enquanto instrumento no âmbito assistencial e gerencial (Fugulin, 1997; Fugulin, 2002; Fugulin et al.; 2012).

Ao analisar a pertinência e importância desse instrumento para conhecer o perfil da clientela nas unidades de internação, o Cofen, na Resolução n 293/04, referendou quatro das cinco categorias de cuidados do SCP de Fugulin et al. (1994) e Fugulin (1997) e, na Resolução nº 0527/2017, 
referendou as cinco categorias de cuidados do SCP de Fugulin $(1994,1997)$, apontadas pelo estudo de Tsukamoto (2010) e Fugulin et al. (2012).

Outro instrumento utilizado no contexto brasileiro é o instrumento de Classificação de Pacientes de Perroca (2000; 2008), construído com base nas necessidades humanas básicas de Horta, o qual apresenta treze indicadores críticos: estado mental e nível de consciência, oxigenação, sinais vitais, nutrição e hidratação, motilidade, locomoção, cuidado corporal, eliminações, terapêutica, educação à saúde, comportamento, comunicação e integridade cutâneo-mucosa. Cada indicador possui cinco níveis de gradação de um a cinco que indicam a intensidade crescente de complexidade de cuidado assistencial (Perroca, 1996; Perroca, Gaidzinski; 2002).

O valor encontrado em cada indicador é somado e em seguida é comparado a uma das categorias de cuidado: cuidados mínimos (13 a 26 pontos), cuidados intermediários (27 a 39 pontos), cuidados semi-intensivos (40 a 52 pontos) e cuidados intensivos (53 a 65 pontos). O paciente ao ser indicado para uma das categorias de cuidado será classificado para o que é possível ser realizado diariamente (Perroca, 1996; Perroca, Gaidzinski; 2002).

Bochembuzio (2002) propôs um SCP que considerava as necessidades de cuidado dos recém-nascidos: ao aplicar o instrumento, considerou que a classificação era limitada, pois não estimava o tempo de dedicação aos cuidados de enfermagem na jornada de trabalho.

Bochembuzio (2007) aplicou o instrumento NAS na área de neonatologia (unidade neonatal e UTI neonatal), o que possibilitou encontrar a proporção de tempo despendido, da equipe de enfermagem, ao recémnascido, além de identificar as variações da frequência das intervenções/atividades de enfermagem que mais despenderam o tempo da equipe.

Dini $(2007,2011)$ construiu e validou um instrumento de classificação de pacientes para a realidade da pediatria a fim de contemplar o perfil e as necessidades deste grupo. Este instrumento subsidia o cálculo do tempo médio de assistência de enfermagem em cinco categorias de cuidado: cuidados mínimos, cuidados intermediários, cuidados de alta dependência, cuidados semi-intensivos e cuidados intensivos. 
O Therapeutic Intervention Scoring System (TISS) ou Sistema de Pontuação das Intervenções Terapêuticas (SPIT) é encontrado na literatura como o primeiro modelo de instrumento utilizado para avaliar os índices de gravidade dos pacientes e a carga de trabalho (Queijo, Padilha, 2009; Canabarro et al., 2010).

O TISS foi construído por Cullen e colaboradores em 1974, no Massachussets General Hospital de Boston, com o objetivo de mensurar a gravidade dos pacientes e calcular a carga de trabalho da equipe de enfermagem em UTI (Cullen et al., 1974; Queijo, Padilha, 2009).

A primeira versão, a TISS-57, contemplava intervenções terapêuticas às quais era atribuída a pontuação de um a quatro, de acordo com o tempo necessário para a realização das atividades de enfermagem. Em seguida, foi revisto e atualizado para TISS-76 por conter 76 intervenções que contemplavam o grau de inatividade e o tempo dispensado pela enfermagem e pelo médico para realizar determinado procedimento, horas de cuidados requeridas - além disso, os pacientes eram classificados de acordo com a necessidade de vigilância e de cuidados. (Keene, Cullen, 1983; Queijo, Padilha, 2009).

O TISS-76 sofreu ampla modificação em que foram determinadas categorias de intervenções com itens e subitens com respectivos pesos, essa nova versão ficou conhecida por TISS-28 por ter 28 itens divididos em sete categorias: atividades básicas, suporte ventilatório, cardiovascular, renal, neurológico, metabólico e intervenções específicas. A estas categorias são aplicadas pontuações em que o escore total permite a determinação da carga de trabalho da equipe de enfermagem: cada ponto equivale a 10,6 minutos de tempo de trabalho de um enfermeiro em um turno de trabalho em UTI (Miranda, Rijk, Schaufeli, 1996; Queijo, Padilha, 2009).

O TISS-28 foi elaborado por Miranda e colaboradores em 1996 e representa uma versão simplificada e atualizada do TISS-76. Mede a gravidade do paciente segundo o grau de inatividade das intervenções, identifica o tempo dispensado para a realização de determinados procedimentos nas 24 horas. É utilizado para análise das atividades assistenciais e administrativas, pois avalia a carga de trabalho de 
enfermagem, contribuiu para o dimensionamento de pessoal e a alocação de recursos humanos de enfermagem (Gonçalves et al., 2006; Queijo, Padilha, 2009).

Com o objetivo de mensurar a carga de trabalho nas UTIs, este instrumento sofreu nova modificação que resultou no Nursing Activities Score (NAS) (Miranda, Raoul, Rijk, 2003; Queijo, Padilha, 2009).

O instrumento Project Research of Nursing (PRN) foi proposto no período de 1980 a 1987 pela Health Administration Department of Montreal no Canadá. Consta de uma lista de atividades de enfermagem em que eram atribuídos pontos de acordo com as necessidades dos pacientes a serem atendidos em unidade de terapia intensiva (Guccione et al., 2004).

O Sistema MATRIX foi desenvolvido nos Estados Unidos por volta de 1980, o qual é um instrumento utilizado para classificar os pacientes e estruturado em forma de uma matriz com o sistema de classificação de pacientes - este é realizado de acordo com a categoria profissional e o turno de trabalho, em que é possível encontrar as horas totais de cuidados por níveis de cuidado determinado. A aplicação desse instrumento apresentou as horas de assistência de enfermagem em quatro níveis de complexidade de cuidado, o que implicou que a Joint Comission on Acreditation of Hospitals (JCAH) recomendasse que os serviços de enfermagem implementassem um método para estabelecer as necessidades de cuidados (Barham, Schneider; 1980 in: Fugulin, 2002).

Acute Physiology and Chronic Health Evaluation (APACHE II) é um sistema de fácil coleta em que o escore apresenta a probabilidade de óbito hospitalar de cada paciente internado em UTI. Além disso, apresenta a classificação de gravidade da doença, fornece uma medida geral da gravidade da doença, pode ser usado de pontuação para avaliar o uso dos recursos hospitalares e comparar a eficácia da terapia intensiva em diferentes hospitais ou ao longo do tempo (Knaus, Draper, Wagner, 1983; 1985).

Esse modelo também pode ser utilizado para avaliar a mortalidade padronizada (número de óbitos observados/número de óbitos previstos), a gravidade dos pacientes que internam no setor, os critérios para a triagem dos 
pacientes para serem internados na UTI e planejar as melhorias operacionais e de equipamentos (Rocco et al., 2003; Khan, Maitree, Radhika, 2015).

Simplified Acute Physiology Score (SAPS II) foi desenvolvido por Le Gall e colaboradores em 1981 e tem sido implementado em unidades de terapia intensiva. Auxilia na previsão da mortalidade hospitalar. É composto por dezessete variáveis que são avaliadas no momento da admissão do paciente na UTI. Segundo esse autor, identificar o risco de morte de um paciente favorece o planejamento minucioso do cuidado a ser prestado desde a sua admissão até a sua alta, porém acredita que deva fazer parte da filosofia e da política da intuição, para que estes dados sejam coletados com qualidade e em quantidade adequados para fazer a previsão correta. A sua utilização está relacionada coma avaliação do desempenho dos serviços de saúde em especial das UTIs (Le Gall, Lemeshow, Saulnier, 1993).

O Omega Scoring System (Omega) foi proposto em 1986 pela Comissão de Avaliação Francesa (Commission D'Evaluation de la Societé de Reanimation da Langue Française). Nele, são descritas 47 atividades terapêuticas agrupadas em três categorias: categoria 1 - composta por 28 intervenções que são indicadas pelo menos uma vez durante a internação; categoria 2 - composta por 11 intervenções que são registradas a cada hora e categoria 3 - composta por intervenções que são registradas a cada dia. As intervenções estão associadas a pontuações que são expressas em unidade de tempo e representam uma medida global sobre o uso de recursos humanos e materiais para o desenvolvimento do trabalho e podem ser utilizadas para avaliar as intervenções realizadas pelos médicos e/ou pelos enfermeiros. (Guccione et al.,2004).

Time Oriented Score System (TOSS) foi desenvolvido e testado, em 1991, pelo grupo multicêntrico de pesquisa da Itália (Italian Multicenter Group of ICU Research) e é um sistema de pontuação orientado pelo tempo. O TOSS foi validado em unidades de cuidados intensivos e considerado um método de quantificação direta da carga de trabalho dos enfermeiros exigidos pelos pacientes de UTI. Cada atividade de enfermagem é cronometrada e a média dos resultados é agrupada em listas que incluem atividades de emergência e atividades ocasionais. As atividades são computadas na admissão, durante a 
permanência do paciente e podem fornecer informações sobre a razão entre enfermeiros/pacientes necessários, em uma unidade específica (Guccione et al., 2004).

Logistic Organ Dysfunction System (LODS) é empregado para classificar os pacientes internados em UTI, segundo a gravidade e o risco de morte - quanto mais elevado o escore, maior é a gravidade do paciente. $\mathrm{O}$ LODS, além de identificar a gravidade, ainda identifica o grau de comprometimento dos sistemas neurológico, cardiovascular, respiratório, pulmonar, hematológico e hepático (Silva et al., 2012).

Utilizado com o SAPS II, a aplicação destes instrumentos auxilia a investigação da caracterização dos pacientes assistidos, a diferenciação dos grupos de pacientes com diferentes riscos de morte, a categorização da gravidade dos pacientes, a avaliação da qualidade da assistência dispensada, podendo ainda auxiliar o enfermeiro na tomada de decisões clínicas e gerenciais (Silva et al., 2012).

Nine Equivalents of Nursing Manpower Use Score (NEMS) foi desenvolvido no período de 1994 a 1996 pela Foundation for Research on Intensive Care in Europe (FRICE). Sua construção foi baseada no TISS-28, em que analisaram as 28 intervenções terapêuticas e construíram uma versão simplificada com nove intervenções terapêuticas, o que reduziu o consumo de tempo no preenchimento dos índices terapêuticos. Este instrumento é considerado adequado para medir e avaliar a carga de trabalho de enfermagem diária em UTI, pois compara a carga de trabalho da UTI em estudos multicêntricos, auxilia à previsão e o planejamento do pessoal de enfermagem e identifica a carga de trabalho requerida pelo paciente (Miranda, Moreno, Lapichino, 1997).

O Nursing Activities Score (NAS) foi desenvolvido por Miranda e colaboradores em 2001 e é um instrumento que avalia as necessidades de cuidados, mede a carga de trabalho, uma vez que verifica o tempo em que a equipe de enfermagem gasta para realizar os cuidados diretos aos pacientes internados em UTI e, assim, fornece evidências para o planejamento adequado da assistência (Queijo, 2002; Miranda et al., 2003; Gonçalves et al., 2006; Padilha et al., 2010). 
O NAS determina as atividades de enfermagem que melhor descrevem a carga de trabalho na unidade de cuidados intensivos e os pesos são expressos por meio de escores para essas atividades. A pontuação atingida descreve o tempo médio gasto para a realização dessas atividades, assim possibilita identificar e avaliar o tempo de assistência de enfermagem de acordo com as necessidades requeridas pelos pacientes (Miranda et al., 2003).

O NAS passou a ser mais completo e expressivo, porque reunia mais números de atividades a serem realizadas como as relacionadas à higiene, suporte e cuidados aos familiares/pacientes, tarefas administrativas e gerenciais e, além de medir a real carga de trabalho, também quantificava e elencava o grau de complexidade dos cuidados de enfermagem que estavam sendo realizados (Queijo, 2002 p. 11; Queijo, Padilha, 2009; Miranda et al., 2003; Gonçalves et al., 2006).

Valoracion de Cargas de Trabajo y Tempos de Enfermeria (VACTE®) tem como proposta inicial é de apresentar uma escala representativa de todas as tarefas e cuidados realizados pela equipe de enfermagem, determinar resultados mais precisos e objetivos para a medida da carga de trabalho e calcular as taxas de paciente/enfermeira. $O$ instrumento consta de treze seções compostas por tarefas e cuidados que podem ser realizados pelo pessoal de enfermagem. A pontuação equivale ao tempo médio (em minutos) para executar cada um dos cuidados em 24 horas (Marcos et al, 2007).

O instrumento mede o tempo para a execução de cada cuidado realizado por paciente e com isso foi possível encontrar um valor mínimo, chamado de cuidados mínimos de 230 minutos. A escala pode alcançar um valor máximo de cuidados de 895 minutos. Marcos et al. (2007) utilizaram análise estatística para comparar as escalas APACHE II, NEMS e VACTE®. Este instrumento mostrou-se mais representativo das atividades de enfermagem e mais eficaz quando comparado com o NEMS para determinar a carga de trabalho.

Bochembuzio (2007) apresentou os instrumentos que medem a gravidade dos pacientes e a carga de trabalho em UTI Pediátrica e Neonatal. 
Instrumentos utilizados para as unidades pediátricas:

TISS Pediátrico, 1983;

PSI - Physiological Stability Index, 1984;

PRISM - Pediatric Risk of Mortality Score, 1988;

PRISM III - Pediatric Risk of Mortality Score III, 1988;

PRISA II - Pediatric Risk of Hospital Admission Score II, 2005.

Instrumentos utilizados para as unidades neonatais:

PSI adaptado - Physiological Stability Index, 1989;

NTISS - Neonatal Therapeutic Intervention Scoring System, 1992;

CRIB - Clinical Risk Index for Babies, 1993;

SNAP - Score for Neonatal Acute Psysiology, 1993;

NAS - Nursing Activities Score, 2001;

MINT - Mortality Index for Neonatal Transportation Score, 2004.

Esses instrumentos avaliam a gravidade do paciente em função do número de intervenções terapêuticas durante as primeiras 24 horas de admissão do recém-nascido na UTI neonatal. Com estes dados, é possível realizar associações com as taxas de mortalidades que acontecem dentro do hospital, rever os processos assistenciais, verificar a alocação de recursos para a realização do tratamento adequado, avaliar a qualidade da assistência intensiva e compará-la com as taxas de mortalidade (Bochembuzio, 2007).

Auxiliam a monitorar e quantificar as intervenções terapêuticas com o objetivo de avaliar a gravidade da doença, a instabilidade clínica e os custos, porém a pontuação atingida não está relacionada com o tempo de assistência (Bochembuzio, 2007).

A taxonomia Nursing Interventions Classification (NIC) tem sido muito utilizada por pesquisadores do Grupo de Pesquisa "Gerenciamento de recursos humanos: conceitos, instrumentos e indicadores do processo de 
dimensionamento de pessoal", na identificação das intervenções/atividades e no tempo despendido pela equipe de saúde na assistência prestada aos pacientes em diferentes tipos de serviços (Bulecheck et al., 2016).

A NIC é uma lista ordenada que engloba as intervenções de enfermagem classificadas segundo alguns critérios, em que utiliza linguagem padronizada abrangente que descreve os tratamentos realizados pelos enfermeiros e pode ser utilizada em vários contextos de atendimento à saúde (Bulecheck et al., 2016).

A NIC tem sido adotada por muitas instituições de saúde que a utilizam para elaborar protocolos, para planejar e documentar os cuidados de enfermagem - o que tem facilitado à construção de bancos de dados e sistemas de informação dos cuidados prestados de enfermagem - estudar a eficácia e o custo dos tratamentos de enfermagem, proporcionar a continuidade dos cuidados de enfermagem, melhorar a comunicação entre a equipe e realizar a avaliação por competências (Bulecheck et al., 2016).

A primeira edição, elaborada e publicada em 1992, era composta por 336 intervenções em ordem alfabética; a segunda edição com 433; a terceira com 486; a quarta com 514 e a quinta edição com 542 intervenções. Desde sua publicação, foram desenvolvidas, adicionadas e validadas novas intervenções que fundamentaram a construção da estrutura taxonômica da NIC que possui, atualmente, na sexta edição, sete domínios, trinta classes e 554 intervenções. As intervenções têm sido associadas aos diagnósticos de enfermagem, os quais estão servindo de apoio para a construção de um sistema de informação de enfermagem (Bulecheck et al., 2016).

Segundo a NIC, intervenção de enfermagem é definida como "qualquer tratamento baseado no julgamento e no conhecimento clínico realizado por um enfermeiro para melhorar os resultados do paciente" (Bulecheck et al., 2016, p. xvii).

Cada intervenção é composta por um rótulo ou nome de designação, uma definição, um conjunto de atividades que um enfermeiro poderia realizar em uma ordem lógica (Bulecheck et al., 2016, p. xvii).

As intervenções são classificadas em intervenções de cuidados diretos e intervenções de cuidados indiretos. As intervenções de cuidado direto "são 
tratamentos realizados por meio da interação com o paciente", já as intervenções de cuidado indireto "são tratamentos realizados à distância do paciente, mas em seu benefício, como por exemplo, a supervisão do ambiente de assistência" que dá suporte à efetividade das intervenções de assistência direta (Bulecheck et al., 2016, p. 2).

Há um elenco de atividades que não apresentam correspondência com a taxonomia NIC e que podem ser agrupadas em atividades associadas e atividades pessoais (Hurst, 2002).

As atividades associadas ao trabalho são aquelas que podem ser executadas por outros trabalhadores de outras categorias, mas que os profissionais de saúde assumem; já as atividades pessoais são consideradas as pausas necessárias na jornada de trabalho para 0 atendimento das necessidades fisiológicas e de comunicação pessoal e que estão relacionadas às necessidades dos trabalhadores (Hurst, 2002; Mello, 2011 p. 197; Bonfim, 2014 p. 98).

A partir da identificação das intervenções em determinados grupos de pacientes é possível planejar os recursos materiais e humanos para a realização da assistência de enfermagem, estabelecer o nível de cuidado desejado e estimar o tempo despendido necessário para a execução de cada uma das intervenções por categoria profissional (Bulecheck et al., 2016).

A identificação e análise das intervenções/atividades e a distribuição do tempo de trabalho para realizá-las foram objetos de estudo de pesquisadores internacionais como subsídio para estabelecer a carga de trabalho e a produtividade da equipe de enfermagem (Adler, Icenhour, 1993; Cardona et al., 1997; Urden, Roode, 1997; Upenieks, 1998; Hughes, 1999; Hurst, 2002; Kiekkas et al., 2005; Chaboyer et al., 2008; Munysia, Yu, Hailey, 2011; Yoon et al., 2015).

Ao identificar as intervenções e analisar a distribuição do tempo foi possível identificar que as intervenções de higiene bucal, cuidados com a pele e orientação para o paciente e família não foram realizadas quando a carga de trabalho foi excessiva (Aiken et al., 2001).

No Brasil, a taxonomia NIC tem sido utilizada para identificar as intervenções/atividades e o tempo médio necessário para desenvolvê-las e, 
consequentemente, medir a carga de trabalho da equipe de enfermagem no âmbito hospitalar (Santos, 2006; Bordin, 2008; Soares, 2009; Garcia, 2009; Soares, Gaidzinski, Cirico, 2010; Garcia, 2011; Mello, 2011; Possari, 2011; Cruz, Gaidzinski; 2013; Martin, 2013; Souza, Jericó, Perroca, 2013; Andrade, 2014;Rogenski, 2014; Cruz, 2012, 2015; Guimarães, 2015) e na atenção primária (Bonfim, 2010; 2014).

Para proporcionar o atendimento de alta qualidade e alcançar os melhores resultados para os pacientes é necessário dispor de uma equipe de saúde especializada que interaja e utilize de forma eficaz e eficiente a tecnologia em saúde disponível (Khan, Maitree, Radhika, 2015).

Os profissionais de saúde e os gestores são questionados sobre os critérios de admissão e os resultados do tratamento, sendo necessário realizar medidas que apresentem o tempo despendido nos cuidados requeridos pelos pacientes, bem como o custo com os procedimentos realizados. Os resultados dependem dos recursos disponíveis como: profissionais de saúde, recursos materiais, processos de cuidados implantados, tempo de atendimento dispensado e habilidade dos profissionais (Khan, Maitree, Radhika, 2015).

A aplicação de escores para avaliar os cuidados prestados tem gerado grande interesse dos gestores e economistas, pois estão associados aos custos.

Esses sistemas de pontuação consistem de duas partes que geram muito interesse, pois apresentam um escore de gravidade (quanto maior o número, mais grave é a condição do paciente) e apresentam a probabilidade de mortalidade (Khan, Maitree, Radhika, 2015).

Diante da variedade de instrumentos disponíveis para a medida da carga de trabalho, é possível concluir que são ferramentas com as quais os profissionais de saúde podem captar as necessidades de cuidados, mapear as intervenções terapêuticas requeridas pelos pacientes, identificar a gravidade dos pacientes, classificar os pacientes em níveis de gravidade, auxiliar no planejamento da assistência a ser prestada, prever os recursos materiais necessários para o desenvolvimento das atividades e diagnosticar a necessidade de recursos humanos necessários para a realização de assistência necessária ao paciente. 


\subsection{A IMPORTÂNCIA DA CONSTRUÇÃO DE INSTRUMENTOS PARA SUBSIDIAR O DIMENSIONAMENTO DE PESSOAL}

Para realizar o dimensionamento de pessoal existem alguns métodos que, no Brasil, o oficial e mais utilizado, até o momento, é o proposto pela Resolução Cofen no 293/04 e atualizada pela Resolução Cofen n 0527/2017.

Diante da importância do dimensionamento de enfermagem, o Cofen regulamentou parâmetros mínimos para dimensionar o quantitativo de profissionais das diferentes categorias de enfermagem para serviços/locais em que são realizadas atividades de enfermagem.

Estes parâmetros são constituídos de normas técnicas mínimas para orientar os gestores, gerentes e enfermeiros dos serviços de saúde na realização do planejamento do quantitativo de profissionais necessários para a realização das ações de enfermagem (Cofen, 2017).

A referência mínima para constituir o quadro de profissionais de enfermagem nas 24 horas em unidades de internação considera o SCP, as horas de assistência de enfermagem, a distribuição percentual do total de profissionais de enfermagem e a proporção profissionais/paciente (Cofen, 2017).

"O dimensionamento de pessoal de enfermagem é um instrumento gerencial para a busca da qualidade da assistência, pois procura adequar o quadro de pessoal disponível às necessidades dos pacientes e do serviço do serviço de saúde" (Gaidzinski, Kurcgant, 1998).

Gaidzinski (1994) desenvolveu um método de análise de desempenho em função do tempo das atividades que foram realizadas pelos profissionais de enfermagem. As execuções destas atividades podem variar a depender da unidade de saúde a ser analisada.

A avaliação e análise da carga de trabalho de enfermagem são temas de interesse para os gestores, pois, por um lado uma equipe superestimada demanda alto custo, por outro, uma equipe reduzida gera queda na qualidade da assistência, aumento nos dias de internação e consequente aumento do custo relacionado ao tratamento dos pacientes (Gaidzinski, 1994). 
Para realizar esse processo é necessário conhecer a carga de trabalho da unidade, a qual depende das necessidades de assistência dos pacientes e do padrão de cuidado que a instituição pretende atingir (Gaidzinski, 1998).

Os estudos realizados sobre o dimensionamento de pessoal de enfermagem permitiram o refinamento do método, o que proporcionou a análise e o cálculo de inúmeras variáveis que descrevem a realidade dos serviços de saúde na perspectiva da enfermagem (Gaidzinski et al., 2009).

Sendo assim, o dimensionamento de profissionais de enfermagem é um processo sistemático que fundamenta o planejamento e a avaliação do quantitativo e qualitativo de profissionais de enfermagem, necessário para prover assistência de enfermagem, de acordo com a especificidade do serviço de saúde e que garanta condições de segurança aos usuários e aos trabalhadores (Fugulin, Gaidzinski, Lima, 2016).

Para justificar a necessidade de adequar o quadro de pessoal, os gestores encontram muitos obstáculos; por um lado, há a necessidade de racionalizar e conter os custos e oferecer mais serviços, por outro, é necessário melhorar a qualidade da assistência e atender o aumento da demanda de assistência que são determinadas pelos administradores (Fugulin, 2002 p. 12).

\subsection{O TEMPO EFETIVO DE TRABALHO}

A determinação do tempo despendido para realizar os cuidados diretos e indiretos à saúde e atender às necessidades assistenciais é considerada uma etapa complexa, porém importante para compor a operacionalização do método de dimensionamento de pessoal dos serviços de saúde (Gaidzinski, 1994).

As medidas das horas de enfermagem por paciente por dia têm sido muito utilizadas para auxiliar o gerente de enfermagem a justificar e negociar a necessidade do quantitativo da equipe de enfermagem e assegurar qualidade aos cuidados prestados (Min, Scott, 2016).

A utilização de um padrão de tempo requerido considera não só as exigências da equipe de enfermagem e as necessidades de cuidado aos 
pacientes, mas, também, a situação financeira do país, o sistema de saúde em vigor, as leis de proteção do consumidor, as leis do exercício profissional e trabalhistas, além da atual política salarial (Fugulin, 1997 p.7).

O tempo médio diário de assistência, representado na identificação da carga de trabalho, é a principal variável dos métodos de dimensionamento de profissionais de enfermagem.

"Para adequar o quadro de pessoal em enfermagem, é necessário conhecer o tempo despendido na realização das atividades de enfermagem e intervenções de cuidado direto, indireto e atividades associadas e, dessa forma, conhecer o tempo produtivo da equipe" (Mello, 2011).

"A maior dificuldade encontrada na operacionalização dos métodos de dimensionamento de pessoal está relacionada à identificação do tempo médio despendido no atendimento das necessidades assistenciais dos pacientes, em decorrência de um conjunto de fatores, referentes à instituição, ao amparo legal, ao serviço de enfermagem e a clientela, que interferem na sua determinação" (Fugulin, 2010; Guimarães, 2015).

Como esses fatores podem diferir entre as instituições, Fugulin, Gaidzinski e Lima (2016, p.116) "consideram que o ideal seria que cada unidade levantasse o tempo de assistência de enfermagem de acordo com o padrão de assistência pretendido. No entanto, diante das dificuldades instrumentais e operacionais para a identificação desses parâmetros, referem que os tempos de assistência de enfermagem indicados na literatura podem ser testados e validados na realidade de cada serviço".

As pesquisas realizadas por esses autores têm procurado determinar as horas médias de cuidado de enfermagem por meio da identificação do tipo e frequência das intervenções de enfermagem requeridas pelos pacientes, mensurando o tempo médio utilizado para a sua realização com base na NIC.

Identificar o tempo médio de assistência tem sido tendência para analisar os processos de trabalho. Já identificar as intervenções/atividades e o tempo necessário para a equipe desenvolvê-las aponta quais intervenções/atividades utilizam mais tempo da equipe por categoria profissional, e quais atividades podem ser modificadas, modernizadas, 
otimizadas para que outras atividades possam ser realizadas com mais qualidade.

\subsection{MÉTODOS DE ESTUDO DE TEMPO E MOVIMENTO}

Os primeiros estudos dos tempos foram realizados por Frederick Taylor que realizava observações detalhadas dos trabalhadores utilizando cronômetro para medir o tempo necessário para realizar as tarefas e acreditava que, utilizando esse método, conseguiria melhorar a eficiência produtiva dos trabalhadores (Lopetegui, et al, 2014).

Frank Bunker Gilbreth e Lillian Molle, o casal Gilbreth, foram discípulos de Taylor e os pioneiros no método do estudo do movimento. Esse método tinha como objetivo reduzir o número de ações ao realizar uma tarefa a fim de aumentar a produtividade. Também estudaram os hábitos de trabalho dos colaboradores de uma empresa e desenvolveram técnicas para reduzir o número de movimentos para desenvolver determinada atividade diminuindo a fadiga e aumentando a produtividade. Propuseram o redesenho do ambiente de trabalho, a redução das horas diárias de trabalho e a implantação de dias de descanso remunerado (Lopetegui, et al, 2014).

$\mathrm{Na}$ adminstração contemporânea, essas duas técnicas, estudos de tempo e estudos de movimento foram integradas em um método conhecido como estudo dos tempos e movimentos (Lopetegui, et al, 2014).

Em resumo, o estudo de tempos e movimentos é o estudo do trabalho, que determina o tempo para realizar uma tarefa, e o estudo de movimentos onde são realizados o registro e a análise para encontrar a melhor maneira de realizar uma atividade.

Os estudos de tempo e movimento têm despertado interesse na área da saúde, pois a sua aplicação tem apresentado informações detalhadas sobre os processos de trabalho (Oliveira, 2016).

Os estudos de tempo e movimento foram aplicados para estudar os custos, a ineficiência na prestação de cuidados de saúde e para a qualidade e segurança dos pacientes (Lopetegui et al., 2014). 
Conhecer o processo de trabalho, as melhores práticas de trabalho, a quantidade de trabalhadores e o tempo gasto para realizar as atividades são informações que colaboram com a melhoria da qualidade de assistência ao paciente (Pelletier, Duffield, 2003).

Lopetegui et al. (2014) realizaram revisão sobre os estudos de tempo e movimento com ampla amostra de pesquisas realizadas na área da saúde. Encontraram amplo espectro de métodos que se referiam aos estudos de tempo de movimento e destacam-se o autorrelato em que os sujeitos a serem estudados fornecem os dados a serem analisados, a observação contínua e a amostragem do trabalho em que os dados de tempo e movimento são produzidas por observadores externos.

No método de autorrelato, os próprios sujeitos fornecem o dado relacionado ao tempo que destinaram para a realização das intervenções/atividades. É um método de baixo custo, porém os trabalhadores podem avaliar de forma subjetiva, o que pode gerar discrepâncias e resultar em estimativas superestimadas com relação ao tempo dedicado à atividade (Lopetegui et al.,2014).

$\mathrm{Na}$ observação contínua ou tempo contínuo de observação, o observador externo mantém a atenção sobre um sujeito continuamente - em tempo necessário para desempenhar uma tarefa, o observador registra o tempo despendido para a realização da atividade sem interrupções. Esta é uma abordagem útil para atividades de curta duração, pois fornece dados detalhados sobre como as atividades estão sendo desenvolvidas e capta os dados detalhados requerendo um observador para um sujeito (Lopetegui et al.,2014).

A amostragem do trabalho estima a proporção de tempo para a realização de uma atividade, identifica a tarefa que está sendo executada em um dado instante, repetindo a medida em intervalos fixos ou aleatórios predefinidos. Parte do princípio de que o trabalho tem natureza repetitiva e. utiliza a probabilidade para descrever como os trabalhadores gastam seu tempo. A amostragem do trabalho tem sido eficiente para estudos em que as atividades são elencadas em categorias, sendo possível classificar e descrever as atividades mais e menos frequentes (Lopetegui et al.,2014). 
A amostragem do trabalho tem como princípio as leis da probabilidade, que parte do argumento de que "durante um longo período de tempo, um número menor de ocorrências seguirá a mesma distribuição" (Hagerty, Chang, Spengler,1985).

A revisão bibliográfica realizada por Pelletier (2003) verificou que a amostragem do trabalho permite identificar como os trabalhdores estão gastando seu tempo com o objetivo de melhorar a qualidade dos cuidados prestados, fornecer informações necessárias para o planejamento e subsidiar as mudanças necessárias na unidade, reconhecer as competências que estão presentes e que precisam ser devolvidas e analisar as intervenções e os custos.

As pesquisadoras Gaidizinski e Fugulin têm realizado estudos e orientações que aplicam os métodos de tempo e movimento para compreender o processo de trabalho da equipe de enfermagem nos serviços de saúde no Brasil.

A definição utilizada sobre a técnica de amostragem do trabalho consiste em realizar observações diretas de modo intermitente, instantâneo e ao acaso, a fim de estimar a proporção do tempo gasto por um trabalhador para realizar as atividades no período de sua jornada diária de trabalho (Mello, 2011; Martins, Laugeni, 2000; Ampt et al., 2007).

O método de amostragem do trabalho empregado para estimar o tempo despendido pela equipe de enfermagem na realização de suas intervenções/atividades, em diferentes cenários, possibilitou a estimativa do tempo utilizado para a realização das intervenções/atividades e do tempo produtivo da equipe de enfermagem (Mello, 2002, 2011; Bordin, 2008; Soares, 2009; Garcia, 2009; Bonfim, 2010, 2014; Oliveira, 2016).

O método desenvolvido nos estudos do GP, cadastrado junto ao diretório do CNPq, liderados por Gaidzinski e Fugulin, com o objetivo de mensurar os tempos médios de assistência por tipo e frequência das intervenções/atividades nas unidades de saúde, revelou como o tempo de trabalho da equipe de enfermagem está sendo utilizado.

Estudos de Rogenski (2006, 2014), ao utilizar esse método, evidenciaram as proporções de tempo dedicado às intervenções de 
enfermagem e o tempo destinado a atividades, durante a jornada de trabalho, concluindo que o gerente do serviço tem subsídios para realizar mudanças nos processos de trabalho, no sentido de rever as práticas assistenciais para melhorar as condições de trabalho sem perder o foco na qualidade da assistência e na segurança do paciente e dos profissionais. 
4 MÉTODO 


\section{MÉTODO}

\subsection{TIPO DE ESTUDO}

Foi realizado um estudo secundário do tipo pesquisa documental, exploratório descritivo, de natureza quantitativa, com a finalidade de identificar os instrumentos de medida de carga de trabalho dos profissionais de saúde, as intervenções e o tempo médio despendido e a distribuição da carga de trabalho dos trabalhadores da saúde.

Os estudos secundários são necessários para integrar resultados de diversos estudos experimentais correlatos e que procuram estabelecer conclusões a partir de estudos primários, sendo possível estudar e registrar as probabilidades associadas a determinadas ações, intervenções ou tratamentos (Campana, 1999; Mafra, Travassos, 2006).

Esses estudos fornecem conhecimento e informação aos profissionais de saúde, aos gestores e pesquisadores para auxiliar o planejamento, a administração de serviços de saúde e definição de novas estratégias de pesquisa (Egger, Davey, Altman; 2001).

Quando há vários estudos primários que apresentam em comum o método, é necessário tirar conclusões sobre o corpo de dados científicos gerados para auxiliar a prática de enfermagem tanto assistencial quanto gerencial que deve se basear mais fortemente em dados de resultados de pesquisas (Polit, Beck; 2011 p.31).

Dados gerados a partir de estudos cumulativos são superiores a outros, pois as pesquisas realizadas em um formato sistematizado são fontes mais sofisticadas de aquisição de conhecimento (Polit, Beck; 2011 p. 33).

A evidência oferece caminhos para a tomada de decisão mais adequada, compreende resultados de pesquisas e consenso de especialistas reconhecidos (Galvão, Sawada, Rossi; 2002).

É possível dar oportunidade para alguns estudos, os quais podem ser tratados estatisticamente, gerando uma síntese estatística dos resultados numéricos dos trabalhos estudados (Campana, 1999).

O estudo exploratório descritivo trata da organização, extração e descrição de um conjunto de dados para compreender o comportamento das 
variáveis e, para isso, são utilizados gráficos tabelas e cálculos de medidas (Martins, 2005 p.19).

A pesquisa quantitativa utiliza procedimentos estruturados e instrumentos formais para coletar sistematicamente os dados, analisa e descreve de forma numérica as informações (Polit, Beck; 2011).

\subsection{FONTES DO ESTUDO}

As informações necessárias para a realização deste estudo serão obtidas a partir de dados primários que já foram coletados, tabulados, ordenados e analisados e estão catalogados e à disposição em bibliotecas físicas e virtuais (Mattar, 1996; Martins, 2005).

Gaidzinski (1998) apresentou um método de dimensionamento de pessoal de enfermagem que permitiu identificar e analisar as variáveis intervenientes nesse processo, o que tornou o dimensionamento um instrumento capaz de ajudar no planejamento e avaliação dos serviços de saúde (Fugulin, 2010).

O estudo do método de dimensionamento de pessoal proposto não se esgotava e necessitava de pesquisas que 0 aprimorassem, assim foi formado o GP "Gerenciamento de recursos humanos: conceitos, instrumentos e indicadores do processo de dimensionamento de pessoal", que está cadastrado no CNPq desde 1994, liderado por Raquel Rapone Gaidzinski e Fernanda Maria Togeiro Fugulin.

O GP desenvolveu estudos teóricos embasados no método Gaidzinski (1998). À medida que foi sendo estudado e aplicado em várias realidades, geraram dissertações, teses e artigos que produziram dados confiáveis, a fim de fornecer e compartilhar o conhecimento com alunos, pesquisadores, professores, enfermeiros e gerentes de serviços de saúde.

Diante da disseminação de informação e do conhecimento gerado, é necessário encontrar evidências para sustentar e apoiar o processo de tomada de decisão nas organizações (Galvão, Sawada, Mendes, 2003; Botelho, Cunha Macedo, 2011), o que pode favorecer a reorganização dos processos de trabalhos dos serviços de saúde. 
Para identificar os instrumentos de medida de carga de trabalho dos profissionais de saúde, as intervenções/atividades, a frequência e o tempo médio despendido e a distribuição da carga de trabalho dos trabalhadores da saúde, foi realizada pesquisa documental em fontes primárias (dissertações e teses) como fontes de informações bibliográficas, em que os estudos foram tratados de forma sistemática para que fosse possível analisar 0 conhecimento já construído sobre o tema. Foram eleitas as dissertações e teses por considerar que estas apresentaram informações mais completas sobre o tema.

A utilização dos estudos, desenvolvidos pelo GP, foi uma decisão intencional, pois, por um lado, podem gerar uma configuração de um estado endógeno; por outro, podem organizar o conhecimento já produzido e identificar lacunas e limitações para realização de novas pesquisas.

\subsection{PROCEDIMENTOS METODOLÓGICOS}

\subsubsection{Levantamento das dissertações e teses}

Para serem identificadas todas as dissertações e teses, orientadas por Gaidzinski e Fugulin, foram consultadas as bases de dados da Biblioteca Digital de Teses e Dissertações da Universidade de São Paulo (TESES-USP) e o banco de dados bibliográficos da USP (DEDALUS).

As bases de dados são sistemas de indexação de periódicos, livros, teses, relatórios, anais de eventos, instrumentos que facilitam a recuperação e a utilização do conhecimento científico em pesquisa (Lacerda, Ensslin, Ensslin; 2012).

A base TESES-USP foi criada em 2001 e permite o acesso das comunidades nacional e internacional aos estudos defendidos na Universidade de São Paulo, cujo material é disponibilizado na íntegra no link http://www.teses.usp.br/.

Já o Sistema DEDALUS é um catálogo de consulta, em que é possível pesquisar todas as obras de interesse acadêmico, permite a localização do material no acervo da universidade e está disponível no link http://dedalus.usp.br. 
A partir do ano de 2001, as teses e dissertações estão disponíveis na íntegra no banco de TESES-USP.

Para encontrar todas as dissertações e teses, foi utilizada a estratégia de busca que contemplava as informações abaixo e, com elas, foi construído o banco de dados inicial:

- Nome do orientador: Gaidzinski e/ou Fugulin;

- Autor;

- Ano;

- Tipo de material: dissertação ou tese;

- Título;

- Descritores;

- Objetivo Geral;

- Objetivo Específico;

- Instrumento;

- SCP - Sistema de Classificação de Paciente;

- Estudou a variável Tempo;

- Usou NIC;

- Usou NAS;

- Técnica para obtenção do tempo de trabalho (Método para medir o tempo);

- Localização DEDALUS nº de localização na biblioteca da EEUSP;

- Localização TESES-USP.

\subsubsection{Critérios de inclusão}

As dissertações e teses foram selecionadas a partir da triagem dos títulos e análise dos resumos. Para a constituição da amostra, foram selecionados os estudos que apresentaram os seguintes critérios de inclusão:

- Descreve a construção de instrumentos para a medida de carga de trabalho; 
- Utiliza técnicas para medir o tempo de trabalho;

- Apresenta o mapeamento das atividades/intervenções fundamentado no referencial teórico da taxonomia Classificação das Intervenções de Enfermagem (NIC);

- Investiga a medida e a distribuição da variável Tempo médio para a realização das intervenções/atividades;

- Apresenta a distribuição da carga de trabalho dos profissionais de saúde.

\subsubsection{Definição das informações a serem extraídas dos estudos}

Nesta etapa, foi realizada a leitura dos estudos e deles foram extraídas as informações para a construção do banco de dados em planilha eletrônica (Apêndice 1):

- Autor;

- Ano;

- Unidade estudada;

- Categoria profissional;

- Método utilizado para encontrar o tempo médio: amostragem do trabalho, cronometragem, tempo contínuo, outros;

- Instrumento construído;

- Tipo de validação (de rosto, clínico);

- Número de intervenção/atividade;

- Intervenções de cuidado direto e indireto, atividades associadas e pessoais e outras;

- Domínios da NIC que estão presentes;

- Jornada de trabalho;

- Quantidade de amostras em cada estudo. 


\subsubsection{Tratamento, análise e interpretação dos dados encontrados}

Os dados coletados foram organizados e armazenados em banco de dados e realizada análise descritiva que deram subsídio para atender aos objetivos propostos neste estudo.

Os resultados estão apresentados em forma de quadros, gráficos e tabelas.

\subsubsection{Apresentação e discussão dos resultados}

Concluídas as etapas citadas, foi possível identificar nos estudos analisados: as categorias profissionais envolvidas; as unidades/áreas de saúde; as intervenções/atividades identificadas que contribuíram com a carga de trabalho; o método utilizado para medir o tempo; a distribuição percentual do tempo despendido na realização das intervenções/atividades, segundo as categorias profissionais e unidades/áreas de saúde.

Por tratar-se de um estudo documental, cuja fonte principal é de origem de documentos de acesso público, o presente estudo não foi submetido ao Comitê de Ética de Pesquisas com Seres Humanos. 


\section{RESULTADOS: APRESENTAÇ̃̃O E DISCUSSÃO}




\section{RESULTADOS: APRESENTAÇÃO E DISCUSSÃO}

\subsection{APRESENTAÇÃO DOS ESTUDOS SELECIONADOS}

As bases de dados consultadas foram DEDALUS e TESES-USP, em que foi realizada a busca de dissertações e teses orientadas por Gaidzinski e Fugulin, elaboradas pelos alunos de pós-graduação do Programa de Pós-graduação em Gerenciamento em Enfermagem (PPGEn) e integrantes do grupo de pesquisa "Gerenciamento de recursos humanos: conceitos, instrumentos e indicadores do processo de dimensionamento de pessoal", cadastrado junto ao CNPq. A busca foi realizada dezembro de 2016.

Quadro 1 - Distribuição da produção de dissertações e teses do grupo de pesquisa Gerenciamento de recursos humanos: conceitos, instrumentos e indicadores do processo de dimensionamento de pessoal. São Paulo, 2017.

\begin{tabular}{|c|c|c|c|c|c|c|c|}
\hline \multirow{3}{*}{$\begin{array}{l}\text { Tipo de } \\
\text { estudo }\end{array}$} & \multicolumn{4}{|c|}{ Orientador } & \multirow{2}{*}{\multicolumn{2}{|c|}{ Total }} & \multirow[b]{3}{*}{ Total } \\
\hline & \multicolumn{2}{|c|}{ Gaidzinski } & \multicolumn{2}{|c|}{ Fugulin } & & & \\
\hline & Concluído & $\begin{array}{c}\text { Em } \\
\text { andamento }\end{array}$ & Concluído & $\begin{array}{c}\text { Em } \\
\text { andamento }\end{array}$ & $\begin{array}{c}\text { Total } \\
\text { concluído }\end{array}$ & $\begin{array}{c}\text { Total em } \\
\text { andament } \\
0\end{array}$ & \\
\hline Dissertação & 17 & & 11 & 1 & 28 & 1 & 29 \\
\hline Tese & 12 & 3 & 4 & 1 & 16 & 4 & 20 \\
\hline $\begin{array}{l}\text { Livre- } \\
\text { docência }\end{array}$ & 1 & & 1 & & 2 & & 2 \\
\hline Total & 30 & 3 & 16 & 2 & 46 & 5 & 51 \\
\hline
\end{tabular}

Em 1994, Gaidzinski iniciou suas atividades na orientação, coordenação e desenvolvimento de projetos de investigação, o que tornou possível criar, junto ao CNPq, o Grupo de Pesquisa "Gerenciamento de recursos humanos: conceitos, instrumentos e indicadores do processo de dimensionamento de pessoal".

Em 1998, Fugulin ingressou como docente do Departamento de Orientação Profissional da Escola de Enfermagem da USP (EEUSP), em seguida foi credenciada no Programa de Pós-Graduação da (EEUSP) e 
iniciou parceria na orientação, coordenação e desenvolvimento de projetos no grupo de pesquisa.

No Quadro 1, são apresentadas as dissertações e teses, orientadas por Gaidzinski e Fugulin, que contribuíram de forma expressiva para a construção do conhecimento na área de gerenciamento em enfermagem, demonstrado por Meneses (2014) que identificou, dentre os principais referenciais teóricos utilizados na análise de pesquisas sobre administração em enfermagem, o método e os instrumentos de dimensionamento da força de trabalho de enfermagem propostos por estas pesquisadoras.

Figura 1 - Fluxograma de seleção das teses e dissertações que trataram da construção de instrumentos de medida da carga de trabalho. São Paulo, 2017.

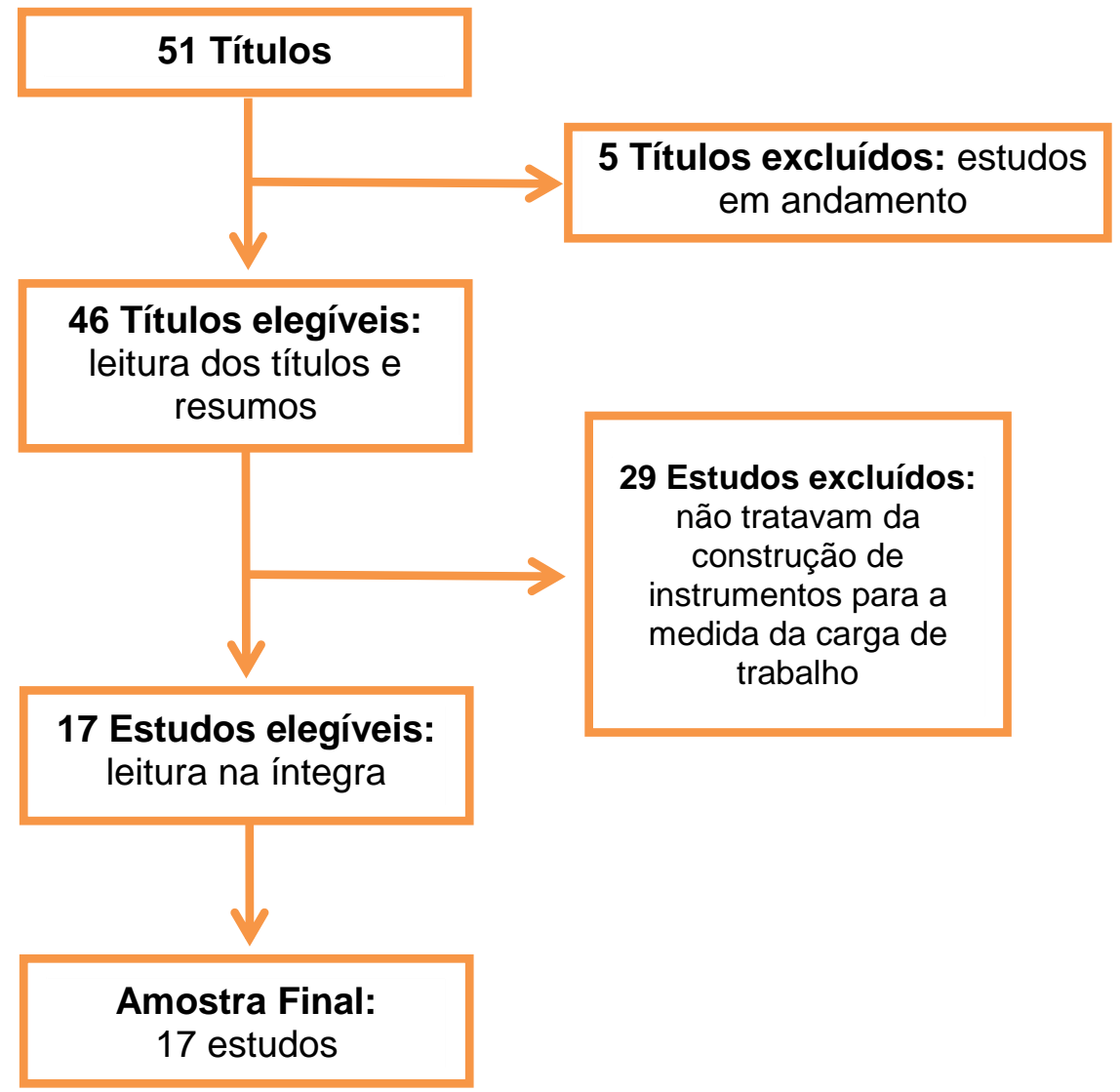

Foram encontrados 51 títulos de dissertações e teses; destes, cinco foram excluídos, pois se tratavam de estudos em andamento na 
ocasião da coleta de dados. Assim, 46 estudos concluídos foram

submetidos à leitura do título e do resumo, Quadro 2.

Quadro 2 - Identificação das dissertações e teses concluídas pelos integrantes do grupo de pesquisa gerenciamento de recursos humanos: conceitos, instrumentos e indicadores do processo de dimensionamento de pessoal. São Paulo 2017.

(continua)

\begin{tabular}{|c|c|}
\hline Estudo & Referência \\
\hline E1 & $\begin{array}{l}\text { Perroca MG. Sistema de classificação de pacientes: construção e validação de um instrumento } \\
\text { [dissertação]. São Paulo: Escola de Enfermagem, Universidade de São Paulo; } 1996 .\end{array}$ \\
\hline E2 & $\begin{array}{l}\text { Fugulin FMT. Sistema de classificação de pacientes: análise das horas de assistência de } \\
\text { enfermagem [dissertação]. São Paulo: Escola de Enfermagem, Universidade de São Paulo; } \\
\text { 1997. }\end{array}$ \\
\hline E3 & $\begin{array}{l}\text { Gaidzinski RR. Dimensionamento do pessoal de enfermagem em instituições hospitalares [tese } \\
\text { livre-docêncial. São Paulo: Escola de Enfermaqem, Universidade de São Paulo: } 1998 .\end{array}$ \\
\hline E4 & $\begin{array}{l}\text { Ortiz DCF. Administração de recursos materiais: custo do material de consumo na visão dos } \\
\text { profissionais de enfermagem [dissertação]. São Paulo: Escola de Enfermagem, Universidade } \\
\text { de São Paulo; } 1998 .\end{array}$ \\
\hline E5 & $\begin{array}{l}\text { Pavani LMD. Análise do dimensionamento de pessoal de enfermagem na unidade pós- } \\
\text { operatória de cirurgia cardíaca de um hospital universitário especializado em cardiologia } \\
\text { [dissertação]. São Paulo: Escola de Enfermagem, Universidade de São Paulo; } 2000 .\end{array}$ \\
\hline E6 & $\begin{array}{l}\text { Possari JF. Dimensionamento de pessoal de enfermagem em centro cirúrgico no período } \\
\text { transoperatório: estudo das horas de assistência segundo o porte cirúrgico [dissertação]. São } \\
\text { Paulo: Escola de Enfermagem, Universidade de São Paulo; } 2001 \text {. }\end{array}$ \\
\hline E7 & $\begin{array}{l}\text { Perroca MG. Instrumento de classificação de pacientes de Perroca: validação clínica [tese]. } \\
\text { São Paulo: Escola de Enfermagem, Universidade de São Paulo; } 2001 .\end{array}$ \\
\hline E8 & $\begin{array}{l}\text { Bochembuzio L. Instrumento para classificação de recém-nascidos de acordo com o grau de } \\
\text { dependência [dissertação]. São Paulo: Escola de Enfermagem, Universidade de São Paulo; } \\
2002 .\end{array}$ \\
\hline E9 & $\begin{array}{l}\text { Nomura FH. Rotatividade da equipe de enfermagem: estudo em um hospital-escola } \\
\text { [dissertação]. São Paulo: Escola de Enfermagem, Universidade de São Paulo; } 2002 .\end{array}$ \\
\hline E10 & $\begin{array}{l}\text { Alves NRC. Sistema de classificação de pacientes (SCP): aplicação do instrumento de Perroca } \\
\text { (2000) em hospital geral [dissertação]. São Paulo: Escola de Enfermagem, Universidade de } \\
\text { São Paulo; 2002. }\end{array}$ \\
\hline E11 & $\begin{array}{l}\text { Mello MC. Estudo do tempo no trabalho da enfermagem: construção de instrumento de } \\
\text { classificação de atividades para implantação do método de amostragem do trabalho } \\
\text { [dissertaça]. São Paulo: Escola de Enfermagem, Universidade de São Paulo; } 2002 .\end{array}$ \\
\hline E12 & $\begin{array}{l}\text { Fugulin FMT. Dimensionamento de pessoal de enfermagem: avaliação do quadro de pessoal } \\
\text { de unidade de internação de hospital de ensino [tese]. São Paulo: Escola de Enfermagem, } \\
\text { Universidade de São Paulo; 2002.. }\end{array}$ \\
\hline E13 & $\begin{array}{l}\text { Farias FAC. Dimensionamento de pessoal de enfermagem pronto-socorro especializado em } \\
\text { afecções cardiovascular [tese]. São Paulo: Escola de Enfermagem, Universidade de São Paulo; } \\
2003 \text {. }\end{array}$ \\
\hline E14 & $\begin{array}{l}\text { Conishi RMY. Avaliação do NAS -Nursing Activities Score - como instrumento de medida de } \\
\text { carga de trabalho em UTI [dissertação]. São Paulo: Escola de Enfermagem, Universidade de } \\
\text { São Paulo; } 2005 .\end{array}$ \\
\hline E15 & $\begin{array}{l}\text { Dal Ben LW. Dimensionamento do pessoal de enfermagem em assistência domiciliária: } \\
\text { percepção de gerentes e enfermeiras [tese]. São Paulo: Escola de Enfermagem, Universidade } \\
\text { de São Paulo; } 2005 . .\end{array}$ \\
\hline E16 & $\begin{array}{l}\text { Rogenski KE. Tempo de assistência de enfermagem: identificação e análise em instituição } \\
\text { hospitalar de ensino [dissertação]. São Paulo: Escola de Enfermagem, Universidade de São } \\
\text { Paulo; } 2006 \text {. }\end{array}$ \\
\hline E17 & $\begin{array}{l}\text { Santos NC. Construção de instrumento para identificação da carga de trabalho da equipe de } \\
\text { enfermagem em unidades pediátricas [dissertação]. São Paulo: Escola de Enfermagem, } \\
\text { Universidade de São Paulo; } 2006 . .\end{array}$ \\
\hline
\end{tabular}


(continuação)

\begin{tabular}{|c|c|}
\hline Estudo & Referência \\
\hline E18 & $\begin{array}{l}\text { Dias MCCBD. Aplicação do Nursing Activities Score (NAS) como instrumento de medida de } \\
\text { carga de trabalho de enfermagem em UTI Cirúrgica Cardiológica [dissertação]. São Paulo: } \\
\text { Escola de Enfermagem, Universidade de São Paulo; 2006. }\end{array}$ \\
\hline E19 & $\begin{array}{l}\text { Bochembuzio L. Avaliação do instrumento Nursing Activities Score (NAS) em neonatologia } \\
\text { [tese]. São Paulo: Escola de Enfermagem, Universidade de São Paulo; } 2007 .\end{array}$ \\
\hline E20 & $\begin{array}{l}\text { Bordin LC. Distribuição do tempo das enfermeiras: identificação e análise em unidade médico- } \\
\text { cirúrgica [dissertação]. São Paulo: Escola de Enfermagem, Universidade de São Paulo; } 2008 .\end{array}$ \\
\hline E21 & $\begin{array}{l}\text { Garcia EA. Distribuição do tempo de trabalho das enfermeiras em unidades de emergência } \\
\text { [dissertação]. São Paulo: Escola de Enfermagem, Universidade de São Paulo; } 2009 .\end{array}$ \\
\hline E22 & $\begin{array}{l}\text { Costa JA. Atividades de enfermagem no centro de material e esterilização: subsídios para o } \\
\text { dimensionamento de pessoal [dissertação]. São Paulo: Escola de Enfermagem, Universidade } \\
\text { de São Paulo; 2009. }\end{array}$ \\
\hline E23 & $\begin{array}{l}\text { Sancinetti TR. Absenteísmo por doença na equipe de enfermagem: taxa, diagnóstico médico e } \\
\text { perfil dos profissionais [tese]. São Paulo: Escola de Enfermagem, Universidade de São Paulo; } \\
2009 \text {. }\end{array}$ \\
\hline E24 & $\begin{array}{l}\text { Soares AVN. Carga de trabalho de enfermagem no sistema de alojamento conjunto [tese]. } \\
\text { São Paulo: Escola de Enfermagem, Universidade de São Paulo; } 2009 .\end{array}$ \\
\hline E25 & $\begin{array}{l}\text { Bonfim D. Identificação das intervenções de enfermagem na atenção básica à saúde como } \\
\text { parâmetro para o dimensionamento de trabalhadores [dissertação]. São Paulo: Escola de } \\
\text { Enfermagem, Universidade de São Paulo; } 2009 \text {. }\end{array}$ \\
\hline E26 & $\begin{array}{l}\text { Tsukamoto R. Tempo médio de cuidado ao paciente de alta dependência de enfermagem, } \\
\text { segundo o Nursing Activities Score (NAS) [dissertação]. São Paulo: Escola de Enfermagem, } \\
\text { Universidade de São Paulo; } 2010 \text {. }\end{array}$ \\
\hline E27 & $\begin{array}{l}\text { Fugulin FMT. Parâmetros oficiais para o dimensionamento de profissionais de enfermagem } \\
\text { em instituições hospitalares: análise da Resolução COFEN no } 293 / 04 \text { [tese livre-docência]. } \\
\text { São Paulo: Escola de Enfermagem, Universidade de São Paulo; } 2010 .\end{array}$ \\
\hline E28 & $\begin{array}{l}\text { Garcia PC. Tempo de assistência de enfermagem em UTI e indicadores de qualidade } \\
\text { assistencial: análise correlacional [dissertação]. São Paulo: Escola de Enfermagem, } \\
\text { Universidade de São Paulo; 2011. }\end{array}$ \\
\hline E29 & $\begin{array}{l}\text { Possari JF. Dimensionamento de pessoal de enfermagem em centro cirúrgico especializado } \\
\text { em oncologia: análise dos indicadores intervenientes [tese]. São Paulo: Escola de } \\
\text { Enfermagem, Universidade de São Paulo; } 2011 .\end{array}$ \\
\hline E30 & $\begin{array}{l}\text { Rossetti AC. Dimensionamento de pessoal de enfermagem em unidade de pronto socorro } \\
\text { geral [dissertação]. São Paulo: Escola de Enfermagem, Universidade de São Paulo; } 2011 .\end{array}$ \\
\hline E31 & $\begin{array}{l}\text { Mello MC. Carga de trabalho de enfermagem: indicadores de tempo de unidades de clínica } \\
\text { médica, cirúrgica e terapia intensiva adulto [tese]. São Paulo: Escola de Enfermagem, } \\
\text { Universidade de São Paulo; } 2011 .\end{array}$ \\
\hline E32 & $\begin{array}{l}\text { Pereira IM. Dimensionamento informatizado de profissionais de enfermagem: avaliação de um } \\
\text { software [dissertação]. São Paulo: Escola de Enfermagem, Universidade de São Paulo; } 2011 .\end{array}$ \\
\hline E33 & $\begin{array}{l}\text { Cruz CWM. Construção de instrumento de medida do tempo de trabalho da enfermagem em } \\
\text { centro de diagnóstico por imagem [dissertação]. São Paulo: Escola de Enfermagem, } \\
\text { Universidade de São Paulo; } 2012 \text {. }\end{array}$ \\
\hline E34 & $\begin{array}{l}\text { Ricardo CM. Tempo das intervenções e atividades de enfermagem na sala de recuperação } \\
\text { pós-anestésica: subsídio para determinação da carga de trabalho [dissertação]. São Paulo: } \\
\text { Escola de Enfermagem, Universidade de São Paulo; } 2013 .\end{array}$ \\
\hline E35 & $\begin{array}{l}\text { Coelho MA. Dimensionamento de pessoal em instituições de saúde [tese]. Goiás: Faculdade } \\
\text { de Enfermagem, Universidade Federal de Goiás; } 2013\end{array}$ \\
\hline E36 & $\begin{array}{l}\text { Martin LGR. Carga de trabalho de enfermagem em ambulatório de oncologia e hematologia } \\
\text { [dissertação]. São Paulo: Escola de Enfermagem, Universidade de São Paulo; } 2013 .\end{array}$ \\
\hline E37 & $\begin{array}{l}\text { Vieira FPC. Correlação entre tempo de assistência de enfermagem e indicadores de qualidade } \\
\text { assistencial em UTI Pediátrica e Neonatal [dissertação]. São Paulo: Escola de Enfermagem, } \\
\text { Universidade de São Paulo; } 2014 .\end{array}$ \\
\hline E38 & $\begin{array}{l}\text { Andrade ACR. Distribuição do tempo de trabalho dos profissionais de enfermagem em } \\
\text { unidade de pediatria [dissertação]. São Paulo: Escola de Enfermagem, Universidade de São } \\
\text { Paulo; } 2014 \text {. }\end{array}$ \\
\hline
\end{tabular}




\section{(continuação)}

\begin{tabular}{|c|c|}
\hline Estudo & Referência \\
\hline E39 & $\begin{array}{l}\text { Leal AERB. Carga de trabalho do profissional administrativo na atenção primária à saúde } \\
\text { [dissertação]. São Paulo: Escola de Enfermagem, Universidade de São Paulo; } 2014 .\end{array}$ \\
\hline E40 & $\begin{array}{l}\text { Bonfim D. Planejamento da força de trabalho de enfermagem na Estratégia de Saúde da } \\
\text { Família: indicadores de carga de trabalho [tese]. São Paulo: Escola de Enfermagem, } \\
\text { Universidade de São Paulo; } 2014 .\end{array}$ \\
\hline E41 & $\begin{array}{l}\text { Rogenski KE. Carga de trabalho de enfermagem em unidade de pediatria [tese]. São Paulo: } \\
\text { Escola de Enfermagem, Universidade de São Paulo; } 2014 .\end{array}$ \\
\hline E42 & $\begin{array}{l}\text { Costa JA. Carga de trabalho da equipe de enfermagem em centro de material e esterilização: } \\
\text { proposta de instrumento [tese]. São Paulo: Escola de Enfermagem, Universidade de São } \\
\text { Paulo; } 2015 \text {. }\end{array}$ \\
\hline E43 & $\begin{array}{l}\text { Guimarães CP. Tempo médio de assistência de enfermagem em unidade de terapia intensiva } \\
\text { pediátrica [dissertação]. São Paulo: Escola de Enfermagem, Universidade de São Paulo; } \\
2015 .\end{array}$ \\
\hline E44 & $\begin{array}{l}\text { Cruz CWM. Carga de trabalho de profissionais de enfermagem em centro de diagnóstico por } \\
\text { imagem [tese]. São Paulo: Escola de Enfermagem, Universidade de São Paulo; } 2015 .\end{array}$ \\
\hline E45 & $\begin{array}{l}\text { Oliveira CA. Carga de trabalho do nutricionista clínico: estudo de tempo e movimento contínuo } \\
\text { em unidades de internação hospitalar [tese]. São Paulo: Escola de Enfermagem, Universidade } \\
\text { de São Paulo; } 2016 \text {. }\end{array}$ \\
\hline E46 & $\begin{array}{l}\text { Garcia PC. Correlação entre tempo de assistência de enfermagem e indicadores de qualidade } \\
\text { assistencial em unidades de terapia intensiva [tese]. São Paulo: Escola de Enfermagem, } \\
\text { Universidade de São Paulo; } 2016 \text {. }\end{array}$ \\
\hline
\end{tabular}

(conclusão)

Após a leitura do título e do resumo, para verificar quais estudos contemplavam os critérios de inclusão desta pesquisa, foram selecionados 17 estudos (figura 1 e 2). Esses estudos foram lidos na íntegra para extração dos dados necessários para alcançar os objetivos propostos.

Figura 2 - Estudos concluídos que contemplaram os critérios de inclusão. São Paulo, 2017.

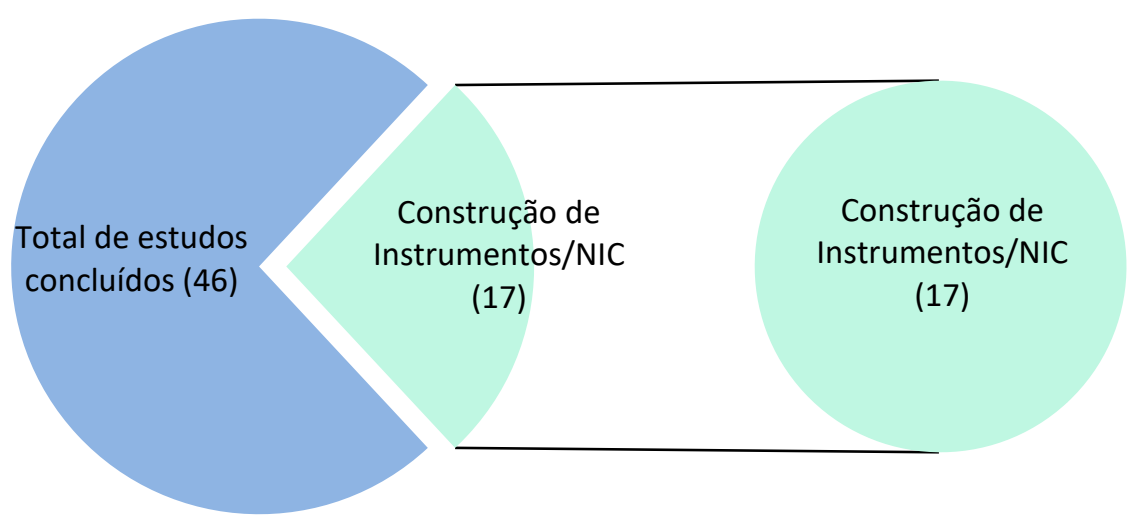


O Quadro 3 apresenta os 17 estudos (dissertações e teses), que utilizaram o referencial da taxonomia NIC, segundo autor, nome do instrumento utilizado, tipo de unidade, tipo de serviço, quantidade de unidades estudadas.

\subsection{IDENTIFICAÇÃO E APRESENTAÇÃO DOS INSTRUMENTOS DE MEDIDA DE CARGA DE TRABALHO}

Quadro 3 - Identificação das dissertações e teses selecionadas que utilizaram a taxonomia NIC, segundo autor, nome do instrumento, tipo de unidade, tipo de serviço e número de unidades/serviços. São Paulo, 2017.

\begin{tabular}{|c|c|c|c|c|c|}
\hline \multicolumn{6}{|c|}{ (continua) } \\
\hline ID & Estudo & Nome do instrumento & Unidade & $\begin{array}{l}\text { Tipo de } \\
\text { serviço }\end{array}$ & $\begin{array}{c}\text { Número de } \\
\text { unidades/ } \\
\text { serviços }\end{array}$ \\
\hline 1 & $\begin{array}{l}\text { Santos, } \\
2006\end{array}$ & $\begin{array}{l}\text { Instrumento para identificação da carga de } \\
\text { trabalho da equipe de enfermagem de } \\
\text { unidades pediátricas. }\end{array}$ & $\begin{array}{l}\text { Unidade de } \\
\text { internação } \\
\text { pediátrica }\end{array}$ & Hospitalar & 1 \\
\hline 2 & $\begin{array}{l}\text { Bordin, } \\
2008\end{array}$ & Instrumento próprio para coleta de dados. & $\begin{array}{l}\text { Unidade de } \\
\text { internação de } \\
\text { clínica médico- } \\
\text { cirúrgica } \\
\end{array}$ & Hospitalar & 2 \\
\hline 3 & $\begin{array}{l}\text { Garcia, } \\
2009\end{array}$ & $\begin{array}{l}\text { Medida do tempo de trabalho das enfermeiras } \\
\text { em unidade de emergência. }\end{array}$ & Emergência & Hospitalar & 1 \\
\hline 4 & $\begin{array}{l}\text { Soares, } \\
2009\end{array}$ & $\begin{array}{l}\text { Instrumento para mensuração da carga de } \\
\text { trabalho do Alojamento Conjunto pela } \\
\text { amostragem do trabalho. }\end{array}$ & $\begin{array}{l}\text { Alojamento } \\
\text { conjunto }\end{array}$ & Hospitalar & 1 \\
\hline 5 & $\begin{array}{l}\text { Bonfim, } \\
2009\end{array}$ & $\begin{array}{l}\text { Instrumento para amostragem do trabalho da } \\
\text { enfermagem na atenção básica à saúde. }\end{array}$ & $\begin{array}{l}\text { Unidade Básica de } \\
\text { Saúde }\end{array}$ & $\begin{array}{l}\text { Unidade de } \\
\text { saúde da } \\
\text { família }\end{array}$ & 1 \\
\hline 6 & $\begin{array}{l}\text { Possari, } \\
2011\end{array}$ & $\begin{array}{l}\text { Instrumento para identificar a carga de } \\
\text { trabalho dos profissionais de enfermagem do } \\
\text { centro cirúrgico especializado em oncologia. }\end{array}$ & $\begin{array}{l}\text { Centro cirúrgico de } \\
\text { oncologia }\end{array}$ & Hospitalar & 1 \\
\hline 7 & $\begin{array}{l}\text { Mello, } \\
2011\end{array}$ & $\begin{array}{l}\text { Instrumento para mensuração de carga de } \\
\text { trabalho das unidades de clínica médica, } \\
\text { clínica cirúrgica e terapia intensiva adulto. }\end{array}$ & \begin{tabular}{|l|} 
Clínica Médica, \\
Clínica Cirúrgica, \\
Unidade de Terapia \\
Intensiva Adulto \\
\end{tabular} & Hospitalar & 3 \\
\hline 8 & Cruz, 2012 & $\begin{array}{l}\text { Instrumento de medida da distribuição do } \\
\text { tempo de trabalho dos profissionais de } \\
\text { enfermagem em centro de diagnóstico por } \\
\text { imagem. }\end{array}$ & $\begin{array}{l}\text { Mamografia, } \\
\text { Radiologia } \\
\text { convencional, } \\
\text { Ressonância } \\
\text { Nuclear Magnética, } \\
\text { Tomografia } \\
\text { Computadorizada e } \\
\text { Ultrassonografia }\end{array}$ & Hospitalar & 5 \\
\hline 9 & $\begin{array}{l}\text { Ricardo, } \\
2013\end{array}$ & $\begin{array}{l}\text { Instrumento de coleta de dados - Listagem } \\
\text { das intervenções e atividades - recuperação } \\
\text { pós-anestésica. }\end{array}$ & \begin{tabular}{|l|} 
Sala de \\
recuperação pós- \\
anestésica
\end{tabular} & Hospitalar & 1 \\
\hline 10 & $\begin{array}{l}\text { Martin, } \\
2013\end{array}$ & $\begin{array}{l}\text { Intervenções essenciais para enfermagem } \\
\text { oncológica e oncologia pediátrica. }\end{array}$ & $\begin{array}{l}\text { Ambulatório } \\
\text { especializado em } \\
\text { oncologia e } \\
\text { hematologia (adulto } \\
\text { e infantil) }\end{array}$ & Ambulatório & 1 \\
\hline
\end{tabular}


(continuação)

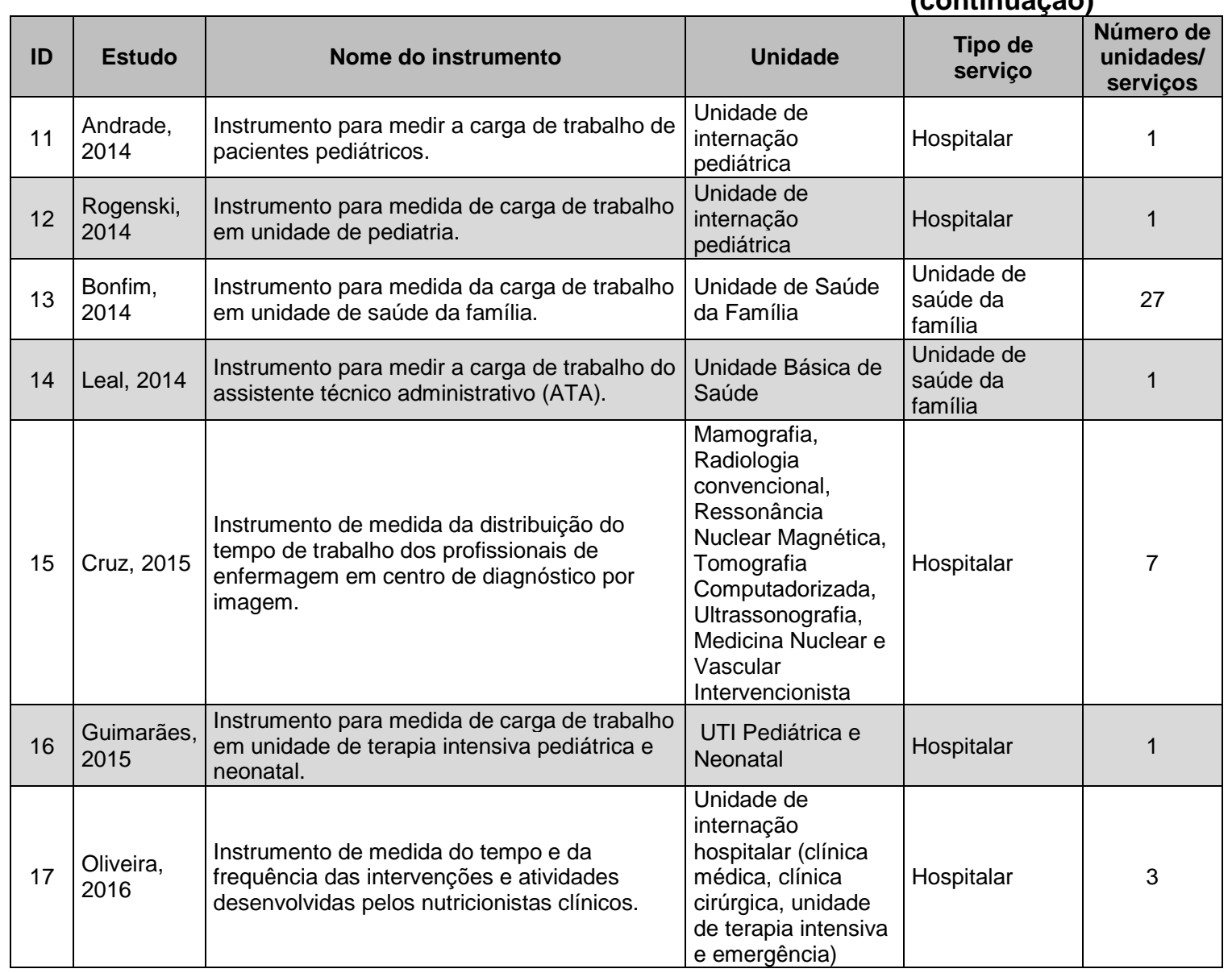

(conclusão)

Ao observar o tipo de serviço na construção dos instrumentos, houve predomínio de instrumentos para medir a carga de trabalho em unidades hospitalares. Em 2009, foi desenvolvido o primeiro instrumento para unidade de saúde da família que foi, posteriormente, em 2014, ampliado e aplicado em 27 unidades das cinco regiões geográficas do Brasil. Em 2012 e 2015, foi elaborado e aperfeiçoado o instrumento para medir a carga de trabalho para centro de diagnóstico por imagem. Em 2013, foram utilizadas as intervenções essenciais para área de enfermagem oncológica, propostas pela NIC, no instrumento para medida de carga de trabalho de ambulatório de oncologia e hematologia. Em 2016, foi desenvolvido o instrumento para medir a carga de trabalho de nutricionistas clínicos. 
Gráfico 1 - Instrumentos construídos, segundo categoria profissional. São Paulo, 2017.

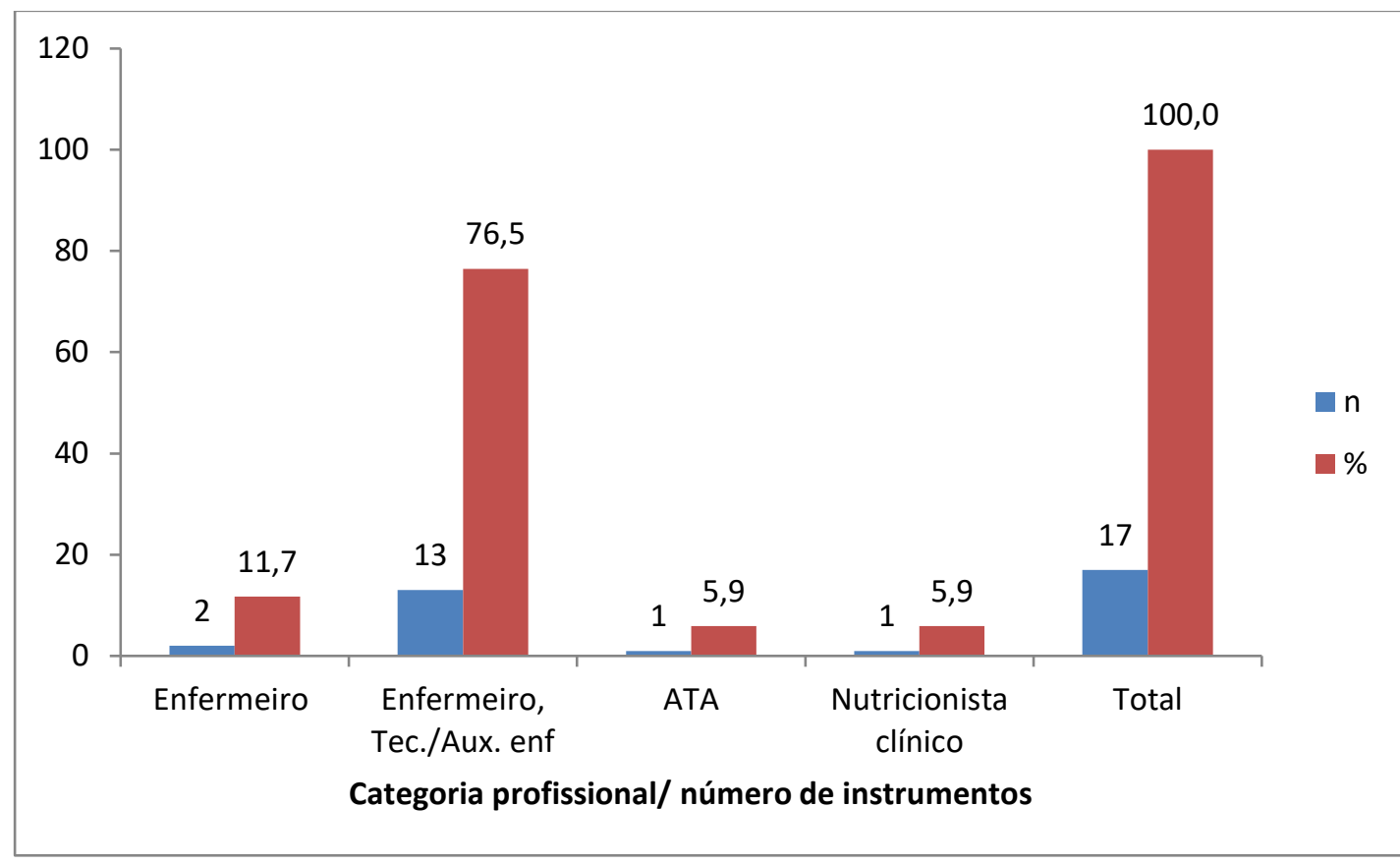

No que refere à categoria profissional estudada, os instrumentos de Santos (2006) e Bordin (2008) foram construídos para enfermeiros $(11,7 \%)$. Os instrumentos de Leal (2014) e Oliveira (2016) para assistente técnico administrativo (5,9\%) e nutricionista (5,9\%), respectivamente. Os demais instrumentos (76,5\%) para a equipe de enfermagem composta por enfermeiros e técnicos/auxiliares de enfermagem. Ressalta-se que, embora a tese de Bonfim (2014) tenha analisado os profissionais de enfermagem, o instrumento foi elaborado para todas as categorias da equipe de saúde da família (Bonfim et al., 2015).

Essas produções ocorreram no período de dez anos (Gráfico 2), a medida em que os instrumentos foram sendo aperfeiçoados e aplicados a outras categorias profissionais, foi possível evidenciar que 0 método proposto, para medida de carga de trabalho, por Gaidzinski e Fugulin, alicerçado nas intervenções da taxonomia da NIC, podia ser aplicado a outras categorias profissionais além da enfermagem. 
Gráfico 2 - Produção dos instrumentos de medida da carga de trabalho, segundo a NIC, período de 2006 a 2016. São Paulo, 2017.

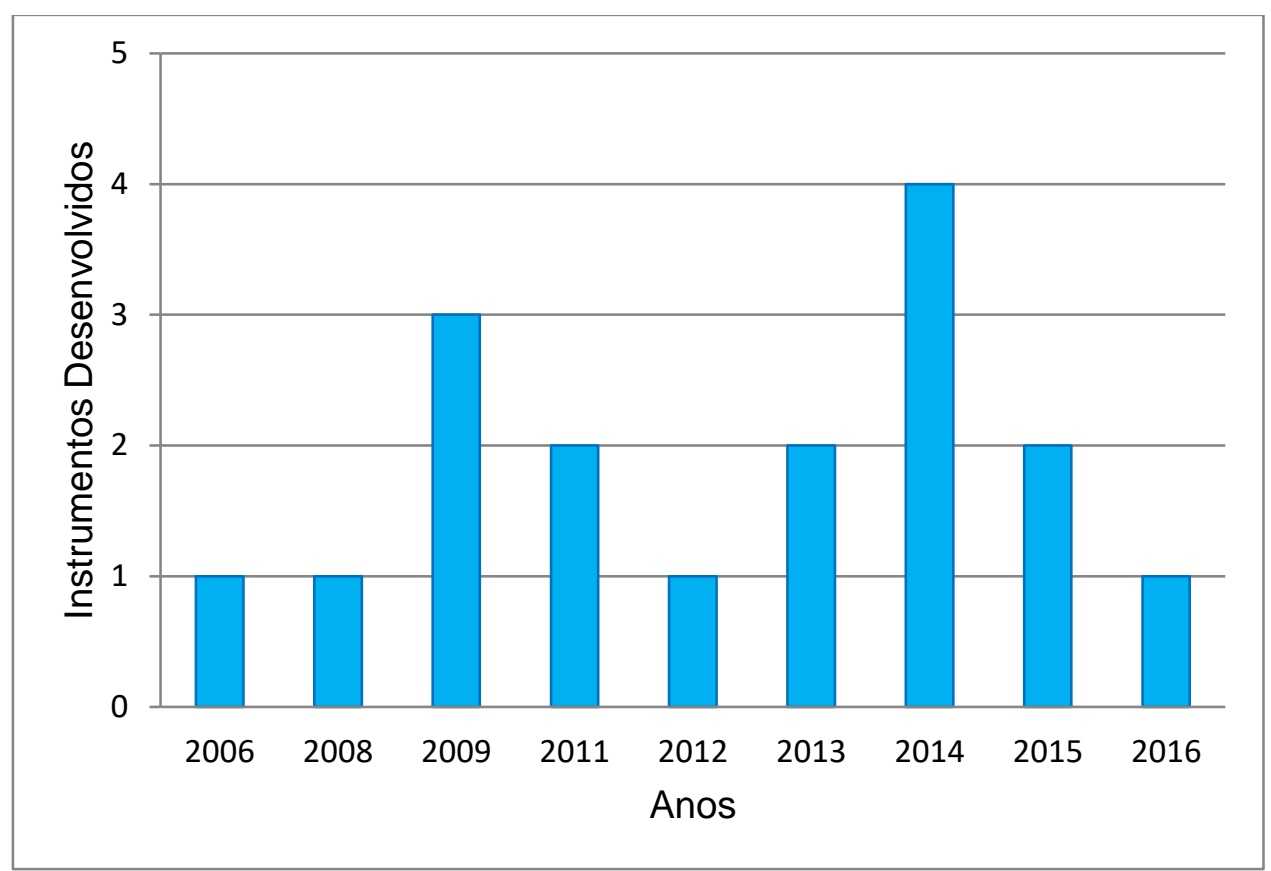

Quadro 4 - Identificação dos estudos por tipo de unidade/serviço. São Paulo, 2017.

\begin{tabular}{|l|l|}
\hline \multicolumn{1}{|c|}{ Tipo de unidade/serviço } & \multicolumn{1}{c|}{ Estudos } \\
\hline Pediatria & $\begin{array}{l}\text { Santos, 2006; Andrade, 2014; } \\
\text { Rogenski, 2014. }\end{array}$ \\
\hline Clínica Médica & $\begin{array}{l}\text { Bordin, 2008; Mello, 2011; } \\
\text { Oliveira, 2016. }\end{array}$ \\
\hline Clínica Cirúrgica & $\begin{array}{l}\text { Bordin, 2008; Mello, 2011, } \\
\text { Oliveira, 2016. }\end{array}$ \\
\hline Emergência & Garcia, 2009; Oliveira, 2016. \\
\hline Alojamento Conjunto & Soares, 2009. \\
\hline Centro Cirúrgico & Possari, 2011; Ricardo, 2013. \\
\hline Unidade de Saúde da Família & $\begin{array}{l}\text { Bonfim, 2009; Bonfim, 2014; } \\
\text { Leal, 2014. }\end{array}$ \\
\hline UTI Adulto & Mello, 2011, Oliveira, 2016. \\
\hline UTI Pediátrica e Neonatal & Guimarães, 2015. \\
\hline Ambulatório de Oncologia & Martin, 2013. \\
\hline Centro de diagnóstico por imagem & Cruz, 2012 e Cruz, 2015. \\
\hline Serviço de Nutrição & Oliveira, 2016. \\
\hline
\end{tabular}


Quadro 5 - Apresentação da estrutura dos instrumentos quanto à categorização de intervenções/atividades. São Paulo, 2017.

\begin{tabular}{|c|c|c|c|c|c|c|}
\hline Instrumento de... & Intervenções & $\begin{array}{l}\text { Atividades } \\
\text { associadas }\end{array}$ & $\begin{array}{c}\text { Atividades } \\
\text { pessoais }\end{array}$ & $\begin{array}{c}\text { Tempo } \\
\text { de } \\
\text { espera }\end{array}$ & $\begin{array}{l}\text { Ausência } \\
\text { /atraso }\end{array}$ & Deslocamento \\
\hline \multicolumn{7}{|l|}{ Santos, 2006} \\
\hline Bordin, 2008 & 45 & 8 & 5 & & & \\
\hline Garcia, 2009 & 63 & 23 & 10 & & & \\
\hline Soares, 2009 & 43 & 2 & 5 & & & \\
\hline Bonfim, 2009 & 46 & 11 & 6 & & & \\
\hline Possari, 2011 & 49 & 8 & 6 & & & \\
\hline Mello, 2011 & 125 & 14 & 9 & & & \\
\hline Cruz, 2012 & 32 & 7 & 10 & & & \\
\hline Ricardo, 2013 & 33 & 23 & 9 & 1 & & \\
\hline Martin, 2013 & 34 & 1 & 1 & 1 & & \\
\hline Bonfim, 2014 & 39 & 11 & 7 & 1 & 1 & \\
\hline Leal, 2014 & 17 & 0 & 6 & 1 & 1 & \\
\hline Andrade, 2014 & 53 & 30 & 13 & & & \\
\hline Rogenski, 2014 & 53 & 30 & 9 & & & \\
\hline Guimarães, 2015 & 62 & 15 & 5 & & & \\
\hline Cruz, 2015 & 33 & 7 & 10 & & & \\
\hline Oliveira, 2016 & 16 & 3 & 9 & 1 & 1 & 1 \\
\hline Total & 743 & 193 & 120 & 5 & 3 & 1 \\
\hline
\end{tabular}

O Quadro 5 mostra um panorama da estrutura dos instrumentos, composta por intervenções segundo a taxonomia NIC, atividades associadas e atividades pessoais. Durante esse período, foi possível analisar o comportamento das intervenções e das atividades em diferentes unidades de saúde, bem como, sua evolução metodológica.

Santos (2006) construiu o primeiro instrumento utilizando o sistema de linguagem padronizada e classificou as atividades 
realizadas, pelos enfermeiros da unidade de pediatria, segundo as classes da taxonomia NIC.

No decorrer dos estudos, a estrutura dos instrumentos foi sofrendo modificações para torná-los mais representativos das realidades estudas, sendo necessário incluir novas categorias.

Ricardo (2013) percebeu a necessidade de propor a atividade tempo de espera, por se tratar de uma unidade em que os profissionais ficam à espera da demanda de atendimento. Essa categoria de análise da distribuição do tempo foi incorporada aos instrumentos de Martin (2013), Bonfim (2014), Leal (2014) e Oliveira (2016).

Ausência/atraso foi identificada pela primeira vez no instrumento proposto por Mello (2011), compondo o elenco das atividades pessoais. Em seguida, foi incorporada aos instrumentos de Cruz (2012 e 2015), Andrade (2014), Rogenski (2014) e Guimarães (2015). Já no instrumento de Bonfim (2014), Leal (2014) e Oliveira (2016), esta categoria foi separada das atividades pessoais.

Oliveira (2016) acrescentou ao instrumento o deslocamento do profissional dentro da instituição como uma categoria de análise do tempo durante a jornada de trabalho.

Martin (2013) não especificou as atividades associadas ao trabalho e as atividades associadas que encontrou.

Embora os autores tenham utilizado a NIC como referencial teórico e realizado o mapeamento cruzado das atividades em intervenções de cuidado, em alguns casos foi necessário a criação de uma nova intervenção, quando não foi encontrada na classificação NIC uma que correspondesse àquela atividade específica, realizada na unidade em estudo.

Cruz $(2012,2015)$ identificou duas novas intervenções: Reunião administrativa e Administração de radiofármacos; Bonfim (2014) identificou a intervenção Visita domiciliar, que na NIC pode ser considerada como atividade da intervenção Gerenciamento de caso, mas para realidade brasileira não especifica os cuidados que são realizados. 
Quadro 6 - Apresentação das intervenções presentes nos instrumentos, em domínios NIC. São Paulo, 2017.

\begin{tabular}{|c|c|c|c|c|c|c|c|c|}
\hline \multicolumn{9}{|c|}{ Distribuição das intervenções em domínios NIC } \\
\hline Instrumento de... & FB & FC & C & $\mathbf{S}$ & $\mathbf{F}$ & SS & COM & $\begin{array}{c}\text { Total de } \\
\text { intervenções }\end{array}$ \\
\hline Santos, 2006 & * & * & * & * & * & * & * & * \\
\hline Bordin, 2008 & 9 & 14 & 2 & 3 & 1 & 16 & 0 & 45 \\
\hline Garcia, 2009 & 19 & 16 & 3 & 5 & 0 & 20 & 0 & 63 \\
\hline Soares, 2009 & 11 & 4 & 2 & 7 & 7 & 12 & 0 & 43 \\
\hline Possari, 2011 & 5 & 17 & 5 & 6 & 1 & 14 & 1 & 49 \\
\hline Mello, 2011 & 48 & 29 & 8 & 11 & 3 & 25 & 1 & 125 \\
\hline Cruz, 2012 & 4 & 2 & 2 & 3 & 1 & 18 & 1 & 31 \\
\hline Cruz, 2015 & 4 & 2 & 2 & 3 & 1 & 20 & 1 & 31 \\
\hline Ricardo, 2013 & 9 & 8 & 0 & 4 & 1 & 11 & 0 & 33 \\
\hline Martin, 2013 & 7 & 8 & 5 & 3 & 1 & 10 & 0 & 34 \\
\hline Andrade, 2014 & 19 & 8 & 3 & 5 & 2 & 16 & 0 & 53 \\
\hline Rogenski, 2014 & 20 & 8 & 3 & 5 & 1 & 16 & 0 & 53 \\
\hline Guimarães, 2015 & 18 & 15 & 2 & 8 & 1 & 18 & 0 & 62 \\
\hline Bonfim, 2009 & 5 & 6 & 3 & 6 & 1 & 19 & 6 & 46 \\
\hline Bonfim, 2014 & * & * & * & * & * & * & * & * \\
\hline Leal, 2014 & * & * & * & * & * & * & * & * \\
\hline Oliveira, 2016 & 3 & 0 & 2 & 2 & 0 & 9 & 0 & 16 \\
\hline Total & 181 & 137 & 42 & 71 & 21 & 224 & 10 & 686 \\
\hline
\end{tabular}

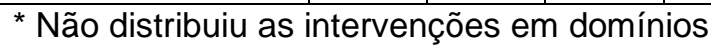

FB - Fisiológico Básico, FC - Fisiológico Complexo, C - Comportamental, S - Segurança, F - Família, SS - Sistema de Saúde, COM - Comunidade. 
Santos (2006) elencou as atividades e as classes, segundo a NIC, mas não realizou o mapeamento cruzado em intervenções e em domínios dessa classificação.

Das 743 intervenções NIC, constantes nos instrumentos, 686 foram classificadas nos domínios, sendo que 56 intervenções não foram classificadas em domínios NIC, 39 intervenções do instrumento de Bonfim (2014) e 17 intervenções de Leal (2014), como mostra o Quadro 6. Oliveira (2016) fez uma adaptação dos domínios da NIC para o serviço de nutrição.

Gráfico 3 - Distribuição das intervenções presentes nos instrumentos, em domínios NIC. São Paulo, 2017.

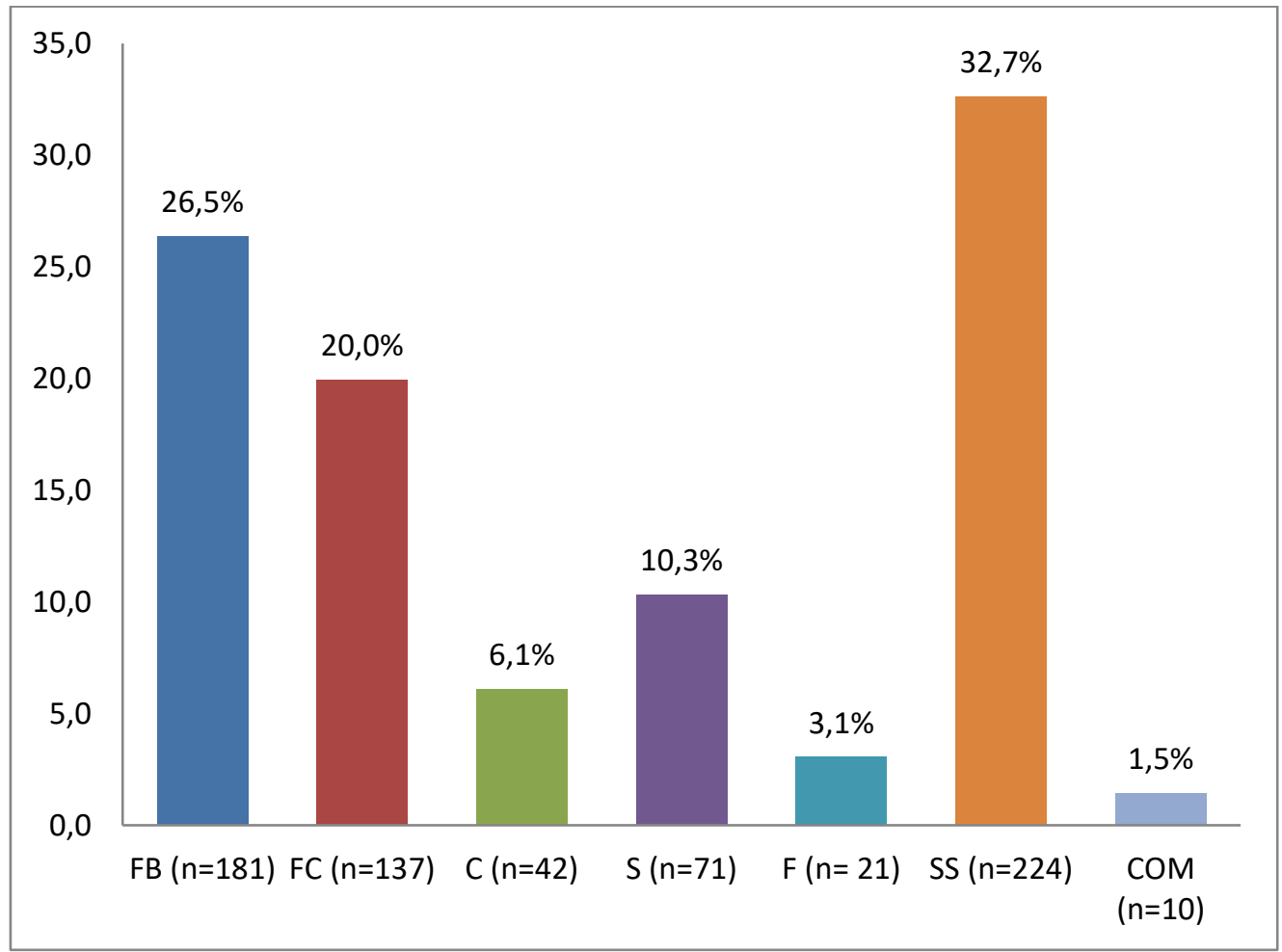

FB - Fisiológico Básico, FC - Fisiológico Complexo, C - Comportamental, S - Segurança, F - Família, SS - Sistema de Saúde, COM - Comunidade.

O Quadro 6 e o Gráfico 3 apresentam a distribuição das intervenções, segundo os domínios NIC. É possível verificar que todos os sete domínios da NIC - Fisiológico Básico, Fisiológico Complexo, Comportamental, Segurança, Família, Sistema de Saúde e Comunidade (Bulechek, et al., 2016) - foram contemplados e que sua 
representatividade está relacionada, sem dúvida, ao enfoque que cada unidade tem sobre o cuidado.

O Domínio 6, referente ao Sistema de Saúde (32,7\%), foi o mais representativo nos instrumentos e agrupa "os cuidados que dão suporte ao uso efetivo do sistema de atendimento à saúde" ((Bulechek, et al., 2016, p.56). O Domínio 1, referente ao Fisiológico Básico, está relacionado "aos cuidados que dão suporte ao funcionamento físico" (Bulechek, et.al., 2016, p.42) e contribuiu com $26,5 \%$ das intervenções presentes nos instrumentos, podendo indicar a maior dependência do paciente em relação aos profissionais.

O Domínio 2, Fisiológico Complexo, contribuiu com $20 \%$ das intervenções e está relacionado com "cuidados que dão suporte à regulação homeostática” (Bulechek, et.al., 2016, p.44).

O Domínio 4, Segurança, contribui com 10,3\% das intervenções presentes nos instrumentos e refere-se aos "cuidados que dão suporte à proteção contra danos" (Bulechek, et.al., 2016, p.52) - este grupo de intervenções esteve presente com maior frequência em unidades onde os pacientes são mais dependentes da assistência.

O Domínio 3, Comportamental, contribuiu com 6,1\% e representa as intervenções que estão presentes em "cuidados que dão suporte ao funcionamento psicossocial e facilitam mudanças no estilo de vida" (Bulechek, et.al., 2016, p.50).

O Domínio 5, Família, contribuiu com 3,1\% das intervenções e representam as intervenções de "cuidados que dão suporte à família" (Bulechek, et.al., 2016, p.54).

O Domínio 7, Comunidade, apresentou $1,5 \%$ das intervenções e referem-se aos "cuidados que dão suporte à saúde da comunidade" (Bulechek, et.al., 2016, p.58).

$\mathrm{Na}$ tabela 1, a pesquisadora agrupou as intervenções constantes nos instrumentos nas classes propostas pela NIC com a finalidade detalhar como se distribuíram os cuidados. 
Tabela 1 - Distribuição do total das intervenções, constantes nos instrumentos, nos domínios e classes, segundo o referencial da NIC. São Paulo, 2017.

\begin{tabular}{|c|c|c|c|}
\hline DOMÍNIOS NIC & CLASSE & $\mathbf{N}$ & $\%$ \\
\hline \multirow{7}{*}{ FB } & A - Controle de atividade & 9 & 1,3 \\
\hline & B - Controle de Eliminações & 34 & 5,0 \\
\hline & C - Controle da imobilidade & 27 & 3,9 \\
\hline & D - Apoio nutricional & 41 & 6,0 \\
\hline & E - Promoção do conforto físico & 23 & 3,4 \\
\hline & F - Facilitação do autocuidado & 47 & 6,9 \\
\hline & & 181 & 26,4 \\
\hline \multirow{9}{*}{ FC } & G - Controle eletrolítico e ácido-básico & 8 & 1,2 \\
\hline & $\mathrm{H}$ - Controle de Medicamentos & 29 & 4,2 \\
\hline & I - Controle Neurológico & 6 & 0,9 \\
\hline & J- Cuidados Perioperatórios & 11 & 1,6 \\
\hline & K - Controle Respiratório & 16 & 2,3 \\
\hline & L - Controle de Pele/Feridas & 27 & 3,9 \\
\hline & M - Termorregulação & 6 & 0,9 \\
\hline & $\mathrm{N}$ - Controle da perfusão tissular & 34 & 5,0 \\
\hline & & 137 & 20,0 \\
\hline \multirow{7}{*}{ C } & O - Terapia Comportamental & 1 & 0,1 \\
\hline & P - Terapia Cognitiva & 1 & 0,1 \\
\hline & Q - Melhora da Comunicação & 10 & 1,5 \\
\hline & $\mathrm{R}$ - Assistência no enfrentamento & 8 & 1,2 \\
\hline & S - Educação do paciente & 17 & 2,5 \\
\hline & T - Promoção do conforto psicológico & 5 & 0,7 \\
\hline & & 42 & 6,1 \\
\hline \multirow{3}{*}{$\mathbf{S}$} & U - Controle na crise & 9 & 1,3 \\
\hline & V - Controle de risco & 62 & 9,0 \\
\hline & & 71 & 10,3 \\
\hline \multirow{4}{*}{$\mathbf{F}$} & X - Cuidados ao longo da vida & 12 & 1,7 \\
\hline & W - Cuidados no nascimento de filhos & 7 & 1,0 \\
\hline & Z - Cuidados na educação de filhos & 2 & 0,3 \\
\hline & & 21 & 3,1 \\
\hline \multirow{4}{*}{ SS } & a - Controle do sistema de saúde & 144 & 21,0 \\
\hline & b - Controle de informações & 56 & 8,2 \\
\hline & Y - Mediação com o sistema de saúde & 24 & 3,5 \\
\hline & & 224 & 32,7 \\
\hline \multirow{2}{*}{ COM } & d - Controle de riscos na comunidade & 10 & 1,5 \\
\hline & & 10 & 1,5 \\
\hline & TOTAL & 686 & 100,0 \\
\hline
\end{tabular}




\subsection{MÉTODO PARA A CONSTRUÇÃO DOS INSTRUMENTOS DE MEDIDA DE CARGA DE TRABALHO}

À medida que os instrumentos foram desenvolvidos, foram elaboradas e fundamentadas etapas, claramente descritas para sua construção, o que evidenciou o crescente rigor científico necessário. Ao analisar o método de construção dos instrumentos, foram identificadas quatro etapas, apresentadas na figura 3.

Figura 3 - Etapas para a construção dos instrumentos de medida da carga de trabalho dos profissionais de saúde. São Paulo, 2017.

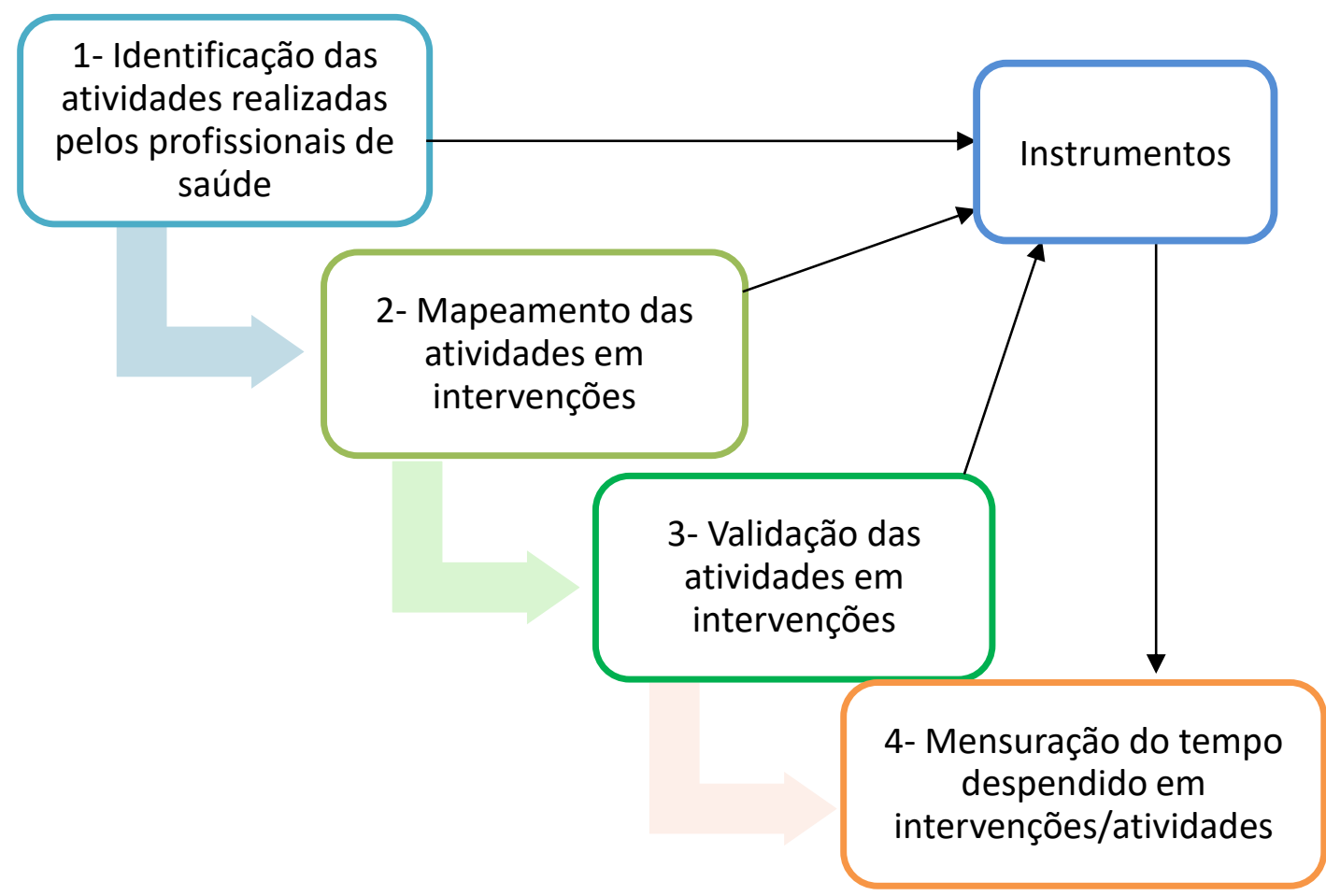

\subsubsection{Identificação das atividades realizadas pelos profissionais de saúde}

Nesta etapa, é necessário identificar as atividades realizadas pelos profissionais de saúde que representam a assistência prestada na unidade e/ou serviço e que impactam na carga de trabalho dos profissionais de saúde. 
O levantamento das atividades foi realizado por meio de revisão e busca na literatura de protocolos e instrumentos já existentes: experiência do pesquisador, entrevista com os profissionais de saúde, levantamento do registro da assistência prestada nos prontuários dos pacientes, fichas de atendimento e observação direta dos profissionais, observação direta da execução das atividades, seleção das intervenções da NIC e das respectivas atividades.

\subsubsection{Mapeamento das atividades identificadas em intervenções}

Em seguida, as atividades identificadas foram classificada sem intervenções da NIC pela técnica de mapeamento cruzado. Com esta técnica, foi possível realizar estudos utilizando dados existentes que podem ser mapeados nas classificações propostas pela NIC e adaptálos para a linguagem padronizada.

Para realizar o mapeamento cruzado, os autores dos instrumentos utilizaram o referencial de Lucena e Barros (2005) seguindo os passos:

1. Selecionar para cada intervenção, uma intervenção da NIC, baseada na semelhança entre o item e a definição da intervenção da NIC e atividades sugeridas pela NIC;

2. Determinar uma "palavra-chave" da atividade para auxiliar na identificação das intervenções apropriadas da NIC;

3. Usar verbos como as "palavras-chave" na intervenção;

4. Mapear a intervenção partindo do rótulo da intervenção NIC para a atividade;

5. Manter a consistência entre a intervenção mapeada e a definição da intervenção NIC;

6. Identificar e descrever as atividades de enfermagem que não puderam ser mapeadas.

Santos (2006) não realizou o mapeamento cruzado, pois classificou as atividades encontradas nas classes NIC. Bonfim (2014) 
mapeou as atividades em intervenções, adaptando a linguagem da NIC, utilizada em 2009 a assistência primária à saúde, realizada em conjunto com pesquisadores dos observatórios de recurso humanos do Ministério da Saúde/Organização Pan-americana de Saúde.

Leal (2014) construiu um instrumento para medir a carga de trabalho do Assistente Técnico Administrativo (ATA) e embora não tenha utilizado as intervenções NIC, seguiu o modelo taxonômico proposta pela NIC, uma vez que agrupou as atividades encontradas para esta categoria profissional em intervenções, atividades pessoais, tempo de espera e ausência.

As atividades que não tiveram correspondência com as intervenções NIC foram classificadas em atividades associadas e atividades pessoais, ou ainda criadas novas intervenções sugeridas por especialistas, em oficinas de validação das intervenções dos instrumentos, ou que foram encontradas na observação direta junto aos profissionais de saúde, seguindo a formação proposta pela NIC.

Dessa forma, foram construídos instrumentos com a relação das intervenções/atividades para possibilitar a observação direta dos profissionais de saúde no cotidiano da prática profissional e três novas intervenções foram propostas: Cruz $(2012 ; 2015)$ identificou duas novas intervenções Reunião administrativa e Administração de radiofármacos e Bonfim (2014) identificou a intervenção Visita domiciliar.

\subsubsection{Validação das atividades em intervenções}

Os instrumentos desenvolvidos foram submetidos a métodos de validação e teste de confiabilidade para, em seguida, serem aplicados para a medida da carga de trabalho por meio da observação direta dos profissionais na prática.

A validade de conteúdo foi a mais utilizada pelos autores, a qual consiste em avaliar o grau em que cada elemento de um instrumento de medida é relevante e representativo de um constructo específico (Haynes, Richard, Kubany, 1995), e verifica, por meio do consenso de 
especialistas, a legibilidade e a clareza de conteúdo do instrumento (Lobiondo-Wood, Haber, 2001).

A oficina de trabalho mostrou-se apropriada para o processo de validação, na visão dos autores dos instrumentos, pois favoreceu 0 espaço para discussão com o objetivo de retomar os conhecimentos sobre o assunto a ser tratado, pois facilitou a expressão, a comunicação e a discussão do pesquisador e com os especialistas sobre os conteúdos propostos (Chiesa, Westphal, 1995).

Os dados obtidos nessas oficinas contribuíram para melhorias e ajustes dos instrumentos, possibilitando um roteiro para a observação direta dos profissionais de saúde nas unidades estudadas para verificar a frequência e a distribuição do tempo despendido para a realização das intervenções/atividades.

\subsubsection{Mensuração do tempo despendido nas intervenções/ atividades}

Para medir a distribuição do tempo, na realização das intervenções/atividades, foram realizados estudos do tempo em que foram empregadas as técnicas de tempos cronometrados e amostragem do trabalho.

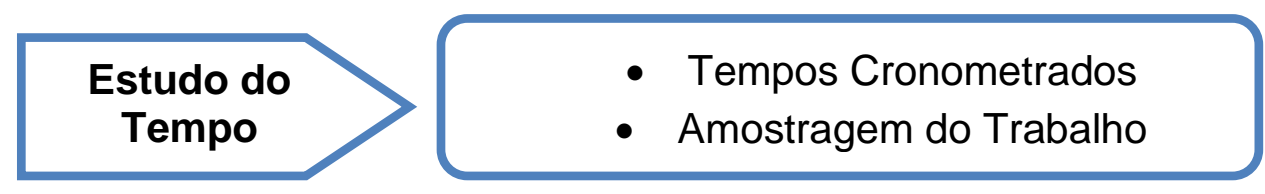

A técnica dos tempos cronometrados foi utilizada por Ricardo (2013) que realizou a observação direta e cronometrou o tempo utilizado para a execução de cada intervenção/atividade realizada, estabeleceu o tempo-padrão para executar uma tarefa específica. Segundo Ricardo (2013), esta técnica se mostrou eficiente devido às características da unidade estudada (sala de recuperação pós-anestésica) que apresentava características peculiares como execução de atividades repetitivas, de curta duração e breves períodos de permanência dos pacientes na área. 
Oliveira (2016) realizou a observação direta e sistemática dos nutricionistas clínicos, cronometrou o tempo utilizado para a execução de cada intervenção/atividades.

Os demais autores utilizaram a técnica de amostragem do trabalho em que realizaram a observação direta das atividades de forma intermitente. Bordin (2008), Bonfim (2009), Possari (2011) utilizaram o intervalo de observação de 15 minutos, os demais autores adotaram 0 intervalo de observação de 10 minutos. A amostragem do trabalho consiste de observações intermitentes, instantâneas e ao acaso e foi adotada para estimar o tempo despendido em intervenções/atividades (Martins, Laugeni, 2000; Ampt, 2007; Mello, 2011).

Mostrou-se uma técnica eficiente para verificar a frequência e estimar o tempo despendido dos profissionais na realização das intervenções/atividades.

\subsubsection{Amostras do número de observações dos profissionais de saúde}

Quadro 7 - Distribuição do número de amostras de observações dos profissionais de saúde, nas unidades estudadas. São Paulo, 2017.

\begin{tabular}{|l|l|l|c|}
\hline Estudo & Unidade & Categoria Profissional & Amostra \\
\hline Santos, 2006 & PED & $*$ & \\
\hline Bordin, 2008 & CM-CC & Enfermeiro & 1032 \\
\hline Garcia, 2009 & EMER & Enfermeiro & 1512 \\
\hline \multirow{3}{*}{ Soares, 2009 } & \multirow{2}{*}{ AC } & Enfermeiro & 1260 \\
\cline { 3 - 4 } & & Téc./Aux. & 1512 \\
\cline { 3 - 4 } & Equipe & 4998 \\
\hline Bonfim, 2009 & UBS & Equipe & 1128 \\
\hline \multirow{3}{*}{ Possari, 2011 } & \multirow{2}{*}{ CCO } & Enfermeiro & 4561 \\
\cline { 3 - 4 } & & Tec. Enf. & 5689 \\
\cline { 3 - 4 } & & Equipe & \\
\end{tabular}




\begin{tabular}{|c|c|c|c|}
\hline & & & ontinuação) \\
\hline Estudo & Unidade & Categoria Profissional & Amostra \\
\hline Mello, 2011 & $\mathrm{CM}$ & Equipe & 9108 \\
\hline Mello, 2011 & CC & Equipe & 9000 \\
\hline Mello, 2011 & UTI-A & Equipe & 7200 \\
\hline Cruz, 2012 & CDI & Equipe & \\
\hline Ricardo, 2013 & SRPA & Equipe & 6032 \\
\hline \multirow{3}{*}{ Martin, 2013} & \multirow{3}{*}{$\mathrm{AEOH}$} & Enfermeiro & 2980 \\
\hline & & Tec. Enf. & 714 \\
\hline & & Equipe & 3694 \\
\hline \multirow{3}{*}{ Andrade, 2014} & \multirow{3}{*}{ PED } & Enfermeiro & 1944 \\
\hline & & Tec./Aux. & 6444 \\
\hline & & Equipe & 8388 \\
\hline \multirow{3}{*}{ Rogenski, 2014} & \multirow{3}{*}{ PED } & Enfermeiro & 1944 \\
\hline & & Tec./Aux. & 6443 \\
\hline & & Equipe & 8387 \\
\hline \multirow{3}{*}{ Bonfim, 2014} & \multirow{3}{*}{ USF } & Enfermeiros & 9198 \\
\hline & & Tec./Aux. & 18648 \\
\hline & & Equipe & 27846 \\
\hline \multirow{2}{*}{ Leal, 2014} & \multirow{2}{*}{ UBS } & \multirow{2}{*}{ ATA } & 2160 \\
\hline & & & 1920 \\
\hline \multirow{3}{*}{ Guimarães, 2015} & \multirow{3}{*}{ UTIP-NEO } & Enfermeiro & 1440 \\
\hline & & Tec./Aux. & 3384 \\
\hline & & Equipe & 4824 \\
\hline Cruz, 2015 & CDI & Equipe & 19514 \\
\hline Oliveira, 2016 & SN & Nutricionista & 3931 \\
\hline Total & & & 186835 \\
\hline
\end{tabular}

AC - Alojamento Conjunto, AEOH - Ambulatório de Especialidades Oncologia e Hematologia, CM - Clínica Médica, CC - Clínica Cirúrgica, CCO - Centro Cirúrgico de Oncologia, CDI - Centro de Diagnóstico por imagem, CM-CC - Clínica Médica e Clínica Cirúrgica, EMER - Emergência, PED - Unidade de Internação Pediátrica, SN - Serviço de Nutrição, SRPA - Sala de Recuperação Pós-Anestésica, UBS - Unidade Básica de Saúde, USF - Unidade de Saúde da Família, UTI-A - Unidade de Terapia Intensiva Adulto, UTIP-NEO - Unidade de Terapia Intensiva Pediátrica e Neonatal.

Para realizar a técnica de amostragem do trabalho, deve ser considerado o tamanho da amostra, pois quanto maior a amostra, melhor será a estimativa e a representação do universo estudado, o que comprova a validade científica do estudo (Arango, 2005).

O número de observações conferiu ao estudo a precisão da estimativa do tempo gasto no trabalho (Mello, 2002).

No Quadro 7, apresenta-se o número de amostras das observações que foram realizadas nos respectivos estudos. Em todos 
os estudos, foi descrita a forma para obtenção do número de observações necessárias, segundo o número de intervenções do instrumento, o quantitativo da categoria profissional a ser observada nas unidades estudadas e o intervalo entre as observações, mediante orientação de estatístico. Embora Bonfim (2009) e Cruz (2012) tenham utilizado a técnica de amostragem do trabalho, essas autoras não apresentaram as amostras do número de observações.

\subsection{INTERVENÇÕES DE CUIDADO DIRETO E CUIDADO INDIRETO}

Dos 17 estudos selecionados, 16 estudos demonstraram que o tempo de trabalho dos profissionais de saúde foi distribuído nas categorias: intervenções, atividades associadas e pessoais, tempo de espera, deslocamento e ausência.

Para realizar a análise da distribuição do tempo na jornada de trabalho, os autores classificaram as intervenções dos instrumentos em: cuidado direto e cuidado indireto, segundo a NIC, com a finalidade de obter informações mais detalhadas da carga de trabalho para o cálculo do quantitativo e qualitativo de profissionais, por meio dos métodos de dimensionamento, disponíveis na literatura.

A intervenção de cuidado direto refere-se a:

Um tratamento realizado por meio da interação direta com o paciente e família contempla ações fisiológicas, psicossociais, e de apoio e aconselhamento (Bulecheck et al., 2016, p. xvii).

A intervenção de cuidado indireto refere-se a:

Um tratamento realizado à distância, mas favorecendo o paciente ou o grupo de pacientes, apoia a efetividade das intervenções de cuidados diretos e contempla ações de gerenciamento do ambiente, de cuidado do paciente e colaboração multidisciplinar (Bulecheck et al., 2016, p. xvii). 
As atividades associadas representam aquelas que podem ser executadas por outros profissionais (Hurst, 2002), mas que o profissional de saúde assume (Bonfim, 2014).

As atividades pessoais referem-se às pausas previstas durante a jornada de trabalho para serem atendidas as necessidades fisiológicas dos profissionais (Martins, Laugeni, 2000; Hurst, 2002; Mello, 2002).

As atividades tempo de espera, deslocamento e ausência foram classificadas e analisadas, separadamente, por Ricardo (2013) Oliveira (2016) e Bonfim (2014).

Nos estudos de Cruz (2012, 2015), Ricardo (2013), Leal (2014) e Oliveira (2016) foram encontradas 75 intervenções que não haviam sido classificadas em cuidado direto e cuidado indireto pelos autores.

Essas 75 intervenções foram classificadas em 37 intervenções de cuidado direto e 38 de cuidado indireto, pela pesquisadora do presente estudo, para melhor analisar os resultados.

Oliveira (2016) classificou as intervenções em cuidado direto e cuidado indireto, porém algumas intervenções foram classificadas em ambos tipos de cuidado, pois encontrou na mesma intervenção atividades consideradas de cuidado direto e indireto.

Classificar as intervenções em cuidado direto e indireto, segundo o conceito da NIC, é uma tarefa complexa, pois, a depender do contexto e da situação, pode apresentar na sua descrição atividades de cuidado direto e indireto. É o caso da intervenção 6650, Supervisão, “Aquisição, interpretação e síntese contínuas e com finalidade dos dados do paciente para a tomada de decisão clínica", que foi classificada na maioria dos estudos como intervenção de cuidado direto, porém, em um estudo, foi classificada com intervenção de cuidado indireto por considerar o que o profissional estava executando naquele momento.

Nos instrumentos construídos, foram encontradas 188 intervenções classificadas como cuidado direto e 80 intervenções classificadas como cuidado indireto (Quadro 8).

Ao observar o quadro 8, encontramos intervenções que poderiam ser agrupadas em uma única intervenção - é o caso da intervenção 2300, 
Administração de medicamentos, que poderia agrupar as intervenções 2314, Administração de medicamentos: (EV), 2311, Administração de medicamentos: inalação.

Diante das intervenções já mapeadas nos estudos realizados, vislumbra-se avaliar este conjunto de intervenções para propor um instrumento único que possa contemplar o contexto da assistência à saúde, tendo um elenco de intervenções comuns a todos os tipos de unidades e de intervenções específicas a ser utilizado, conforme o tipo de unidade em estudo.

Quadro 8 - Intervenções de cuidado direto e indireto identificadas nos instrumentos dos estudos selecionados. São Paulo, 2017.

\begin{tabular}{|c|c|c|c|c|c|}
\hline & & & & & \\
\hline Id & $\begin{array}{l}\mathrm{NIC/} \\
\text { outros }\end{array}$ & Intervenções de Cuidado Direto & Id & $\begin{array}{l}\mathrm{NIC/} \\
\text { outros }\end{array}$ & $\begin{array}{l}\text { Intervenções de Cuidado } \\
\text { Indireto }\end{array}$ \\
\hline 1 & 4030 & Administração de hemoderivados & 1 & 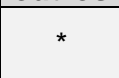 & $\begin{array}{l}\text { Ações educativas dos } \\
\text { trabalhadores de saúde }\end{array}$ \\
\hline 2 & 2300 & Administração de medicamentos & 2 & 8190 & $\begin{array}{l}\text { Acompanhamento por } \\
\text { telefone }\end{array}$ \\
\hline 3 & 2314 & Administração de medicamentos: (EV) & 3 & * & Apoio à gerência \\
\hline 4 & 2311 & $\begin{array}{l}\text { Administração de medicamentos: } \\
\text { inalação }\end{array}$ & 4 & 6402 & $\begin{array}{l}\text { Apoio à proteção contra } \\
\text { abuso: infantil }\end{array}$ \\
\hline 5 & 1200 & $\begin{array}{l}\text { Administração de nutrição parenteral } \\
\text { total }\end{array}$ & 5 & 5250 & Apoio à tomada de decisão \\
\hline 6 & * & Administração de radiofármaco & 6 & 7040 & Apoio ao cuidador \\
\hline 7 & 1050 & Alimentação & 7 & * & Apoio ao ensino e à pesquisa \\
\hline 8 & 1052 & Alimentação por mamadeira & 8 & * & Apoio ao estudante \\
\hline 9 & 1056 & Alimentação por sonda enteral & 9 & 7710 & Apoio ao médico \\
\hline 10 & 4035 & Amostra de sangue capilar & 10 & * & $\begin{array}{l}\text { Atendimento de ligações } \\
\text { telefônicas da unidade }\end{array}$ \\
\hline 11 & 1380 & Aplicação de calor/frio & 11 & 7700 & Avaliação de desempenho \\
\hline 12 & 7710 & Apoio ao médico & 12 & 7760 & Avaliação de produto \\
\hline 13 & 7040 & Apoio ao cuidador & 13 & 8120 & Coleta de dados de pesquisa \\
\hline 14 & 5270 & Apoio emocional & 14 & * & $\begin{array}{l}\text { Coleta de dados de pesquisa } \\
\text { científica }\end{array}$ \\
\hline 15 & 3160 & Aspiração de vias aéreas & 15 & * & Controle da manutenção \\
\hline 16 & 5260 & Assistência ao morrer & 16 & 7880 & Controle da tecnologia \\
\hline 17 & 2900 & Assistência cirúrgica & 17 & 7820 & $\begin{array}{l}\text { Controle de amostras para } \\
\text { exames }\end{array}$ \\
\hline 18 & 7680 & Assistência em exames & 18 & 8820 & $\begin{array}{l}\text { Controle de doenças } \\
\text { transmissíveis }\end{array}$ \\
\hline 19 & 7680 & Assistência em exames - Pré & 19 & 6540 & Controle de infecção \\
\hline 20 & 7680 & Assistência em exames - Intra & 20 & 2380 & Controle de medicamentos \\
\hline 21 & 7680 & Assistência em exames - Pós & 21 & * & $\begin{array}{l}\text { Controle de patrimônio da } \\
\text { USF }\end{array}$ \\
\hline 22 & * & Assistência em exames/procedimentos & 22 & 7800 & Controle de qualidade \\
\hline 23 & 1054 & Assistência na amamentação & 23 & 7840 & Controle de suprimentos \\
\hline
\end{tabular}




\begin{tabular}{|c|c|c|c|c|c|}
\hline Id & $\begin{array}{l}\mathrm{NIC/} \\
\text { outros }\end{array}$ & Intervenções de Cuidado Direto & Id & $\begin{array}{l}\mathrm{NIC} / \\
\text { outros }\end{array}$ & $\begin{array}{l}\text { Intervenções de Cuidado } \\
\text { Indireto }\end{array}$ \\
\hline 24 & 1803 & $\begin{array}{l}\text { Assistência no autocuidado: } \\
\text { alimentação }\end{array}$ & 24 & 6480 & Controle do ambiente \\
\hline 25 & 1801 & $\begin{array}{l}\text { Assistência no autocuidado: } \\
\text { banho/higiene }\end{array}$ & 25 & 6484 & $\begin{array}{l}\text { Controle do ambiente: } \\
\text { comunidade }\end{array}$ \\
\hline 26 & 1806 & $\begin{array}{l}\text { Assistência no autocuidado: } \\
\text { transferência }\end{array}$ & 26 & 6482 & $\begin{array}{l}\text { Controle do ambiente: } \\
\text { conforto }\end{array}$ \\
\hline 27 & 1840 & $\begin{array}{l}\text { Assistência no autocuidado: uso do } \\
\text { vaso sanitário }\end{array}$ & 27 & 6486 & $\begin{array}{l}\text { Controle do ambiente: } \\
\text { segurança }\end{array}$ \\
\hline 28 & 1802 & $\begin{array}{l}\text { Assistência no autocuidado: vestir- } \\
\text { se/arrumar-se }\end{array}$ & 28 & 6489 & $\begin{array}{l}\text { Controle do ambiente: } \\
\text { segurança do trabalhador }\end{array}$ \\
\hline 29 & 1800 & Assistência no autocuidado & 29 & * & $\begin{array}{l}\text { Controle dos serviços } \\
\text { terceirizados da unidade }\end{array}$ \\
\hline 30 & * & Atendimento à demanda espontânea & 30 & 7650 & Delegação \\
\hline 31 & 6520 & Avaliação da saúde & 31 & 7850 & $\begin{array}{l}\text { Desenvolvimento de } \\
\text { funcionários }\end{array}$ \\
\hline 32 & * & $\begin{array}{l}\text { Avaliação do estado nutricional/Controle } \\
\text { nutricional }\end{array}$ & 32 & * & $\begin{array}{l}\text { Desenvolvimento de } \\
\text { processos e rotinas } \\
\text { administrativas }\end{array}$ \\
\hline 33 & 1610 & Banho & 33 & * & $\begin{array}{l}\text { Desenvolvimento de } \\
\text { programa de saúde }\end{array}$ \\
\hline 34 & 4430 & Brinquedo terapêutico & 34 & 7640 & $\begin{array}{l}\text { Desenvolvimento de } \\
\text { protocolos de cuidados }\end{array}$ \\
\hline 35 & 6260 & Captação de órgãos & 35 & 8500 & $\begin{array}{l}\text { Desenvolvimento na saúde } \\
\text { comunitária }\end{array}$ \\
\hline 36 & 7910 & Consulta de enfermagem & 36 & * & $\begin{array}{l}\text { Digitação do mapa de } \\
\text { produção diário dos } \\
\text { profissionais assistenciais }\end{array}$ \\
\hline 37 & 6580 & Contensão física & 37 & * & Documentação \\
\hline 38 & 6430 & Contenção química & 38 & 8100 & Encaminhamento \\
\hline 39 & 2080 & Controle hidroeletrolítico & 39 & * & $\begin{array}{l}\text { Estabelecimento de } \\
\text { protocolos de cuidado }\end{array}$ \\
\hline 40 & 2000 & Controle de eletrólitos & 40 & 7170 & $\begin{array}{l}\text { Facilitação da presença da } \\
\text { família }\end{array}$ \\
\hline 41 & 6412 & Controle da anafilaxia & 41 & 7560 & Facilitação da visita \\
\hline 42 & 1400 & Controle da dor & 42 & 7320 & Gerenciamento de caso \\
\hline 43 & 0590 & Controle da eliminação urinária & 43 & 8550 & $\begin{array}{l}\text { Gerenciamento de recursos } \\
\text { financeiros }\end{array}$ \\
\hline 44 & 2120 & Controle da hiperglicemia & 44 & 6140 & $\begin{array}{l}\text { Gerenciamento do protocolo } \\
\text { de emergência }\end{array}$ \\
\hline 45 & 2130 & Controle da hipoglicemia & 45 & 6610 & Identificação de risco \\
\hline 46 & 1450 & Controle da náusea & 46 & 5580 & $\begin{array}{l}\text { Informações sensoriais } \\
\text { preparatórias }\end{array}$ \\
\hline 47 & 1100 & Controle de nutrição & 47 & 7690 & $\begin{array}{l}\text { Interpretação de dados } \\
\text { laboratoriais }\end{array}$ \\
\hline 48 & 3500 & $\begin{array}{l}\text { Controle da pressão sobre a área do } \\
\text { corpo }\end{array}$ & 48 & * & $\begin{array}{l}\text { Mapeamento e } \\
\text { territorialização }\end{array}$ \\
\hline 49 & 2240 & Controle de quimioterapia & 49 & 5020 & Mediação de conflitos \\
\hline 50 & 3300 & $\begin{array}{l}\text { Controle da ventilação mecânica: } \\
\text { invasiva }\end{array}$ & 50 & * & $\begin{array}{l}\text { Organização do processo de } \\
\text { trabalho }\end{array}$ \\
\hline 51 & 3302 & $\begin{array}{l}\text { Controle da ventilação mecânica: não } \\
\text { invasiva }\end{array}$ & 51 & * & $\begin{array}{l}\text { Organização do ambiente de } \\
\text { trabalho }\end{array}$ \\
\hline 52 & 6410 & Controle de alergias & 52 & * & $\begin{array}{l}\text { Organizar o SAME (Serviço } \\
\text { de Arquivo Médico) }\end{array}$ \\
\hline 53 & 6482 & Controle de ambiente: conforto & 53 & 8140 & Passagem de plantão \\
\hline 54 & 7820 & Controle de amostra para exames & 54 & 7726 & Preceptor: estudante \\
\hline 55 & 2680 & Controle de convulsões & 55 & 7722 & Preceptor: funcionário \\
\hline 56 & * & Controle de doenças transmissíveis & 56 & 7110 & $\begin{array}{l}\text { Promoção do envolvimento } \\
\text { familiar }\end{array}$ \\
\hline 57 & 0180 & Controle de energia & 57 & 6550 & Proteção contra infecção \\
\hline
\end{tabular}




\begin{tabular}{|c|c|c|c|c|c|}
\hline Id & $\begin{array}{l}\mathrm{NIC/} \\
\text { outros }\end{array}$ & Intervenções de Cuidado Direto & Id & $\begin{array}{l}\mathrm{NIC} / \\
\text { outros }\end{array}$ & $\begin{array}{l}\text { Intervenções de Cuidado } \\
\text { Indireto }\end{array}$ \\
\hline 58 & 6530 & Controle de imunização/vacina & 58 & 7460 & $\begin{array}{l}\text { Proteção dos direitos do } \\
\text { paciente }\end{array}$ \\
\hline 59 & 6545 & Controle de infecção: transoperatória & 59 & 4238 & $\begin{array}{l}\text { Punção de vaso: amostra de } \\
\text { sangue venoso }\end{array}$ \\
\hline 60 & 2260 & Controle de sedação & 60 & * & $\begin{array}{l}\text { Referência e contra- } \\
\text { referência }\end{array}$ \\
\hline 61 & 7880 & Controle da tecnologia & 61 & * & $\begin{array}{l}\text { Regulação de demandas de } \\
\text { vagas para os serviços } \\
\text { secundários e terciários }\end{array}$ \\
\hline 62 & 3140 & Controle de vias aéreas & 62 & 7980 & Relato de incidentes \\
\hline 63 & 3180 & Controle de vias aéreas artificiais & 63 & $\begin{array}{l}\text { CRUZ, } \\
2012, \\
2015 \\
\end{array}$ & Reunião administrativa \\
\hline 64 & 6480 & Controle do ambiente & 64 & * & $\begin{array}{l}\text { Reunião dos trabalhadores } \\
\text { para resolução de conflitos }\end{array}$ \\
\hline 65 & 6482 & Controle do ambiente: conforto & 65 & 8020 & $\begin{array}{l}\text { Reunião para avaliação dos } \\
\text { cuidados multidisciplinares }\end{array}$ \\
\hline 66 & 6486 & Controle do ambiente: segurança & 66 & 6650 & Supervisão \\
\hline 67 & 1260 & Controle do peso & 67 & 6650 & $\begin{array}{l}\text { Supervisão da distribuição } \\
\text { das refeições nas unidades }\end{array}$ \\
\hline 68 & 1570 & Controle do vômito & 68 & 7830 & Supervisão de funcionários \\
\hline 69 & 2080 & Controle hidroeletrolítico & 69 & * & $\begin{array}{l}\text { Supervisão dos trabalhadores } \\
\text { da unidade }\end{array}$ \\
\hline 70 & 0430 & Controle intestinal & 70 & 6650 & Supervisão: segurança \\
\hline 71 & 0762 & $\begin{array}{l}\text { Cuidado com aparelho gessado: } \\
\text { manutenção }\end{array}$ & 71 & 7140 & Suporte à família \\
\hline 72 & 1680 & Cuidado com as unhas & 72 & * & $\begin{array}{l}\text { Suporte à gestão de recursos } \\
\text { humanos }\end{array}$ \\
\hline 73 & 4220 & $\begin{array}{l}\text { Cuidado com cateter central de inserção } \\
\text { periférica (PICC) }\end{array}$ & 73 & * & $\begin{array}{l}\text { Suporte às atividades das } \\
\text { equipes e profissionais da } \\
\text { ESF }\end{array}$ \\
\hline 74 & 0740 & Cuidado com o repouso no leito & 74 & * & $\begin{array}{l}\text { Tramitação interna de } \\
\text { documentos }\end{array}$ \\
\hline 75 & 1670 & Cuidado com os cabelos & 75 & 8060 & Transcrição de prescrições \\
\hline 76 & 1650 & Cuidado com os olhos & 76 & 7892 & Transporte: inter-hospitalar \\
\hline 77 & 1640 & Cuidado com os ouvidos & 77 & 7890 & Transporte: intra-hospitalar \\
\hline 78 & 1660 & Cuidado com os pés & 78 & 7960 & $\begin{array}{l}\text { Troca de informações sobre } \\
\text { cuidados de saúde }\end{array}$ \\
\hline 79 & 3584 & $\begin{array}{l}\text { Cuidados com a pele: tratamentos } \\
\text { tópicos }\end{array}$ & 79 & 7620 & $\begin{array}{l}\text { Verificação de substância } \\
\text { controlada }\end{array}$ \\
\hline 80 & 0940 & Cuidados com a tração/imobilização & 80 & 7660 & $\begin{array}{l}\text { Verificação do carrinho de } \\
\text { emergência }\end{array}$ \\
\hline 81 & 3660 & Cuidados com lesões & & & \\
\hline 82 & 3662 & $\begin{array}{l}\text { Cuidados com lesões: drenagem } \\
\text { fechada }\end{array}$ & & & \\
\hline 83 & 3440 & Cuidados com local de incisão & & & \\
\hline 84 & 1750 & Cuidados com o períneo & & & \\
\hline 85 & 0480 & Cuidados com ostomias & & & \\
\hline 86 & 1780 & Cuidados com próteses & & & \\
\hline 87 & 6880 & Cuidados com recém-nascido & & & \\
\hline 88 & 1870 & Cuidados com sondas/drenos & & & \\
\hline 89 & 1874 & Cuidados com sondas: gastrintestinal & & & \\
\hline 90 & 1876 & Cuidados com sondas: urinário & & & \\
\hline 91 & 3520 & Cuidados com úlceras de pressão & & & \\
\hline 92 & 3582 & Cuidados da pele: local da doação & & & \\
\hline 93 & 3583 & Cuidados da pele: local do enxerto & & & \\
\hline 94 & 3584 & Cuidados da pele: tratamento tópicos & & & \\
\hline 95 & 6200 & Cuidados de emergência & & & \\
\hline 96 & * & Cuidados de urgência/emergência & & & \\
\hline
\end{tabular}




\begin{tabular}{|c|c|c|c|c|c|}
\hline & & & & & continua \\
\hline Id & \begin{tabular}{|l|}
$\mathrm{NIC} /$ \\
outros
\end{tabular} & Intervenções de Cuidado Direto & Id & $\begin{array}{l}\mathrm{NIC} / \\
\text { outros }\end{array}$ & $\begin{array}{l}\text { Intervenções de Cuidado } \\
\text { Indireto }\end{array}$ \\
\hline 97 & 7310 & Cuidados na admissão & & & \\
\hline 98 & 0620 & $\begin{array}{l}\text { Cuidados na retenção urinária: } \\
\text { assistência no alívio de distensão } \\
\text { vesical }\end{array}$ & & & \\
\hline 99 & 6930 & Cuidados pós-parto & & & \\
\hline 100 & 2870 & Cuidados pós-anestesia & & & \\
\hline 101 & 1770 & Cuidados pós-morte & & & \\
\hline 102 & * & Desenvolvimento da saúde comunitária & & & \\
\hline 103 & 5510 & Educação em saúde & & & \\
\hline 104 & 5614 & Ensino: dieta prescrita & & & \\
\hline 105 & 5614 & Ensino: orientação da dieta prescrita & & & \\
\hline 106 & 5616 & Ensino: medicamento prescrito & & & \\
\hline 107 & 5604 & Ensino: grupo & & & \\
\hline 108 & 5610 & Ensino: pré-operatório & & & \\
\hline 109 & 5618 & Ensino: procedimento/tratamento & & & \\
\hline 110 & 4920 & Escutar ativamente & & & \\
\hline 111 & 5520 & Facilitação da aprendizagem & & & \\
\hline 112 & 7560 & Facilitação da visita & & & \\
\hline 113 & 3230 & Fisioterapia respiratória & & & \\
\hline 114 & 6924 & Fototerapia: recém-nascido & & & \\
\hline 115 & 7320 & $\begin{array}{l}\text { Gerenciamento de caso/Visita } \\
\text { domiciliária }\end{array}$ & & & \\
\hline 116 & 0910 & Imobilização & & & \\
\hline 117 & 3790 & Indução de hipotermia & & & \\
\hline 118 & 3120 & $\begin{array}{l}\text { Inserção e estabilização de vias aéreas } \\
\text { artificiais }\end{array}$ & & & \\
\hline 119 & 0550 & Irrigação vesical & & & \\
\hline 120 & 0420 & Lavagem intestinal & & & \\
\hline 121 & 2440 & $\begin{array}{l}\text { Manutenção de dispositivos para acesso } \\
\text { venoso }\end{array}$ & & & \\
\hline 122 & 1480 & Massagem simples & & & \\
\hline 123 & 6680 & Monitoração de sinais vitais & & & \\
\hline 124 & * & $\begin{array}{l}\text { Monitoramento do estado } \\
\text { nutricional/controle nutricional }\end{array}$ & & & \\
\hline 125 & 1160 & Monitoração nutricional & & & \\
\hline 126 & 2590 & $\begin{array}{l}\text { Monitoração da pressão intracraniana } \\
\text { (PIC) }\end{array}$ & & & \\
\hline 127 & 4210 & Monitoração Hemodinâmica Invasiva & & & \\
\hline 128 & 4130 & Monitoração hídrica & & & \\
\hline 129 & 2620 & Monitoração neurológica & & & \\
\hline 130 & * & $\begin{array}{l}\text { Orientação alimentar e nutricional na } \\
\text { alta hospitalar }\end{array}$ & & & \\
\hline 131 & 5568 & Orientação aos pais: bebê & & & \\
\hline 132 & 7400 & Orientação quanto ao sistema de saúde & & & \\
\hline 133 & 3320 & Oxigenoterapia & & & \\
\hline 134 & 1020 & Planejamento da dieta & & & \\
\hline 135 & 7370 & Plano de alta & & & \\
\hline 136 & 0840 & Posicionamento & & & \\
\hline 137 & 0842 & Posicionamento transoperatório & & & \\
\hline 138 & 3200 & Precauções contra aspiração & & & \\
\hline 139 & 3840 & Precauções contra hipertermia maligna & & & \\
\hline 140 & 6570 & Precauções no uso de artigos de látex & & & \\
\hline 141 & 6590 & $\begin{array}{l}\text { Precauções no uso de torniquete } \\
\text { pneumático }\end{array}$ & & & \\
\hline 142 & 2930 & Preparo cirúrgico & & & \\
\hline 143 & 5340 & Presença & & & \\
\hline 144 & 6490 & Prevenção de quedas & & & \\
\hline 145 & 3540 & Prevenção de úlcera por pressão & & & \\
\hline
\end{tabular}




\begin{tabular}{|c|c|c|c|c|c|}
\hline & & & & & (continuaçăo) \\
\hline Id & \begin{tabular}{|l|}
$\mathrm{NIC} /$ \\
outros
\end{tabular} & Intervenções de Cuidado Direto & Id & $\begin{array}{l}\mathrm{NIC} / \\
\text { outros }\end{array}$ & $\begin{array}{l}\text { Intervenções de Cuidado } \\
\text { Indireto }\end{array}$ \\
\hline 146 & * & Procedimentos ambulatoriais & & & \\
\hline 147 & 1720 & Promoção da saúde oral & & & \\
\hline 148 & * & Procedimentos coletivos & & & \\
\hline 149 & * & Promoção de ações educativas & & & \\
\hline 150 & 6710 & Promoção de vínculo & & & \\
\hline 151 & 7110 & Promoção do envolvimento familiar & & & \\
\hline 152 & 0200 & Promoção do exercício & & & \\
\hline 153 & 4235 & $\begin{array}{l}\text { Punção de vaso cateterizado: amostra } \\
\text { de sangue }\end{array}$ & & & \\
\hline 154 & 4232 & $\begin{array}{l}\text { Punção de vaso: amostra de sangue } \\
\text { arterial }\end{array}$ & & & \\
\hline 155 & 4238 & $\begin{array}{l}\text { Punção de vaso: amostra de sangue } \\
\text { venoso }\end{array}$ & & & \\
\hline 156 & 4190 & Punção venosa & & & \\
\hline 157 & 6320 & Reanimação cardiopulmonar & & & \\
\hline 158 & * & Recepção dos usuários à USF & & & \\
\hline 159 & 5820 & Redução da ansiedade & & & \\
\hline 160 & 0470 & Redução da flatulência & & & \\
\hline 161 & 3902 & $\begin{array}{l}\text { Regulação da temperatura: } \\
\text { transoperatória }\end{array}$ & & & \\
\hline 162 & 3900 & Regulação da temperatura & & & \\
\hline 163 & 1080 & Sondagem gastrintestinal & & & \\
\hline 164 & 0580 & Sondagem vesical & & & \\
\hline 165 & 0582 & Sondagem vesical intermitente & & & \\
\hline 166 & 6650 & Supervisão & & & \\
\hline 167 & 3590 & Supervisão da pele & & & \\
\hline 168 & 6654 & Supervisão: segurança & & & \\
\hline 169 & 7140 & Suporte à família & & & \\
\hline 170 & 5270 & Suporte emocional & & & \\
\hline 171 & 6870 & Supressão da lactação & & & \\
\hline 172 & 3620 & Sutura & & & \\
\hline 173 & 5880 & Técnica para acalmar & & & \\
\hline 174 & 0221 & Terapia com exercícios: deambulação & & & \\
\hline 175 & 2150 & Terapia de diálise peritoneal & & & \\
\hline 176 & 4200 & Terapia endovenosa & & & \\
\hline 177 & * & Terapia recreacional & & & \\
\hline 178 & 5460 & Toque & & & \\
\hline 179 & 0970 & Transferência & & & \\
\hline 180 & 0960 & Transporte & & & \\
\hline 181 & 7892 & $\begin{array}{l}\text { Transporte: inter- } \\
\text { hospitalar/interinstitucional }\end{array}$ & & & \\
\hline 182 & * & Transporte interinstitucional & & & \\
\hline 183 & 3740 & Tratamento da febre & & & \\
\hline 184 & 3800 & Tratamento de hipotermia & & & \\
\hline 185 & $*$ & Triagem nutricional & & & \\
\hline 186 & 1630 & Vestir & & & \\
\hline 187 & * & Vigilância em saúde & & & \\
\hline 188 & * & Visita domiciliar & & & \\
\hline
\end{tabular}

(conclusão)

* Intervenção proposta.

A NIC foi publicada em seis edições - a cada edição, são realizadas atualizações das intervenções que consistem de inclusão de nova intervenção, revisão de intervenções já existentes por meio da alteração do nome do título, alterações substancias relacionada à 
definição e as atividades que explicam as intervenções, substituição e/ou exclusão da intervenção (Bulecheck, et al, 2016 p.570).

As intervenções encontradas nos instrumentos, que foram objeto deste estudo, foram mapeadas ao longo do tempo, com a $4^{a}$ edição da NIC (2008) e com a $5^{a}$ edição da NIC (2010). Por ocasião do lançamento da 6ª edição da NIC (2016), algumas intervenções sofreram atualizações.

\subsection{IDENTIFICAÇÃO DAS INTERVENÇÕES QUE CONTRIBUEM COM A CARGA DE TRABALHO COM FREQUÊNCIA $\geq 1 \%$}

Os Quadros 9 e 10 apresentam as intervenções de cuidado direto e indireto, respectivamente, que na aplicação dos instrumentos, durante a observação direta, apresentaram ocorrência com frequência $\geq 1 \%$, com a nomenclatura atualizada de acordo com a NIC (2016).

Observa-se que uma mesma intervenção possui várias terminologias semelhantes que foram selecionadas pelos autores na construção do instrumento, sem dúvida, pensando na construção de um instrumento único, poder-se-ia optar por escolher a intervenção que abrangesse as demais, por exemplo - a 1800, Assistência no autocuidado, dispensando as especificações, tais como: 1804 Assistência no autocuidado: uso do vaso sanitário; 1801, Assistência no autocuidado: banho/higiene, ou ainda, substituindo outras intervenções que estariam englobadas, na Assistência no autocuidado como: 1630, Vestir e 1400, Banho.

Nessa perspectiva, a assistência não ficaria pulverizada em tantas intervenções e sua ocorrência teria maior significado na carga de trabalho. 
Quadro 9 - Demonstrativo das Intervenções de cuidado direto, com frequência $\geq 1 \%$, presentes nos instrumentos estudados. São Paulo, 2017.

(continua)

\begin{tabular}{|c|c|c|}
\hline Código & $\begin{array}{l}\text { Título da } \\
\text { intervenção }\end{array}$ & Definição \\
\hline 5244 & $\begin{array}{l}\text { Aconselhamento } \\
\text { para Lactação ** }\end{array}$ & $\begin{array}{l}\text { Auxílio no estabelecimento e manutenção do } \\
\text { aleitamento materno bem-sucedido. }\end{array}$ \\
\hline 2300 & $\begin{array}{l}\text { Administração de } \\
\text { medicamentos }\end{array}$ & $\begin{array}{l}\text { Preparar, administrar e avaliar a eficácia dos } \\
\text { medicamentos com prescrição e dos isentos de } \\
\text { prescrição. }\end{array}$ \\
\hline * & $\begin{array}{l}\text { Administração de } \\
\text { radiofármaco }\end{array}$ & $\begin{array}{l}\text { Preparo, oferta e avaliação da eficácia de } \\
\text { radiofármacos para exames. }\end{array}$ \\
\hline 1050 & Alimentação & $\begin{array}{l}\text { Oferecimento de ingestão nutricional para pacientes } \\
\text { que não conseguem se alimentar sozinhos. }\end{array}$ \\
\hline 1056 & $\begin{array}{l}\text { Alimentação por } \\
\text { sonda enteral }\end{array}$ & $\begin{array}{l}\text { Fornecimento de nutrientes e água por meio de uma } \\
\text { sonda gastrointestinal. }\end{array}$ \\
\hline 4035 & $\begin{array}{l}\text { Amostra de sangue } \\
\text { capilar }\end{array}$ & $\begin{array}{l}\text { Obtenção de amostra arteriovenosa de um local } \\
\text { periférico do corpo, como calcanhar, dedo da mão } \\
\text { ou outro local transcutâneo. }\end{array}$ \\
\hline 5270 & Apoio emocional & $\begin{array}{l}\text { Oferecimento de tranquilidade, aceitação e } \\
\text { encorajamento durante períodos de estresse. }\end{array}$ \\
\hline 7140 & Apoio familiar ** & Promoção de valores, interesses e metas familiares. \\
\hline 3160 & $\begin{array}{l}\text { Aspiração de vias } \\
\text { aéreas }\end{array}$ & $\begin{array}{l}\text { Remoção de secreções das vias aéreas por meio de } \\
\text { inserção de cateter de aspiração na via aérea oral, } \\
\text { nasofarígea ou traqueal do paciente. }\end{array}$ \\
\hline 1804 & $\begin{array}{l}\text { Assistência no } \\
\text { autocuidado: uso do } \\
\text { vaso sanitário }\end{array}$ & Auxílio a outra pessoa nas eliminações. \\
\hline 2900 & Assistência cirúrgica & $\begin{array}{l}\text { Assistência ao cirurgião ou dentista em } \\
\text { procedimentos cirúrgicos e cuidados dispensados ao } \\
\text { paciente cirúrgico. }\end{array}$ \\
\hline 7680 & $\begin{array}{l}\text { Assistência em } \\
\text { exames }\end{array}$ & $\begin{array}{l}\text { Fornecimento de assistência ao paciente e a outro } \\
\text { profissional da saúde durante um procedimento. }\end{array}$ \\
\hline 1801 & $\begin{array}{l}\text { Assistência no } \\
\text { autocuidado: } \\
\text { banho/higiene }\end{array}$ & $\begin{array}{l}\text { Assistência ao paciente na realização de higiene } \\
\text { pessoal. }\end{array}$ \\
\hline 1806 & $\begin{array}{l}\text { Assistência no } \\
\text { autocuidado: } \\
\text { transferência }\end{array}$ & $\begin{array}{l}\text { Assistência a paciente com limitações dos } \\
\text { movimentos independentes para aprender a mudar } \\
\text { a localização do corpo. }\end{array}$ \\
\hline
\end{tabular}


(continuação)

\begin{tabular}{|c|c|c|}
\hline Código & $\begin{array}{l}\text { Título da } \\
\text { intervenção }\end{array}$ & Definição \\
\hline 1800 & $\begin{array}{l}\text { Assistência no } \\
\text { autocuidado }\end{array}$ & $\begin{array}{l}\text { Auxiliar o outro na realização de atividades da vida } \\
\text { diária. }\end{array}$ \\
\hline * & $\begin{array}{l}\text { Atendimento à } \\
\text { demanda } \\
\text { espontânea }\end{array}$ & $\begin{array}{l}\text { Atendimento do usuário sem agendamento prévio, } \\
\text { que inclui práticas de produção e promoção de } \\
\text { saúde com co-responsabilização da equipe/ usuário. }\end{array}$ \\
\hline 6520 & Avaliação da saúde & $\begin{array}{l}\text { Detecção de riscos à saúde ou problemas por meio } \\
\text { de histórico, exames e outros procedimentos. }\end{array}$ \\
\hline * & $\begin{array}{l}\text { Avaliação do estado } \\
\text { nutricional }\end{array}$ & $\begin{array}{l}\text { Obtenção e análise de indicadores diretos(clínicos, } \\
\text { bioquímicos e antropométricos) e indiretos ( } \\
\text { consumo alimentar, renda, disponibilidade de } \\
\text { alimentos, entre outros) que tem como conclusão o } \\
\text { diagnóstico nutricional na admissão). }\end{array}$ \\
\hline 1610 & Banho & $\begin{array}{l}\text { Limpeza do corpo com o propósito de relaxamento, } \\
\text { asseio e restabelecimento. }\end{array}$ \\
\hline 1400 & Controle da dor & $\begin{array}{l}\text { Alívio da dor ou redução da dor até nível de conforto } \\
\text { que seja aceitável para o paciente. }\end{array}$ \\
\hline 1100 & Controle da nutrição & $\begin{array}{l}\text { Fornecimento e promoção de ingestão equilibrada } \\
\text { de nutrientes. }\end{array}$ \\
\hline 2240 & $\begin{array}{l}\text { Controle da } \\
\text { quimioterapia }\end{array}$ & $\begin{array}{l}\text { Auxílio ao paciente e sua família a compreender a } \\
\text { ação e minimizar os efeitos colaterais de agentes } \\
\text { antineoplásicos. }\end{array}$ \\
\hline 4054 & $\begin{array}{l}\text { Controle de } \\
\text { dispositivo de } \\
\text { acesso venoso } \\
\text { central }^{* *}\end{array}$ & $\begin{array}{l}\text { Tratamento do paciente com acesso venoso } \\
\text { prolongado por meio da utilização de um dispositivo } \\
\text { inserido na circulação central. }\end{array}$ \\
\hline 2000 & $\begin{array}{l}\text { Controle de } \\
\text { eletrólitos }\end{array}$ & $\begin{array}{l}\text { Promoção do equilíbrio eletrolítico e prevenção de } \\
\text { complicação resultante de níveis de eletrólitos } \\
\text { séricos anormais e indesejados. }\end{array}$ \\
\hline 6530 & $\begin{array}{l}\text { Controle de } \\
\text { imunização/vacina }\end{array}$ & $\begin{array}{l}\text { Monitoramento do estado de imunização, facilitação } \\
\text { do acesso a imunizações e fornecimento de } \\
\text { imunizações para evitar doenças transmissíveis. }\end{array}$ \\
\hline 6545 & $\begin{array}{l}\text { Controle de infecção: } \\
\text { transoperatória }\end{array}$ & $\begin{array}{l}\text { Prevenção de infecção nosocomial na sala de } \\
\text { operação. }\end{array}$ \\
\hline 3140 & $\begin{array}{l}\text { Controle de vias } \\
\text { aéreas }\end{array}$ & Facilitação da permeabilidade à passagem do ar. \\
\hline 6482 & $\begin{array}{l}\text { Controle do } \\
\text { ambiente: conforto }\end{array}$ & $\begin{array}{l}\text { Manipulação do ambiente paciente para promover o } \\
\text { máximo de conforto. }\end{array}$ \\
\hline
\end{tabular}


(continuação)

\begin{tabular}{|c|c|c|}
\hline Código & $\begin{array}{l}\text { Título da } \\
\text { intervenção }\end{array}$ & Definição \\
\hline 6486 & $\begin{array}{l}\text { Controle do } \\
\text { ambiente: segurança }\end{array}$ & $\begin{array}{l}\text { Monitoramento e manipulação do ambiente físico } \\
\text { para a promoção de segurança. }\end{array}$ \\
\hline 2080 & $\begin{array}{l}\text { Controle } \\
\text { hidroeletrolítico }\end{array}$ & $\begin{array}{l}\text { Regulação e prevenção de complicações } \\
\text { decorrentes de níveis alterados de líquidos e/ou } \\
\text { eletrólitos. }\end{array}$ \\
\hline 0430 & Controle intestinal & $\begin{array}{l}\text { Estabelecimento e manutenção de um padrão } \\
\text { regular de eliminação intestinal. }\end{array}$ \\
\hline 4220 & $\begin{array}{l}\text { Cuidado com cateter } \\
\text { central de inserção } \\
\text { periférica (PICC) }\end{array}$ & $\begin{array}{l}\text { Inserção e manutenção de um cateter inserido } \\
\text { perifericamente para acesso à circulação central. }\end{array}$ \\
\hline 3660 & $\begin{array}{l}\text { Cuidados com } \\
\text { lesões }\end{array}$ & $\begin{array}{l}\text { Prevenção de complicações e promoção de } \\
\text { cicatrização de lesões. }\end{array}$ \\
\hline 3440 & $\begin{array}{l}\text { Cuidados com local } \\
\text { de incisão }\end{array}$ & $\begin{array}{l}\text { Limpeza, monitoramento e promoção da cicatrização } \\
\text { de uma ferida que é fechada com suturas, clipes ou } \\
\text { grampos. }\end{array}$ \\
\hline 3584 & $\begin{array}{l}\text { Cuidados da pele: } \\
\text { tratamentos tópicos }\end{array}$ & $\begin{array}{l}\text { Aplicação de substâncias tópicas ou manipulação de } \\
\text { dispositivos para promoção da integridade e } \\
\text { minimização de rupturas na pele. }\end{array}$ \\
\hline 7310 & $\begin{array}{l}\text { Cuidados na } \\
\text { admissão }\end{array}$ & $\begin{array}{l}\text { Facilitação da entrada de um paciente na instituição } \\
\text { de prestação de cuidados de saúde. }\end{array}$ \\
\hline 2870 & $\begin{array}{l}\text { Cuidados pós- } \\
\text { anestesia }\end{array}$ & $\begin{array}{l}\text { Monitoramento e manejo do paciente recentemente } \\
\text { submetido a anestesia geral ou regional. }\end{array}$ \\
\hline 5604 & Ensino: grupo & $\begin{array}{l}\text { Desenvolvimento, implementação e avaliação de } \\
\text { programa de ensino do paciente por um grupo de } \\
\text { indivíduos com a mesma condição de saúde. }\end{array}$ \\
\hline 5602 & $\begin{array}{l}\text { Ensino: processo de } \\
\text { doença }\end{array}$ & $\begin{array}{l}\text { Assistência ao paciente para que compreenda } \\
\text { informações relativas a um processo da doença } \\
\text { específico. }\end{array}$ \\
\hline 4920 & Escuta ativa & $\begin{array}{l}\text { Atenção criteriosa e atribuição de significado às } \\
\text { mensagens verbais e não verbais de um paciente. }\end{array}$ \\
\hline 6680 & $\begin{array}{l}\text { Monitoração de } \\
\text { sinais vitais }\end{array}$ & $\begin{array}{l}\text { Coleta e análise de dados cardiovasculares, } \\
\text { respiratórios e da temperatura corporal para } \\
\text { determinar e prevenir contra complicações. }\end{array}$ \\
\hline * & $\begin{array}{l}\text { Monitoramento do } \\
\text { estado nutricional }\end{array}$ & $\begin{array}{l}\text { Coleta e análise de dados do paciente para prevenir } \\
\text { ou minimizar desnutrição. Indica o acompanhamento } \\
\text { da evolução nutricional. }\end{array}$ \\
\hline
\end{tabular}


(continuação)

\begin{tabular}{|c|c|c|}
\hline Código & $\begin{array}{l}\text { Título da } \\
\text { intervenção }\end{array}$ & Definição \\
\hline * & $\begin{array}{l}\text { Orientação alimentar } \\
\text { e nutricional na alta } \\
\text { hospitalar }\end{array}$ & $\begin{array}{l}\text { Orientação para o segmento domiciliar ao } \\
\text { paciente/família/responsável, relativa à sua } \\
\text { alimentação e nutrição. }\end{array}$ \\
\hline 5568 & $\begin{array}{l}\text { Orientação aos pais: } \\
\text { lactente ** }\end{array}$ & $\begin{array}{l}\text { Orientação sobre a nutrição e os cuidados físicos } \\
\text { necessários durante o primeiro ano de vida. }\end{array}$ \\
\hline 7400 & $\begin{array}{l}\text { Orientação quanto } \\
\text { ao sistema de saúde }\end{array}$ & $\begin{array}{l}\text { Facilitação do acesso e uso pelo paciente dos } \\
\text { serviços de saúde adequados. }\end{array}$ \\
\hline 7370 & Plano de alta & $\begin{array}{l}\text { Preparo para a transferência de um paciente de um } \\
\text { nível de cuidado a outro, no âmbito da mesma } \\
\text { instituição de saúde ou para outro local. }\end{array}$ \\
\hline 0840 & Posicionamento & $\begin{array}{l}\text { Movimentação deliberada de um paciente ou parte } \\
\text { corporal para promover bem-estar fisiológico e/ou } \\
\text { psicológico. }\end{array}$ \\
\hline 0842 & $\begin{array}{l}\text { Posicionamento: } \\
\text { intraoperatório }\end{array}$ & $\begin{array}{l}\text { Mobilização do paciente ou parte corporal para } \\
\text { promover a exposição cirúrgica, reduzindo o risco de } \\
\text { desconforto e complicações. }\end{array}$ \\
\hline 2920 & $\begin{array}{l}\text { Precauções } \\
\text { cirúrgicas }\end{array}$ & $\begin{array}{l}\text { Minimização do potencial de lesão iatrogênica ao } \\
\text { paciente relacionada a um procedimento cirúrgico. }\end{array}$ \\
\hline 5340 & Presença & $\begin{array}{l}\text { Fazer companhia, tanto física como } \\
\text { psicologicamente, durante tempos de necessidade. }\end{array}$ \\
\hline * & $\begin{array}{l}\text { Procedimentos } \\
\text { ambulatoriais }\end{array}$ & $\begin{array}{l}\text { Aplicação de conhecimento especializado e } \\
\text { habilidade específica para a realização de } \\
\text { procedimentos clínicos e/ou cirúrgicos. }\end{array}$ \\
\hline * & $\begin{array}{l}\text { Promoção de ações } \\
\text { educativas }\end{array}$ & $\begin{array}{l}\text { Desenvolvimento de ações de educação em saúde } \\
\text { para indivíduos, famílias, grupos ou comunidades, } \\
\text { bem como a orientação específica de um usuário, } \\
\text { família, acompanhante ou cuidador visando a sua } \\
\text { compreensão sobre um procedimento ou tratamento } \\
\text { prescrito. }\end{array}$ \\
\hline
\end{tabular}

\begin{tabular}{|lll}
4238 & $\begin{array}{l}\text { Punção de vaso: } \\
\text { amostra de sangue } \\
\text { venoso }\end{array}$ & $\begin{array}{l}\text { Coleta e amostra de sangue venoso a partir de uma } \\
\text { veia não canulada. }\end{array}$ \\
\hline $4190 \quad \begin{array}{l}\text { Punção endovenosa } \\
* *\end{array}$ & $\begin{array}{l}\text { Inserção de agulha canulada em uma veia periférica } \\
\text { para o propósito de administrar líquidos, sangue ou } \\
\text { medicamentos. }\end{array}$
\end{tabular}

6320 Reanimação Realização de medidas de emergência para cardiopulmonar manutenção da vida. 
(continuação)

\begin{tabular}{|c|c|c|}
\hline Código & $\begin{array}{l}\text { Título da } \\
\text { intervenção }\end{array}$ & Definição \\
\hline * & $\begin{array}{l}\text { Recepção dos } \\
\text { usuários à USF }\end{array}$ & \\
\hline 3900 & $\begin{array}{l}\text { Regulação da } \\
\text { temperatura }\end{array}$ & $\begin{array}{l}\text { Obtenção ou manutenção da temperatura corporal } \\
\text { dentro de uma variação normal. }\end{array}$ \\
\hline 3902 & $\begin{array}{l}\text { Regulação da } \\
\text { temperatura: } \\
\text { perioperatória ** }\end{array}$ & $\begin{array}{l}\text { Obtenção e/ou manutenção da temperatura corporal } \\
\text { desejada durante o evento cirúrgico. }\end{array}$ \\
\hline 0580 & Sondagem vesical & $\begin{array}{l}\text { Inserção de sonda na bexiga para drenagem } \\
\text { temporária ou permanente de urina. }\end{array}$ \\
\hline 6650 & Supervisão & $\begin{array}{l}\text { Aquisição, interpretação e síntese contínuas e com } \\
\text { finalidade dos dados do paciente para a tomada de } \\
\text { decisão clínica. }\end{array}$ \\
\hline 6654 & $\begin{array}{l}\text { Supervisão: } \\
\text { segurança }\end{array}$ & $\begin{array}{l}\text { Coleta e análise proposital e contínua de } \\
\text { informações sobre o paciente e o ambiente para o } \\
\text { uso na promoção e manutenção da segurança do } \\
\text { paciente. }\end{array}$ \\
\hline 5880 & Técnica para acalmar & $\begin{array}{l}\text { Redução da ansiedade em pacientes com } \\
\text { sofrimento agudo. }\end{array}$ \\
\hline 2150 & $\begin{array}{l}\text { Terapia de diálise } \\
\text { peritoneal }\end{array}$ & $\begin{array}{l}\text { Administração e monitoramento da solução de } \\
\text { diálise entrando e saindo da cavidade peritoneal. }\end{array}$ \\
\hline 4200 & Terapia endovenosa & $\begin{array}{l}\text { Administração e monitoramento de líquidos e } \\
\text { medicamentos intravenosos. }\end{array}$ \\
\hline 5460 & Toque & $\begin{array}{l}\text { Oferecimento de conforto e comunicação por meio } \\
\text { de contato tátil proposital. }\end{array}$ \\
\hline 0970 & Transferência & $\begin{array}{l}\text { Movimentação de paciente com limitação de } \\
\text { movimentos independentes. }\end{array}$ \\
\hline 7892 & $\begin{array}{l}\text { Transporte: Intra- } \\
\text { hospitalar/institucional }\end{array}$ & $\begin{array}{l}\text { Mudança de um paciente de uma área de instituição } \\
\text { para outra. }\end{array}$ \\
\hline 1630 & Triagem nutricional & $\begin{array}{l}\text { Processo de identificação das características que se } \\
\text { sabe estarem associadas a problemas dietéticos ou } \\
\text { nutricionais. Busca identificar indivíduos em risco de } \\
\text { desnutrição, com o propósito de verificar se uma } \\
\text { avaliação nutricional adicional é necessária. }\end{array}$ \\
\hline 1630 & Vestir & $\begin{array}{l}\text { Escolha, colocação e retirada de roupas de uma } \\
\text { pessoa que não consegue fazê-lo sozinha. }\end{array}$ \\
\hline
\end{tabular}


(continuação)

\begin{tabular}{ccc} 
Código & $\begin{array}{c}\text { Título da } \\
\text { intervenção }\end{array}$ & \multicolumn{1}{c}{ Definição } \\
\hline * & Vigilância em saúde & $\begin{array}{l}\text { Ações de impacto nas causas evitáveis no âmbito } \\
\text { epidemiológico, sanitário e ambiental. }\end{array}$ \\
\hline * $\quad$ Visita domiciliar & $\begin{array}{l}\text { Realização de cuidados a usuários/população para } \\
\text { integrar e otimizar o uso de recursos, assegurar a } \\
\text { qualidade dos cuidados de saúde e alcanças os } \\
\text { resultados desejados na perspectiva de favorecer a } \\
\text { interação com a dinâmica das relações familiares e } \\
\text { o estabelecimento de vínculos. }\end{array}$ \\
\hline
\end{tabular}

(conclusão)

* Intervenção proposta.

** Intervenções que foram atualizadas segundo NIC, 2016. Veja Quadro 11.

Quadro 10 - Demonstrativo das Intervenções de cuidado indireto, com frequência $\geq 1 \%$, presentes nos instrumentos estudados. São Paulo, 2017.

(continua)

\begin{tabular}{|c|c|c|}
\hline Código & Título da intervenção & Definição \\
\hline * & $\begin{array}{l}\text { Ações educativas dos } \\
\text { trabalhadores de saúde }\end{array}$ & $\begin{array}{l}\text { Desenvolvimento e participação de ações } \\
\text { de educação permanente }\end{array}$ \\
\hline 8190 & $\begin{array}{l}\text { Acompanhamento por } \\
\text { telefone }\end{array}$ & $\begin{array}{l}\text { Fornecimento de resultados de exames ou } \\
\text { avaliação da resposta do paciente e } \\
\text { determinação do potencial para problemas } \\
\text { como resultado de tratamento, exame ou } \\
\text { testes anteriores, pelo telefone }\end{array}$ \\
\hline * & Apoio à gerência & \\
\hline 7710 & Apoio ao médico & $\begin{array}{l}\text { Colaboração com médicos para fornecer } \\
\text { cuidados de qualidade ao paciente }\end{array}$ \\
\hline 7620 & $\begin{array}{l}\text { Checagem de substância } \\
\text { controlada ** }\end{array}$ & $\begin{array}{l}\text { Promoção do uso adequado e manutenção } \\
\text { da segurança das substâncias controladas }\end{array}$ \\
\hline 8120 & $\begin{array}{l}\text { Coleta de dados de } \\
\text { pesquisa }\end{array}$ & Coleta de dados de pesquisa \\
\hline 7880 & Controle da tecnologia & $\begin{array}{l}\text { Uso de equipamentos e dispositivos } \\
\text { tecnológicos para monitorar a condição do } \\
\text { paciente ou manter a sua vida }\end{array}$ \\
\hline
\end{tabular}


(continuação)

\begin{tabular}{|lll}
\hline Código & Título da intervenção & \multicolumn{1}{c}{ Definição } \\
\hline 7820 & $\begin{array}{l}\text { Controle de amostras } \\
\text { para exames }\end{array}$ & $\begin{array}{l}\text { Obtenção, preparo e conservação de } \\
\text { amostra para exames laboratorial }\end{array}$ \\
\hline 6540 & Controle de infecção & $\begin{array}{l}\text { Minimização da aquisição e transmissão } \\
\text { de agentes infecciosos }\end{array}$ \\
\hline 7800 & $\begin{array}{l}\text { Controle de } \\
\text { medicamentos }\end{array}$ & $\begin{array}{l}\text { Facilitação do uso seguro e eficaz de } \\
\text { fármacos vendidos com prescrição e } \\
\text { isentos de prescrição }\end{array}$ \\
\hline & Controle de qualidade & $\begin{array}{l}\text { Coleta e análise dos indicadores de } \\
\text { qualidade de uma organização com o } \\
\text { propósito de melhorar os cuidados para o } \\
\text { paciente }\end{array}$ \\
\hline
\end{tabular}

\begin{tabular}{|c|c|c|}
\hline 7840 & Controle de suprimentos & $\begin{array}{l}\text { Garantia de aquisição e manutenção de } \\
\text { itens apropriados para o oferecimento de } \\
\text { cuidados ao paciente }\end{array}$ \\
\hline 6480 & Controle do ambiente & $\begin{array}{l}\text { Manipulação do ambiente do paciente } \\
\text { visando a benefício terapêutico, apelo } \\
\text { sensorial e bem-estar psicológico }\end{array}$ \\
\hline 7650 & Delegação & $\begin{array}{l}\text { Transferência de responsabilidade pela } \\
\text { realização do cuidado do paciente, ao } \\
\text { mesmo tempo em que mantém a } \\
\text { responsabilidade pelos resultados }\end{array}$ \\
\hline 7850 & $\begin{array}{l}\text { Desenvolvimento de } \\
\text { funcionários }\end{array}$ & $\begin{array}{l}\text { Desenvolvimento, manutenção e } \\
\text { monitoramento da competência da equipe }\end{array}$ \\
\hline * & $\begin{array}{l}\text { Digitação do mapa de } \\
\text { produção diário dos } \\
\text { profissionais } \\
\text { assistenciais }\end{array}$ & \\
\hline 7920 & Documentação & $\begin{array}{l}\text { Registro dos dados pertinentes do paciente } \\
\text { em prontuário clínico }\end{array}$ \\
\hline 7320 & Gerenciamento de caso & $\begin{array}{l}\text { Coordenação dos cuidados e amparo a } \\
\text { determinados indivíduos a populações de } \\
\text { pacientes de diferentes locais para reduzir } \\
\text { custos e uso de recursos, melhorar a } \\
\text { qualidade dos cuidados de saúde e } \\
\text { alcançar os resultados desejados }\end{array}$ \\
\hline
\end{tabular}


(continuação)

\begin{tabular}{|c|c|c|}
\hline Código & Título da intervenção & Definição \\
\hline 7690 & $\begin{array}{l}\text { Interpretação de dados } \\
\text { laboratoriais }\end{array}$ & $\begin{array}{l}\text { Análise crítica dos dados laboratoriais dos } \\
\text { pacientes, a fim de auxiliar na tomada de } \\
\text { decisão clínica }\end{array}$ \\
\hline * & $\begin{array}{l}\text { Organização do } \\
\text { ambiente de trabalho }\end{array}$ & \\
\hline * & $\begin{array}{l}\text { Organização do processo } \\
\text { de trabalho }\end{array}$ & $\begin{array}{l}\text { Organização e distribuição das atividades } \\
\text { do trabalho nos serviços de saúde }\end{array}$ \\
\hline * & $\begin{array}{l}\text { Organizar o SAME } \\
\text { (Serviço de Arquivo } \\
\text { Médico) }\end{array}$ & \\
\hline 8140 & Passagem de plantão & $\begin{array}{l}\text { Troca de informações essenciais sobre o } \\
\text { cuidado do paciente com outra equipe de } \\
\text { enfermagem na mudança de turno }\end{array}$ \\
\hline 7726 & Preceptor: estudante & $\begin{array}{l}\text { Auxílio e apoio às experiências de } \\
\text { aprendizado para um estudante }\end{array}$ \\
\hline 7722 & Preceptor: funcionário & $\begin{array}{l}\text { Auxílio e apoio a um funcionário novo ou } \\
\text { transferido através de uma orientação } \\
\text { planejada para uma área clínica específica }\end{array}$ \\
\hline 6550 & Proteção contra infecção & $\begin{array}{l}\text { Prevenção e detecção precoce da infecção } \\
\text { em um paciente em risco }\end{array}$ \\
\hline * & $\begin{array}{l}\text { Regulação de demandas } \\
\text { de vagas para os } \\
\text { serviços secundários e } \\
\text { terciários }\end{array}$ & \\
\hline
\end{tabular}

Reunião administrativa para planejamento,

* Reunião administrativa discussão e avaliação de assuntos técnicos e administrativos relacionados à organização do serviço

$\begin{array}{cl}* & \begin{array}{l}\text { Reunião dos } \\ \text { trabalhadores para } \\ \text { resolução de conflitos }\end{array} \\ 8020 \quad \begin{array}{l}\text { Reunião para avaliação } \\ \text { dos cuidados } \\ \text { multidisciplinares }\end{array}\end{array}$

Planejamento e avaliação do cuidado do paciente com os profissionais de saúde de outras disciplinas 
(continuação)

\begin{tabular}{cll}
\hline Código & Título da intervenção & \multicolumn{1}{c}{ Definição } \\
\hline 6650 & Supervisão & $\begin{array}{l}\text { Aquisição, interpretação e síntese } \\
\text { contínuas e com finalidade dos dados do } \\
\text { paciente para a tomada de decisão clínica }\end{array}$ \\
\hline * & $\begin{array}{l}\text { Supervisão da } \\
\text { distribuição das refeições } \\
\text { nas unidades }\end{array}$ & \\
\hline & $\begin{array}{l}\text { Supervisão de } \\
\text { funcionários }\end{array}$ & $\begin{array}{l}\text { Facilitação do oferecimento de cuidados } \\
\text { altamente qualificado ao paciente por } \\
\text { outras pessoas }\end{array}$ \\
\hline & $\begin{array}{l}\text { Suporte à gestão de } \\
\text { recursos humanos }\end{array}$ & \\
\hline
\end{tabular}

\begin{tabular}{|c|c|c|}
\hline 8060 & $\begin{array}{l}\text { Transcrição de } \\
\text { prescrições }\end{array}$ & $\begin{array}{l}\text { Transferência de informações de folhas de } \\
\text { prescrição ao planejamento da assistência } \\
\text { de enfermagem e sistema de } \\
\text { documentação }\end{array}$ \\
\hline
\end{tabular}

7960

Troca de informações sobre cuidados de saúde

Fornecimento de informações sobre o cuidado do paciente a outros profissionais de saúde

7660 Verificação do carrinho
de emergência

Revisão e manutenção sistemáticas do conteúdo de um carrinho de emergência a intervalos de tempo estabelecidos

(conclusão)

* Intervenção proposta.

** Intervenções que foram atualizadas segundo NIC, 2016. Veja Quadro 11.

O Quadro 11 apresenta os itens que as intervenções foram alteradas de acordo com a NIC (2016). 
Quadro 11 - Demonstrativo das intervenções presentes nos instrumentos estudados, com frequência $\geq 1 \%$, atualizadas segundo NIC, 2016. São Paulo, 2017.

(continua)

\begin{tabular}{lllll}
\hline Código & Título & Definição & NIC, ano & Alterações \\
\hline \multirow{2}{*}{1054} & $\begin{array}{l}\text { Assistência na } \\
\text { amamentação }\end{array}$ & $\begin{array}{l}\text { Preparo da mãe novata para } \\
\text { amamentar seu bebê }\end{array}$ & NIC, & $\begin{array}{l}\text { Código } \\
\text { numérico, } \\
\text { título, } \\
\text { definição, } \\
\end{array}$ \\
& & 2010 & & atividades
\end{tabular}

\begin{tabular}{|c|c|c|c|c|}
\hline 5244 & $\begin{array}{l}\text { Aconselhamento } \\
\text { para Lactação }\end{array}$ & $\begin{array}{l}\text { Auxílio no estabelecimento e } \\
\text { manutenção do aleitamento } \\
\text { materno bem-sucedido }\end{array}$ & $\begin{array}{l}\text { NIC, } \\
2016\end{array}$ & \\
\hline 2440 & $\begin{array}{l}\text { Manutenção de } \\
\text { dispositivos para } \\
\text { acesso venoso }\end{array}$ & $\begin{array}{l}\text { Controle de paciente com } \\
\text { acesso venoso prolongado via } \\
\text { cateter tunelizado e não } \\
\text { tunelizado (percutâneo) e por } \\
\text { cateteres implantados }\end{array}$ & $\begin{array}{l}\text { NIC, } \\
2010\end{array}$ & $\begin{array}{l}\text { Código } \\
\text { numérico, } \\
\text { título, } \\
\text { definição, } \\
\text { atividades }\end{array}$ \\
\hline 4054 & $\begin{array}{l}\text { Controle de } \\
\text { dispositivo de acesso } \\
\text { venoso central }\end{array}$ & $\begin{array}{l}\text { Tratamento do paciente com } \\
\text { acesso venoso prolongado por } \\
\text { meio da utilização de um } \\
\text { dispositivo inserido na } \\
\text { circulação central }\end{array}$ & $\begin{array}{l}\text { NIC, } \\
2016\end{array}$ & \\
\hline 5568 & $\begin{array}{l}\text { Orientação aos pais: } \\
\text { bebê }\end{array}$ & $\begin{array}{l}\text { Orientação sobre a criação e os } \\
\text { cuidados físicos necessários } \\
\text { durante o primeiro ano de vida } \\
\text { do bebê }\end{array}$ & $\begin{array}{l}\text { NIC, } \\
2010\end{array}$ & $\begin{array}{l}\text { Título, } \\
\text { definição }\end{array}$ \\
\hline
\end{tabular}

5568 Orientação aos pais: Orientação sobre a nutrição e os NIC, lactente cuidados físicos necessários 2016 durante o primeiro ano de vida

\begin{tabular}{llll}
\hline 0842 Posicionamento & $\begin{array}{l}\text { Mobilização do paciente ou } \\
\text { transoperatório }\end{array}$ & $\begin{array}{l}\text { Narte corporal para promover a } \\
\text { exposição cirúrgica, reduzindo o } \\
\text { risco de desconforto e } \\
\text { complicações }\end{array}$ & Título \\
$0842 \quad \begin{array}{l}\text { Posicionamento: } \\
\text { intraoperatório }\end{array}$ & $\begin{array}{l}\text { Mobilização do paciente ou } \\
\text { parte corporal para promover a } \\
\text { exposição cirúrgica, reduzindo o } \\
\text { risco de desconforto e } \\
\text { complicações }\end{array}$ & NIC, \\
& &
\end{tabular}


(continuação)

\begin{tabular}{|c|c|c|c|c|}
\hline & & & & \\
\hline Código & Título & Definição & NIC, ano & Alterações \\
\hline 4190 & Punção venosa & $\begin{array}{l}\text { Inserção de uma agulha em uma } \\
\text { veia periférica para administração } \\
\text { de líquidos, sangue ou } \\
\text { medicamentos }\end{array}$ & $\begin{array}{l}\text { NIC, } \\
2010\end{array}$ & Título \\
\hline 4190 & $\begin{array}{l}\text { Punção } \\
\text { endovenosa }\end{array}$ & $\begin{array}{l}\text { Inserção de agulha canulada em } \\
\text { uma veia periférica para o } \\
\text { propósito de administrar líquidos, } \\
\text { sangue ou medicamentos }\end{array}$ & $\begin{array}{l}\text { NIC, } \\
2016\end{array}$ & \\
\hline 3902 & $\begin{array}{l}\text { Regulação da } \\
\text { temperatura: } \\
\text { transoperatória }\end{array}$ & $\begin{array}{l}\text { Obtenção e/ou manutenção da } \\
\text { temperatura corporal desejada no } \\
\text { transoperatório }\end{array}$ & $\begin{array}{l}\text { NIC, } \\
2010\end{array}$ & $\begin{array}{l}\text { Título, } \\
\text { definição, }\end{array}$ \\
\hline 3902 & $\begin{array}{l}\text { Regulação da } \\
\text { temperatura: } \\
\text { perioperatória }\end{array}$ & $\begin{array}{l}\text { Obtenção e/ou manutenção da } \\
\text { temperatura corporal desejada } \\
\text { durante o evento cirúrgico }\end{array}$ & $\begin{array}{l}\text { NIC, } \\
2016\end{array}$ & \\
\hline 7140 & Suporte à família & $\begin{array}{l}\text { Promoção de valores, interesses } \\
\text { e metas familiares }\end{array}$ & $\begin{array}{l}\text { NIC, } \\
2010\end{array}$ & Título \\
\hline 7140 & Apoio familiar & $\begin{array}{l}\text { Promoção de valores, interesses } \\
\text { e metas familiares }\end{array}$ & $\begin{array}{l}\text { NIC, } \\
2016\end{array}$ & \\
\hline 0960 & Transporte & Movimentação de um paciente de & $\mathrm{NIC}$ & Excluída. \\
\hline & & um local para outro & 2008 & $\begin{array}{l}\text { Dividida em } \\
\text { duas outras } \\
\text { intervenções }\end{array}$ \\
\hline 7890 & $\begin{array}{l}\text { Transporte: Inter- } \\
\text { hospitalar }\end{array}$ & $\begin{array}{l}\text { Mudança de paciente de uma } \\
\text { instituição para outra }\end{array}$ & $\begin{array}{l}2010 \\
2016\end{array}$ & \\
\hline 7892 & $\begin{array}{l}\text { Transporte: Intra- } \\
\text { hospitalar }\end{array}$ & $\begin{array}{l}\text { Mudança de um paciente de uma } \\
\text { área de instituição para outra }\end{array}$ & $\begin{array}{l}2010 \\
2016\end{array}$ & \\
\hline 7620 & $\begin{array}{l}\text { Verificação de } \\
\text { substância } \\
\text { controlada }\end{array}$ & $\begin{array}{l}\text { Promoção do uso adequado e } \\
\text { manutenção da segurança das } \\
\text { substâncias controladas }\end{array}$ & $\begin{array}{l}\text { NIC, } \\
2010\end{array}$ & Título \\
\hline 7620 & $\begin{array}{l}\text { Checagem de } \\
\text { substância } \\
\text { controlada }\end{array}$ & $\begin{array}{l}\text { Promoção do uso adequado e } \\
\text { manutenção da segurança das } \\
\text { substâncias controladas }\end{array}$ & $\begin{array}{l}\text { NIC, } \\
2016\end{array}$ & \\
\hline
\end{tabular}

(conclusão)

Destaca-se que as intervenções 7890, Transporte: inter-hospitalar e 7892, Transporte: intra-hospitalar, de acordo com as definições apresentadas, seriam melhor nominadas como Transporte interinstitucional e transporte intrainstitucional. 


\subsection{INTERVENÇÕES DE CUIDADO DIRETO E INDIRETO QUE CONTRIBUEM PARA A CARGA DE TRABALHO DOS PROFISSIONAIS DE SAÚDE}

Dos 17 instrumentos que foram construídos, o proposto por Santos (2006) não foi aplicado na prática; o de Bordin (2008) e o de Garcia (2009) apenas foram desenvolvidos e aplicados para categoria de enfermeiro; o de Oliveira (2016), para categoria de nutricionista clínico e o de Leal(2014), para o assistente técnico administrativo.

Os 16 instrumentos que foram aplicados na prática apresentaram um elenco de intervenções de cuidado direto e indireto mostradas no Quadro 8; no entanto, muitas delas não foram observadas no cotidiano da prática ou não obtiveram uma frequência, maior ou igual a $1 \%$ (Gráfico 4 e Tabela 2).

Gráfico 4 - Número de intervenções de cuidado direto e indireto presentes nos instrumentos, número de intervenções observadas com frequência $\geq 1 \%$ e menor que 1\%. São Paulo, 2017.

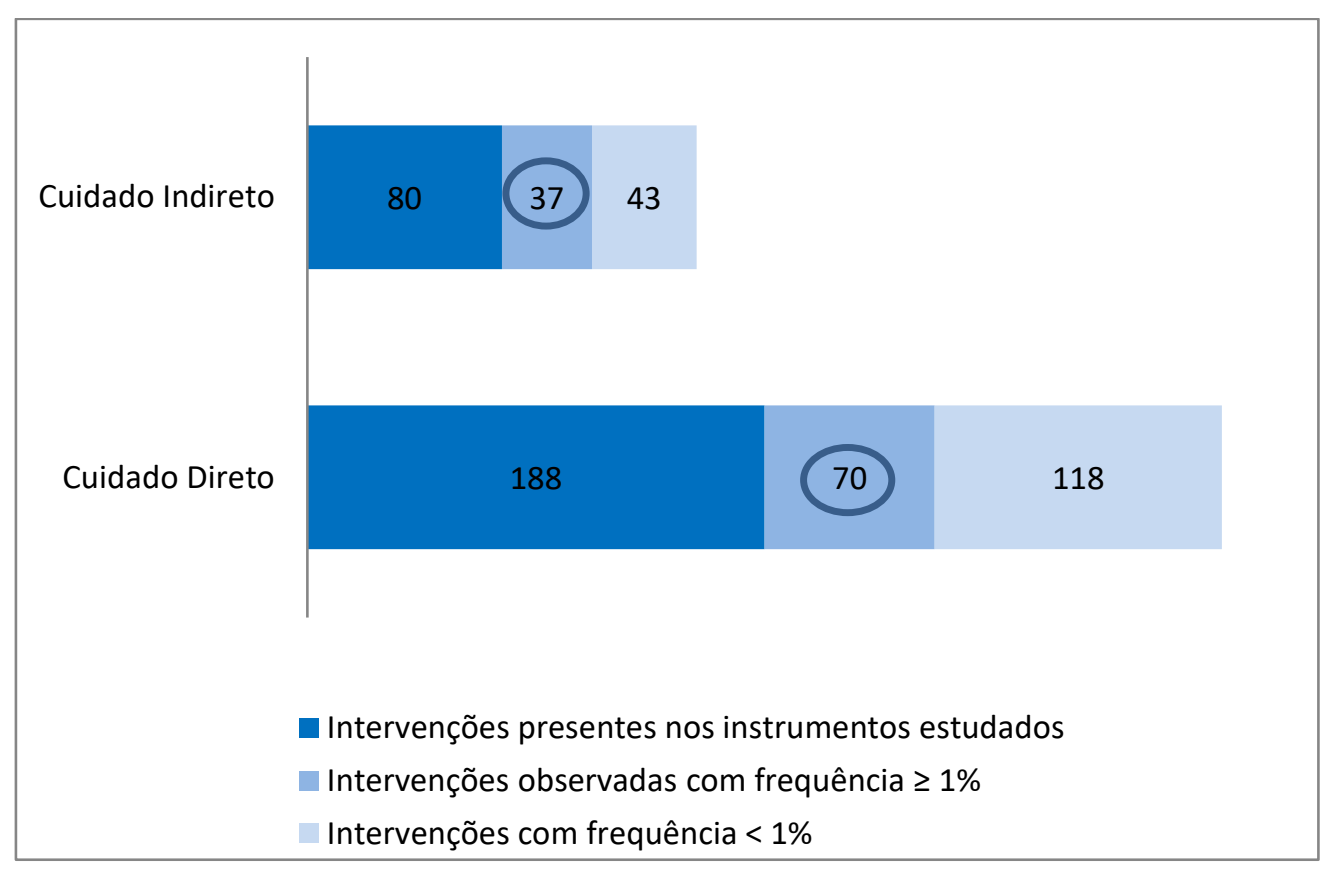


Tabela 2 - Distribuição das intervenções identificadas nos instrumentos, segundo frequência de observação. São Paulo, 2017

\begin{tabular}{|c|c|c|c|c|c|c|}
\hline \multirow[t]{2}{*}{ Intervenções } & \multicolumn{2}{|c|}{$\begin{array}{l}\text { Intervenções dos } \\
\text { instrumentos }\end{array}$} & \multicolumn{2}{|c|}{$\begin{array}{l}\text { Intervenções } \\
\text { observadas } \\
\text { (freq } \geq 1 \% \text { ) }\end{array}$} & \multicolumn{2}{|c|}{$\begin{array}{l}\text { Intervenções } \\
\text { observadas } \\
\text { (freq< } 1 \% \text { ) }\end{array}$} \\
\hline & $\mathrm{n}$ & $\%$ & $\mathrm{n}$ & $\%$ & $\mathrm{n}$ & $\%$ \\
\hline Cuidado Direto & 188 & 70,1 & 70 & 26,1 & 118 & 44,0 \\
\hline Cuidado Indireto & 80 & 29,9 & 37 & 13,8 & 43 & 16,0 \\
\hline Total & 268 & 100,0 & 107 & 39,9 & 161 & 60,1 \\
\hline
\end{tabular}

A Tabela 2 evidencia que apenas $40 \%$ das intervenções descritas nos instrumentos foram observadas com frequência $\geq 1 \%$; os resultados dos estudos de Urder, Rode (1997), Duffield, Wise (2003), Chaboyer et al.(2008) e WHO (2010) evidenciaram que apenas 4 a 5 intervenções têm maior ocorrência nas unidades de saúde.

\subsubsection{Intervenções de Cuidado Direto}

A análise das 70 intervenções de cuidados diretos, com frequência de ocorrência maior ou igual a 1\%, demonstrou que estas se distribuíram de forma variada nas categorias profissionais e nas diferentes unidades estudadas. Devido ao elevado número de intervenções encontradas foi necessário agrupá-las de acordo com o seguinte critério:

\begin{tabular}{|l|l|}
\hline \multirow{2}{*}{$\begin{array}{l}\text { Intervenções com } \\
\text { frequência } \geq 1 \%\end{array}$} & Observadas em três ou mais unidades \\
\cline { 2 - 2 } & Observadas em duas unidades \\
\cline { 2 - 2 } & Observadas em uma unidade \\
\hline
\end{tabular}


Gráfico 5 - Distribuição das intervenções de cuidado direto com frequência $\geq 1 \%$, segundo o número de unidades em que foram observadas. São Paulo, 2017.

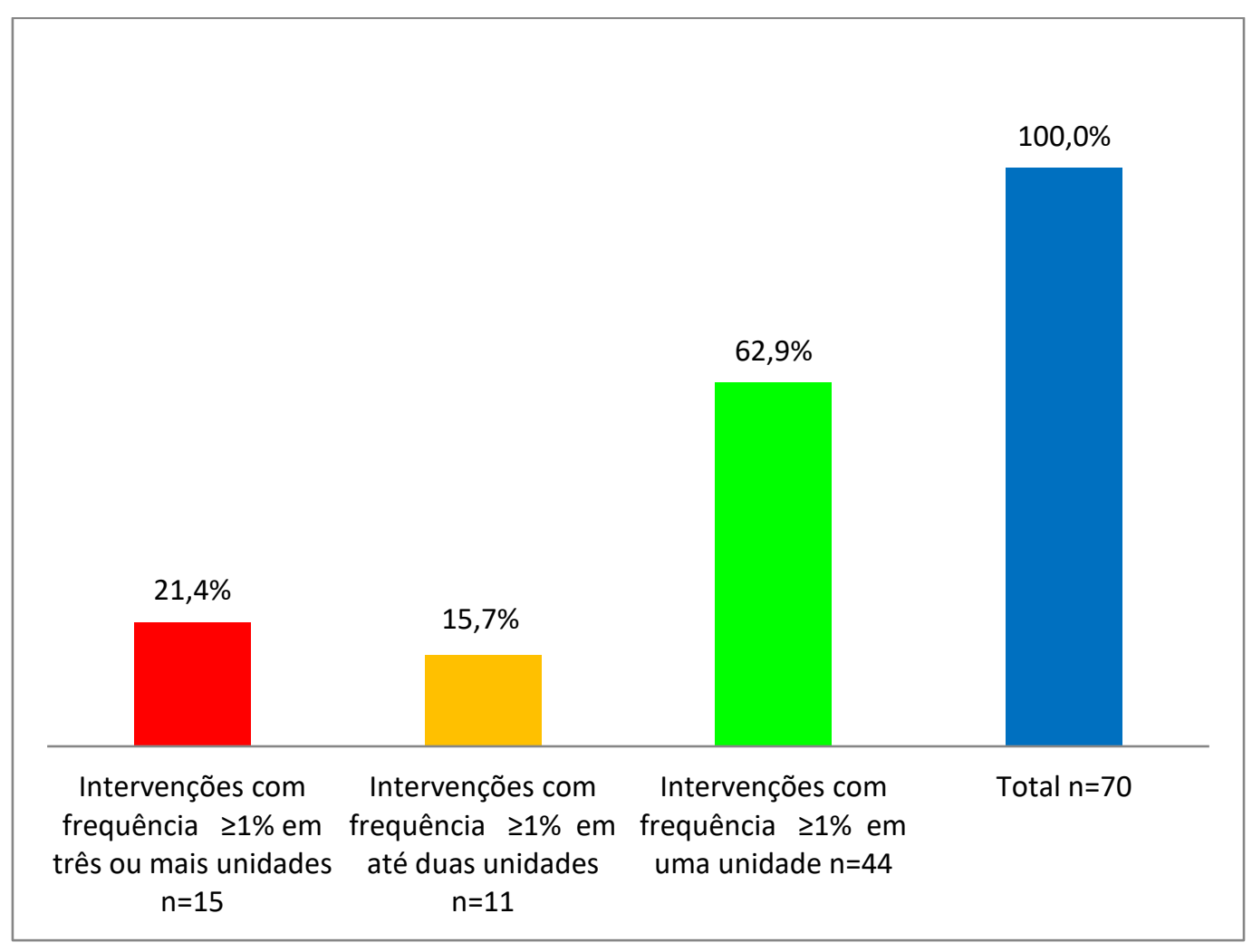

Das intervenções de cuidado direto (Gráfico 5), 21,4\% e 15,7\% foram observadas em três ou mais unidades e em até duas unidades, respectivamente. As intervenções destes grupos, que tiveram maior probabilidade de ocorrência nos serviços de saúde, segundo a categoria profissional, são apresentadas nos Quadros 12 e 13.

Verifica-se, também, no Gráfico 5 que 62,9\% das intervenções foram observadas em apenas uma unidade. Essas intervenções caracterizam a singularidade da categoria profissional que foi observada tipo de assistência prestada na unidade (Quadro 14), consideradas intervenções essenciais por especialidade, segundo a NIC, as quais representam uma área/unidade específica (Bulecheck et al., 2016, p.432). 
Quadro 12 - Intervenções de cuidado direto com frequência $\geq 1 \%$ que foram observadas em três ou mais unidades por categoria profissional. São Paulo, 2017.

\begin{tabular}{|c|l|c|c|c|c|}
\hline \multirow{2}{*}{$n$} & \multicolumn{2}{|c|}{ Intervenção } & \multicolumn{3}{c|}{ Categoria Profissional } \\
\cline { 3 - 7 } & & Enf & Tec/Aux & Nut & ATA \\
\hline 1 & Administração de medicamentos & $\mathrm{X}$ & $\mathrm{X}$ & & \\
\hline 2 & Alimentação & $\mathrm{X}$ & $\mathrm{X}$ & & \\
\hline 3 & Assistência em exames & $\mathrm{X}$ & $\mathrm{X}$ & & \\
\hline 4 & Banho & $\mathrm{X}$ & $\mathrm{X}$ & & \\
\hline 5 & Controle de dispositivo de acesso venoso central *1 & $\mathrm{X}$ & $\mathrm{X}$ & & \\
\hline 6 & Controle de imunização/vacina & $\mathrm{X}$ & $\mathrm{X}$ & & \\
\hline 7 & Controle do ambiente: conforto & $\mathrm{X}$ & $\mathrm{X}$ & & \\
\hline 8 & Cuidados na admissão & $\mathrm{X}$ & & & \\
\hline 9 & Ensino: processo de doença & $\mathrm{X}$ & & & \\
\hline 10 & Escuta ativa & $\mathrm{X}$ & $\mathrm{X}$ & & \\
\hline 11 & Monitoração de sinais vitais & $\mathrm{X}$ & $\mathrm{X}$ & & \\
\hline 12 & Plano de alta & $\mathrm{X}$ & & & \\
\hline 13 & Punção endovenosa & $\mathrm{X}$ & $\mathrm{X}$ & & \\
\hline 14 & Supervisão & $\mathrm{X}$ & $\mathrm{X}$ & & \\
\hline 15 & Transporte: Intra-hospitalar & $\mathrm{X}$ & & & \\
\hline
\end{tabular}

Os Gráficos de 6 a 20 apresentam a distribuição de cada intervenção de cuidado direto, constante no Quadro 12.

Gráfico 6 - Demonstrativo da intervenção Administração de medicamentos, com frequência $\geq 1 \%$, nas unidades de saúde estudadas por categoria profissional. São Paulo, 2017.

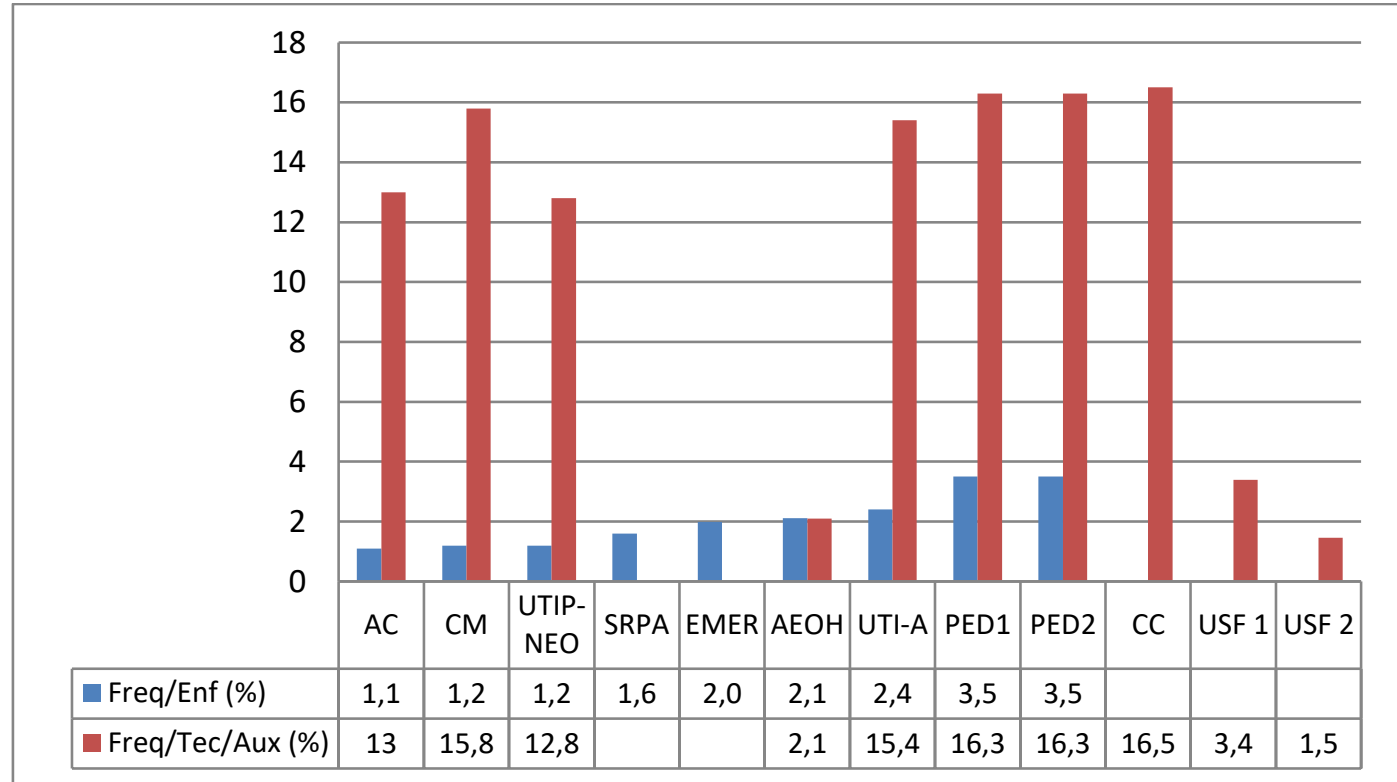

AC - Alojamento Conjunto, AEOH - Ambulatório de Especialidades Oncologia e Hematologia, CM - Clínica Médica, CC - Clínica Cirúrgica, EMER - Emergência, PED - Unidade de Internação Pediátrica, SRPA - Sala de Recuperação Pós-Anestésica, USF - Unidade de Saúde da Família, UTI-A - Unidade de Terapia Intensiva Adulto, UTIP-NEO - Unidade de Terapia Intensiva Pediátrica e Neonatal. 
A intervenção Administração de medicamentos esteve presente, praticamente, em todas as unidades de saúde em que foi observada a equipe de enfermagem, demandou maior proporção do tempo de trabalho para categoria téc./aux. de enfermagem, a exceção da SRPA e EMER em que esta intervenção ocorreu para os enfermeiros.

Gráfico 7 - Demonstrativo da intervenção Alimentação, com frequência $\geq$ $1 \%$, nas unidades de saúde estudadas por categoria profissional. São Paulo, 2017.

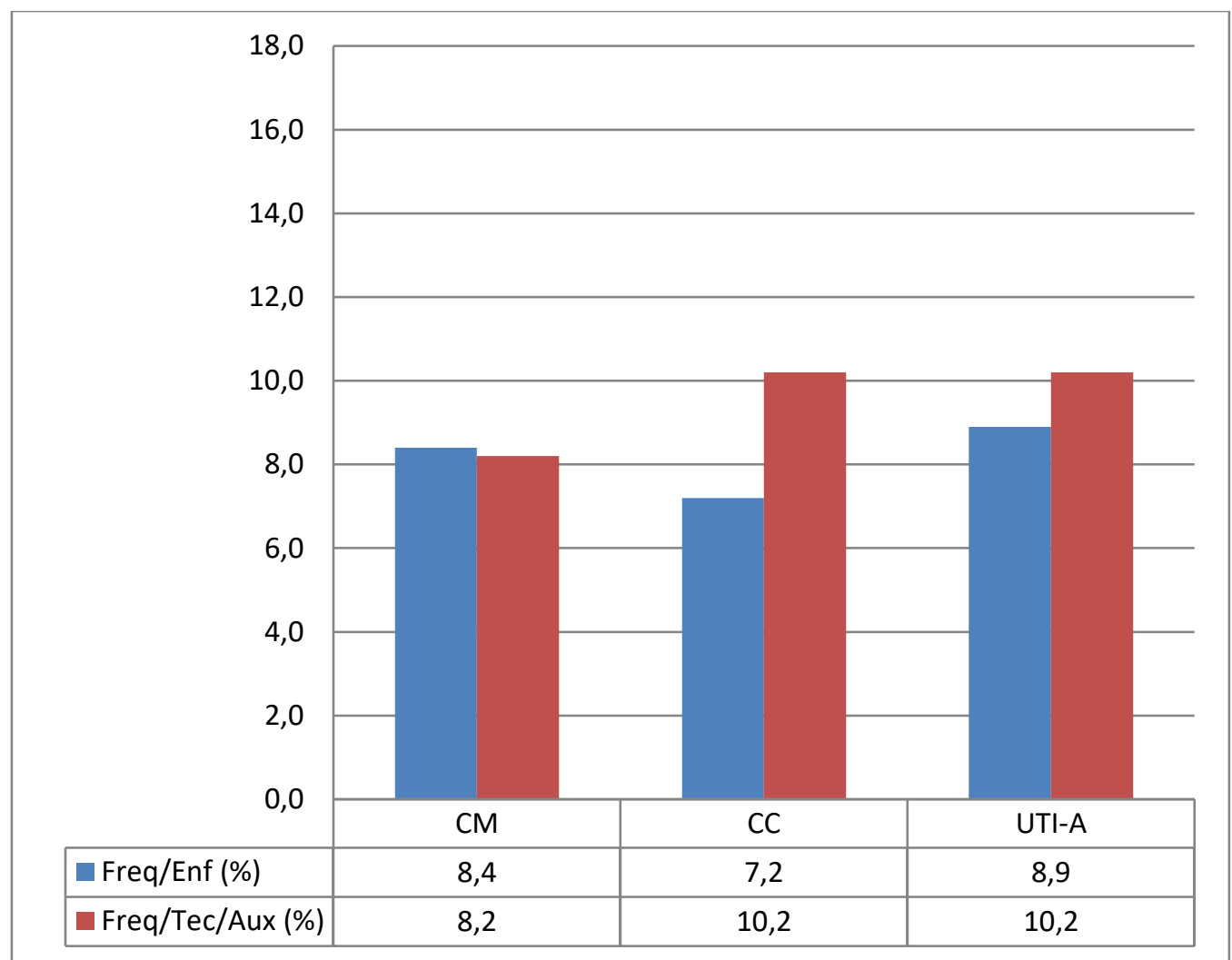

CM - Clínica Médica, CC - Clínica Cirúrgica, UTI-A - Unidade de Terapia Intensiva Adulto.

A intervenção Alimentação foi expressiva nas unidades de CM, CC e UTI-A, o que pode ser um indicativo do maior grau de dependência dos pacientes nessas unidades. Participaram da realização dessa intervenção, os enfermeiros e os téc./aux. de enfermagem. Essa intervenção é considerada essencial para as unidades médico-cirúrgica, segundo a NIC (Bulecheck et al., 2016, p.432). 
Gráfico 8 - Demonstrativo da intervenção Assistência em exames, com frequência $\geq 1 \%$, nas unidades de saúde estudadas por categoria profissional. São Paulo, 2017.

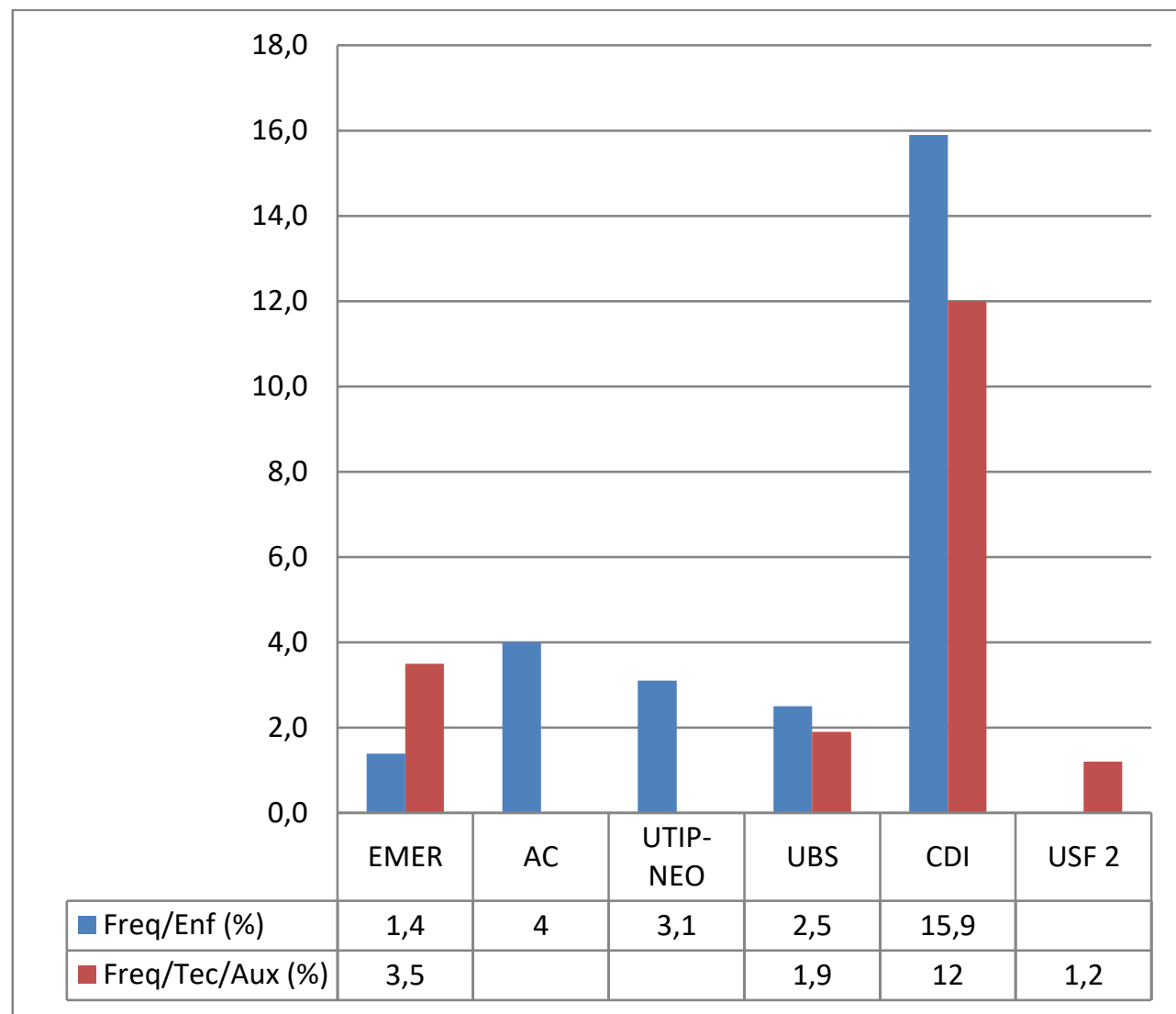

AC - Alojamento Conjunto, CDI - Centro de Diagnóstico por Imagem, EMER Emergência, UBS - Unidade Básica de Saúde, USF - Unidade de Saúde da Família, UTIP-NEO - Unidade de Terapia Intensiva Pediátrica e Neonatal.

A intervenção Assistência em exames/procedimentos, proposta pelo instrumento de Bonfim (2014) para USF, foi incorporada à intervenção Assistência em exames. Esta intervenção é expressiva no CDI já que sua finalidade é a realização de exames para diagnóstico.

Esta intervenção é considera essencial para unidades ambulatoriais, segundo a NIC, porém, na realidade das unidades estudadas, ocorreu para o diagnóstico e para o apoio ao tratamento realizado, o que impacta na carga de trabalho da unidade, uma vez que há a necessidade de um profissional disponível durante o procedimento de exames. 
Gráfico 9 - Demonstrativo da intervenção Banho, com frequência $\geq 1 \%$, nas unidades de saúde estudadas por categoria profissional. São Paulo, 2017.

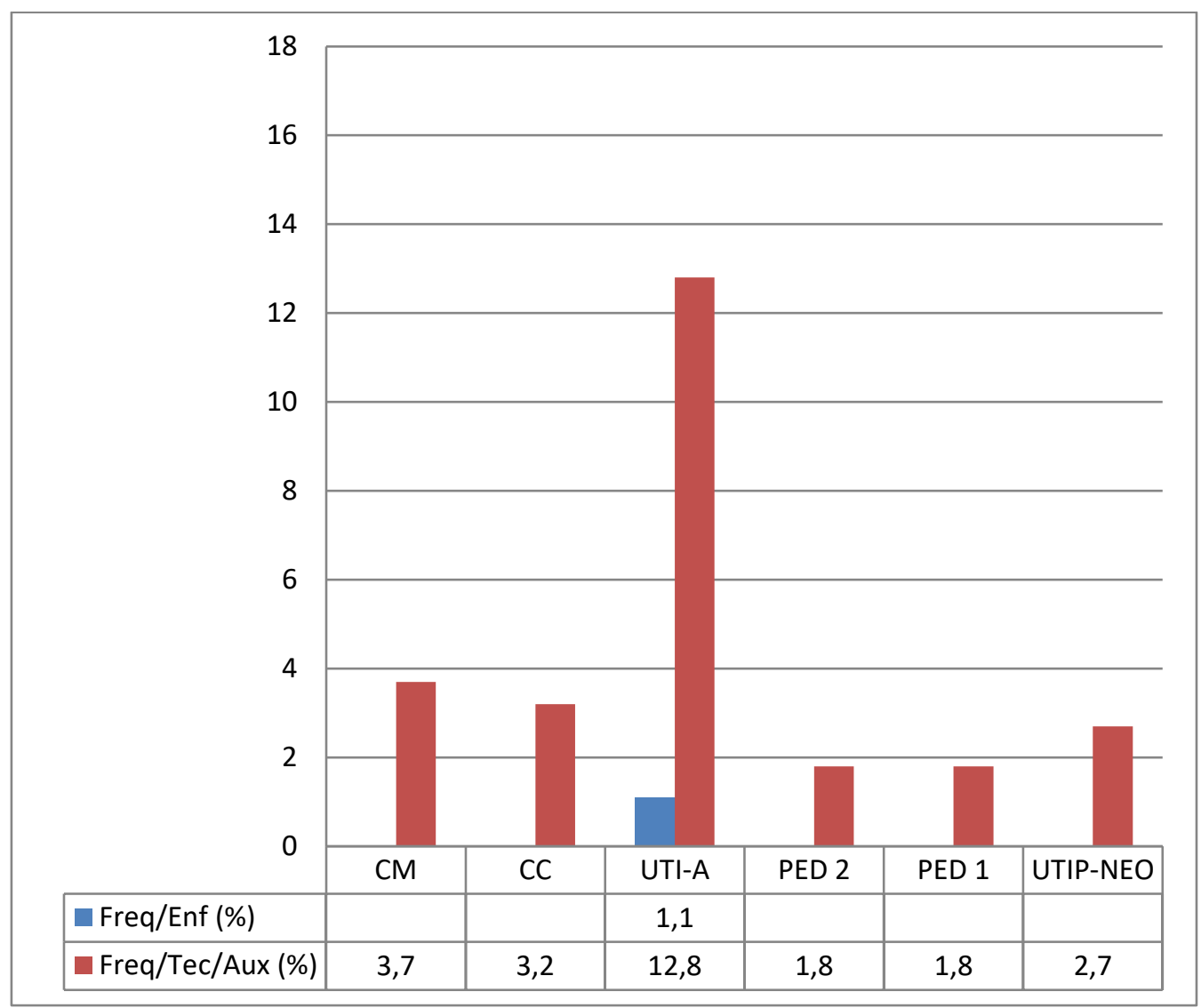

CM - Clínica Médica, CC - Clínica Cirúrgica, PED - Unidade de Internação Pediátrica, UTI-A - Unidade de Terapia Intensiva Adulto, UTIP-NEO - Unidade de Terapia Intensiva Pediátrica e Neonatal.

As unidades apresentadas no gráfico 9 apresentaram percentual expressivo da intervenção Banho, por se tratar de unidades na quais os pacientes internados que requerem auxilio ou necessitam que o téc./aux. de enfermagem realize esse cuidado por ele. Percebe-se a participação do enfermeiro na UTI-A, provavelmente pela gravidade dos pacientes e do maior número desses profissionais nessas unidades. 
Gráfico 10 - Demonstrativo da intervenção Controle de dispositivos para acesso venoso, com frequência $\geq 1 \%$, nas unidades de saúde estudadas, por categoria profissional. São Paulo, 2017.

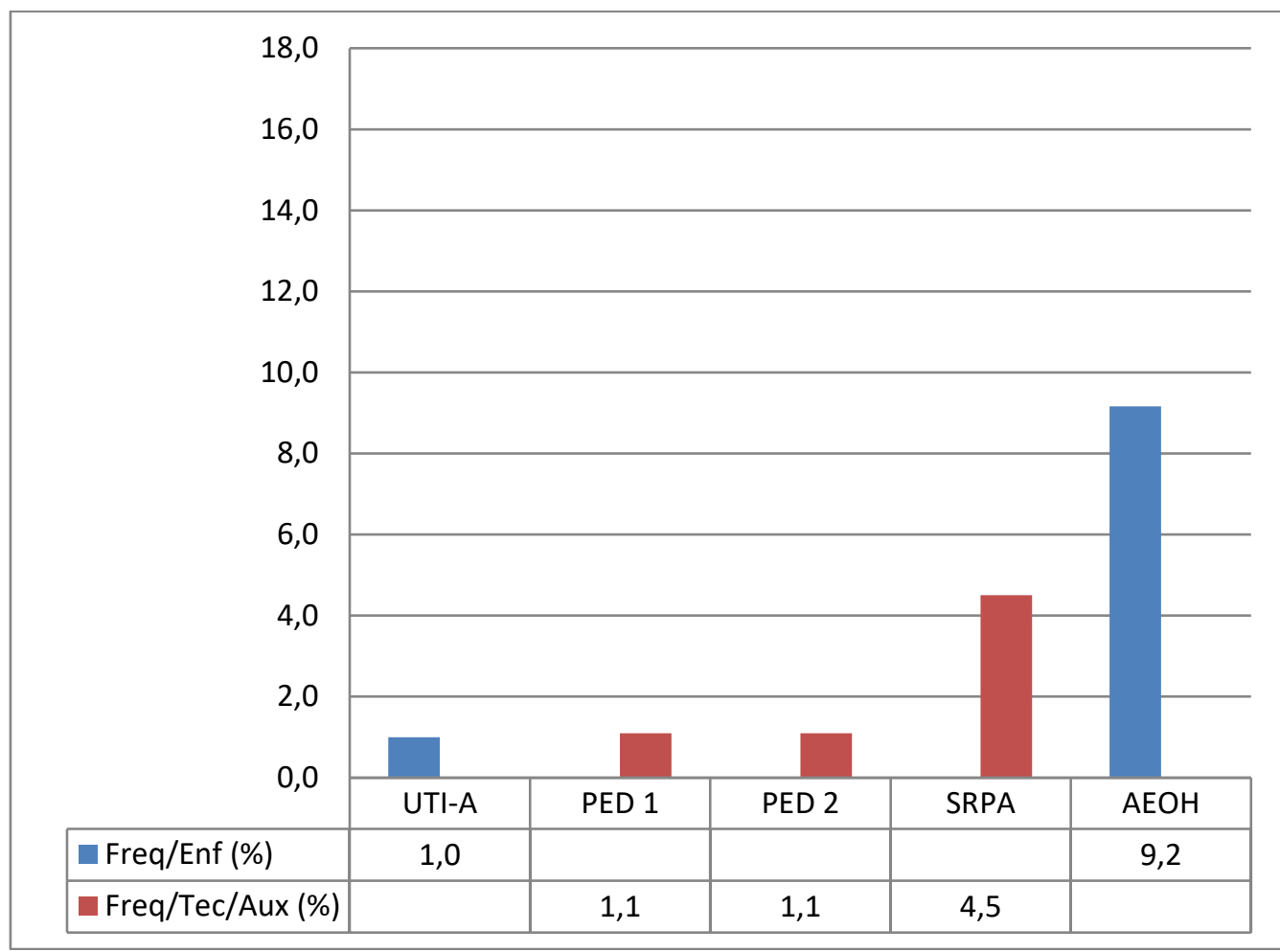

$\mathrm{AEOH}$ - Ambulatório de Especialidades Oncologia e Hematologia, PED - Unidade de Internação Pediátrica, SRPA - Sala de Recuperação Pós-Anestésica, UTI-A - Unidade de Terapia Intensiva Adulto.

A intervenção Controle de dispositivo para acesso venoso foi expressiva na SRPA, em que demandou maior proporção do tempo de trabalho do tec./aux. de enfermagem e no $\mathrm{AEOH}$ do enfermeiro, uma vez que é uma intervenção exclusiva desse profissional, nas unidades com pacientes oncológicos na administração de quimioterápicos considerada intervenção essencial para as áreas de cuidados médicocirúrgica, de oncologia e de neonatologia, segundo a NIC (Bulecheck et al., 2016, p.432). 
Gráfico 11 - Demonstrativo da intervenção Punção endovenosa, com frequência $\geq 1 \%$, com frequência $\geq 1 \%$, nas unidades de saúde estudadas, por categoria profissional. São Paulo, 2017.

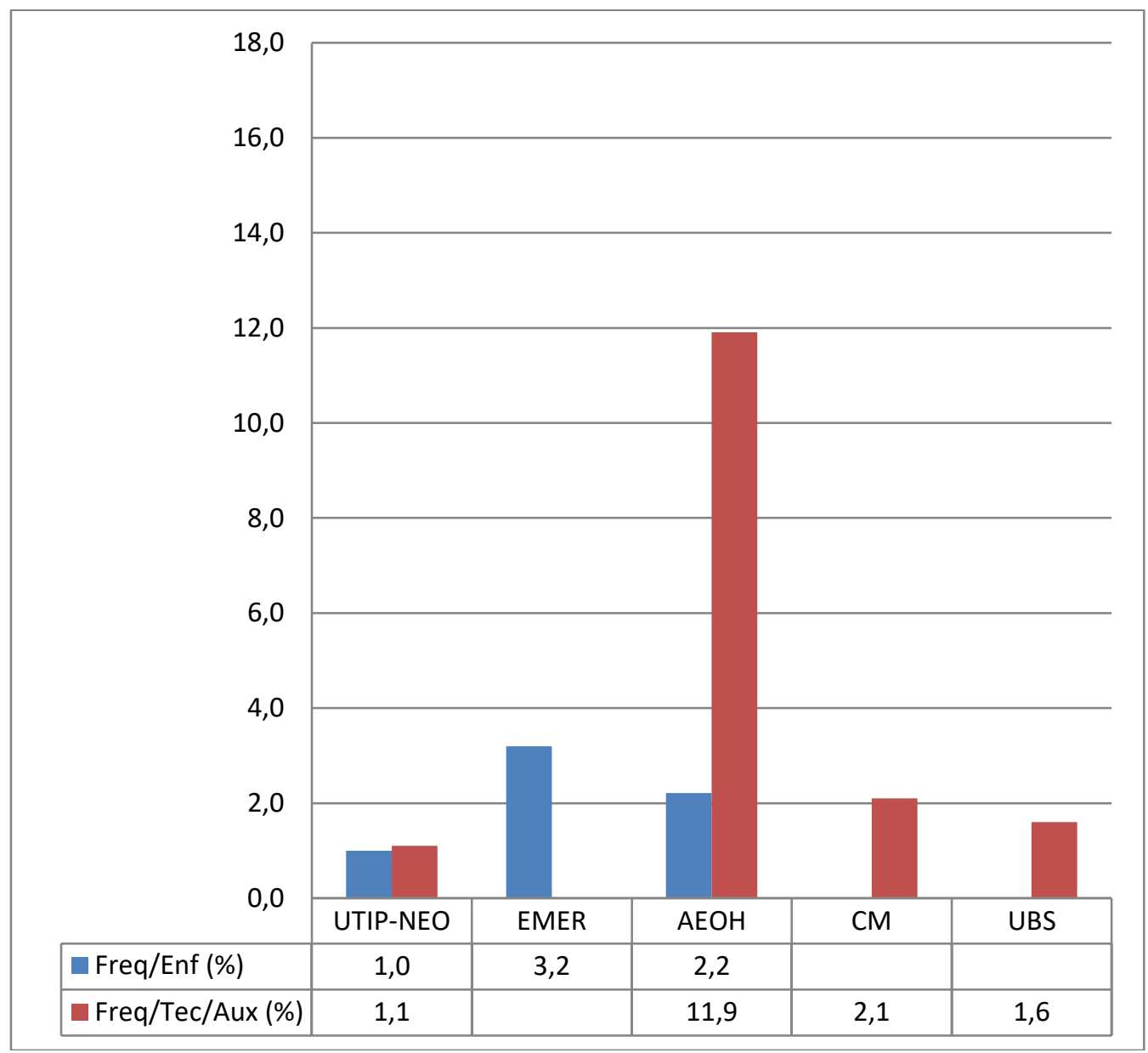

$\mathrm{AEOH}$ - Ambulatório de Especialidades Oncologia e Hematologia, CM - Clínica Médica, EMER - Emergência, UBS - Unidade Básica de Saúde, UTIP-NEO - Unidade de Terapia Intensiva Pediátrica e Neonatal.

A ocorrência da intervenção Punção endovenosa foi expressiva na unidade $\mathrm{AEOH}$, especialmente para téc./aux. de enfermagem, provavelmente para infusão de drogas anti-eméticas ou para reposição de volume - geralmente os pacientes oncológicos possuem cateteres de longa permanência e para infusão de drogas quimioterápicas, com manuseio exclusivo dos enfermeiros. Na EMER, foi observada a categoria de enfermeiros. 
Gráfico 12 - Demonstrativo da intervenção Controle de imunização/vacina, com frequência $\geq 1 \%$, nas unidades de saúde estudadas, por categoria profissional. São Paulo, 2017.

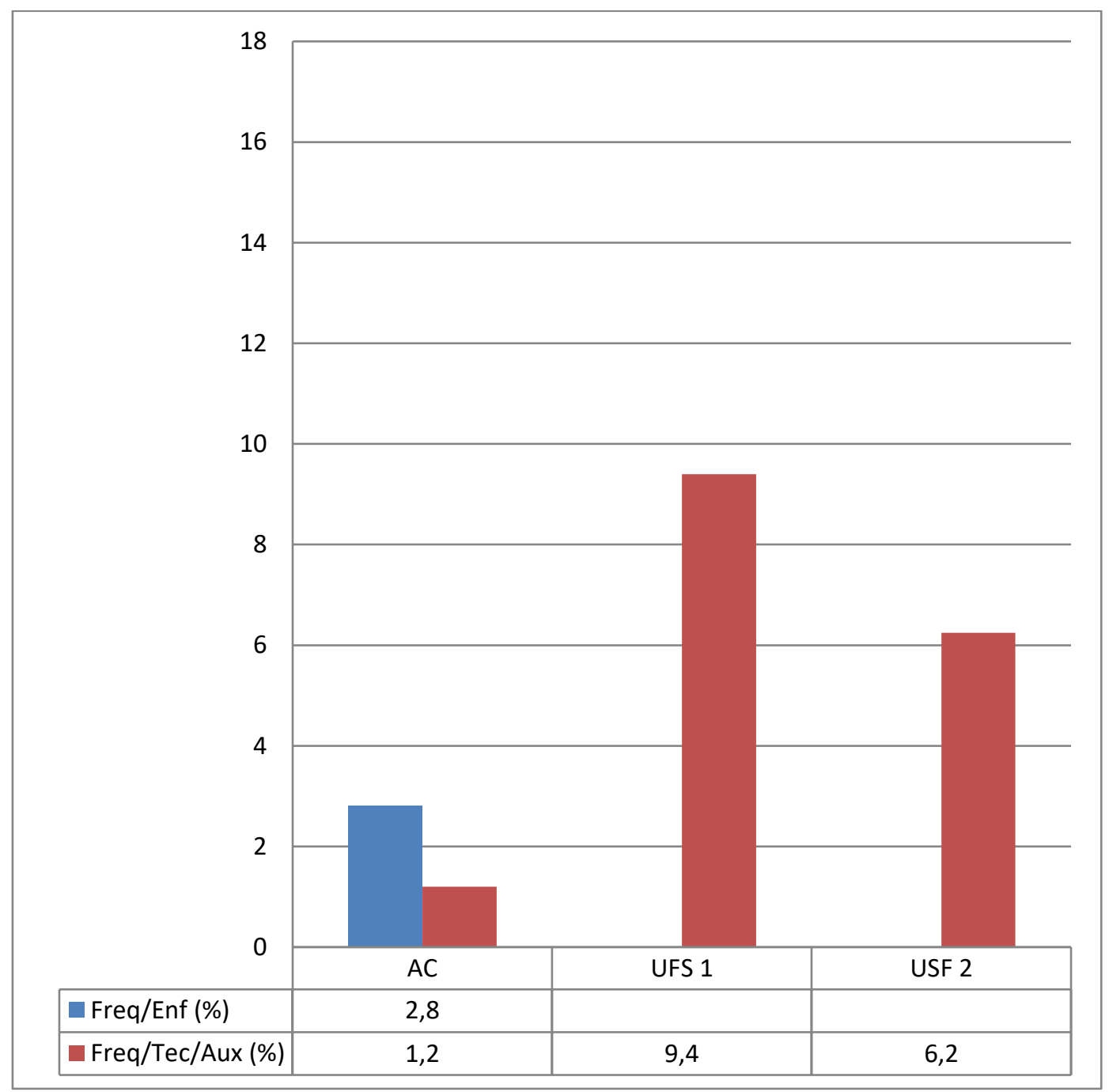

AC - Alojamento Conjunto, USF - Unidade de Saúde da Família.

A intervenção Controle de imunização/vacina foi relevante nas USF, sendo realizada pelo téc./aux. de enfermagem. Observada, também, no AC, a qual foi realizada pelos téc./aux. de enfermagem e por enfermeiros por se tratar de unidade que presta assistência ao binômio mãe-filho.

É citada como intervenção essencial para ambulatórios, saúde ocupacional, saúde pública e comunitária, pediatria, segundo NIC (Bulecheck et al., 2016, p.432). 
Gráfico 13 - Demonstrativo da intervenção Controle do ambiente: conforto, com frequência $\geq 1 \%$, nas unidades de saúde estudadas, por categoria profissional. São Paulo, 2017.

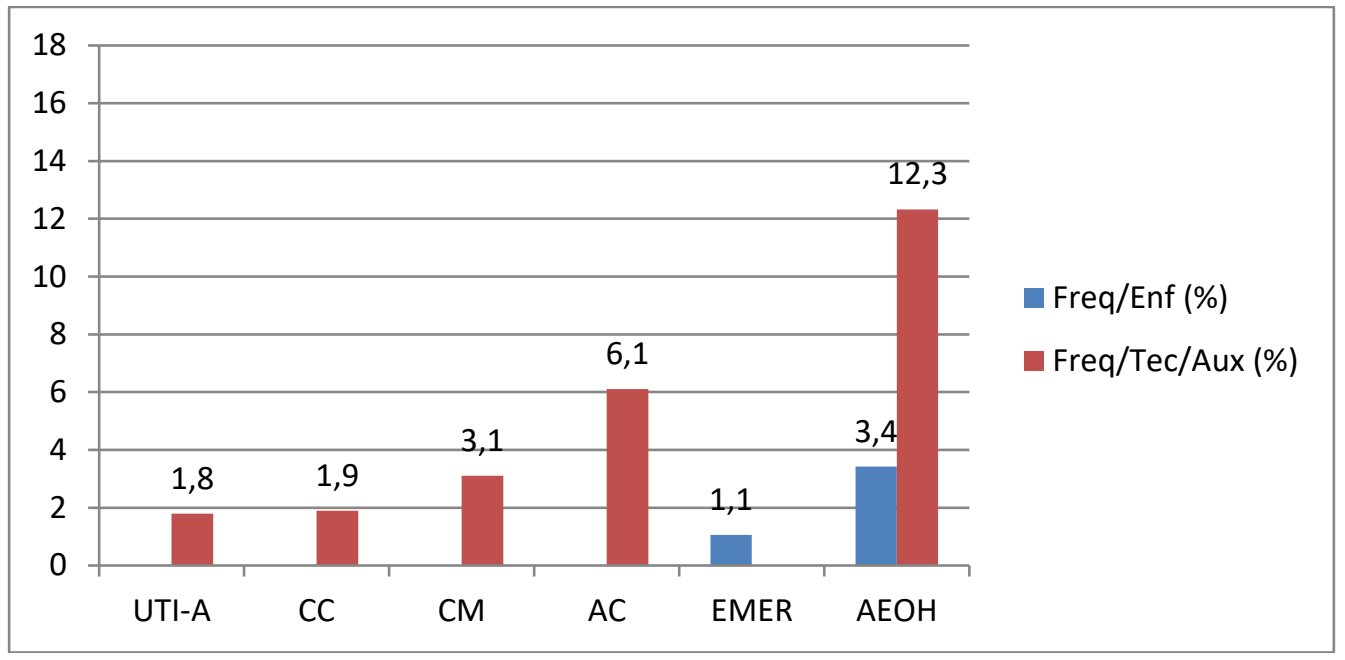

AC - Alojamento Conjunto, AEOH - Ambulatório de Especialidades Oncologia e Hematologia, CM - Clínica Médica, CC - Clínica Cirúrgica, EMER - Emergência, UTIA - Unidade de Terapia Intensiva Adulto.

A intervenção Controle do ambiente: conforto ocorreu de forma significativa nas unidades de $\mathrm{AEOH}, \mathrm{AC}$ e $\mathrm{CM}$, sendo realizada principalmente por téc./aux. de enfermagem em todas as unidades apresentadas.

Gráfico 14 - Demonstrativo da intervenção Cuidados na admissão, com frequência $\geq 1 \%$, nas unidades de saúde estudadas, por categoria profissional. São Paulo, 2017.

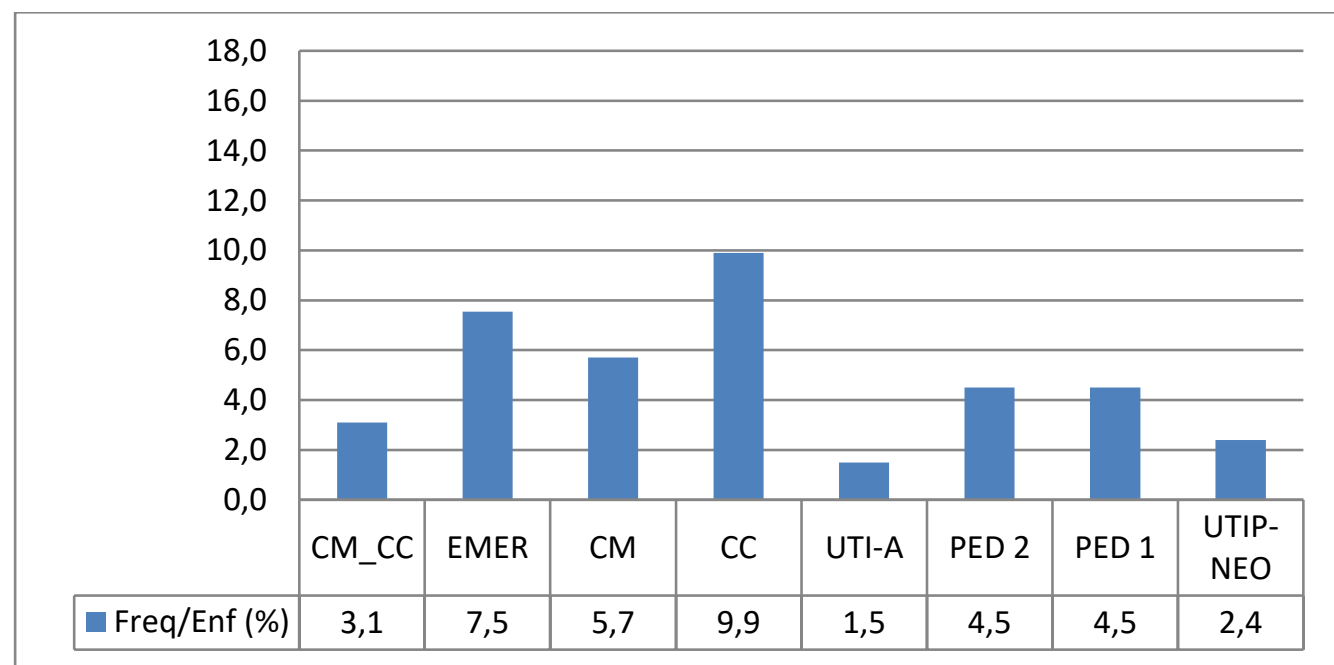

CM - Clínica Médica, CC - Clínica Cirúrgica, CM-CC - Clínica Médica e Clínica Cirúrgica, EMER - Emergência, PED - Unidade de Internação Pediátrica, UTI-A Unidade de Terapia Intensiva Adulto, UTIP-NEO - Unidade de Terapia Intensiva Pediátrica e Neonatal. 
A intervenção Cuidados na admissão foi significativa em todas as unidades de internação e observada na categoria dos enfermeiros, por se tratar uma intervenção que agrupa atividades relacionadas às orientações quanto às rotinas do serviço e do levantamento de informações necessárias para o planejamento da assistência.

Gráfico 15 - Demonstrativo da intervenção Ensino: processo de doença, com frequência $\geq 1 \%$, nas unidades de saúde estudadas, por categoria profissional. São Paulo, 2017.

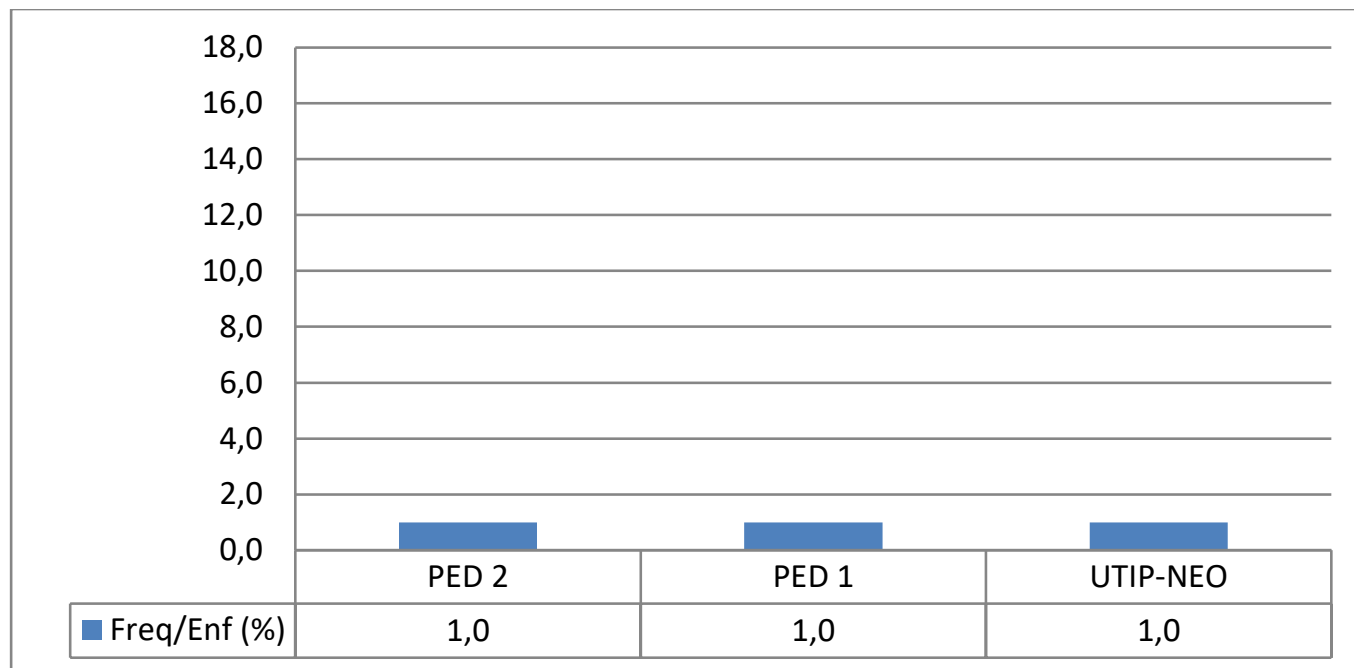

PED - Unidade de Internação Pediátrica, UTIP-NEO - Unidade de Terapia Intensiva Pediátrica e Neonatal.

Gráfico 16 - Demonstrativo da intervenção Plano de alta, com frequência $\geq$ $1 \%$, nas unidades de saúde estudadas, por categoria profissional. São Paulo, 2017.

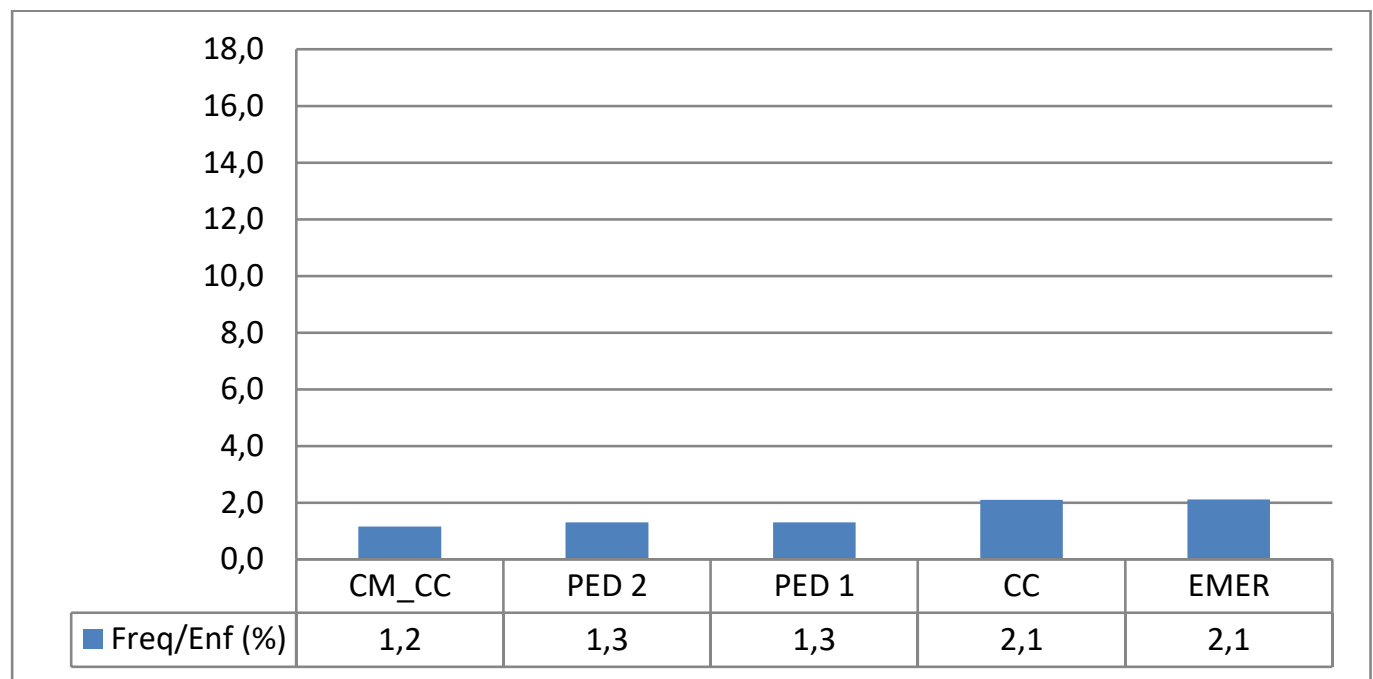

CC - Clínica Cirúrgica, CM-CC - Clínica Médica e Clínica Cirúrgica, EMER Emergência, PED - Unidade de Internação Pediátrica. 
Gráfico 17 - Demonstrativo da intervenção Escuta ativa, com frequência $\geq$ $1 \%$, nas unidades de saúde estudadas, por categoria profissional. São Paulo, 2017.

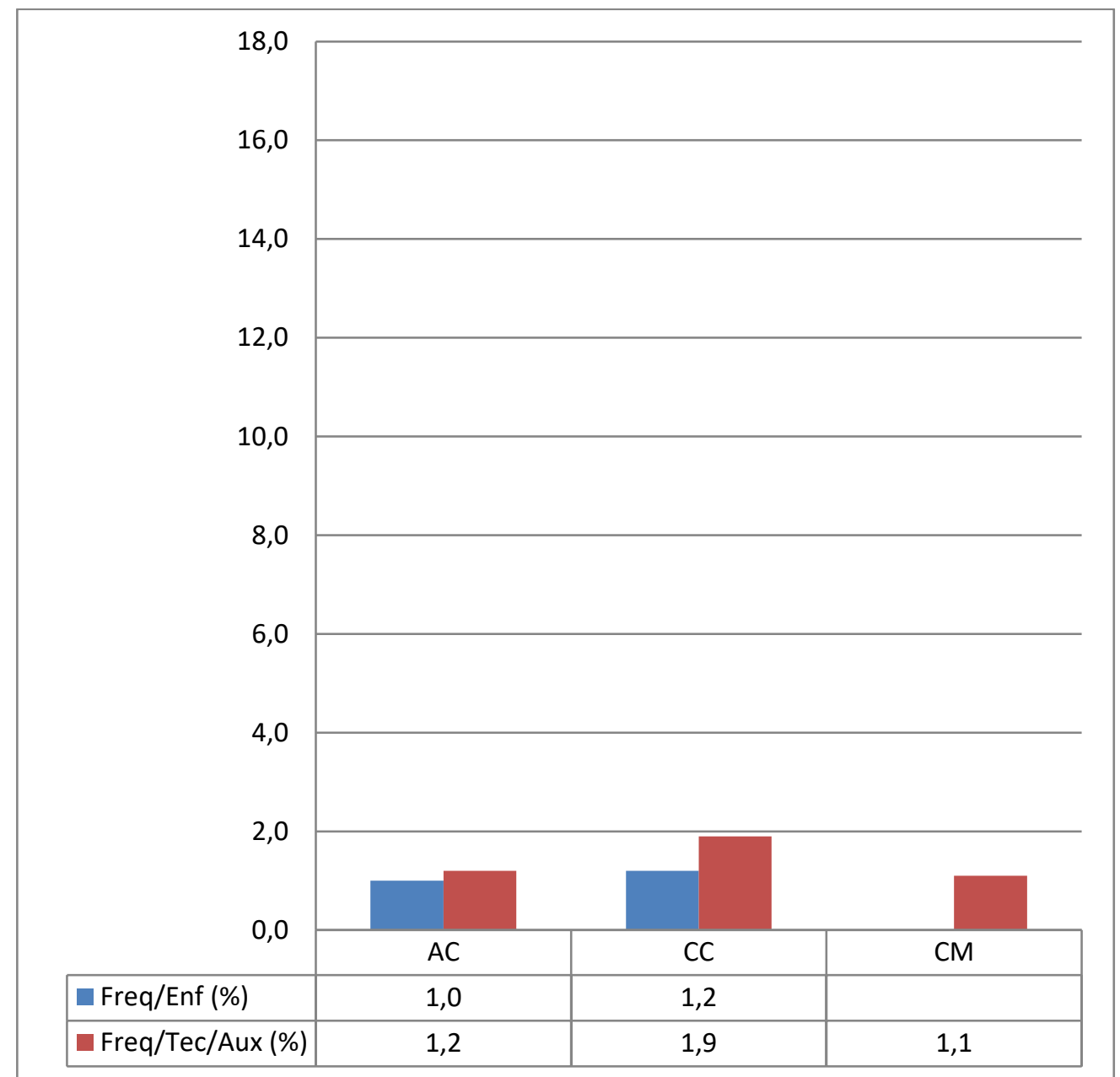

AC - Alojamento Conjunto, CM - Clínica Médica, CC - Clínica Cirúrgica.

As intervenções Ensino: processo de doença (Gráfico 15), Plano de Alta (Gráfico 16) e Escuta ativa (Gráfico 16) ocorreram com frequência insignificante, provavelmente, porque essas intervenções aconteçam concomitantes à outras intervenções de cuidado direto e não isoladamente.

A intervenção Escuta ativa é considerada uma intervenção essencial para a área obstétrica e perioperatória, segundo a NIC (Bulecheck et al., 2016, p.432). 
Gráfico 18 - Demonstrativo da intervenção Monitoração de sinais vitais, com frequência $\geq 1 \%$, nas unidades de saúde estudadas, por categoria profissional. São Paulo, 2017.

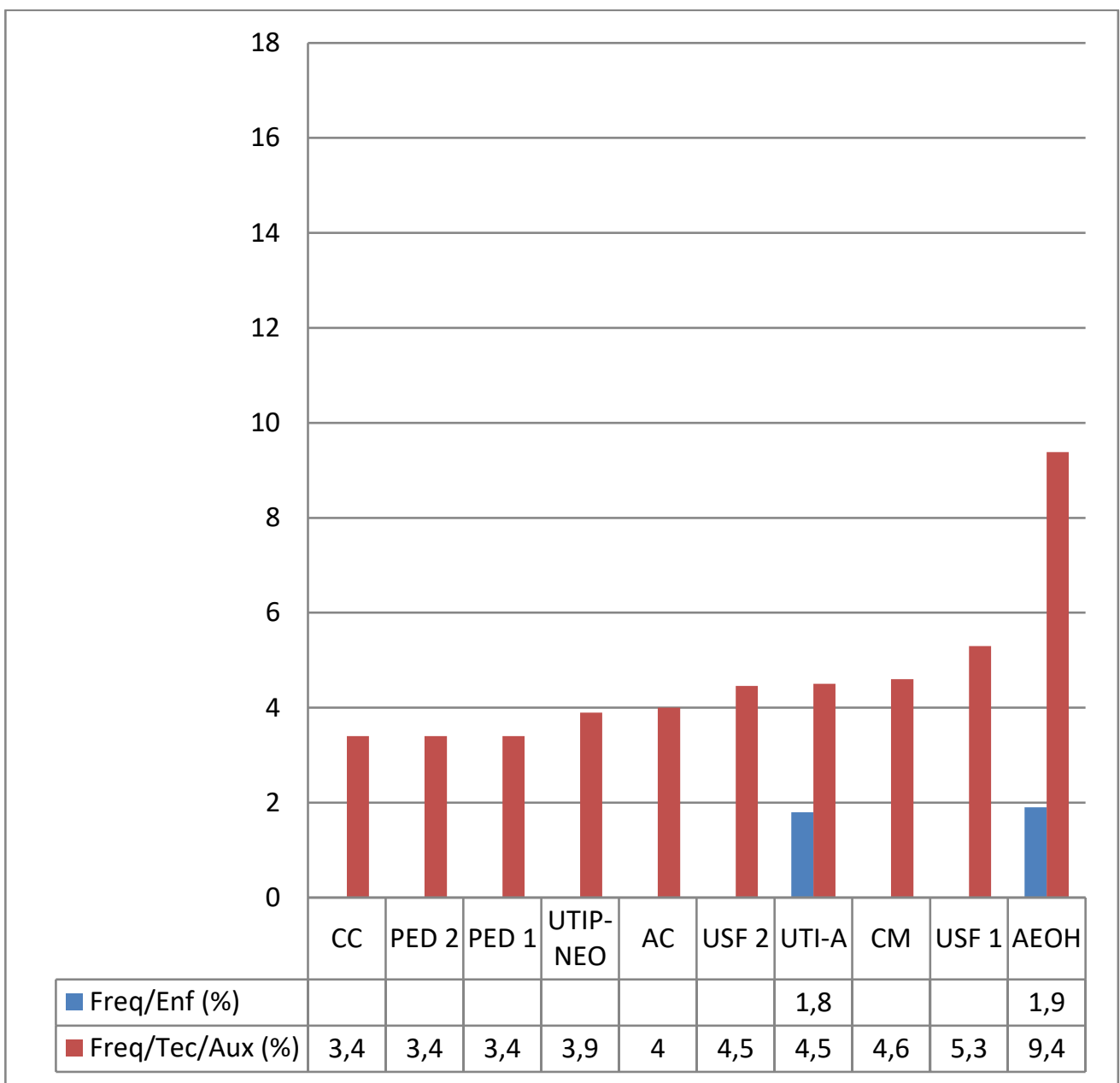

AC - Alojamento Conjunto, AEOH - Ambulatório de Especialidades Oncologia e Hematologia, CM - Clínica Médica, CC - Clínica Cirúrgica, PED - Unidade de Internação Pediátrica, USF - Unidade de Saúde da Família, UTI-A - Unidade de Terapia Intensiva Adulto, UTIP-NEO - Unidade de Terapia Intensiva Pediátrica e Neonatal.

A intervenção Monitoração de sinais vitais foi observada nas unidades de internação, na unidade ambulatorial e nas unidades de saúde da família - basicamente, realizada pela categoria profissional tec./aux. de enfermagem.

Considerada uma intervenção essencial em unidades ambulatoriais, de terapia intensiva adulto pediátrica e neonatal, médicocirúrgica, de emergência e perioperatória, segundo a NIC (Bulecheck et al., 2016, p.432). 
Gráfico 19 - Demonstrativo da intervenção Supervisão, com frequência $\geq$ $1 \%$, nas unidades de saúde estudadas, por categoria profissional. São Paulo, 2017.

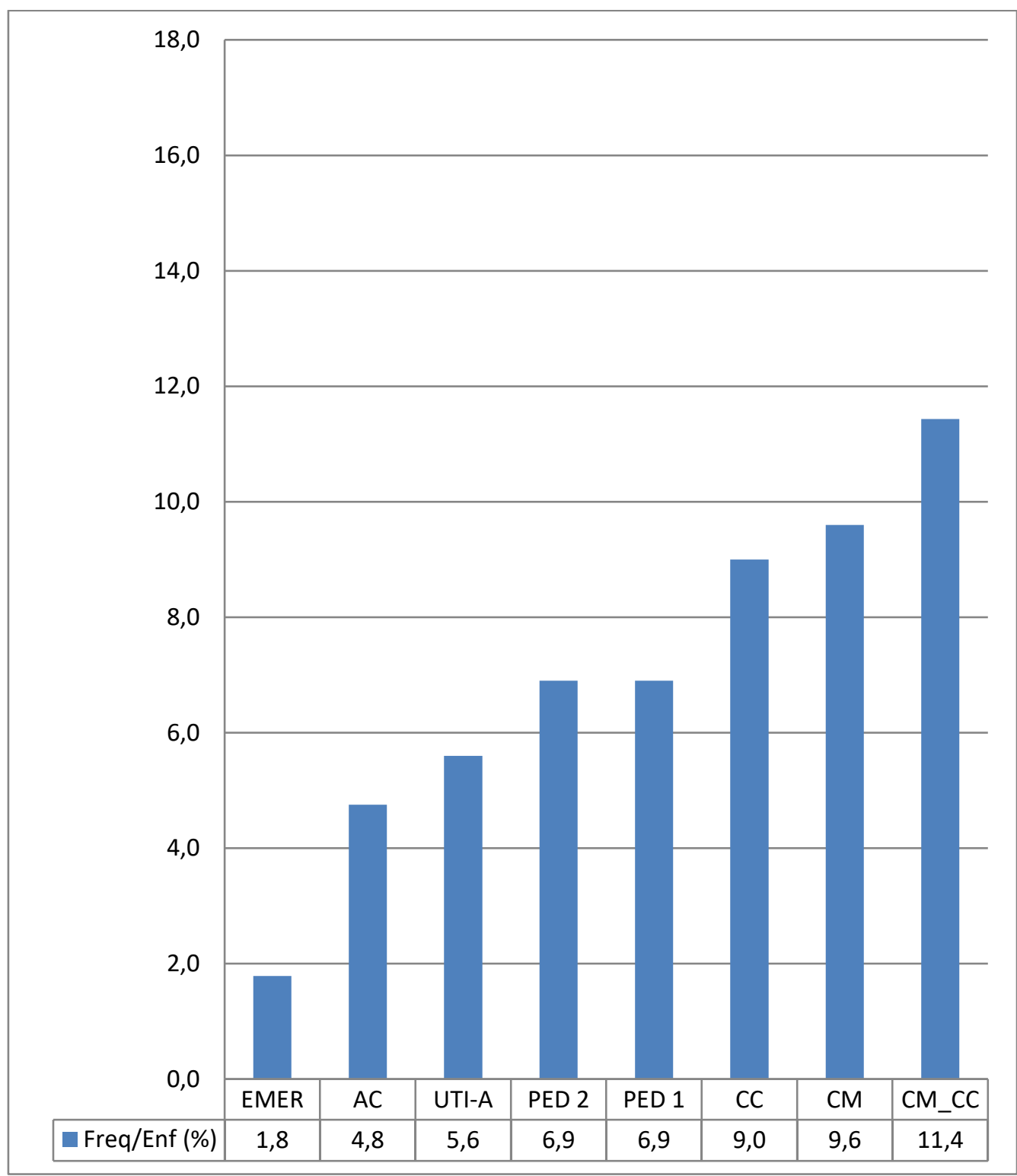

AC - Alojamento Conjunto, CM - Clínica Médica, CC - Clínica Cirúrgica, CM-CC Clínica Médica e Clínica Cirúrgica, EMER - Emergência, PED - Unidade de Internação Pediátrica, UTI-A - Unidade de Terapia Intensiva Adulto.

Embora todos os profissionais de saúde possam e devam realizar a supervisão, esta intervenção foi expressiva e demonstrou sua relevância na carga de trabalho, na categoria de enfermeiros e foi observada em todas as unidades de internação estudadas - a exceção da UTIP-NEO, a qual a intervenção foi classificada como cuidados indiretos. 
Gráfico 20 - Demonstrativo da intervenção Transporte: intra-hospitalar, com frequência $\geq 1 \%$, nas unidades de saúde estudadas, por categoria profissional. São Paulo, 2017.

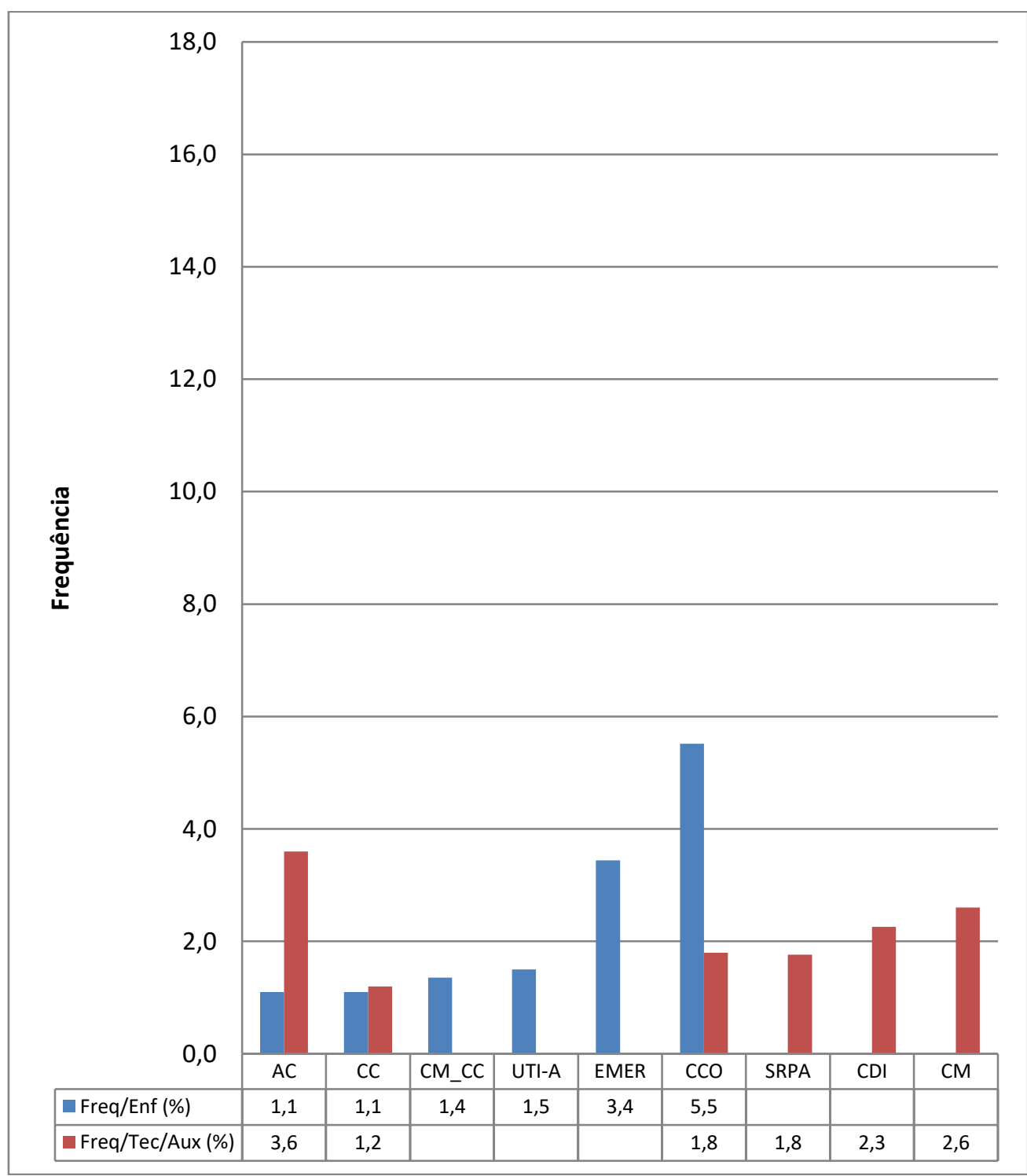

AC - Alojamento Conjunto, CM - Clínica Médica, CC - Clínica Cirúrgica, CCO - Centro Cirúrgico de Oncologia, CDI - Centro de Diagnóstico por Imagem, CM-CC - Clínica Médica e Clínica Cirúrgica, EMER - Emergência, SRPA - Sala de Recuperação PósAnestésica, UTI-A - Unidade de Terapia Intensiva Adulto.

A intervenção Transporte: intra-hospitalar foi expressiva na unidade $\mathrm{CCO}$, sendo observada principalmente para os enfermeiros; ocorreu nas categorias enfermeiro e téc./aux. de enfermagem nas unidades $\mathrm{AC}, \mathrm{CC}$ e $\mathrm{CCO}$, foi observada somente na categoria enfermeiros nas unidades de CM-CC, UTI-A e EMER; e dos tec./aux. de enfermagem nas unidades de SRPA,CDI e CM. 
Quadro 13 - Intervenções de cuidado direto com frequência $\geq 1 \%$ que foram observadas em duas unidades por categoria profissional. São Paulo, 2017.

\begin{tabular}{|c|l|c|c|c|c|}
\hline \multirow{2}{*}{$n$} & \multicolumn{2}{|c|}{ Intervenção } & \multicolumn{3}{c|}{ Categoria Profissional } \\
\cline { 3 - 6 } & & Enf & Tec/Aux & Nut & ATA \\
\hline 1 & Alimentação por sonda enteral & & $X$ & & \\
\hline 2 & $\begin{array}{l}\text { Assistência no autocuidado: uso do vaso } \\
\text { sanitário }\end{array}$ & & $X$ & & \\
\hline 3 & Assistência no autocuidado: transferência & & $X$ & & \\
\hline 4 & Controle da nutrição & & $X$ & & \\
\hline 5 & Cuidados com lesões & $X$ & $X$ & & \\
\hline 6 & Cuidados da pele: tratamentos tópicos & $X$ & & & \\
\hline 7 & Orientação quanto ao sistema de saúde & $X$ & $X$ & & \\
\hline 8 & Presença & $X$ & $X$ & & \\
\hline 9 & Regulação da temperatura & $X$ & $X$ & & \\
\hline 10 & Técnica para acalmar & $X$ & $X$ & & \\
\hline 11 & Visitar domiciliar & $X$ & $X$ & & \\
\hline
\end{tabular}

Cada uma das intervenções apresentadas no Quadro 13 foram observadas em duas unidades. Para apresentar as distribuições destas intervenções, estas foram agrupadas em intervenções com frequência entre os intervalos de $\geq 1 \%$ a $\leq 2 \%$, Gráfico 21 , e intervenções com frequência $>2 \%$, Gráfico 22 .

As intervenções de cuidado direto com frequência $\geq 1 \%$ a $\leq 2 \%$ realizadas pelos enfermeiros foram Orientação quanto ao sistema de saúde observada na USF 1, Cuidados com a pele: tratamento tópico na unidade PED 1 e PED 2.

Para os téc./aux.de enfermagem, chamou atenção as intervenções Técnicas para acalmar, Orientação quanto ao sistema de saúde, Ensino procedimento/tratamento, Cuidados com lesões, Controle de nutrição e Alimentação por sonda enteral, como pode ser verificado no Gráfico 21. 
Gráfico 21 - Demonstrativo das Intervenções de Cuidado Direto observadas em até duas unidades com frequência $\geq 1 \%$ a $\leq 2 \%$, por categoria profissional. São Paulo, 2017.

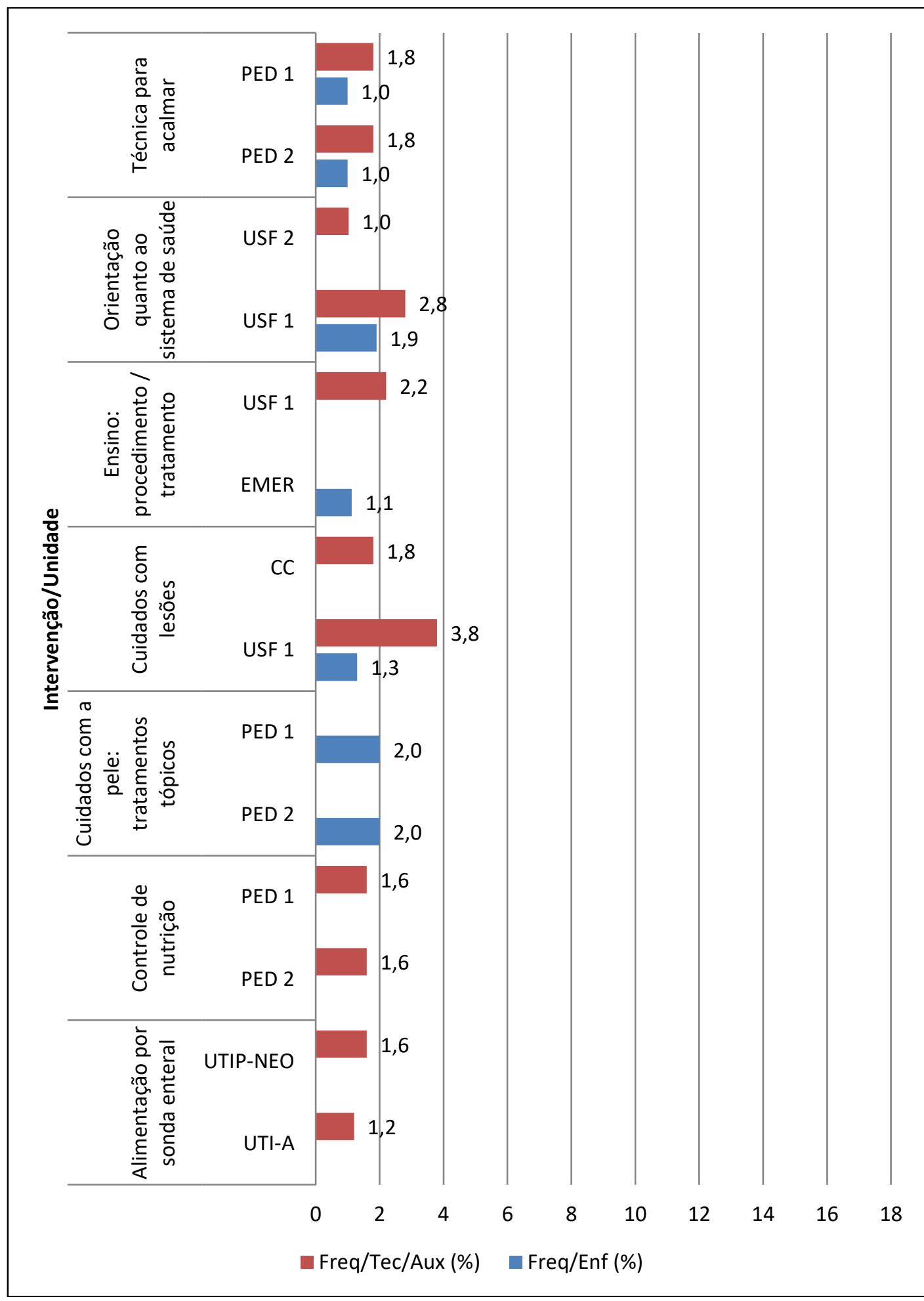

CC - Clínica Cirúrgica, EMER - Emergência, PED - Unidade de Internação Pediátrica, USF - Unidade de Saúde da Família, UTI-A - Unidade de Terapia Intensiva Adulto, UTIP-NEO - Unidade de Terapia Intensiva Pediátrica e Neonatal. 
Gráfico 22 - Demonstrativo das Intervenções de Cuidado Direto observadas em até duas unidades com frequência $>2 \%$, por categoria profissional. São Paulo, 2017.

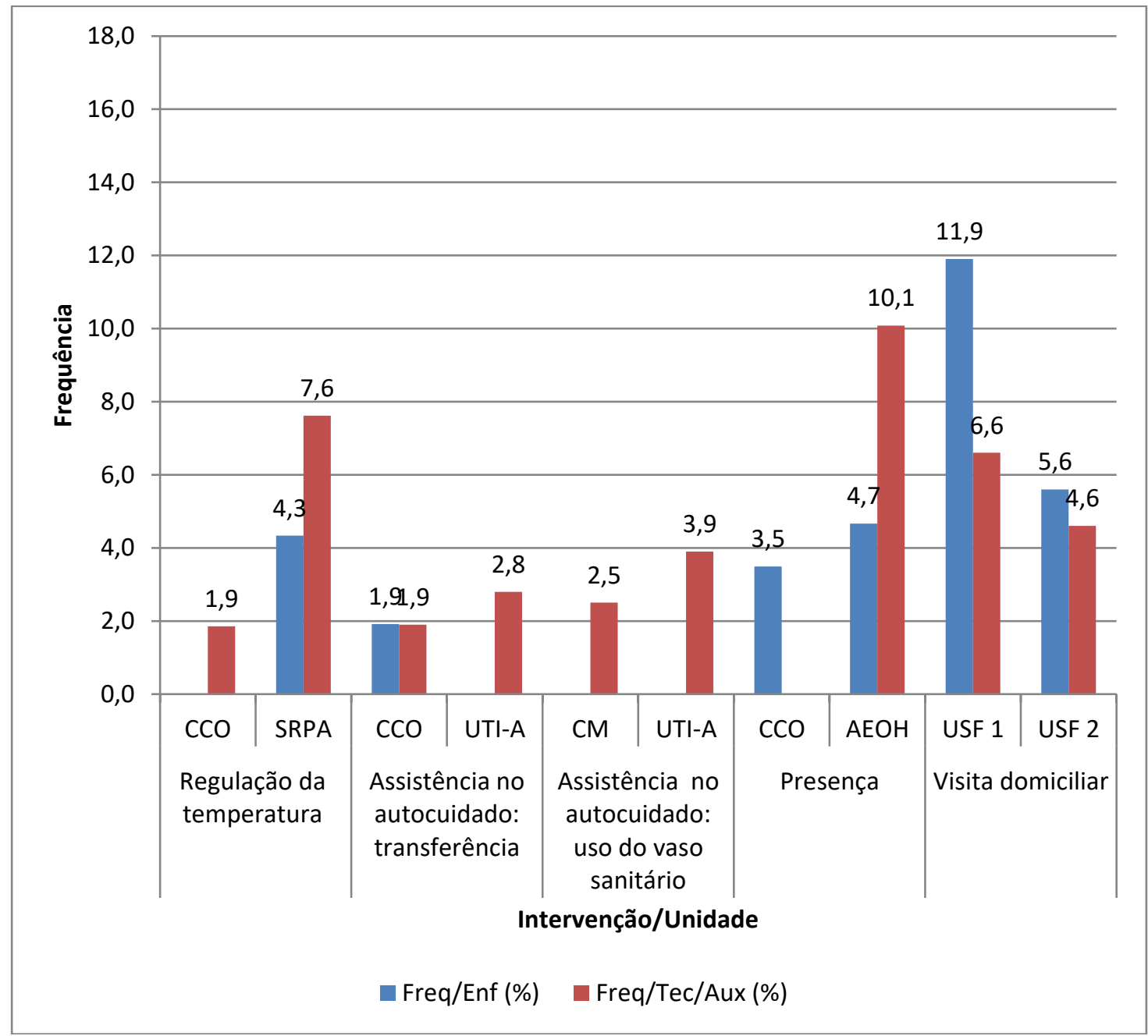

AEOH - Ambulatório de Especialidades Oncologia e Hematologia, CM - Clínica Médica, CCO - Centro Cirúrgico de Oncologia, SRPA - Sala de Recuperação PósAnestésica, USF - Unidade de Saúde da Família, UTI-A - Unidade de Terapia Intensiva Adulto.

As intervenções mais frequentes, neste grupo de intervenções, foram observadas nas categorias profissionais de enfermeiros e téc./aux. de enfermagem.

As intervenções mais frequentes observadas nos enfermeiros foram Regulação de temperatura, Presença e Visita domiciliar. Para os téc./aux. de enfermagem, as mais frequentes observadas foram Regulação de temperatura, Assistência no autocuidado: uso do vaso sanitário, Presença e Visita domiciliar. 
No Quadro 14, foram elencadas 44 intervenções, cada uma destas intervenções foi observada em apenas uma unidade. Para apresentar as distribuições destas intervenções nas unidades, estas foram agrupadas em intervenções com frequência entre os intervalos de $\geq 1 \%$ a $\leq 2 \%$, na Tabela 4 , e intervenções com frequência $>2 \%$, na Tabela 5 .

Quadro 14 - Intervenções de Cuidado Direto com frequência $\geq 1 \%$ que foram observadas em uma unidade, por categoria profissional. São Paulo, 2017.

\begin{tabular}{|c|c|c|c|c|c|}
\hline & & & (continu & & \\
\hline P & IIt & Cat & egoria $\mathrm{Pl}$ & ofissi & onal \\
\hline$n$ & Intervençao & Enf & Tec/Aux & Nut & ATA \\
\hline 1 & Administração de radiofármaco & & $\mathrm{X}$ & & \\
\hline 2 & Aconselhamento para Lactação & $\mathrm{X}$ & $\mathrm{X}$ & & \\
\hline 3 & Amostra de sangue capilar & & $\mathrm{X}$ & & \\
\hline 4 & Apoio emocional & & $\mathrm{X}$ & & \\
\hline 5 & Apoio familiar & $\mathrm{x}$ & & & \\
\hline 6 & Aspiração de vias aéreas & $\mathrm{X}$ & $\mathrm{X}$ & & \\
\hline 7 & Assistência cirúrgica & $\mathrm{X}$ & $\mathrm{X}$ & & \\
\hline 8 & Assistência no autocuidado: banho/higiene & & $\mathrm{X}$ & & \\
\hline 9 & Assistência no autocuidado & & $\mathrm{X}$ & & \\
\hline 10 & Atendimento à demanda espontânea & $\mathrm{X}$ & & & \\
\hline 11 & Avaliação da saúde & $\mathrm{X}$ & $\mathrm{X}$ & & \\
\hline 12 & Avaliação do estado nutricional & & & $\mathrm{x}$ & \\
\hline 13 & Controle da dor & $\mathrm{X}$ & & & \\
\hline 14 & Controle da quimioterapia & $\mathrm{x}$ & & & \\
\hline 15 & Controle de eletrólitos & $\mathrm{X}$ & & & \\
\hline 16 & Controle de infecção: transoperatória & $x$ & $x$ & & \\
\hline 17 & Controle de vias aéreas & & $\mathrm{X}$ & & \\
\hline 18 & Controle do ambiente: segurança & $x$ & $\mathrm{X}$ & & \\
\hline 19 & Controle hidroeletrolítico & $\mathrm{x}$ & & & \\
\hline 20 & Controle intestinal & & $\mathrm{x}$ & & \\
\hline
\end{tabular}




\begin{tabular}{|c|c|c|c|c|c|}
\hline & & & ontinuação & & \\
\hline$n$ & Intonennก̃̃ก & Cat & egoria $\operatorname{Prc}$ & ofissi & onal \\
\hline 11 & interventu̧ao & Enf & Tec/Aux & Nut & ATA \\
\hline 21 & $\begin{array}{l}\text { Cuidado com cateter central de inserção } \\
\text { periférica (PICC) }\end{array}$ & $X$ & & & \\
\hline 22 & Cuidados com local de incisão & & $X$ & & \\
\hline 23 & Cuidados pós-anestesia & $\mathrm{X}$ & $x$ & & \\
\hline 24 & Ensino: grupo & $\mathrm{X}$ & $\mathrm{X}$ & & \\
\hline 25 & Monitoramento do estado nutricional & & & $X$ & \\
\hline 26 & $\begin{array}{l}\text { Orientação alimentar e nutricional na alta } \\
\text { hospitalar }\end{array}$ & & & $\mathrm{X}$ & \\
\hline 27 & Orientação aos pais: lactente & $X$ & & & \\
\hline 28 & Posicionamento & & $X$ & & \\
\hline 29 & Posicionamento: intraoperatório & $x$ & & & \\
\hline 30 & Precauções cirúrgicas & $\mathrm{X}$ & $x$ & & \\
\hline 31 & Procedimentos ambulatoriais & & $X$ & & \\
\hline 32 & Promoção de ações educativas & $x$ & $\mathrm{X}$ & & \\
\hline 33 & Reanimação cardiopulmonar & $X$ & & & \\
\hline 34 & Recepção dos usuários à USF & & & & \\
\hline 35 & Regulação da temperatura: perioperatória & $X$ & & & \\
\hline 36 & Sondagem vesical & $x$ & & & \\
\hline 37 & Supervisão: segurança & $X$ & & & $x$ \\
\hline 38 & Terapia de diálise peritoneal & $x$ & $\mathrm{X}$ & & \\
\hline 39 & Terapia endovenosa & $x$ & & & \\
\hline 40 & Toque & $X$ & $X$ & & \\
\hline 41 & Transferência & & $X$ & & \\
\hline 42 & Triagem nutricional & & & $x$ & \\
\hline 43 & Vestir & & $X$ & & \\
\hline 44 & Vigilância em saúde & $X$ & & & \\
\hline
\end{tabular}

As intervenções presentes no quadro 14 foram observadas em uma unidade. Verificou-se que algumas intervenções contribuem com frequências elevadas para determinadas unidades e categorias de profissionais, representadas pelas intervenções Avaliação da saúde, 
Controle do ambiente: segurança e Terapia de diálise peritoneal (Tabela 3).

Outras intervenções caracterizam o processo de trabalho e a especificidade da unidade como é o caso das intervenções Administração de radiofármaco, Avaliação do estado nutricional, Cuidado com cateter central de inserção periférica (PICC), Avaliação da saúde (Tabela 3), e as intervenções Assistência cirúrgica, Atendimento à demanda espontânea, Controle de infecção: transoperatória, Controle de quimioterapia (Tabela 4).

Tabela 3 - Distribuição das intervenções de cuidado direto que foram observados em uma unidade, com frequência $\geq 1 \%$ a $\leq 2 \%$, segundo categoria profissional. São Paulo, 2017.

(continua)

\begin{tabular}{|c|c|c|c|c|c|}
\hline \multirow{2}{*}{ Intervenção } & \multirow{2}{*}{ Unidade } & \multicolumn{4}{|c|}{ Frequência (\%) } \\
\hline & & Enf & Tec & Nut & ATA \\
\hline $\begin{array}{l}\text { Administração de } \\
\text { radiofármaco }\end{array}$ & CDI & & 1,3 & & \\
\hline Amostra de sangue capilar & $\mathrm{CM}$ & & 1,3 & & \\
\hline Apoio emocional & $\mathrm{AEOH}$ & & 1,1 & & \\
\hline Aspiração de vias aéreas & UTI-A & 1,0 & 1,6 & & \\
\hline Assistência no autocuidado & $\mathrm{AC}$ & & 1,7 & & \\
\hline Avaliação da saúde & CDI & 12,9 & 1,6 & & \\
\hline $\begin{array}{l}\text { Avaliação do estado } \\
\text { nutricional }\end{array}$ & SN & & & 1,5 & \\
\hline Controle da dor & SRPA & 1,2 & & & \\
\hline Controle de eletrólitos & CCO & 1,0 & & & \\
\hline Controle de vias aéreas & UTIP-NEO & & 1,2 & & \\
\hline $\begin{array}{l}\text { Controle do ambiente: } \\
\text { segurança }\end{array}$ & SRPA & 1,8 & 4,8 & & \\
\hline Controle intestinal & UTIP-NEO & & 1,2 & & \\
\hline $\begin{array}{l}\text { Cuidado com cateter central } \\
\text { de inserção periférica (PICC) }\end{array}$ & UTIP-NEO & 2,0 & & & \\
\hline Cuidados com local de incisão & $\mathrm{CC}$ & & 1,0 & & \\
\hline $\begin{array}{l}\text { Orientação alimentar e } \\
\text { nutricional na alta hospitalar }\end{array}$ & SN & & & 1,8 & \\
\hline
\end{tabular}


(continuação)

\begin{tabular}{|c|c|c|c|c|c|}
\hline \multirow{2}{*}{ Intervenção } & \multirow{2}{*}{ Unidade } & \multicolumn{4}{|c|}{ Frequência (\%) } \\
\hline & & Enf & Tec & Nut & ATA \\
\hline Posicionamento & UTIP-NEO & & 1,2 & & \\
\hline $\begin{array}{l}\text { Posicionamento: } \\
\text { intraoperatório }\end{array}$ & $\mathrm{CCO}$ & 1,6 & & & \\
\hline Procedimentos ambulatoriais & USF2 & & 1,9 & & \\
\hline $\begin{array}{l}\text { Promoção de ações } \\
\text { educativas }\end{array}$ & USF2 & 2,6 & 1,3 & & \\
\hline Reanimação cardiopulmonar & EMER & 1,5 & & & \\
\hline $\begin{array}{l}\text { Regulação da temperatura: } \\
\text { transoperatória }\end{array}$ & $\mathrm{CCO}$ & 1,4 & & & \\
\hline Sondagem vesical & $\mathrm{CCO}$ & 2,0 & & & \\
\hline Terapia de diálise peritoneal & UTIP-NEO & 1,0 & 4,4 & & \\
\hline Terapia endovenosa & EMER & 1,3 & & & \\
\hline Toque & $\mathrm{AC}$ & 1,2 & 1,5 & & \\
\hline Vigilância em saúde & USF & 1,1 & & & \\
\hline
\end{tabular}

AC - Alojamento Conjunto, AEOH - Ambulatório de Especialidades Oncologia e Hematologia, CM - Clínica Médica, CC - Clínica Cirúrgica, CCO - Centro Cirúrgico de Oncologia, CDI - Centro de Diagnóstico por Imagem, EMER - Emergência, SN Serviço de Nutrição, SRPA - Sala de Recuperação Pós-Anestésica, USF - Unidade de Saúde da Família, UTI-A - Unidade de Terapia Intensiva Adulto, UTIP-NEO - Unidade de Terapia Intensiva Pediátrica e Neonatal.

As intervenções Avaliação da saúde, Controle do ambiente: segurança, Promoção de ações educativas, Terapia de diálise peritoneal, apresentaram as maiores frequências para as unidades de CDI, SRPA, USF2 e UTIP-NEO, respectivamente, onde essas intervenções são consideradas essenciais para esse tipo de unidade (Bulecheck et al., 2016, p.432), e foram verificadas nas categorias de enfermeiros e téc./aux.de enfermagem.

As intervenções Avaliação do estado nutricional, Orientação alimentar e nutricional na alta hospitalar foram propostas para a categoria nutricionista clínicas.

Verifica-se nas Tabelas 3, 4 e Gráfico 23 que as intervenções ficaram pulverizadas entre as unidades e estão distribuídas de forma desigual entre as categorias profissionais, porém estas intervenções apresentaram as frequências mais elevadas e contribuem na carga de 
trabalho dos profissionais nas unidades observadas. Além disso, são consideradas intervenções essenciais para as áreas em que são expressivas, segundo a NIC (Bulecheck et al., 2016, p.432).

Tabela 4 - Distribuição das intervenções de cuidado direto que foram observados em uma unidade, com frequência $>2 \%$ a $\leq 10 \%$, segundo categoria profissional. São Paulo, 2017.

\begin{tabular}{|c|c|c|c|c|c|}
\hline \multirow{2}{*}{ Intervenção } & \multirow{2}{*}{ Unidade } & \multicolumn{4}{|c|}{ Frequência (\%) } \\
\hline & & Enf & Téc & Nut & ATA \\
\hline Assistência cirúrgica & $\mathrm{CCO}$ & 5,5 & 36,3 & & \\
\hline $\begin{array}{l}\text { Aconselhamento para a } \\
\text { lactação }\end{array}$ & & 3,6 & 3,7 & & \\
\hline $\begin{array}{l}\text { Assistência no } \\
\text { autocuidado: } \\
\text { banho/higiene }\end{array}$ & $\mathrm{CC}$ & & 2,2 & & \\
\hline $\begin{array}{l}\text { Atendimento à demanda } \\
\text { espontânea }\end{array}$ & USF & 7,5 & & & \\
\hline $\begin{array}{l}\text { Controle de infecção: } \\
\text { transoperatória } \\
\text { Controle de }\end{array}$ & $\mathrm{CCO}$ & 2,1 & 24,8 & & \\
\hline quimioterapia & $\mathrm{AEOH}$ & 7,9 & & & \\
\hline Controle do ambiente & PED 1 & & 4,3 & & \\
\hline Controle hidroeletrolítico & UTI-A & 2,9 & & & \\
\hline $\begin{array}{l}\text { Ensino: grupo } \\
\text { Orientação aos pais: }\end{array}$ & UBS & 10,0 & 3,8 & & \\
\hline lactente & $A C$ & 2,6 & & & \\
\hline Precauções cirúrgicas & $\mathrm{CCO}$ & 4,6 & 6,1 & & \\
\hline $\begin{array}{l}\text { Promoção de ações } \\
\text { educativas }\end{array}$ & USF & 2,6 & 1,3 & & \\
\hline Supervisão: segurança & $\mathrm{CCO}$ & 8,6 & & & \\
\hline Apoio familiar & $\mathrm{CCO}$ & 3,2 & & & \\
\hline $\begin{array}{l}\text { Terapia de diálise } \\
\text { peritoneal }\end{array}$ & $\begin{array}{l}\text { UTIP- } \\
\text { NFO }\end{array}$ & 10 & 44 & & \\
\hline Transferência & SRPA & 2,6 & 3,8 & & \\
\hline Triagem nutricional & $\mathrm{SN}$ & & & 2,6 & \\
\hline Vestir & SRPA & & 2,7 & & \\
\hline $\begin{array}{l}\text { AC - Alojamento Conjunto, A } \\
\text { Hematologia, CC - Clínica Cir } \\
\text { Unidade de Internação Pediá } \\
\text { Recuperação Pós-Anestésica, } \\
\text { Saúde da Família, UTI-A - Unic } \\
\text { de Terapia Intensiva Pediátrica }\end{array}$ & $\begin{array}{l}\text { 3S - Unic } \\
\text { de de Ter }\end{array}$ & tens & 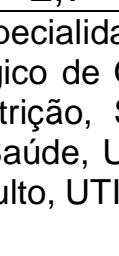 & $\mathrm{Or}$ & $\begin{array}{l}\text { gia e } \\
\text { ED - } \\
\text { la de } \\
\text { de de } \\
\text { idade }\end{array}$ \\
\hline
\end{tabular}


Gráfico 23 - Demonstrativo das Intervenções de Cuidado Direto com frequência > 10, observadas em uma unidade de saúde, segundo categoria profissional. São Paulo,2017.

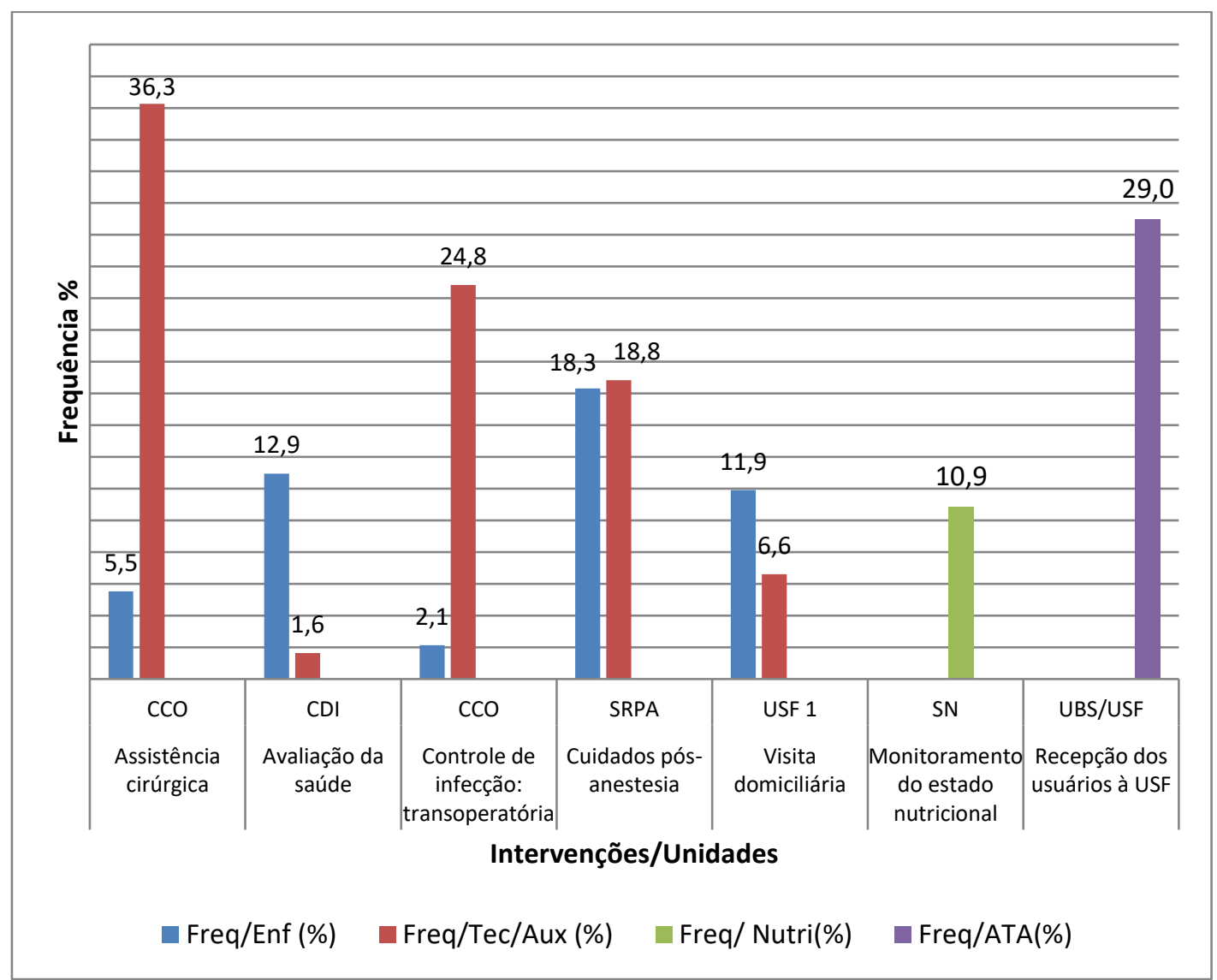

CCO - Centro Cirúrgico de Oncologia, CDI - Centro de Diagnóstico por Imagem, SN Serviço de Nutrição, SRPA - Sala de Recuperação Pós-Anestésica, UBS - Unidade Básica de Saúde, USF - Unidade de Saúde da Família.

O Gráfico 23 apresenta as intervenções com maiores proporções de observações nas unidades. As intervenções Assistência cirúrgica e Controle de infecção: transoperatória foram expressivas na categoria aux./téc. de enfermagem, no CCO. Além disso, são consideradas intervenções essenciais para a área perioperatória, segundo a NIC (Bulecheck et al., 2016, p.432).

As intervenções Avaliação da Saúde e Visita domiciliária foram expressivas na categoria enfermeiro nas unidades de CDI e USF1, respectivamente.

A intervenção Cuidados pós-anestesia teve impacto na SRPA, pois apresentou frequências iguais para as categorias enfermeiro e 
tec./aux. de enfermagem, indicando que nesta unidade o trabalho, durante a realização desta intervenção, foi colaborativo.

A intervenção Monitoramento do estado nutricional foi proposta para a categoria nutricionista - observa-se seu significado nesta categoria, da mesma forma a intervenção Recepção dos usuários à USF proposta para o ATA.

\subsubsection{Intervenções de Cuidado Indireto}

Os dezesseis instrumentos aplicados nas dezesseis unidades foram compostos por oitenta intervenções de cuidado indireto - destas, 37 intervenções foram observadas com frequência $\geq 1 \%$ na prática dos profissionais de saúde(Gráfico 24).

Gráfico 24 - Distribuição das Intervenções de cuidado indireto com frequência $\geq 1 \%$ nas unidades observadas. São Paulo, 2017.

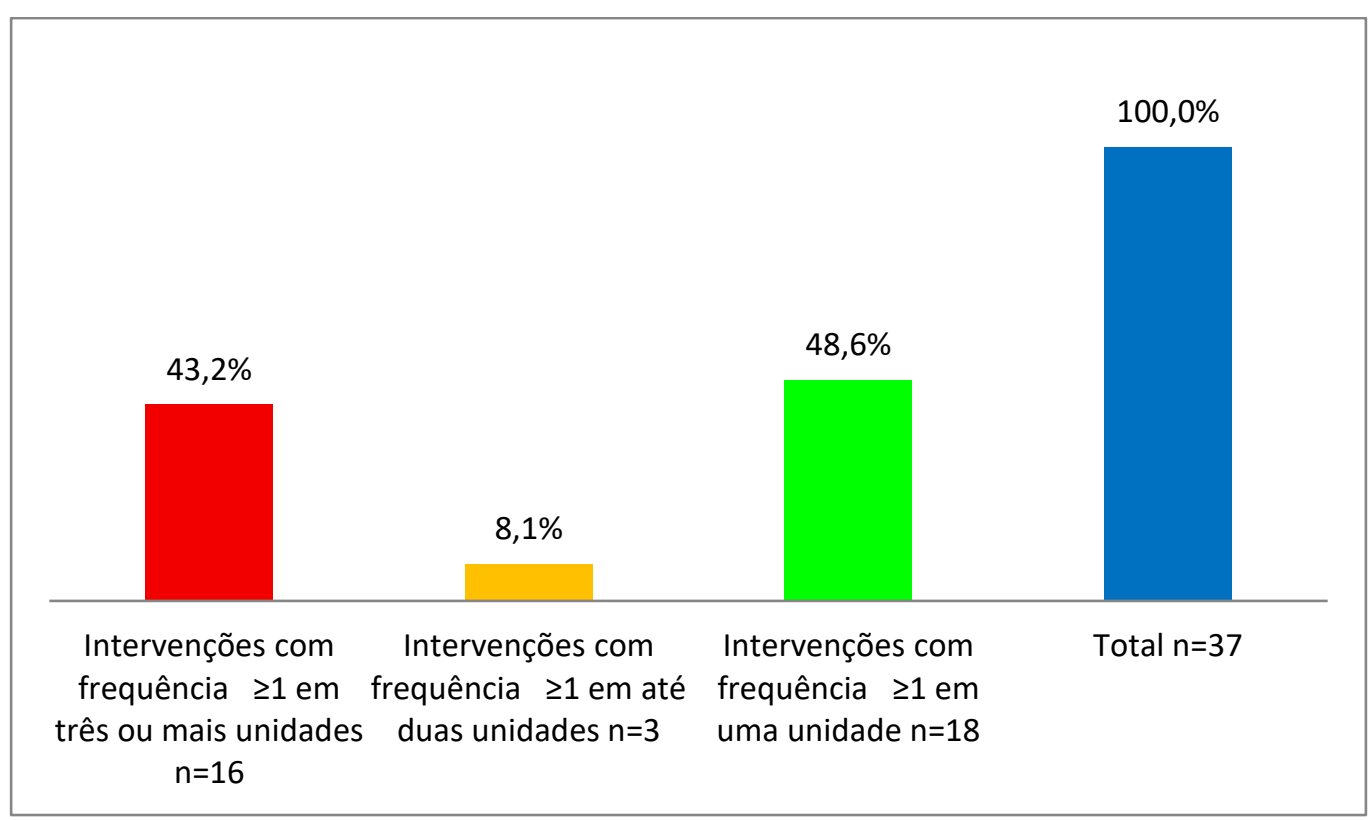

O Gráfico 24 apresenta as intervenções de cuidado indireto com frequência $\geq 1 \%$, das quais $43,2 \%$ ocorreram em três ou mais unidades - as intervenções deste grupo têm maior probabilidade de serem 
observadas nos serviços de saúde e contemplam as intervenções apresentadas no Quadro 15.

Das intervenções de cuidado indireto observadas, $8,1 \%$ foram observadas em duas unidades e estão elencadas no Quadro 16.

Verifica-se ainda no Gráfico 24 que 48,6\% das intervenções foram observadas em, apenas, uma unidade e estão elencadas no Quadro 17.

Quadro 15 - Intervenções de cuidado indireto com frequência $\geq 1 \%$ que foram observadas em três ou mais unidades por categoria profissional. São Paulo, 2017.

\begin{tabular}{|c|l|c|c|c|c|}
\hline \multirow{2}{*}{$\mathrm{n}$} & \multicolumn{2}{|c|}{ Intervenção } & \multicolumn{4}{|c|}{ Categoria Profissional } \\
\cline { 3 - 7 } & & Enf & Tec/Aux & Nut & ATA \\
\hline 1 & Apoio ao médico & $\mathrm{X}$ & & & \\
\hline 2 & Controle de infecção & $\mathrm{X}$ & $\mathrm{X}$ & & \\
\hline 3 & Controle de suprimentos & $\mathrm{X}$ & $\mathrm{X}$ & & \\
\hline 4 & Controle do ambiente & $\mathrm{X}$ & $\mathrm{X}$ & & \\
\hline 5 & Delegação & $\mathrm{X}$ & & & \\
\hline 6 & $\begin{array}{l}\text { Desenvolvimento de } \\
\text { funcionários }\end{array}$ & $\mathrm{X}$ & $\mathrm{X}$ & $\mathrm{X}$ & \\
\hline 7 & Documentação & $\mathrm{X}$ & $\mathrm{X}$ & $\mathrm{X}$ & \\
\hline 8 & Gerenciamento de caso & $\mathrm{X}$ & $\mathrm{X}$ & & \\
\hline 9 & $\begin{array}{l}\text { Interpretação de dados } \\
\text { laboratoriais }\end{array}$ & $\mathrm{X}$ & & & \\
\hline 10 & Passagem de plantão & $\mathrm{X}$ & $\mathrm{X}$ & & \\
\hline 11 & Preceptor: estudante & $\mathrm{X}$ & $\mathrm{X}$ & $\mathrm{X}$ & \\
\hline 12 & Proteção contra infecção & $\mathrm{X}$ & $\mathrm{X}$ & & \\
\hline 13 & $\begin{array}{l}\text { Reunião para avaliação dos } \\
\text { cuidados multidisciplinares }\end{array}$ & $\mathrm{X}$ & $\mathrm{X}$ & & \\
\hline 14 & Supervisão de funcionários & $\mathrm{X}$ & & & \\
\hline 15 & Transcrição de prescrições & $\mathrm{X}$ & & & \\
\hline 16 & $\begin{array}{l}\text { Troca de informações sobre } \\
\text { cuidados de saúde }\end{array}$ & $\mathrm{X}$ & $\mathrm{X}$ & $\mathrm{X}$ & \\
\hline
\end{tabular}

Os Gráficos 25 a 40 representam a distribuição das intervenções apresentadas no Quadro 15. 
Gráfico 25 - Demonstrativo da intervenção Apoio ao médico, com frequência $\geq 1 \%$, nas unidades de saúde estudadas, por categoria profissional. São Paulo, 2017.

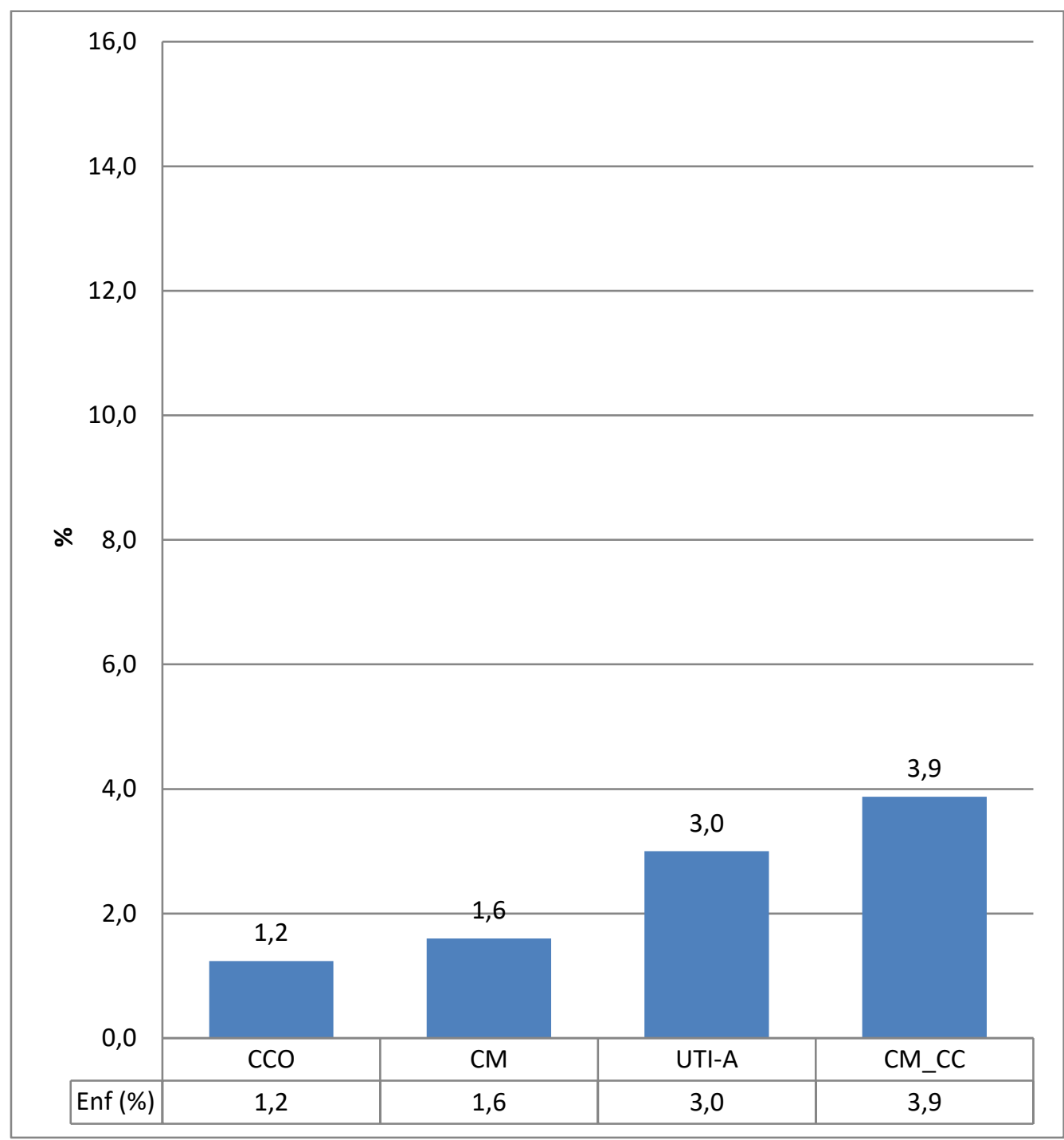

CM - Clínica Médica, CCO - Centro Cirúrgico de Oncologia, CM-CC - Clínica Médica e Clínica Cirúrgica, UTI-A - Unidade de Terapia Intensiva Adulto.

A intervenção Apoio ao médico foi observada em $25 \%$ das unidades estudadas, a qual trata da colaboração para fornecer cuidados de qualidade ao paciente. Foi observada na categoria enfermeiro e mais expressiva nas unidades UTI-A e CM-CC. 
Gráfico 26 - Demonstrativo da intervenção Controle de infecção, com frequência $\geq 1 \%$, nas unidades de saúde estudadas, por categoria profissional. São Paulo, 2017.

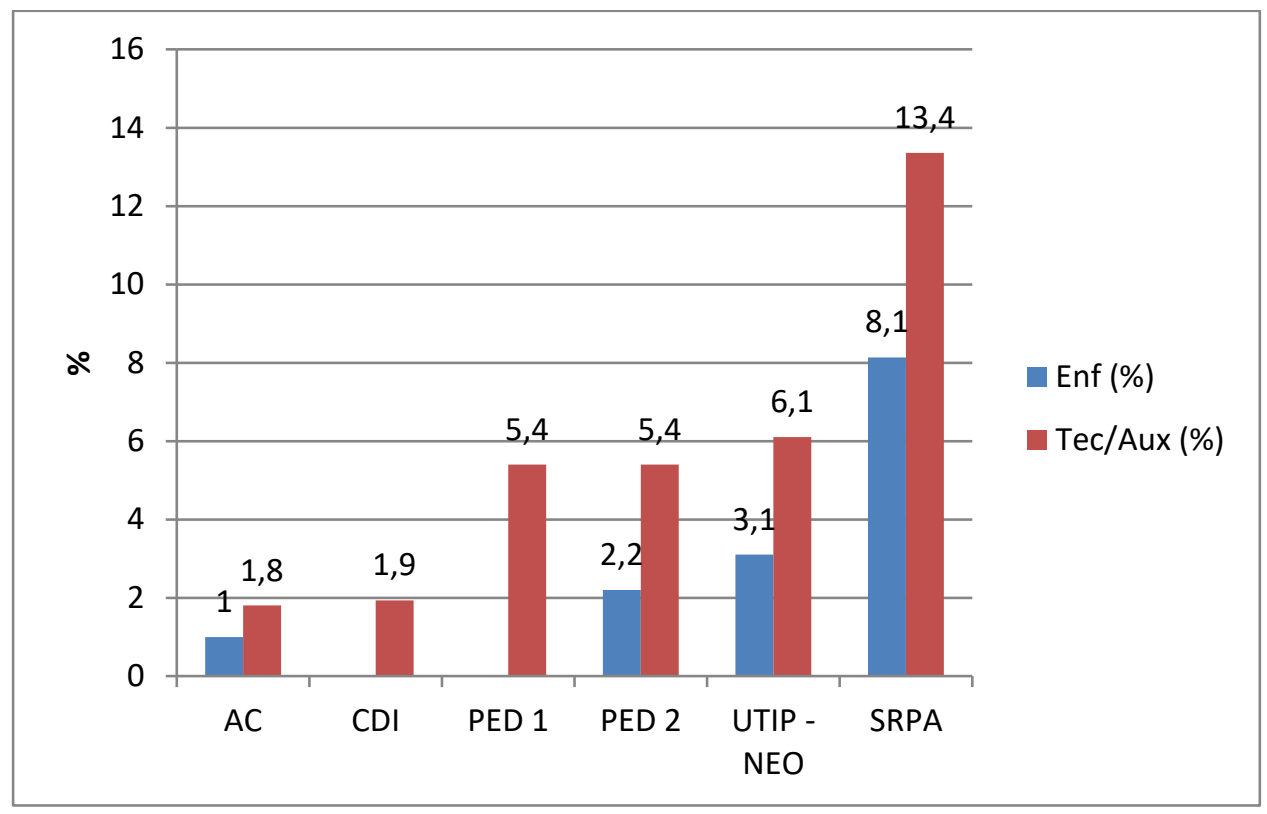

AC - Alojamento Conjunto, CDI - Centro de Diagnóstico por Imagem, PED - Unidade de Internação Pediátrica, UTIP-NEO - Unidade de Terapia Intensiva Pediátrica e Neonatal, SRPA - Sala de Recuperação Pós-Anestésica.

Gráfico 27 - Demonstrativo da intervenção Proteção contra infecção, com frequência $\geq 1 \%$, nas unidades de saúde estudadas, por categoria profissional. São Paulo, 2017.

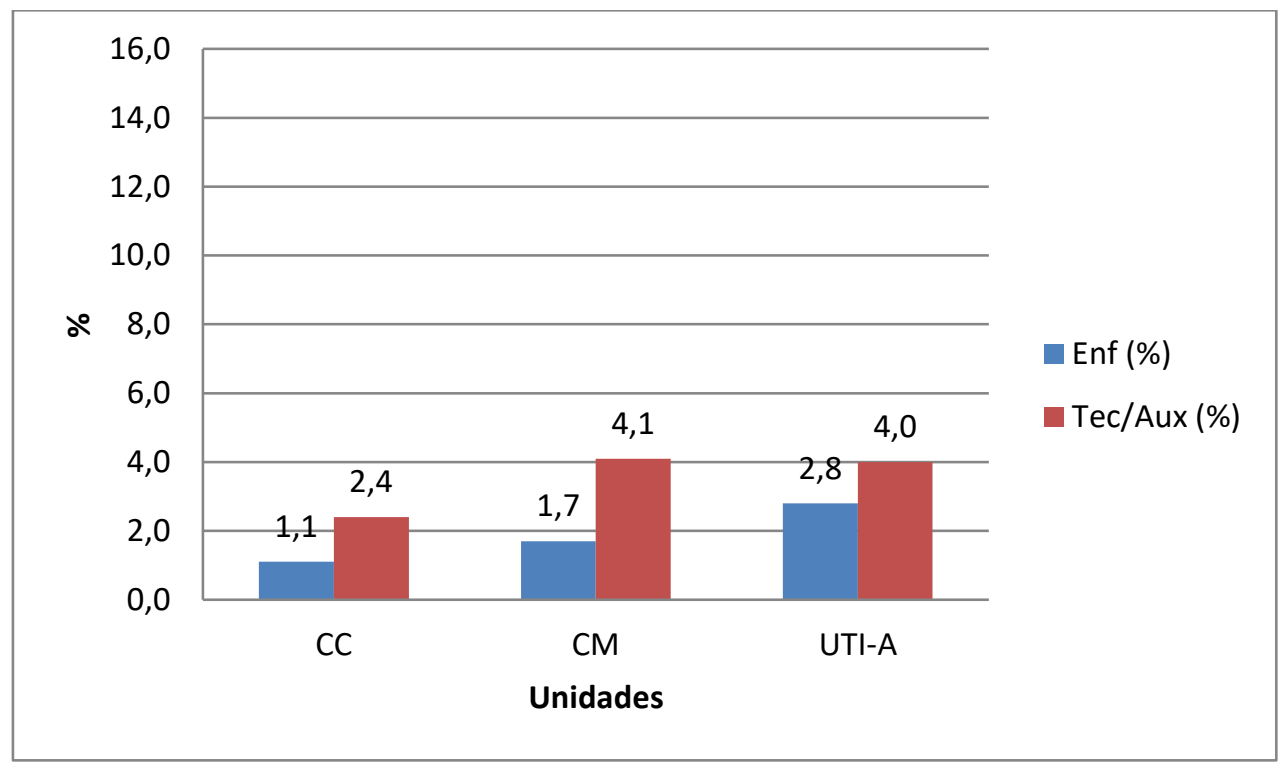

CM - Clínica Médica, CC - Clínica Cirúrgica, UTI-A - Unidade de Terapia Intensiva Adulto. 
A unidade de SRPA apresentou as maiores frequências para a intervenção Controle de infecção nas categorias enfermeiro e téc./aux. de enfermagem. Foi observada em $37,5 \%$ das unidades estudadas (Gráfico 26) e o destaque é a lavagem das mãos, uma das atividades que compõem esta intervenção. Já a intervenção Proteção contra a infecção foi observada em $18,37 \%$ das unidades e apresentou as maiores frequências nas unidades CC, CM e UTIP (Gráfico 27).

Essas intervenções são consideradas intervenções essenciais para áreas de cuidado clínico e cirúrgico adulto e pediátrico, segundo NIC (Bulecheck et al., 2016, p.432), referentes à prevenção de infecções e relacionadas à assistência à saúde (IRAS) que reflete na segurança do paciente e na qualidade dos serviços de saúde (Brasil, 2017).

Gráfico 28 - Demonstrativo da intervenção Controle de suprimentos, com frequência $\geq 1 \%$, nas unidades de saúde estudadas, por categoria profissional. São Paulo, 2017.

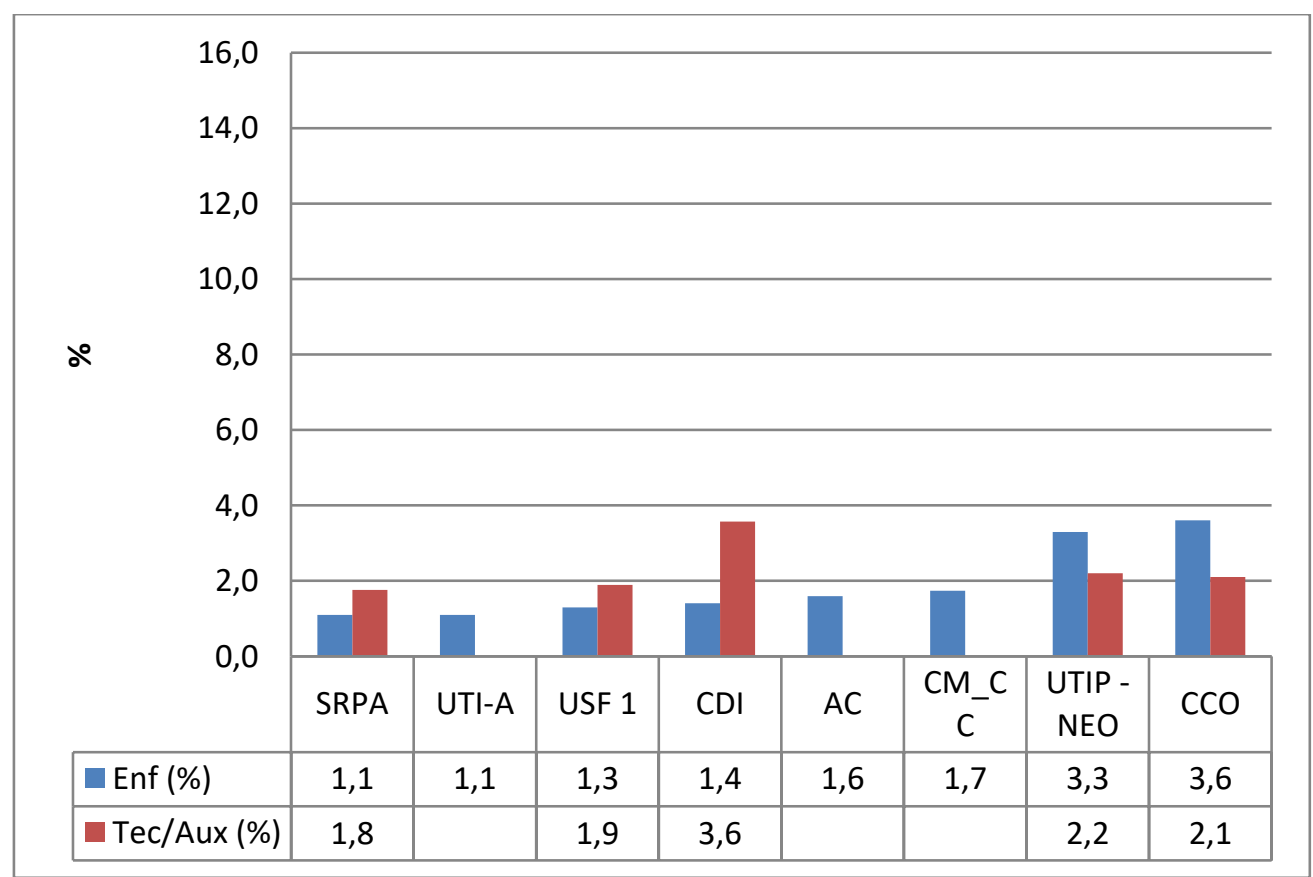

AC - Alojamento Conjunto, CCO - Centro Cirúrgico de Oncologia, CDI - Centro de Diagnóstico por Imagem, CM-CC - Clínica Médica e Clínica Cirúrgica, SRPA - Sala de Recuperação Pós-Anestésica, UTI-A - Unidade de Terapia Intensiva Adulto, USF Unidade de Saúde da Família, UTIP-NEO - Unidade de Terapia Intensiva Pediátrica e Neonatal. 
A intervenção Controle de suprimentos foi identificada em $50 \%$ das unidades e apresentou maiores frequências nas unidades $\mathrm{CCO}$, UTIP-NEO e CDI; provavelmente por essas unidades possuírem um aparato tecnológico que está em constante inovação, sendo necessário procedimento de avaliação da qualidade desses produtos para assegurar a qualidade da assistência prestada, realizada pelos enfermeiros em todas as unidades, onde ocorreu.

Gráfico 29 - Demonstrativo da intervenção Controle do ambiente, nas unidades de saúde estudadas, por categoria profissional. São Paulo, 2017.

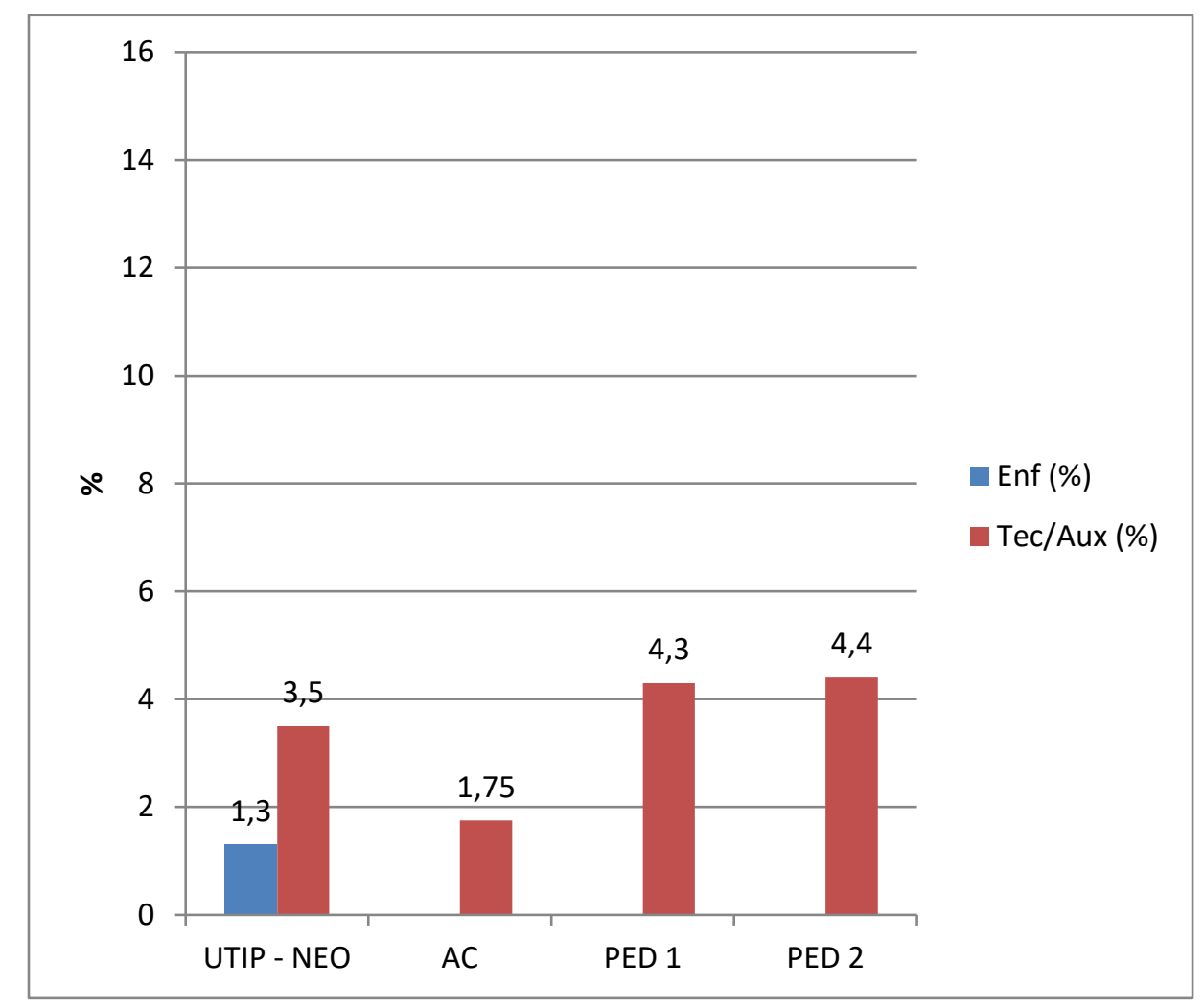

AC - Alojamento Conjunto, UTIP-NEO - Unidade de Terapia Intensiva Pediátrica e Neonatal, PED - Unidade de Internação Pediátrica.

A intervenção Controle do ambiente foi identificada em $25 \%$ das unidades, observada na categoria téc./aux. de enfermagem e na categoria enfermeiro na UTIP-NEO. 
Gráfico 30 - Demonstrativo da intervenção Delegação, com frequência $\geq 1 \%$, nas unidades de saúde estudadas, por categoria profissional. São Paulo, 2017.

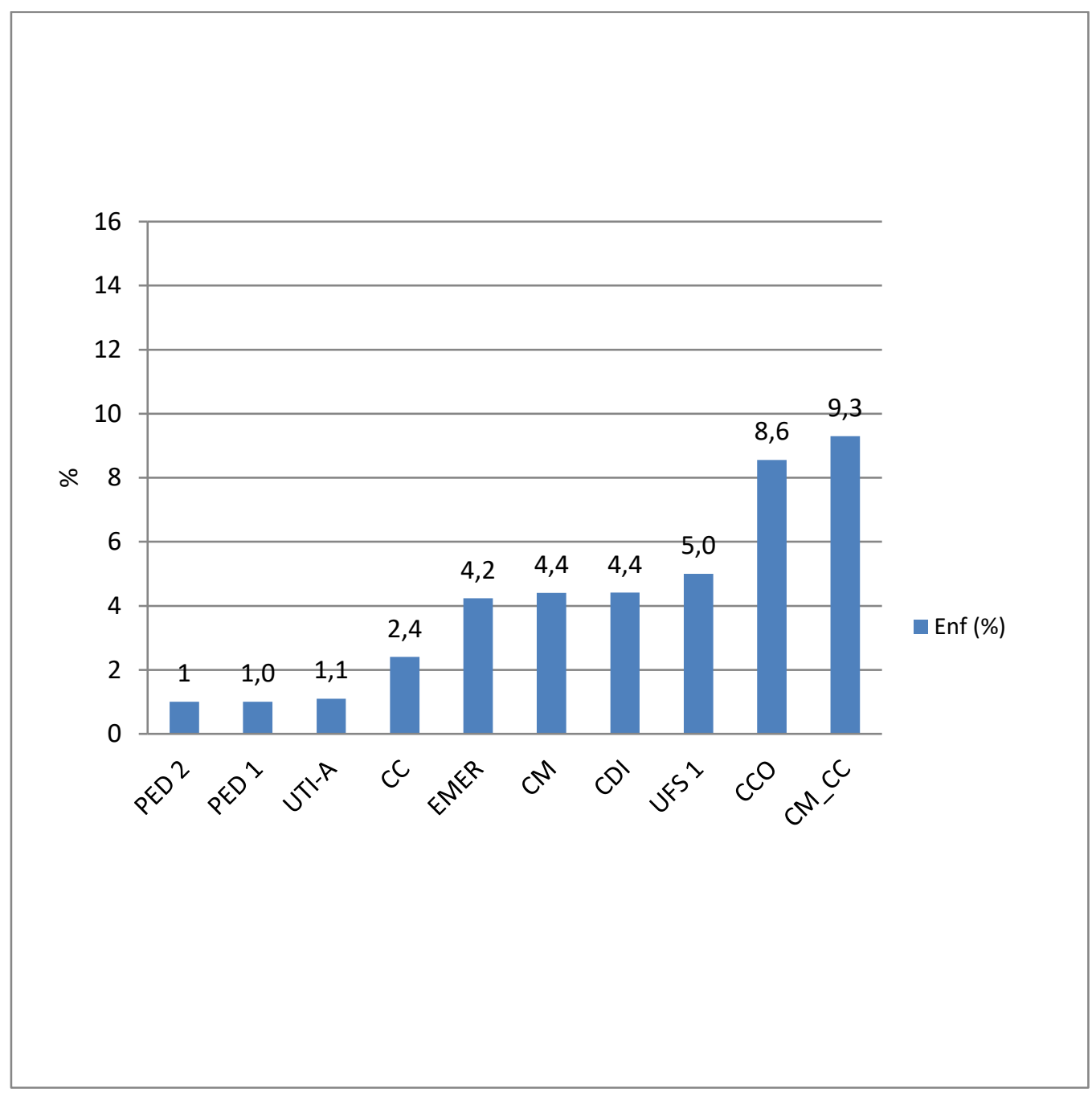

A intervenção Delegação foi identificada em 62,5\% das unidades e observada, apenas, na categoria enfermeiro, sendo mais expressiva no CCO e na CM-CC. A delegação implica em confiar a outro profissional de saúde a realização de intervenções/atividades relacionadas aos cuidados dos pacientes que podem estar relacionadas com a assistência ou com a organização das atividades da unidade (Moretto Neto, Silva, Shmitt, 2007). 
Gráfico 31 - Demonstrativo da intervenção Desenvolvimento de funcionários, com frequência $\geq 1 \%$, nas unidades de saúde estudadas, por categoria profissional. São Paulo, 2017.

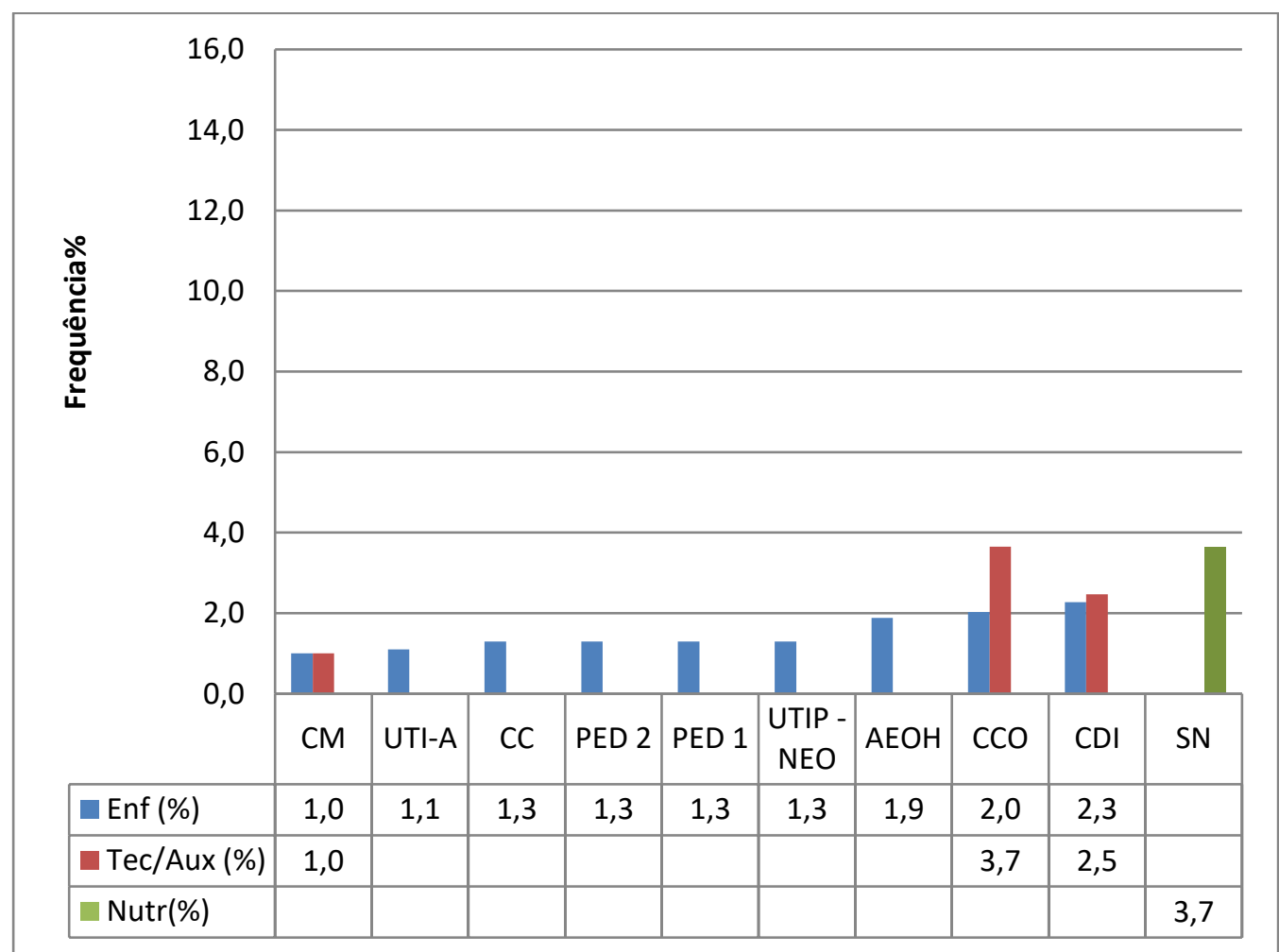

AEOH - Ambulatório de Especialidades Oncologia e Hematologia, CM - Clínica Médica, UTI-A - Unidade de Terapia Intensiva Adulto, CC - Clínica Cirúrgica, PED Unidade de Internação Pediátrica, UTIP-NEO - Unidade de Terapia Intensiva Pediátrica e Neonatal, CCO - Centro Cirúrgico de Oncologia, CDI - Centro de Diagnóstico por Imagem, SN - Serviço de Nutrição.

A intervenção Desenvolvimento de funcionários foi identificada em $62,5 \%$ das unidades, em que sua frequência foi mais expressiva nas CDI, CCO e SN - mais frequente em enfermeiros, téc./aux. de enfermagem e nutricionista. É uma intervenção fundamental para o aprimoramento dos recursos humanos, pois está relacionada ao desenvolvimento de competências, habilidades e atitudes dos profissionais de saúde. 
Gráfico 32 - Demonstrativo da intervenção Documentação, com frequência $\geq 1 \%$, nas unidades de saúde estudadas, por categoria profissional. São Paulo, 2017.

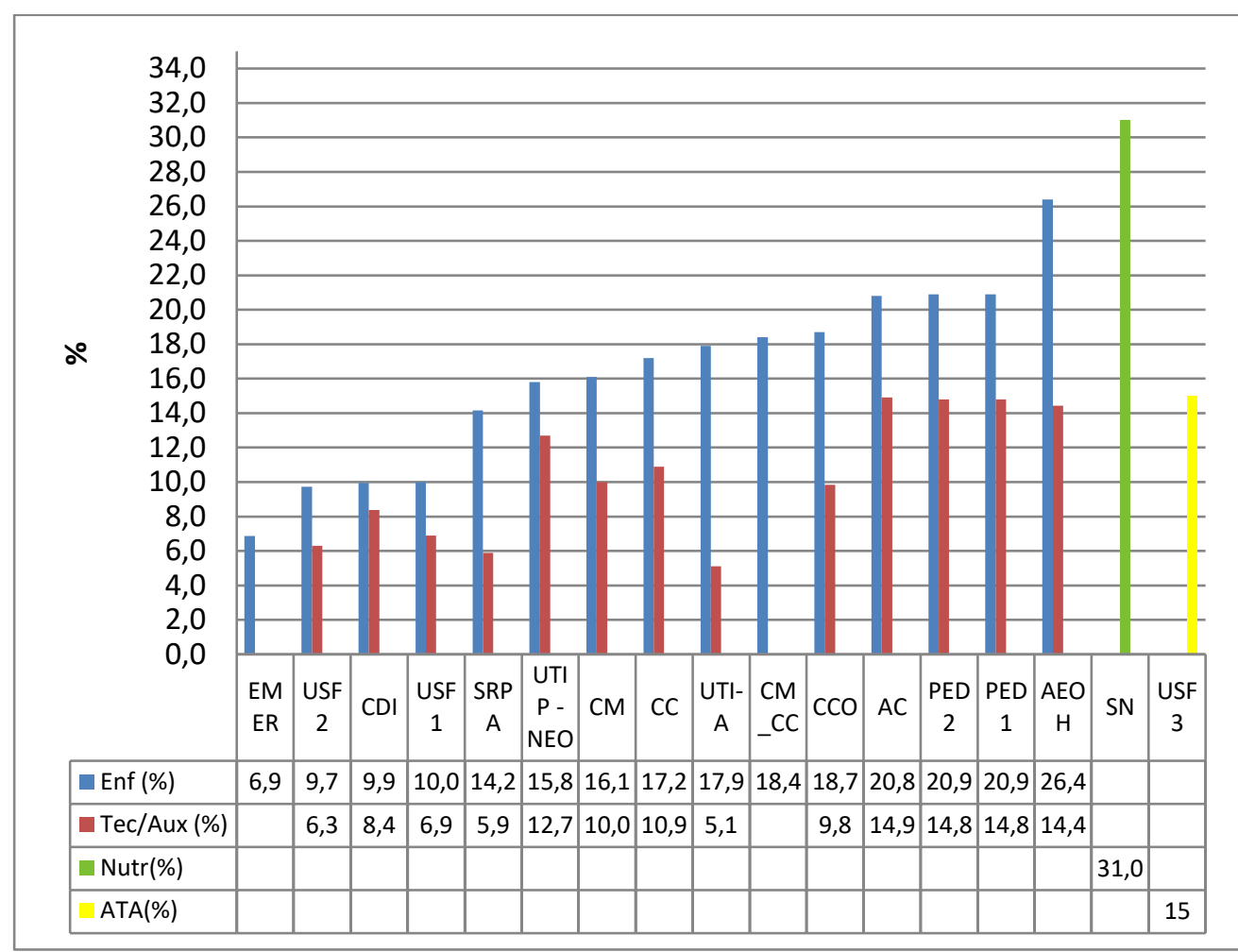

EMER - Emergência, USF - Unidade de Saúde da Família, CDI - Centro de Diagnóstico por Imagem, SRPA - Sala de Recuperação Pós-Anestésica, UTIP-NEO Unidade de Terapia Intensiva Pediátrica e Neonatal, CC - Clínica Cirúrgica, UTI-A Unidade de Terapia Intensiva Adulto, CM-CC - Clínica Médica e Clínica Cirúrgica, CCO - Centro Cirúrgico de Oncologia, AC - Alojamento Conjunto, PED - Unidade de Internação Pediátrica, AEOH - Ambulatório de Especialidades Oncologia e Hematologia, CM - Clínica Médica, SN - Serviço de Nutrição.

A intervenção Documentação teve a frequência de observação muito expressiva e identificada em $100 \%$ das unidades e ocorreu nas categorias profissionais enfermeiro, téc./aux. de enfermagem, nutricionista e ATA. São consideradas as atividades relacionadas ao registro de dados relacionados ao paciente.

Para o ATA, a intervenção documentação apresentada no Gráfico 32 foi resultado do agrupamento de duas intervenções propostas pelo autor: digitação do mapa de produção diário dos profissionais assistenciais e suporte a gestão de recursos humanos. 
Na unidade de EMER e CM-CC, só apareceu para os enfermeiros, porque os autores, nos seus estudos, tiveram como critério observar apenas essa categoria.

Embora a Documentação tenha apresentado frequências elevadas nas unidades estudadas, é fundamental que ela seja realizada pela equipe de saúde, pois possibilita a continuidade da assistência prestada e é um elemento importante para proteção legal dos trabalhadores de saúde e do paciente assistido (Peres et al., 2009).

Gráfico 33 - Demonstrativo da intervenção Gerenciamento de caso, com frequência $\geq 1 \%$, nas unidades de saúde estudadas, por categoria profissional. São Paulo, 2017.

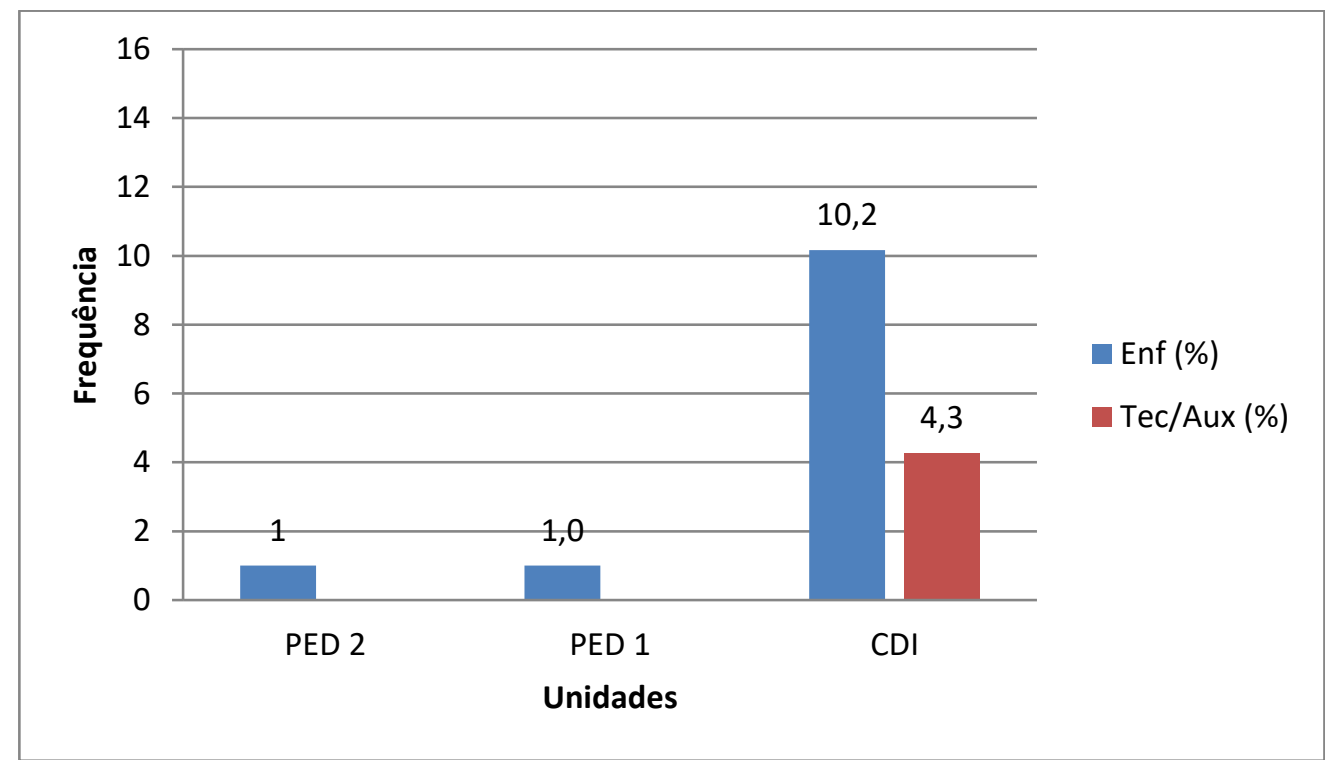

CDI - Centro de Diagnóstico por Imagem, PED - Unidade de Internação Pediátrica.

A intervenção Gerenciamento de caso foi observada em 18,7\% das unidades e expressiva no CDI nas categorias de enfermeiros e téc./aux. de enfermagem. Essa intervenção elenca um conjunto de atividades que estão relacionadas com a coordenação dos cuidados e uso adequado de recursos financeiros e materiais para favorecer a qualidade dos cuidados prestados ao paciente, família e comunidade (Bulecheck et al., 2016, p.276). 
Gráfico 34 - Demonstrativo da intervenção Interpretação de dados laboratoriais, com frequência $\geq 1 \%$, nas unidades de saúde estudadas, por categoria profissional. São Paulo, 2017.

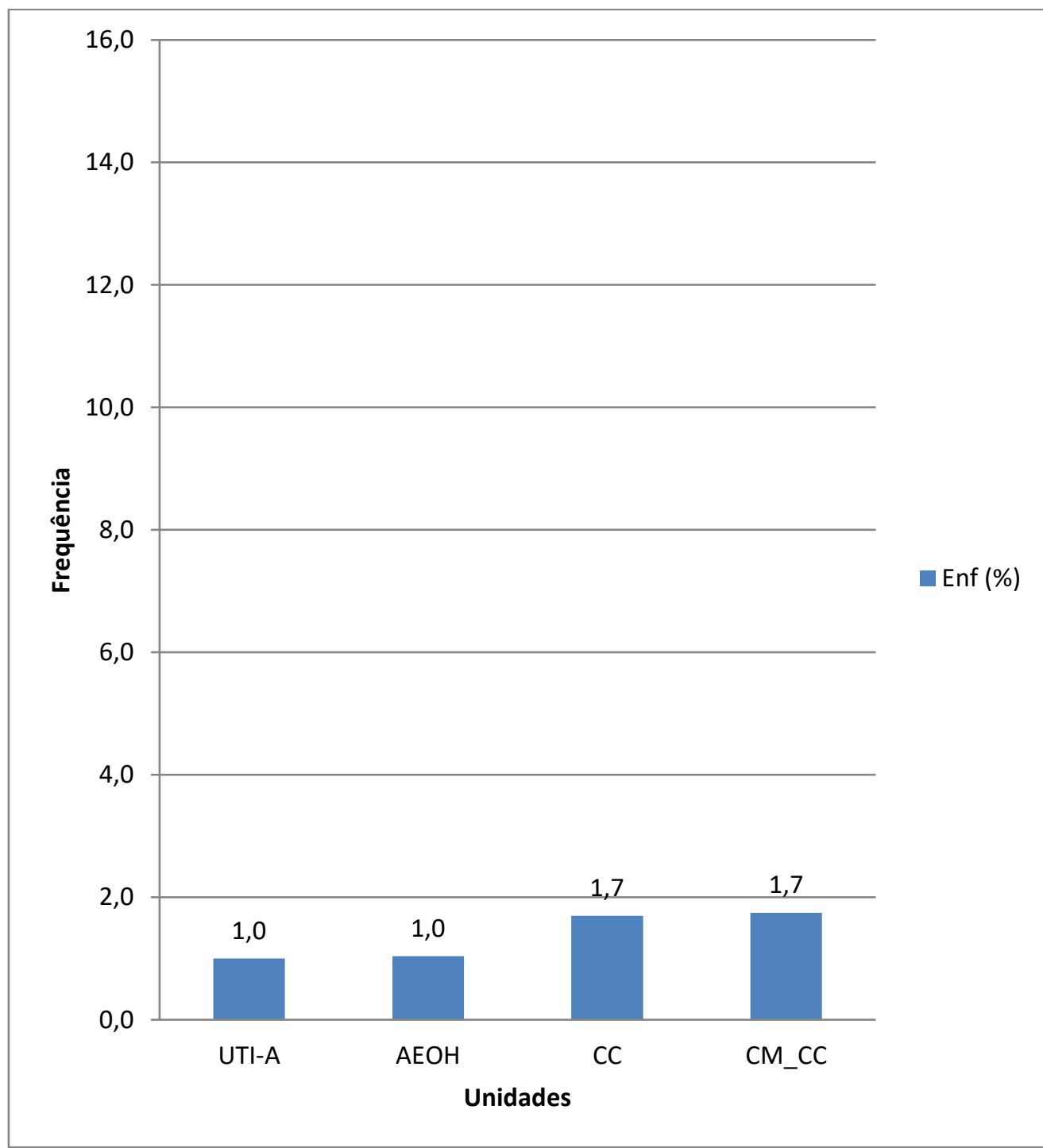

AEOH - Ambulatório de Especialidades Oncologia e Hematologia, CC - Clínica Cirúrgica, CM-CC - Clínica Médica e Clínica Cirúrgica, UTI-A - Unidade de Terapia Intensiva Adulto.

A intervenção Interpretação de dados laboratoriais foi observada em $25 \%$ das unidades e foi realizada por enfermeiros. Essa intervenção auxilia a tomada de decisão clínica e a condução do planejamento assistencial. 
Gráfico 35 - Demonstrativo da intervenção Passagem de plantão, com frequência $\geq 1 \%$, nas unidades de saúde estudadas, por categoria profissional. São Paulo, 2017.

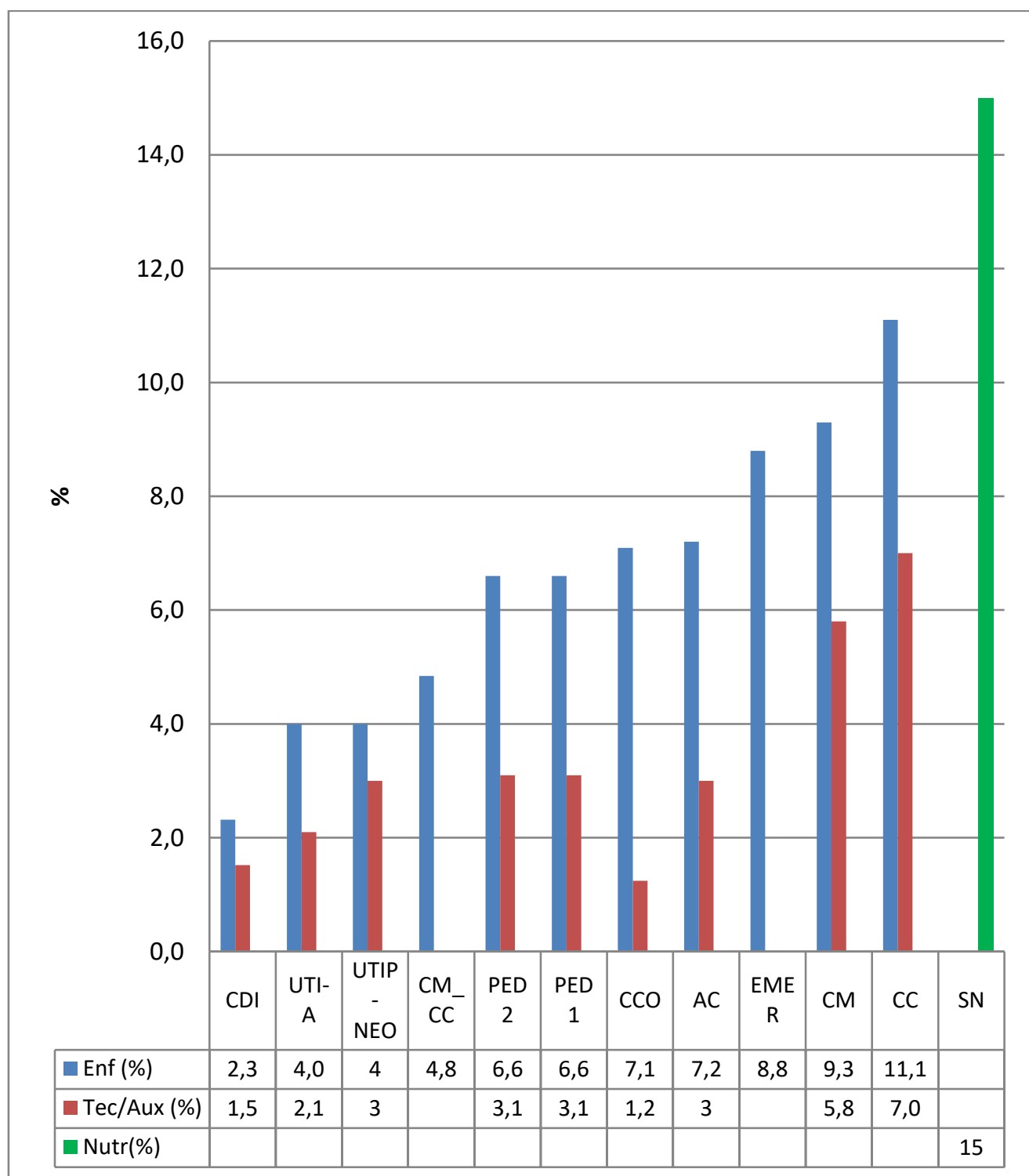

AC - Alojamento Conjunto, CC - Clínica Cirúrgica, CCO - Centro Cirúrgico de Oncologia, CDI - Centro de Diagnóstico por Imagem, CM - Clínica Médica, CM-CC Clínica Médica e Clínica Cirúrgica, EMER - Emergência, PED - Unidade de Internação Pediátrica, SN - Serviço de Nutrição, UTI-A - Unidade de Terapia Intensiva Adulto, UTIP-NEO - Unidade de Terapia Intensiva Pediátrica e Neonatal.

A intervenção Passagem de plantão foi verificada em $70 \%$ das unidades e observada nas categorias de enfermeiros, téc./aux.de enfermagem, exceto na CM-CC, na EMER e nutricionistas. Porém foi mais expressiva para os nutricionistas e enfermeiros. 
Gráfico 36 - Demonstrativo da intervenção Preceptor: estudante, com frequência $\geq 1 \%$, nas unidades de saúde estudadas, por categoria profissional. São Paulo, 2017.

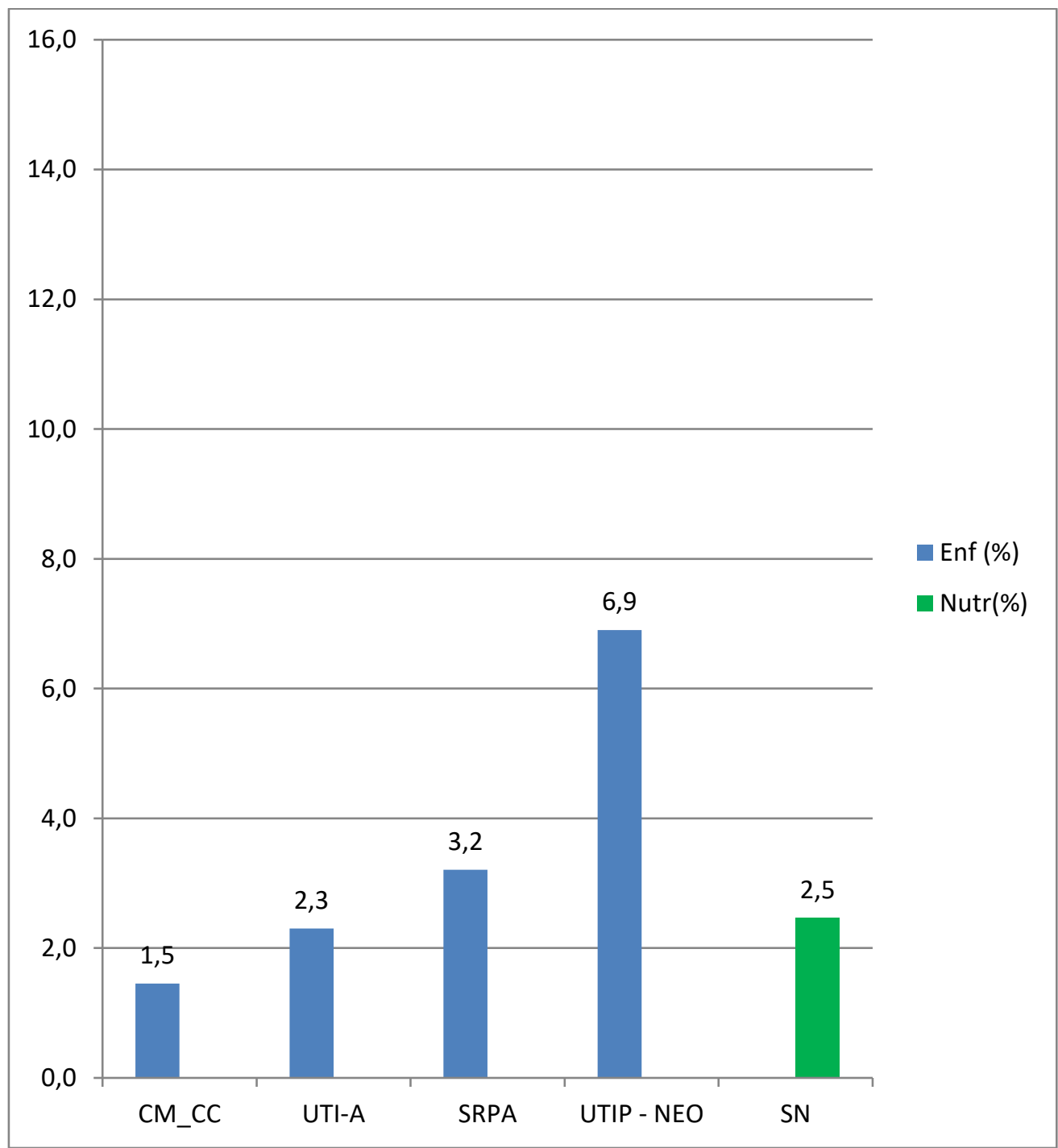

CM-CC - Clínica Médica e Clínica Cirúrgica, SN - Serviço de Nutrição, SRPA - Sala de Recuperação Pós-Anestésica, UTI-A - Unidade de Terapia Intensiva Adulto, UTIPNEO - Unidade de Terapia Intensiva Pediátrica e Neonatal.

A intervenção Preceptor: estudante foi observada em 31,5\% das unidades, nas categorias enfermeiro e nutricionista e expressiva na unidade de UTIP-NEO (6,9\%). Isso se deveu, porque muitas das unidades estudadas são campos de estágio de graduandos de saúde. 
Gráfico 37 - Demonstrativo da intervenção Reunião para avaliação dos cuidados multidisciplinares, com frequência $\geq 1 \%$, nas unidades de saúde estudadas, por categoria profissional. São Paulo, 2017.

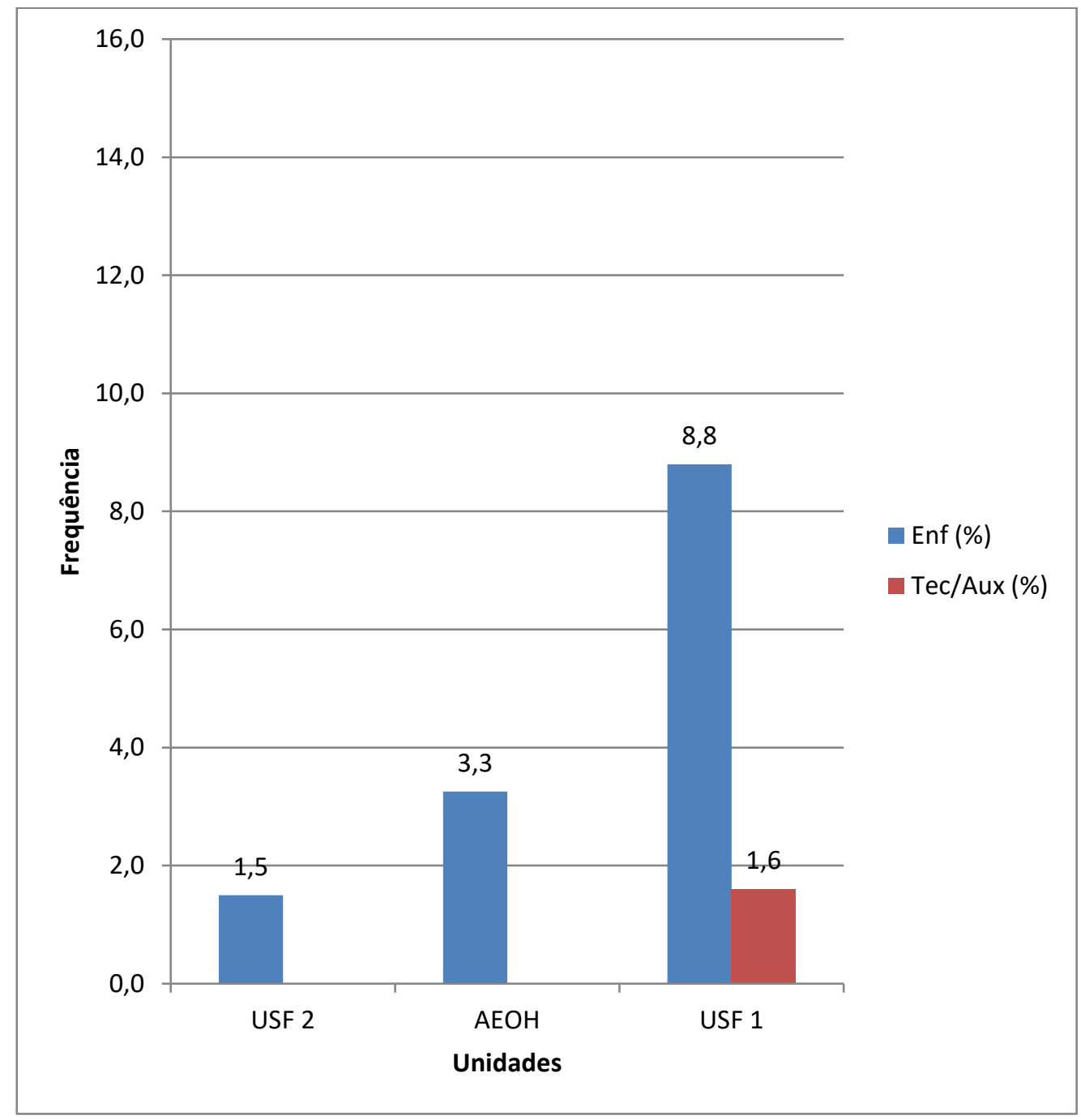

AEOH - Ambulatório de Especialidades Oncologia e Hematologia, USF - Unidade de Saúde da Família.

A intervenção Reunião para avaliação dos cuidados multidisciplinares foi observada em $18,7 \%$ das unidades, onde os enfermeiros foram os que mais realizaram a intervenção - foi verificada também na categoria de téc./aux. de enfermagem na unidade USF 1. 
Gráfico 38 - Demonstrativo da intervenção Supervisão de funcionários, com frequência $\geq 1 \%$, nas unidades de saúde estudadas, por categoria profissional. São Paulo, 2017.

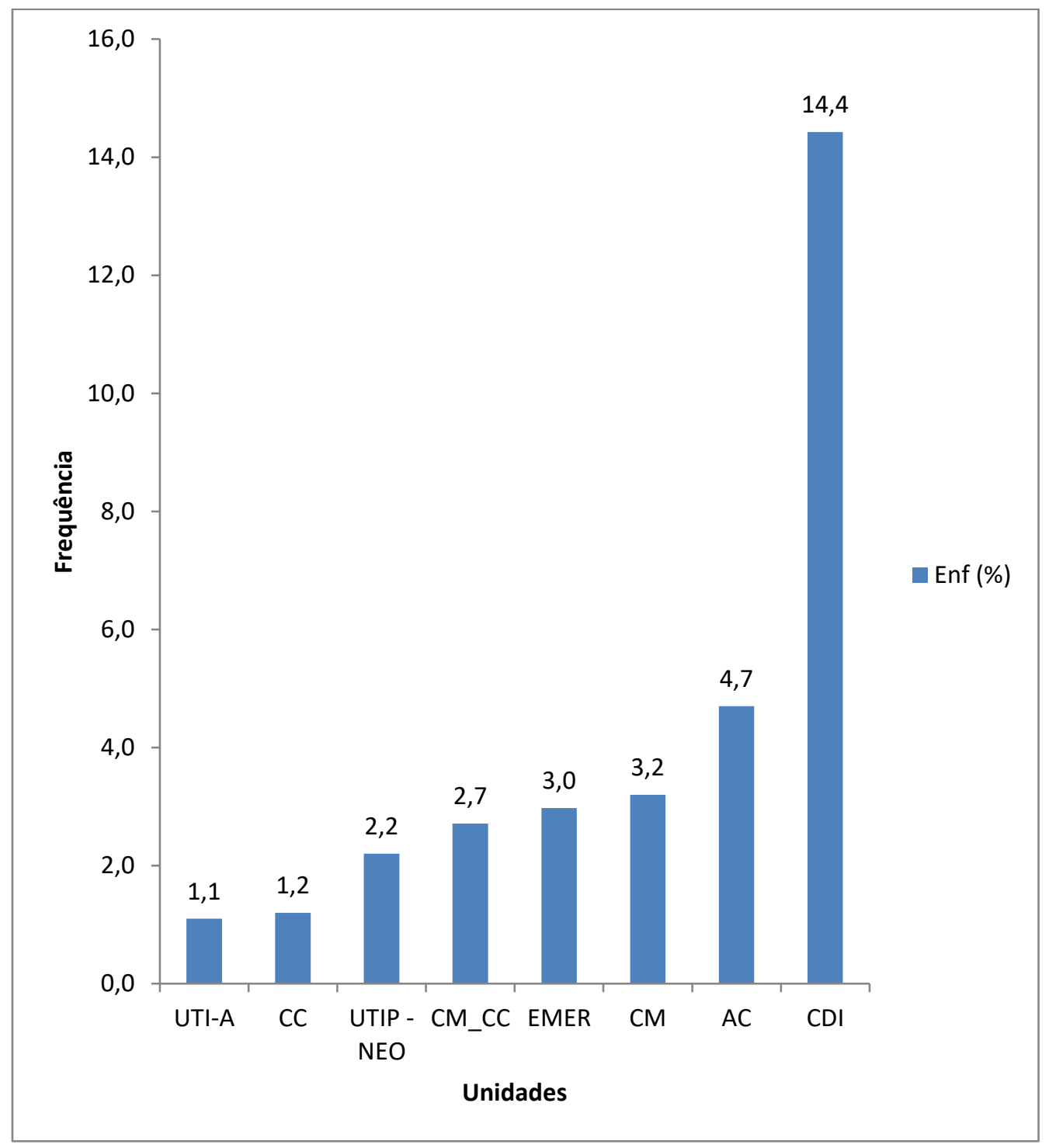

AC - Alojamento Conjunto, CC - Clínica Cirúrgica, CDI - Centro de Diagnóstico por Imagem, CM - Clínica Médica, CM-CC - Clínica Médica e Clínica Cirúrgica, EMER Emergência, UTI-A - Unidade de Terapia Intensiva Adulto, UTIP-NEO - Unidade de Terapia Intensiva Pediátrica e Neonatal.

A intervenção Supervisão de funcionários foi identificada em 50\% das unidades e observada na realização do trabalho dos enfermeiros com mais expressividade no CDI, sendo uma intervenção que contempla atividades relacionadas à avaliação de desempenho, treinamento e desenvolvimento do profissional. 
Gráfico 39 - Demonstrativo da intervenção Transcrição de prescrições, com frequência $\geq 1 \%$, nas unidades de saúde estudadas, por categoria profissional. São Paulo, 2017.

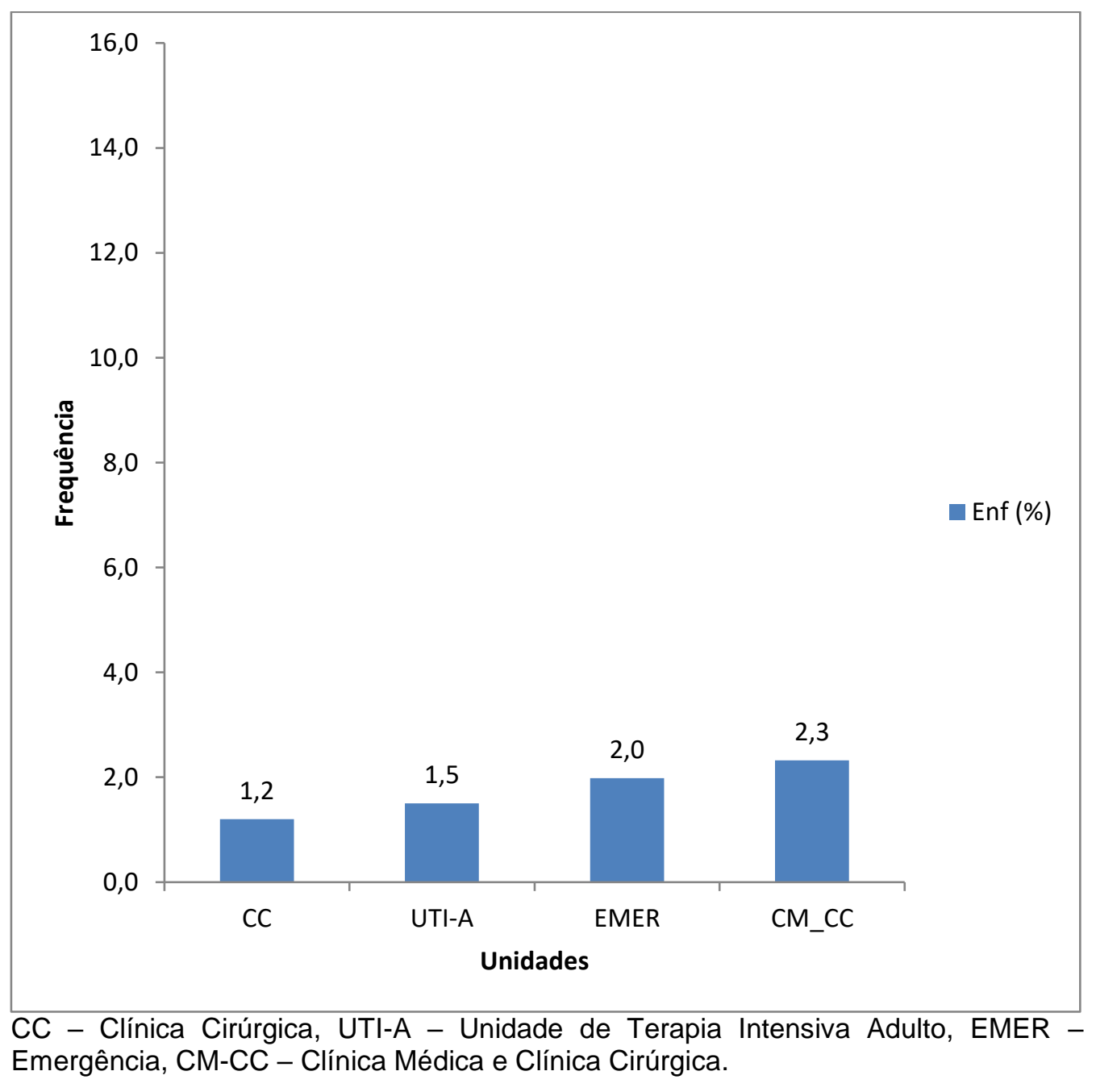

A intervenção Transcrição de prescrições foi identificada em 25\% das unidades, sendo observada na realização do trabalho dos enfermeiros. As atividades elencadas nessa intervenção estão relacionadas às folhas de prescrição - o que pode gerar polêmica, uma vez que a intervenção Documentação contempla atividades semelhantes. 
Gráfico 40 - Demonstrativo da intervenção Troca de informação sobre cuidados de saúde, com frequência $\geq 1 \%$, nas unidades de saúde estudadas, por categoria profissional. São Paulo, 2017.

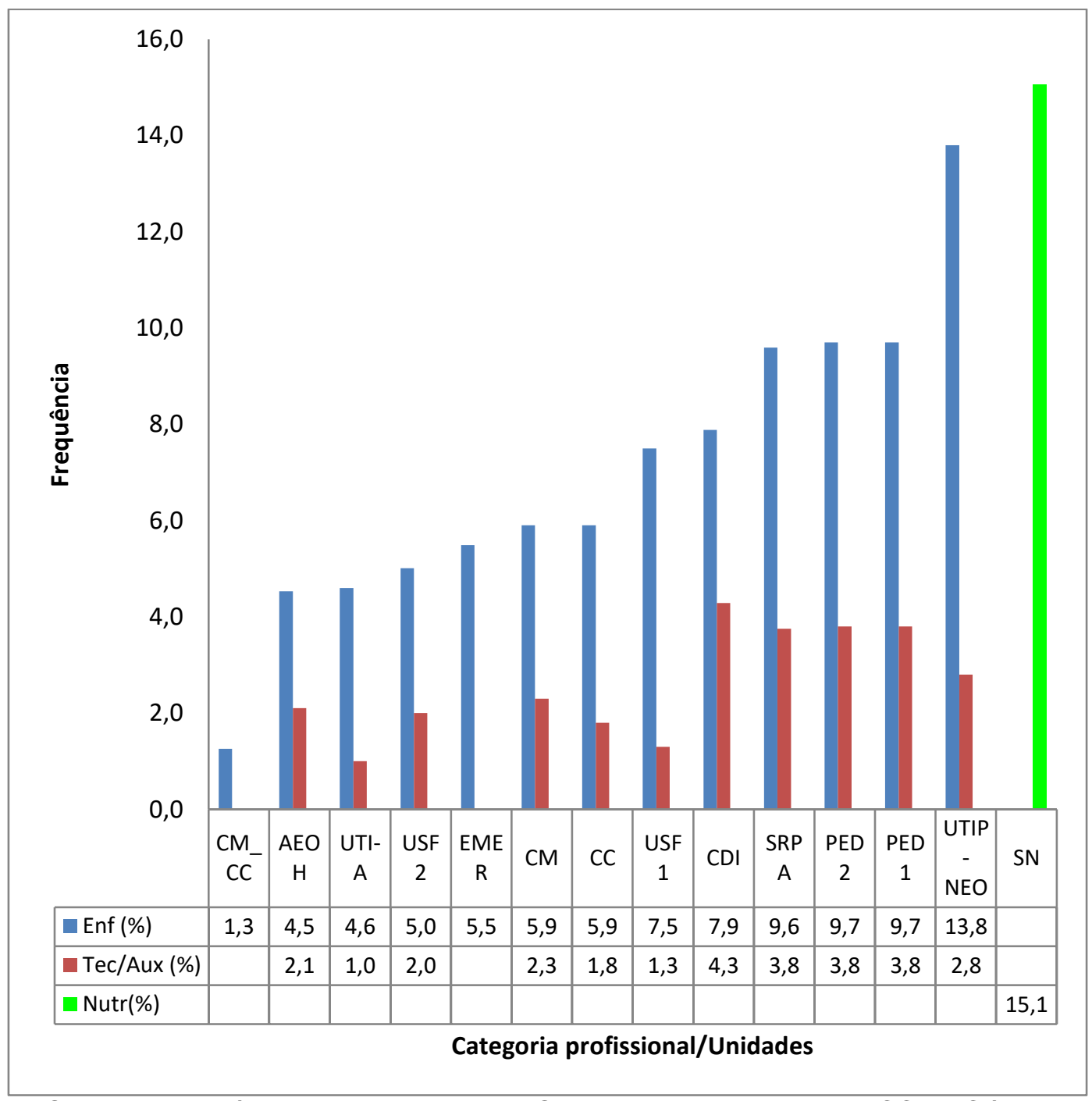

AEOH - Ambulatório de Especialidades Oncologia e Hematologia, CC - Clínica Cirúrgica, CDI - Centro de Diagnóstico por Imagem, CM - Clínica Médica, CM-CC Clínica Médica e Clínica Cirúrgica, EMER - Emergência, PED - Unidade de Internação Pediátrica, SN - Serviço de Nutrição, SRPA - Sala de Recuperação Pós-Anestésica, USF - Unidade de Saúde da Família, UTI-A - Unidade de Terapia Intensiva Adulto, UTIP-NEO - Unidade de Terapia Intensiva Pediátrica e Neonatal.

A intervenção Troca de informação sobre cuidados de saúde foi identificada em $87,5 \%$ das unidades e não foi verifica na unidade $A C$, pois as atividades relacionadas a essa intervenção foram agrupadas na intervenção passagem de plantão por Soares (2009); e no CCO, provavelmente pela existência do prontuário eletrônico, cuja presença diminua a frequência de observação da intervenção. 
Quadro 16 - Intervenções de Cuidado Indireto com frequência $\geq 1 \%$ observadas em até duas unidades por categoria profissional. São Paulo, 2017.

\begin{tabular}{|c|l|c|c|c|c|}
\hline \multirow{2}{*}{$n$} & \multirow{2}{*}{ Intervenção } & \multicolumn{4}{|c|}{ Categoria Profissional } \\
\cline { 3 - 6 } & & Enf & Téc/Aux & Nut & ATA \\
\hline 1 & Acompanhamento por telefone & $X$ & $X$ & & \\
\hline 2 & Controle da tecnologia & $X$ & $X$ & & \\
\hline 3 & Reunião administrativa & $X$ & $X$ & & $X$ \\
\hline
\end{tabular}

A intervenção Reunião dos trabalhadores para resolução de conflitos, citada no instrumento para medida de carga de trabalho dos ATA, foi agrupada à intervenção Reunião administrativa, pois a definição destas intervenções tem similaridades e podem ser aplicadas para as categorias de profissionais estudadas.

Gráfico 41 - Demonstrativo das Intervenções de Cuidado Indireto com frequência $\geq 1 \%$ observadas em até duas unidades por categoria profissional. São Paulo, 2017.

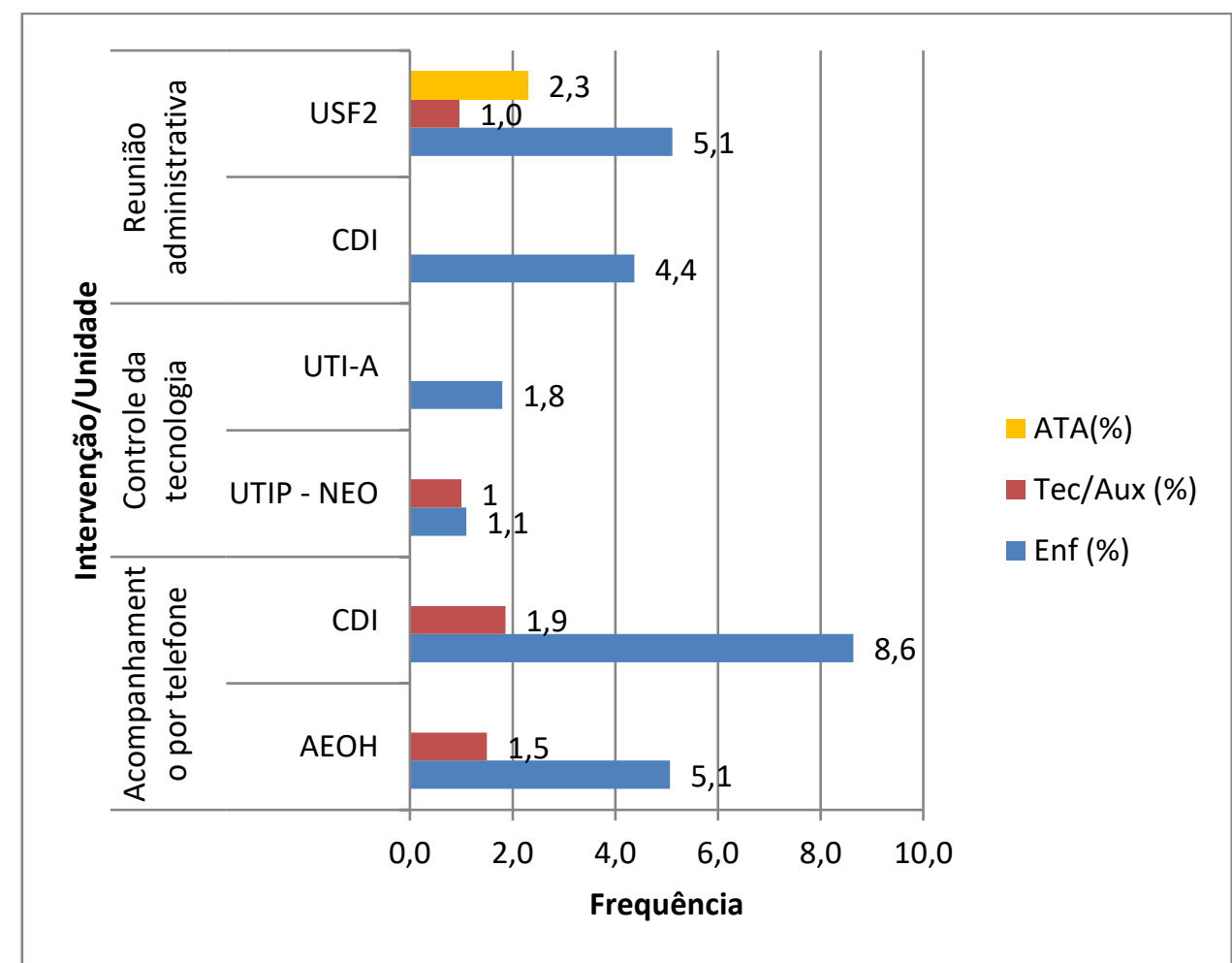

AEOH - Ambulatório de Especialidades Oncologia e Hematologia, CDI - Centro de Diagnóstico por Imagem, USF - Unidade de Saúde da Família, UTI-A - Unidade de Terapia Intensiva Adulto, UTIP-NEO - Unidade de Terapia Intensiva Pediátrica e Neonatal. 
As intervenções de cuidado indireto com frequência $\geq 1 \%$, identificadas em até duas unidades, foram Reunião administrativa observada nas USF 2 e CDI, predominando na categoria enfermeiro; Controle de tecnologia foi verificada na UTI-A e UTI-NEO e Acompanhamento por telefone observada no $\mathrm{CDI}$ e $\mathrm{AEOH}$ nas categorias de enfermeiros e téc./aux. de enfermagem.

Quadro 17 - Intervenções de Cuidado Indireto com frequência $\geq 1 \%$, observadas em uma unidade, por categoria profissional. São Paulo, 2017.

\begin{tabular}{|l|l|c|c|c|c|}
\hline $\mathrm{n}$ & \multicolumn{1}{|c|}{ Intervenção } & Enf & Téc/Aux & Nut & ATA \\
\hline 1 & $\begin{array}{l}\text { Ações educativas dos trabalhadores de } \\
\text { saúde }\end{array}$ & $\mathrm{X}$ & $\mathrm{X}$ & & \\
\hline 2 & Apoio à gerência & & & & $\mathrm{X}$ \\
\hline 3 & Coleta de dados de pesquisa & $\mathrm{X}$ & & & \\
\hline 4 & Controle de amostras para exames & & $\mathrm{X}$ & & \\
\hline 5 & Controle de medicamentos & $\mathrm{X}$ & $\mathrm{X}$ & & \\
\hline 6 & Controle de qualidade & $\mathrm{X}$ & & & \\
\hline 7 & Controle do ambiente: conforto & $\mathrm{X}$ & $\mathrm{X}$ & & \\
\hline 8 & $\begin{array}{l}\text { Digitação do mapa de produção diário } \\
\text { dos profissionais assistenciais }\end{array}$ & & & & $\mathrm{X}$ \\
\hline 9 & Organização do processo de trabalho & $\mathrm{X}$ & & & \\
\hline 10 & Organização do ambiente de trabalho & & & & $\mathrm{X}$ \\
\hline 11 & $\begin{array}{l}\text { Organizar o SAME (Serviço de Arquivo } \\
\text { Médico) }\end{array}$ & & & & $\mathrm{X}$ \\
\hline 12 & Preceptor: funcionário & $\mathrm{X}$ & & & \\
\hline 13 & Supervisão & $\mathrm{X}$ & & & \\
\hline 14 & $\begin{array}{l}\text { Supervisão da distribuição das refeições } \\
\text { nas unidades }\end{array}$ & & & $\mathrm{X}$ & \\
\hline 15 & Suporte à família & $\mathrm{X}$ & & & \\
\hline 16 & Suporte à gestão de recursos humanos & & & & $\mathrm{X}$ \\
\hline 17 & Checagem de substância controlada *9 & $\mathrm{X}$ & & & \\
\hline 18 & Verificação do carrinho de emergência & & $\mathrm{X}$ & & \\
\hline & & & & \\
\hline
\end{tabular}


Gráfico 42 - Demonstrativo das Intervenções de Cuidado Indireto com frequência $\geq 1 \%$, observadas em uma unidade por categoria profissional. São Paulo, 2017.

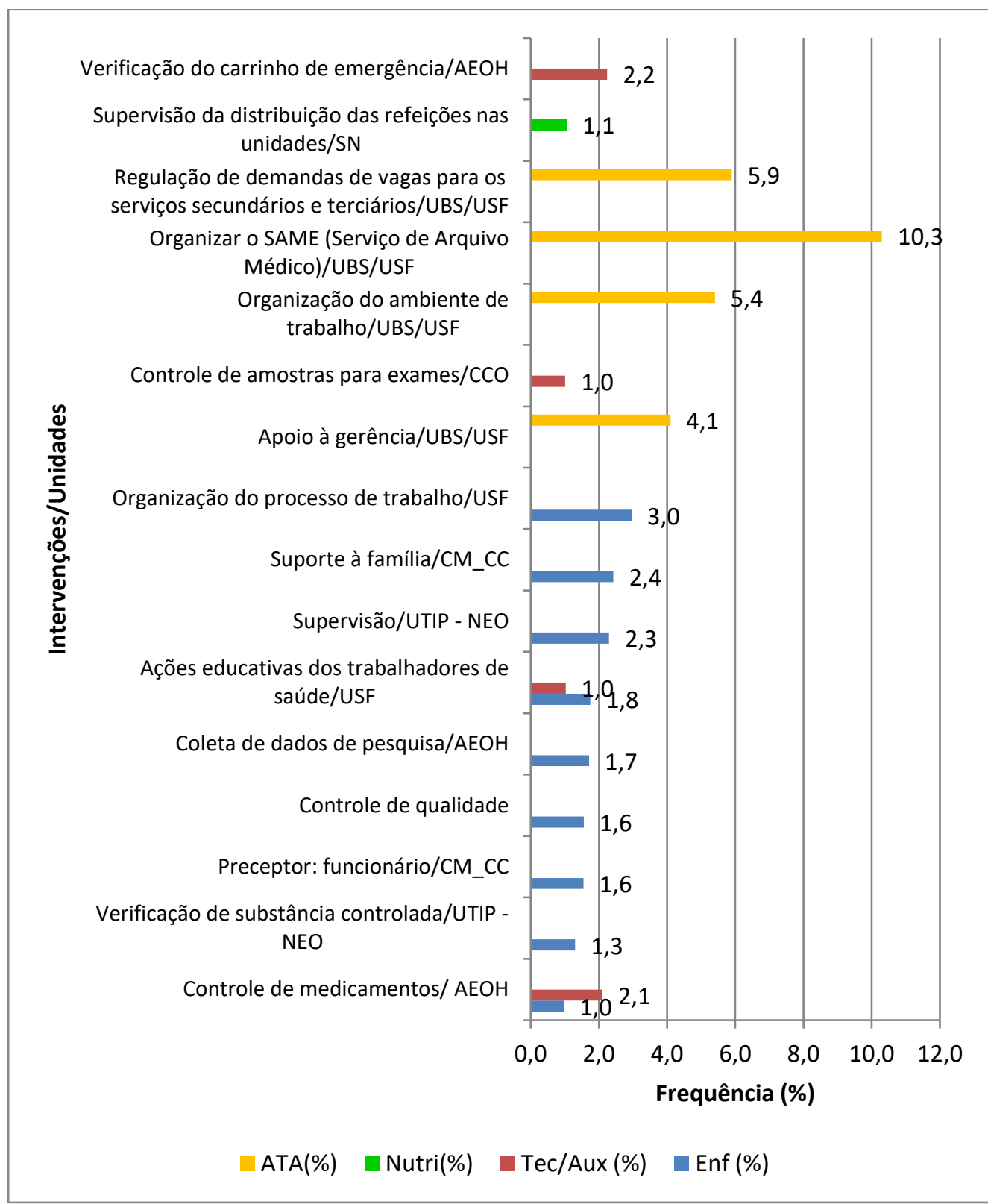

O Gráfico 42 apresenta intervenções que foram identificadas em uma unidade, estas estão dispersas nas unidades e algumas contribuem com frequências mais elevadas como: Regulação de demanda de vagas, Organizar SAME, Organização do ambiente de trabalho e Apoio a gerência realizadas pelos ATAs. 


\subsection{TEMPO PRODUTIVO DOS PROFISSIONAIS DE SAÚDE}

A aplicação dos instrumentos de medida da carga de trabalho possibilitou identificar um elenco de intervenções de cuidado direto, de cuidado indireto, atividades associadas e pessoais, o que permitiu identificar o tempo produtivo dos profissionais de saúde (Figura 4).

Figura 4 - $\quad$ Representação das categorias de análise do tempo produtivo dos profissionais de saúde, segundo o referencial das intervenções/atividades. São Paulo, 2017.

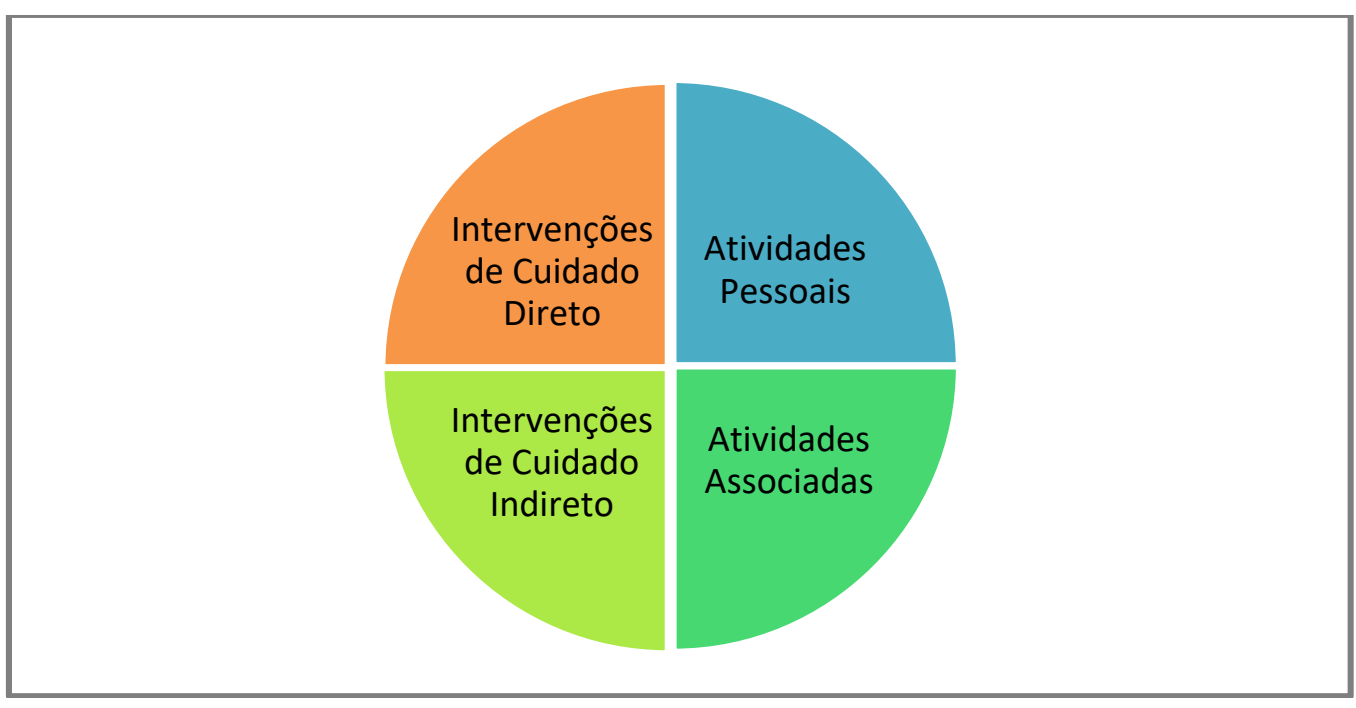

Identificar o tempo produtivo no trabalho dos profissionais de saúde favorece a análise e a evidência de situações que podem comprometer a qualidade da assistência prestada, bem como, situações geradoras de estresse e comprometimento da saúde do profissional, refletindo nos indicadores assistenciais e gerenciais dos serviços.

Analisar o desfecho da produtividade auxilia o mapeamento e a monitoração do desempenho do serviço e das unidades e pode ser considerado indicador gerencial potente e auxiliar nas ações do gerente da unidade e/ou do serviço de saúde.

O tempo produtivo do trabalho dos profissionais de saúde foi obtido por meio da soma das proporções de tempo dedicado às intervenções de cuidado direto, de cuidado indireto e atividades associadas (Gráficos 43 a 46). 
Já o tempo não produtivo, durante a jornada de trabalho, é caracterizado pelo tempo despendido em pausas destinadas ao atendimento das necessidades pessoais dos profissionais.

Gráfico 43 - Distribuição percentual de tempo produtivo dos enfermeiros nas unidades de saúde estudadas. São Paulo, 2017.

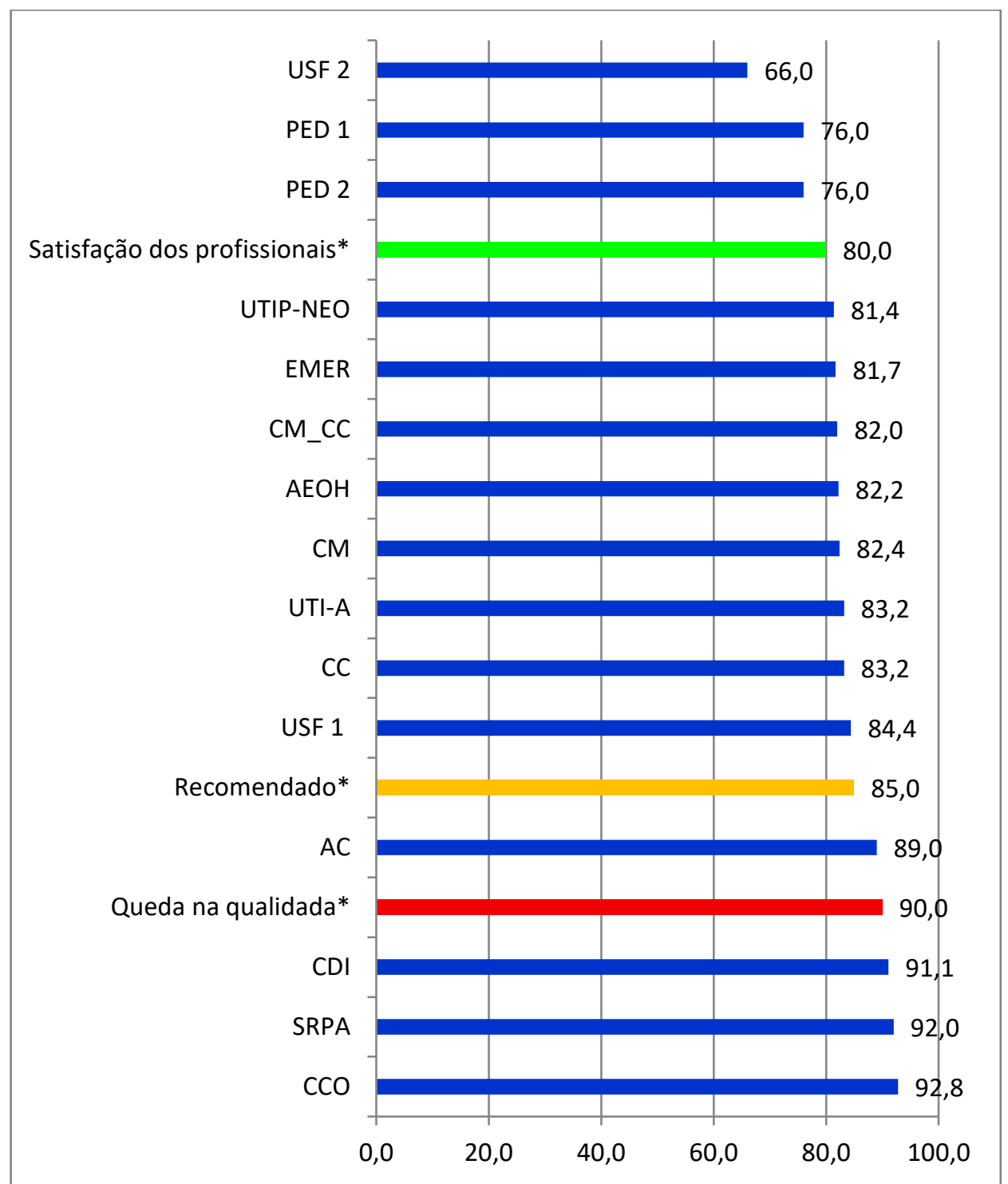

* Níveis de produtividade segundo O'Brien Pallas (2004).

AC - Alojamento Conjunto, AEOH - Ambulatório de Especialidades Oncologia e Hematologia, CM - Clínica Médica, CC - Clínica Cirúrgica, CCO - Centro Cirúrgico de Oncologia, CDI - Centro de Diagnóstico por Imagem, CM-CC - Clínica Médica e Clínica Cirúrgica, EMER - Emergência, PED - Unidade de Internação Pediátrica, SRPA - Sala de Recuperação Pós-Anestésica, USF - Unidade de Saúde da Família, UTI-A Unidade de Terapia Intensiva Adulto, UTIP-NEO - Unidade de Terapia Intensiva Pediátrica e Neonatal. 
Gráfico 44 - Produtividade (\%) dos téc./aux. de enfermagem nas unidades de saúde estudas. São Paulo, 2017.

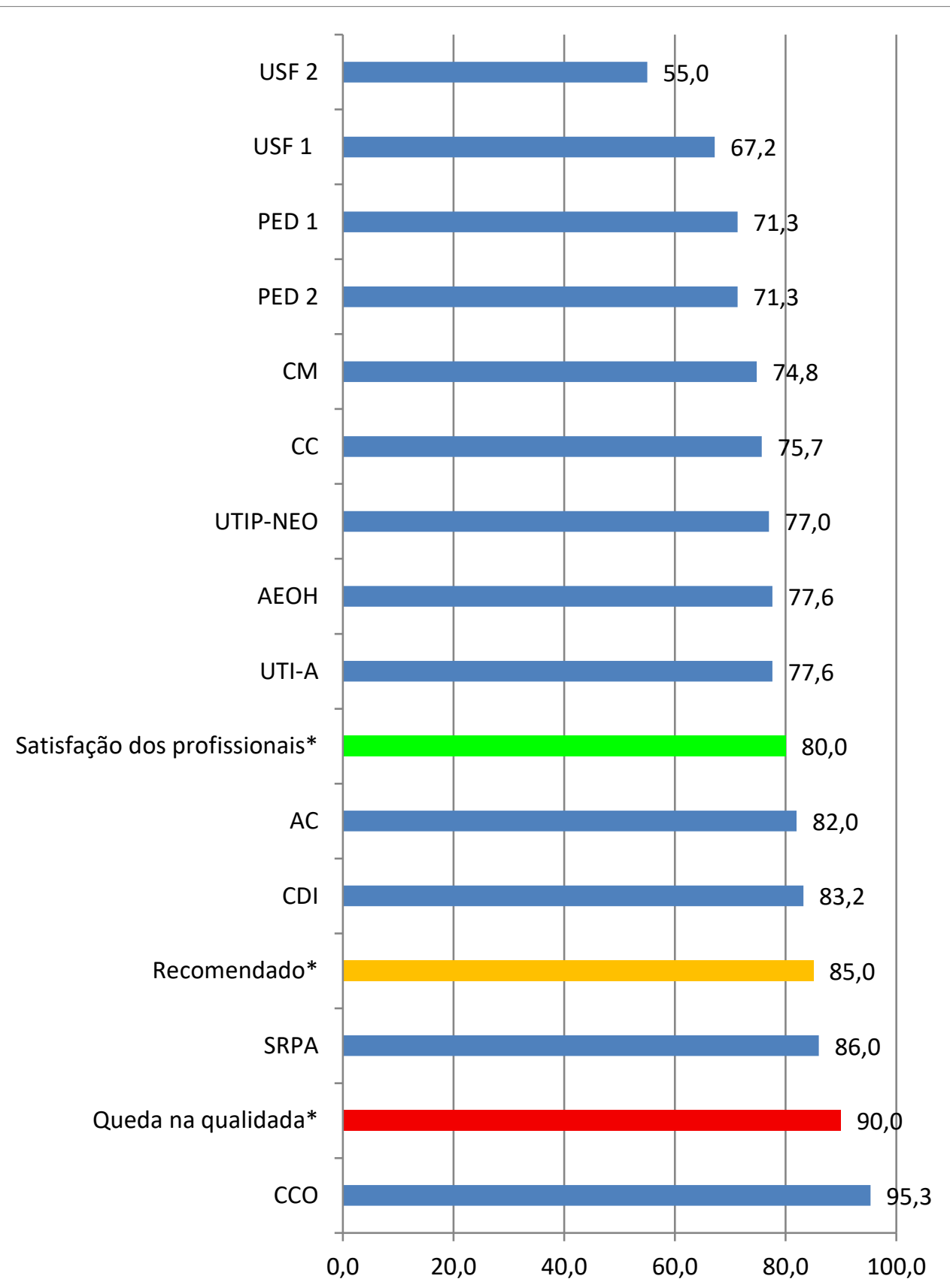

* Níveis de produtividade segundo O'Brien Pallas (2004).

AC - Alojamento Conjunto, AEOH - Ambulatório de Especialidades Oncologia e Hematologia, CM - Clínica Médica, CC - Clínica Cirúrgica, CCO - Centro Cirúrgico de Oncologia, CDI - Centro de Diagnóstico por Imagem, PED - Unidade de Internação Pediátrica, SRPA - Sala de Recuperação Pós-Anestésica, USF - Unidade de Saúde da Família, UTI-A - Unidade de Terapia Intensiva Adulto, UTIP-NEO - Unidade de Terapia Intensiva Pediátrica e Neonatal. 
Gráfico 45 - Produtividade dos nutricionistas nos três hospitais estudados. São Paulo, 2017.

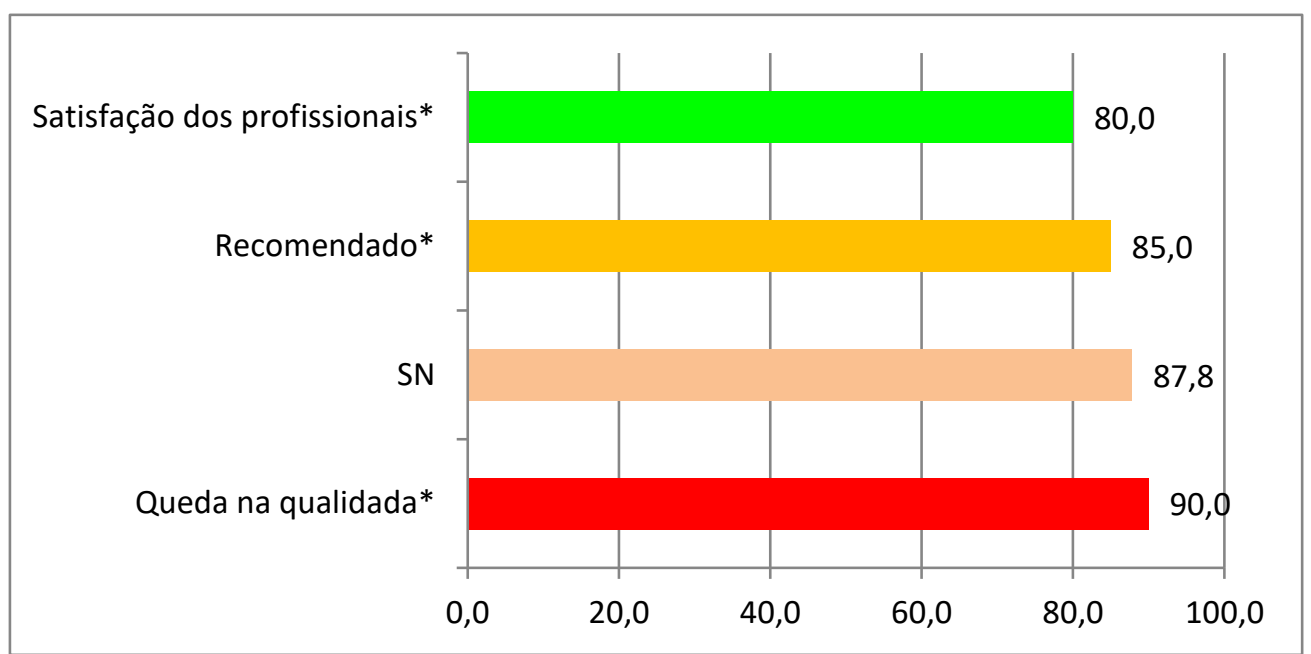

* Níveis de produtividade segundo O'Brien Pallas (2004).

Gráfico 46 - Produtividade dos ATA em unidade de saúde da família. São Paulo, 2017.

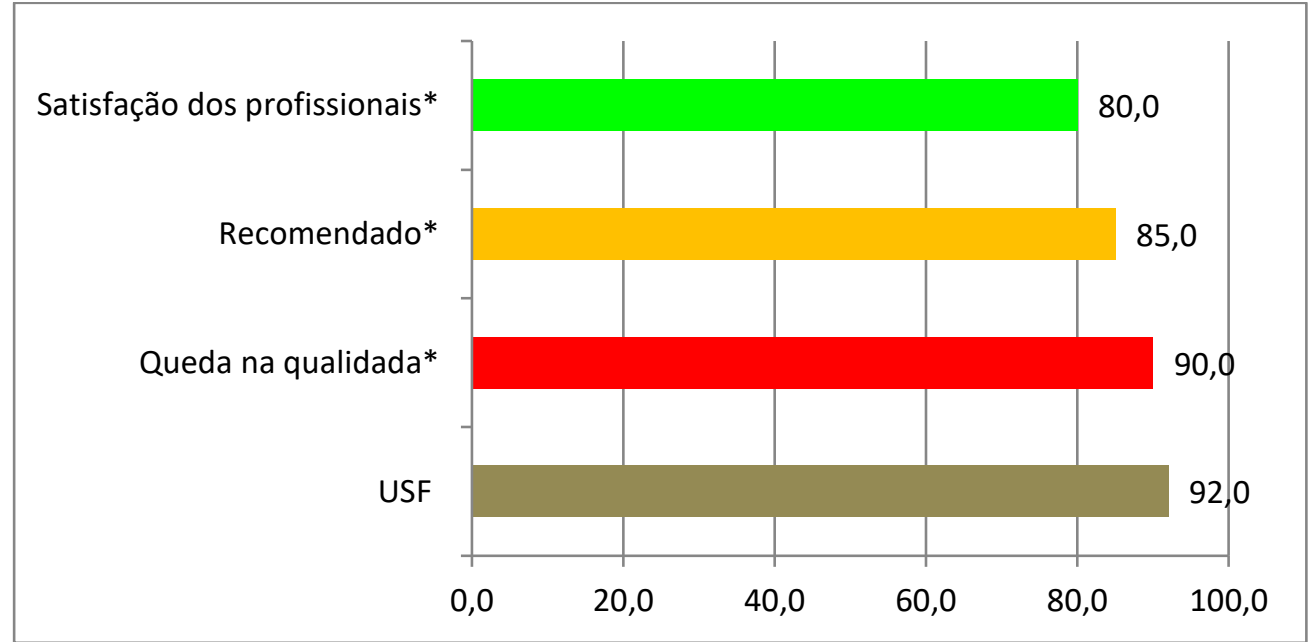

* Níveis de produtividade segundo O’Brien Pallas (2004).

O'Brien Pallas et al. (2004) introduziram três níveis de produtividade, que foram utilizados como referencial teórico, pelos autores desses estudos, de modo que produtividade menor ou igual $80 \%$ indica que há mais probabilidade dos profissionais estarem satisfeitos com o seu trabalho e do absenteísmo ser reduzido; produtividade maior que $80 \%$ e menor que $85 \%$ é considerada recomendada; já a produtividade acima de $90 \%$ é considerada preocupante. 
Biseng (1996) apresentou critérios de avaliação para a distribuição da produtividade, percentuais satisfatórios são considerados entre $60 \%$ e $75 \%$; os percentuais insatisfatórios são inferiores a 60\% e percentuais suspeitos são superiores a $85 \%$. Índices excelentes são aqueles que se encontram entre $75 \%$ e $85 \%$.

Além disso, o estudo e o monitoramento do tempo produtivo proporcionam relação adequada entre a quantidade de produtos ou serviços produzidos e a quantidade de recursos utilizados (Mello, Fugulin, Gaidzinski, 2007).

Manter níveis satisfatórios de produtividade da força de trabalho em saúde é uma necessidade prioritária para o atendimento das crescentes demandas de serviços (Westbrook, Duffield, Creswick, 2011).

Segundo o referencial adotado, unidades que apresentam produtividade acima de $85 \%$ apresentam sobrecarga de trabalho e merecem análise em seu processo de trabalho de maneira a distribuir com mais equilíbrio as intervenções/atividades a serem realizadas, sendo necessário rever e inovar os protocolos instalados, com o objetivo de otimizar os recursos disponíveis sem ferir os princípios científicos.

Já as unidades que apresentam produtividade abaixo de $80 \%$ indicam que os profissionais de saúde podem estar mais satisfeitos com o trabalho e que o absenteísmo pode ser reduzido, porém o gerente da unidade necessita desenvolver ações de monitoramento para identificar se as demandas de assistência à saúde estão sendo realizadas.

Durante a jornada, devem ser previstas pausas no trabalho para serem atendidas necessidades pessoais dos profissionais e permitir que sejam realizados momentos de descanso para alívio da fadiga no trabalho (Martins, Laugeni, 2000).

Atenta a esta questão - a fim de que os trabalhadores possam realizar as necessidades pessoais e fisiológicas, desfrutar de períodos de descanso e de comemorações - Gaidzinski (1998) recomendou que fossem consideradas as perdas de produtividade no cálculo dos recursos humanos para saúde. 
À medida que os estudos foram realizados, houve ampliação desse conceito. Bonfim (2014) introduziu o conceito de produtividade potencial e produtividade real, para unidades de saúde da família. A produtividade real refere-se ao percentual de tempo de trabalho que 0 profissional despende em intervenções de cuidado direto e indireto e em atividades associadas ao trabalho.

Já a produtividade potencial é a produtividade que poderia ser atingida pelo profissional, se não houvesse perdas com tempo de espera e períodos de ausência dos profissionais durante a jornada de trabalho, encontradas na observação direta nessas unidades.

Nos Gráficos 47 a 51 , foram agrupadas as unidades que apresentam similaridades com relação à demanda atendida.

É possível verificar a representação da produtividade das unidades estudadas, evidenciando a demanda de trabalho e o seu desempenho.

Gráfico 47 - Produtividade dos profissionais de saúde das unidades de emergência, clínica médico-cirúrgica, clínica médica, clínica cirúrgica e UTIP. São Paulo, 2017.

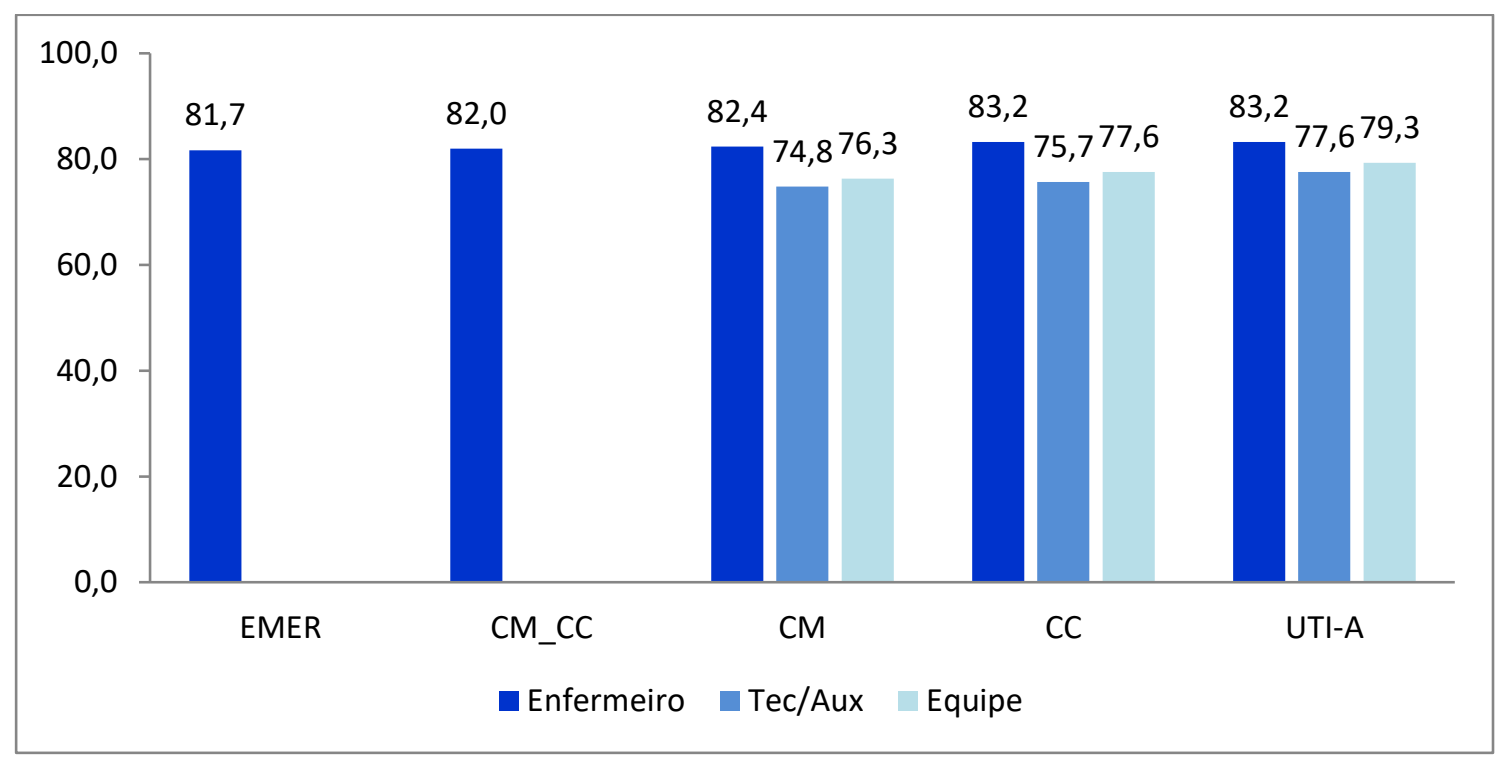

CM - Clínica Médica, CC - Clínica Cirúrgica, CM-CC - Clínica Médica e Clínica Cirúrgica, EMER - Emergência, UTI-A - Unidade de Terapia Intensiva Adulto. 
Gráfico 48 - Produtividade dos profissionais de saúde das unidades de pediatria, UTIP-NEO e AC. São Paulo, 2017.

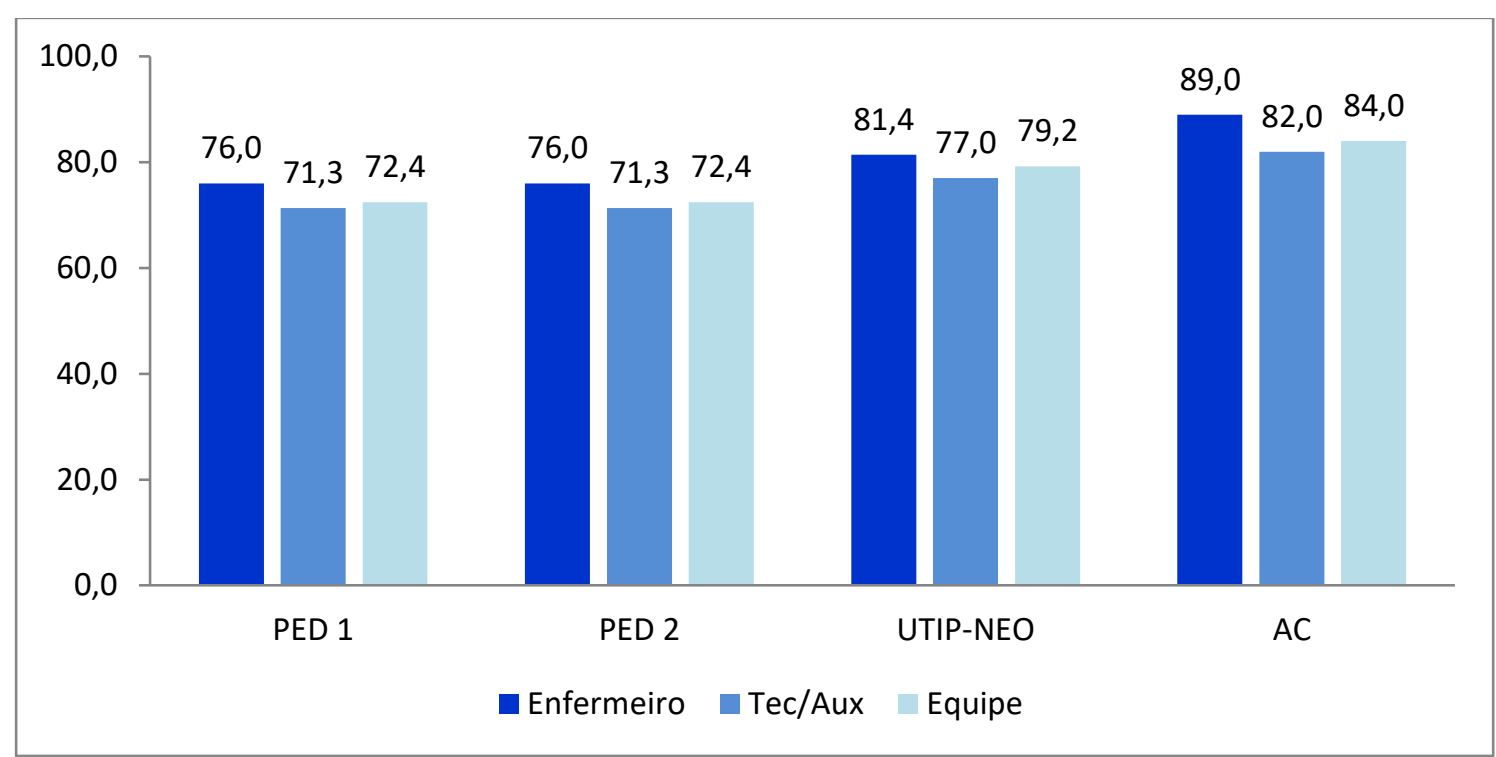

AC - Alojamento Conjunto, PED - Unidade de Internação Pediátrica, UTIP-NEO Unidade de Terapia Intensiva Pediátrica e Neonatal.

Gráfico 49 - Produtividade dos profissionais de saúde das unidades de SRPA e CCO. São Paulo, 2017.

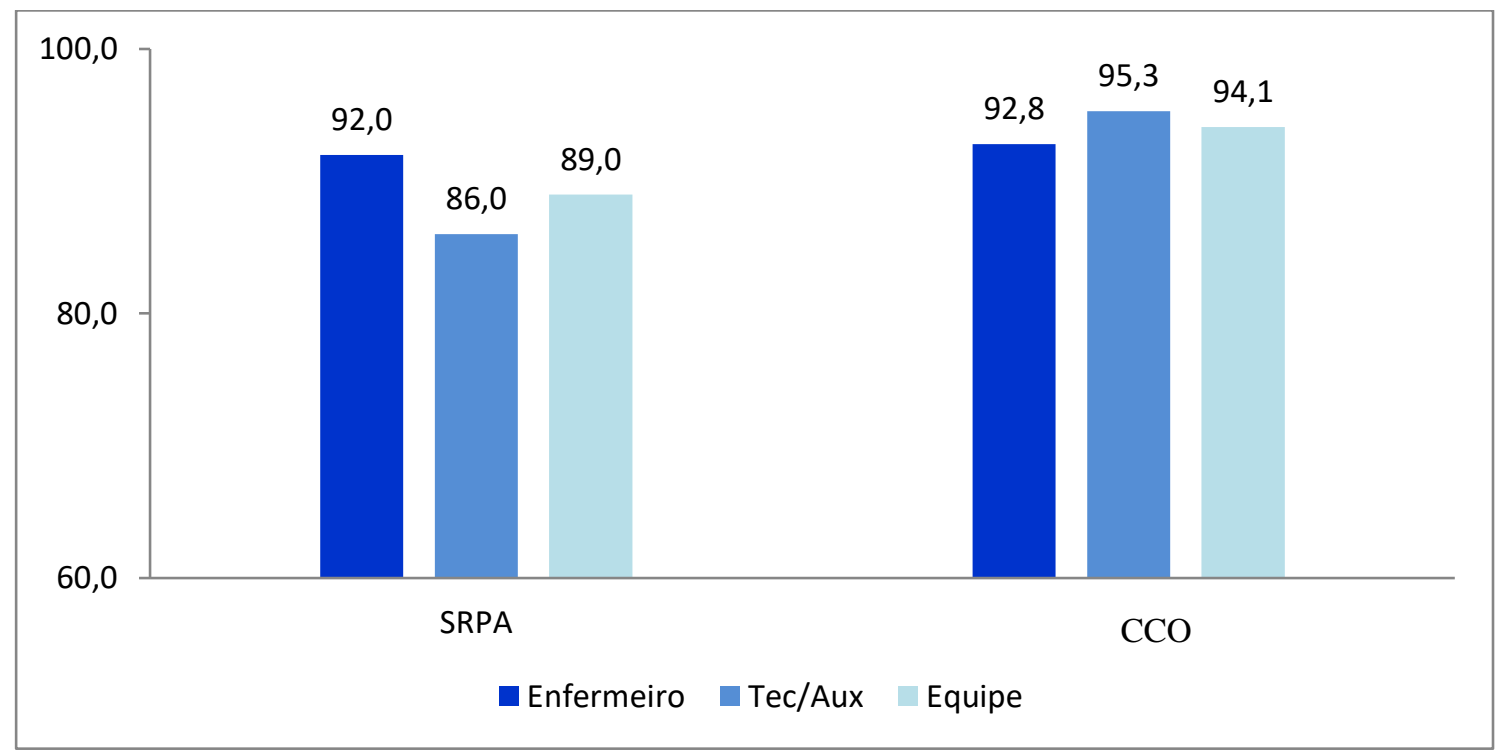

CCO - Centro Cirúrgico de Oncologia, SRPA - Sala de Recuperação PósAnestésica. 
Gráfico 50 - Produtividade dos profissionais de saúde das unidades de CDI e AEOH. São Paulo, 2017.

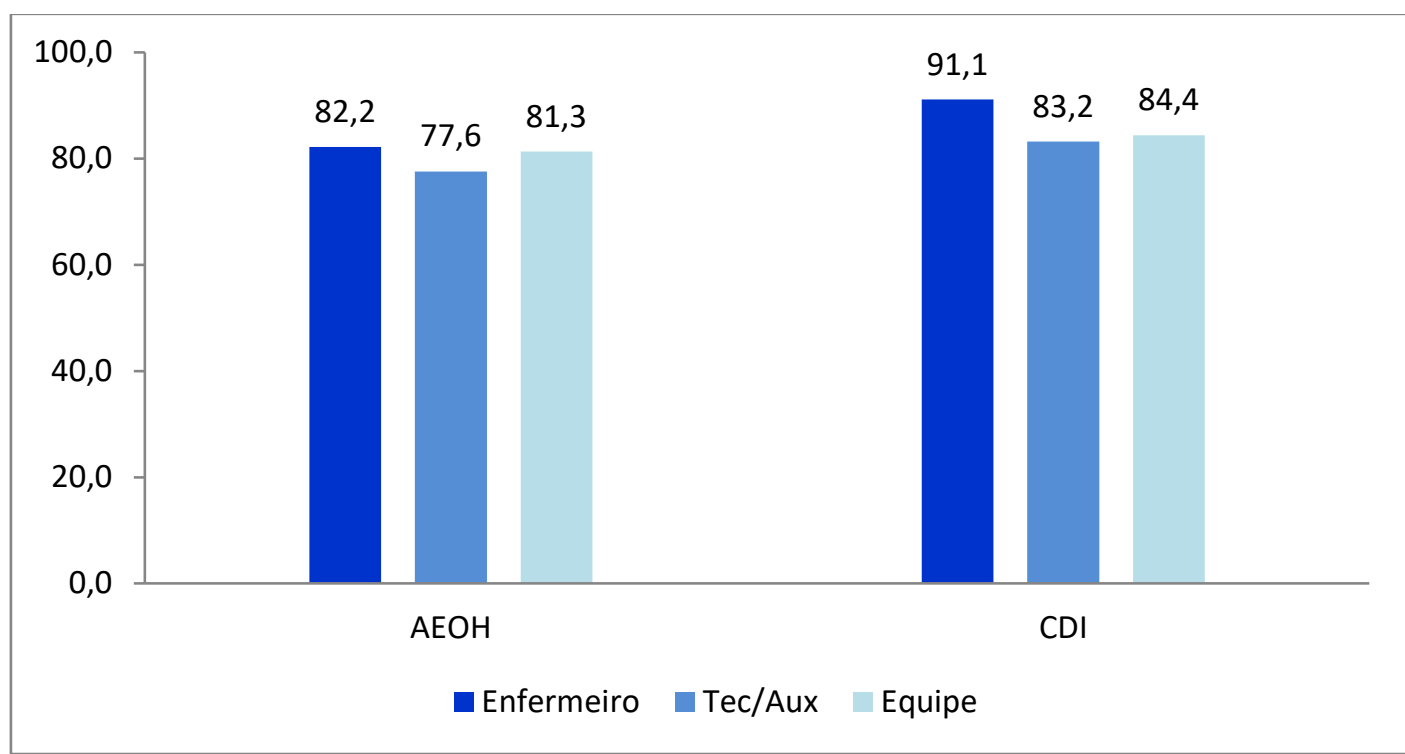

AEOH - Ambulatório de Especialidades Oncologia e Hematologia, CDI - Centro de Diagnóstico por Imagem.

Gráfico 51 - Produtividade dos profissionais de saúde das USF. São Paulo, 2017.

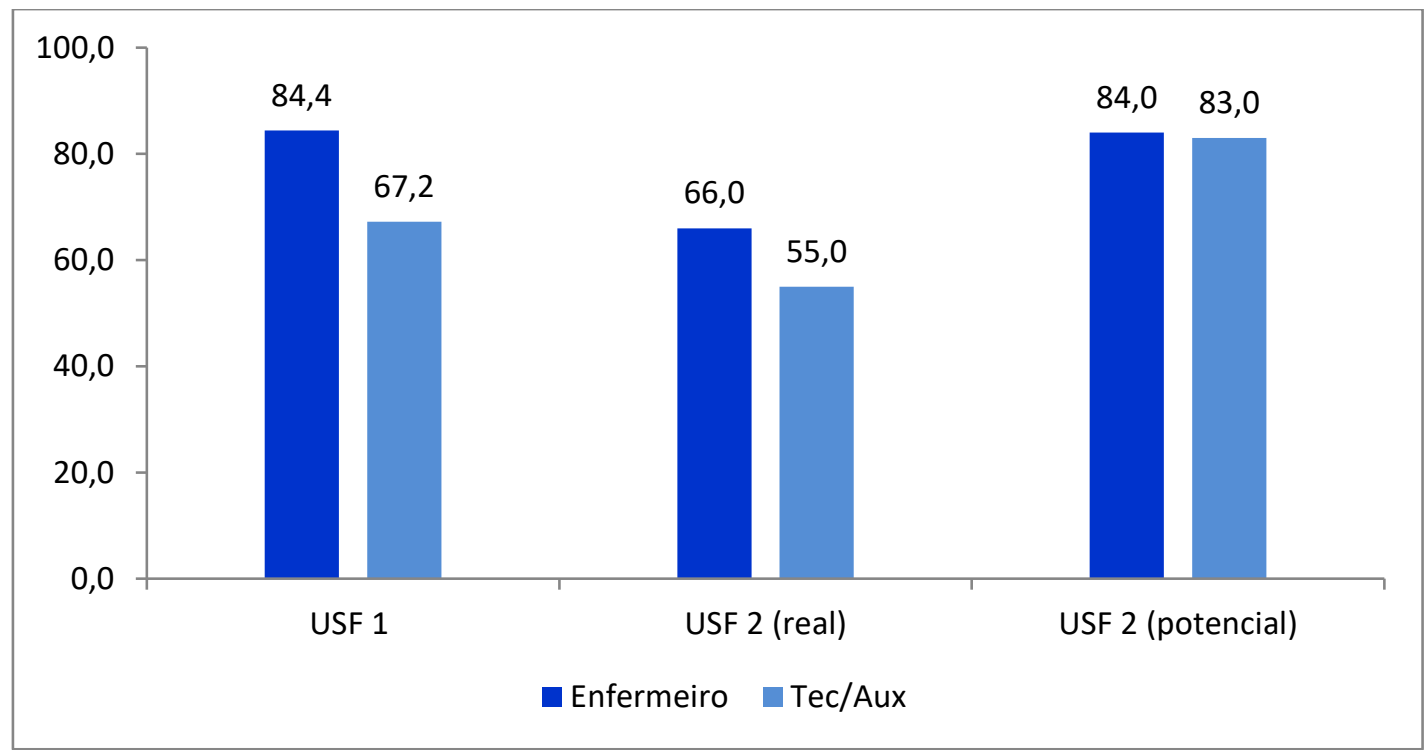

USF - Unidade de Saúde da Família.

Por um lado, os serviços de saúde precisam desenvolver ações para se tornar mais eficientes, aumentar a produtividade e minimizar os gastos. Para isso, necessitam estudar os seus processos de trabalho assistenciais e gerenciais com o objetivo de alinhar os recursos disponíveis e as ações a serem desenvolvidas (Castro, Castilho, 2013). 
Por outro lado, é necessário identificar situações extremas que coloquem em risco à qualidade da assistência, à segurança do paciente e do profissional de saúde.

\subsection{AS CINCO INTERVENÇÕES MAIS FREQUENTES OBSERVADAS NAS UNIDADES}

A construção deste capítulo foi fundamentada nos resultados dos estudos de Urden, Roode (1997), Duffield, Wise (2003), Chaboyer et.al.(2008) que identificaram um conjunto de atividades mais frequentemente observadas. Nos resultados da aplicação do método Workload Indicator Staff Need (WISN), proposto pela Organização Mundial de Saúde, ao verificar que, apenas quatro a cinco intervenções têm mais ocorrência nas unidades de saúde, portanto impacta na carga de trabalho (WHO, 2010).

A seguir, são apresentadas as cinco intervenções mais frequentes observadas em cada unidade:

Os gráficos 52 a 77 apresentam as intervenções que tiveram mais probabilidade de ocorrência nas unidades estudadas e não têm a intenção de reduzir os estudos realizados, pois eles abarcaram a complexidade do contexto onde ocorreu o processo de trabalho observado em saúde. Além disso, proporcionaram a construção de um arcabouço teórico denso e sofisticado e evidenciaram a análise de um conjunto aprimorado de intervenções e atividades que embasaram a construção de instrumentos. Esses estudos merecem a atenção de gerentes de unidades de saúde, profissionais de saúde e de docentes de cursos formadores de profissionais de saúde. 
Gráfico 52 - Distribuição das cinco intervenções mais frequentes observadas, realizadas por enfermeiros na unidade de AC. São Paulo, 2017.

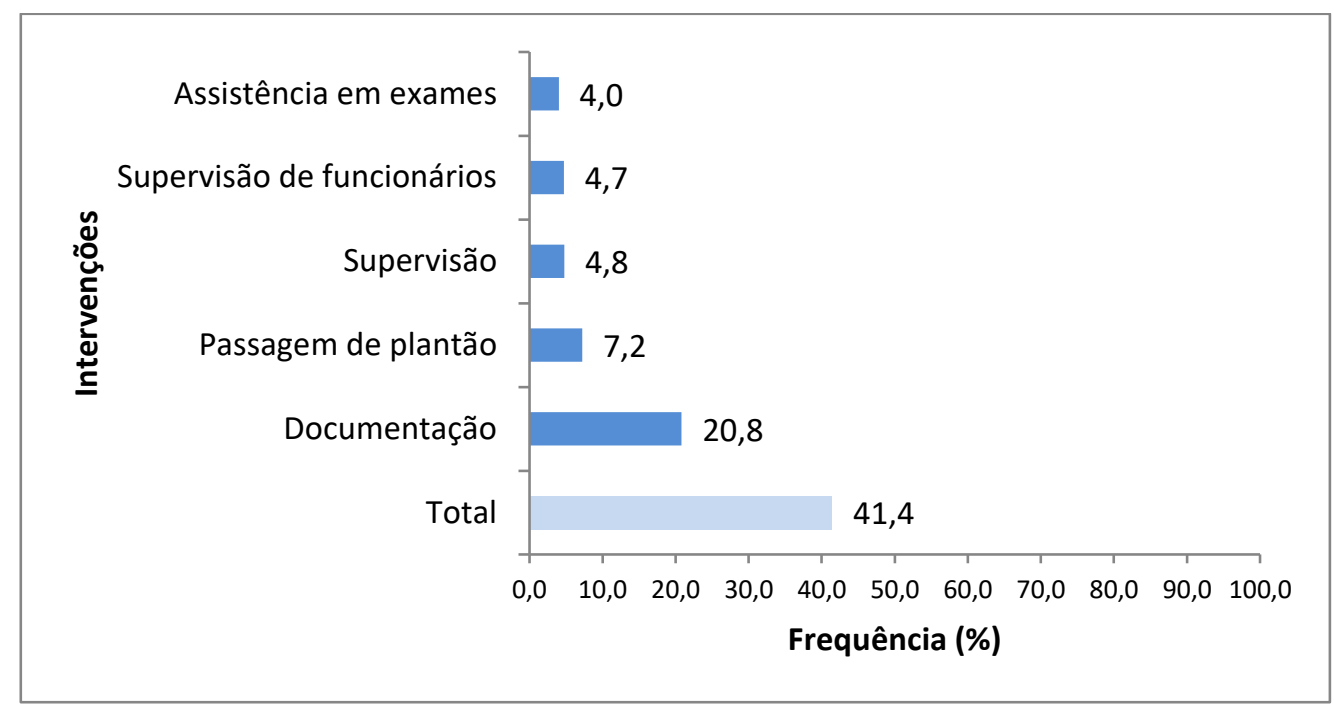

AC - Alojamento Conjunto.

Fonte: Soares (2009).

Gráfico 53 - Distribuição das cinco intervenções mais frequentes observadas, realizadas por téc./aux. de enfermagem na unidade de AC. São Paulo, 2017.

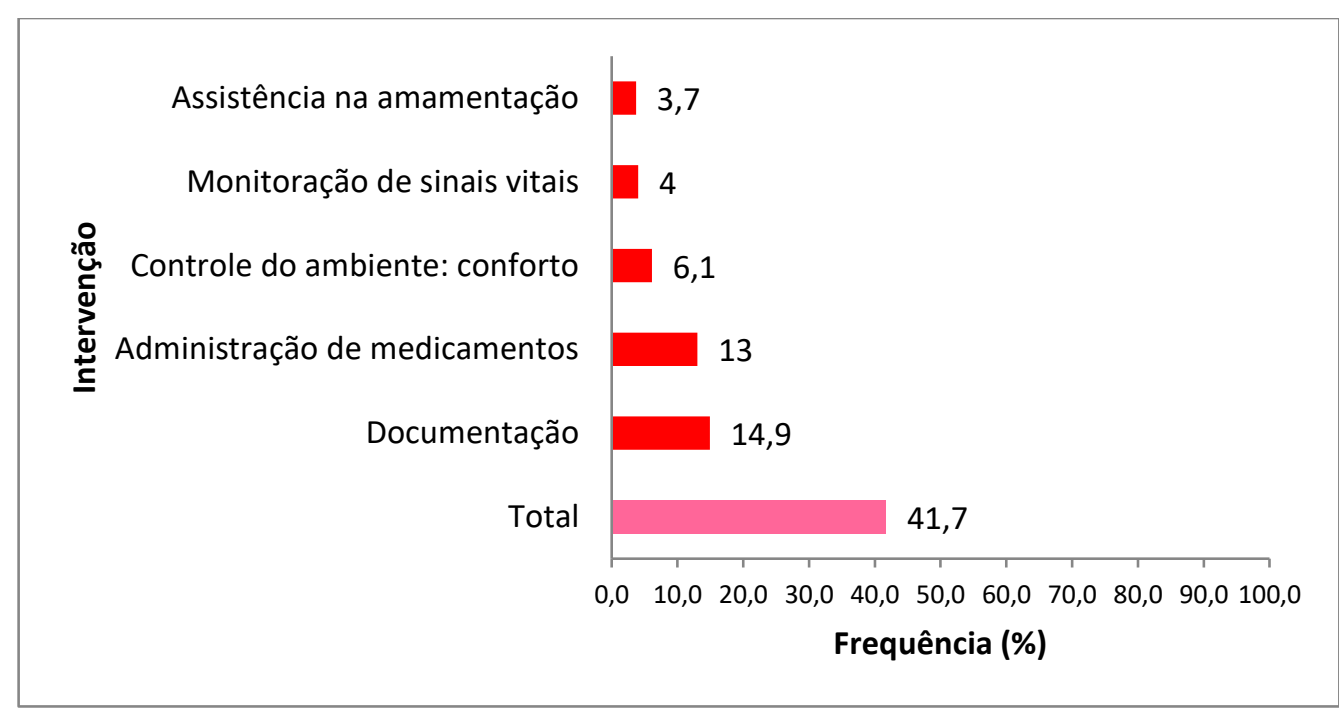

AC - Alojamento Conjunto.

Fonte: Soares (2009).

Os Gráficos 52 e 53 apresentam as cinco intervenções mais frequentes observadas no $A C$ que corresponderam a $41,4 \%$ das observações dos enfermeiros e $41,7 \%$ dos téc./aux. de enfermagem, 
evidenciando que essas cinco intervenções têm mais probabilidade de ocorrer e impactar na carga de trabalho dos profissionais de enfermagem dessa unidade. A intervenção Documentação foi comum para as categorias de enfermeiros e téc./aux. de enfermagem com frequência de $20,8 \%$ e $14,9 \%$, respectivamente.

Com relação ao tipo de cuidado, as intervenções de cuidado direto mais frequentes para os enfermeiros foram: Assistência em exames e Supervisão; para os téc./aux. de enfermagem foram: Assistência na amamentação, Monitoração de sinais vitais, Controle do ambiente: conforto e Administração de medicamentos.

As intervenções de cuidado indireto mais frequentes para os enfermeiros foram: Supervisão de funcionários, Passagem de plantão e Documentação; para os téc./aux. de enfermagem foi Documentação.

Gráfico 54 - Distribuição das cinco intervenções mais frequentes observadas, realizadas por enfermeiros nas PED1 e PED2. São Paulo, 2017.

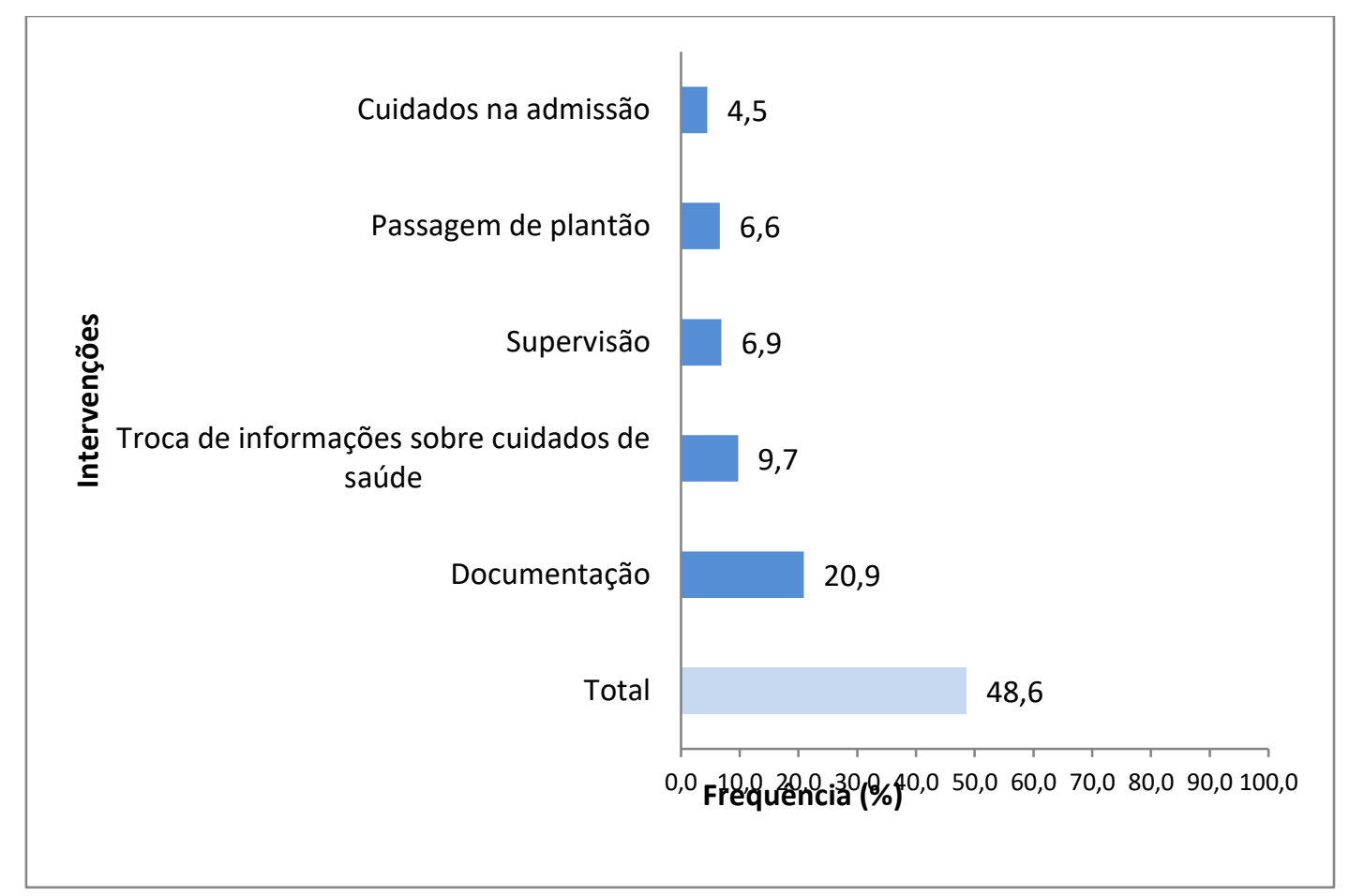

PED - Unidade de Internação Pediátrica.

Fonte: Andrade (2014), Rogenski (2014). 
Gráfico 55 - Distribuição das cinco intervenções mais frequentes observadas, realizadas por téc./aux. de enfermagem nas PED1 e PED 2. São Paulo, 2017.

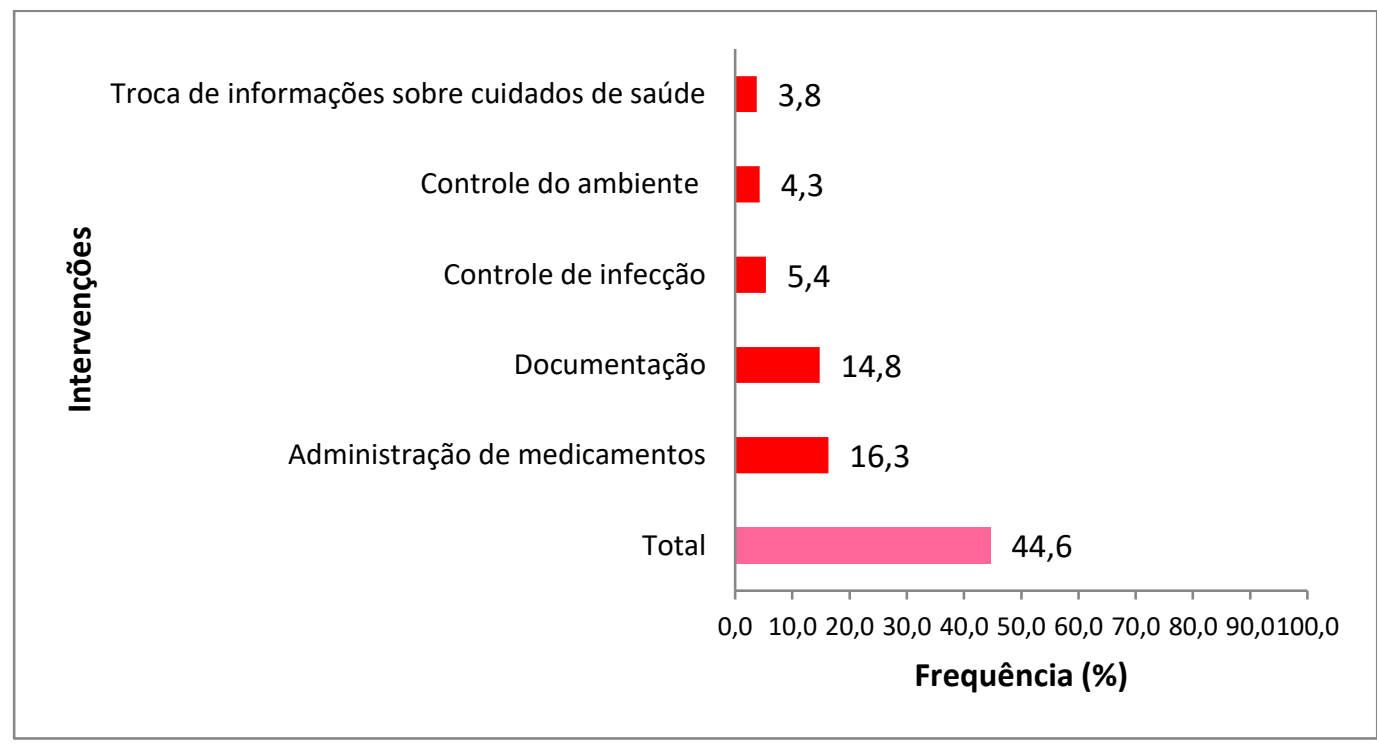

PED - Unidade de Internação Pediátrica.

Fonte: Andrade (2014), Rogenski (2014).

As PED1 e PED2 apresentaram os valores iguais para as intervenções que compuseram esses gráficos, representadas no Gráfico 54 e 55.

As cinco intervenções mais frequentes observadas nessas unidades corresponderam a $48,6 \%$ para os enfermeiros e a $44,6 \%$ para os téc./aux. de enfermagem. A intervenção Documentação foi a mais frequente $(20,9 \%)$ na categoria enfermeiro e Administração de medicamentos foi a mais frequente (16,3\%) para a categoria téc./aux. de enfermagem.

As intervenções de cuidado direto mais frequentes para os enfermeiros foram: Supervisão e Cuidados na admissão; para os téc./aux. de enfermagem foram: Administração de medicamentos e Controle de infecção.

As intervenções de cuidado indireto mais frequentes para os enfermeiros foram: Documentação, Troca de informações sobre cuidados de saúde e Passagem de plantão; para os téc./aux. de 
enfermagem foram: Documentação, Controle do ambiente e Troca de informações sobre cuidados de saúde.

Gráfico 56 - Distribuição das cinco intervenções mais frequentes observadas, realizadas por enfermeiros na UTIP-NEO São Paulo, 2017.

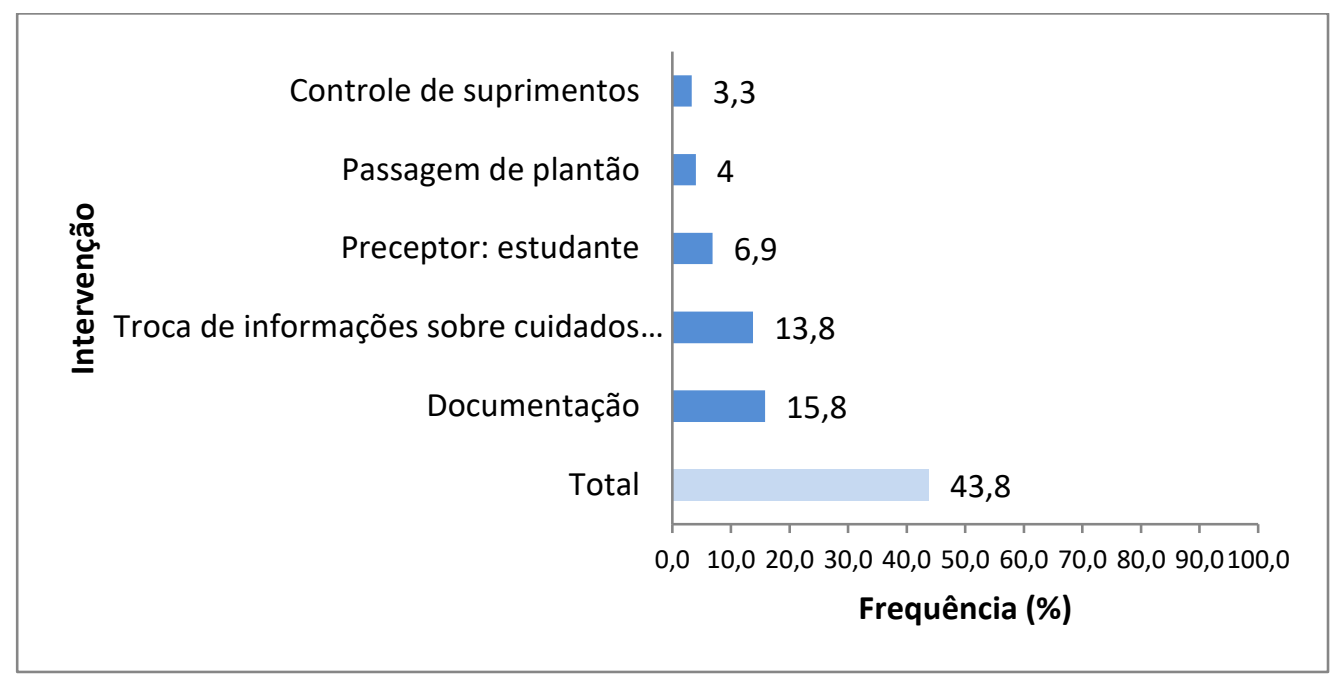

UTIP-NEO - Unidade de Terapia Intensiva Pediátrica e Neonatal.

Fonte: Guimarães (2015).

Gráfico 57 - Distribuição das cinco intervenções mais frequentes observadas, realizadas por téc./aux. de enfermagem na UTIPNEO. São Paulo, 2017.

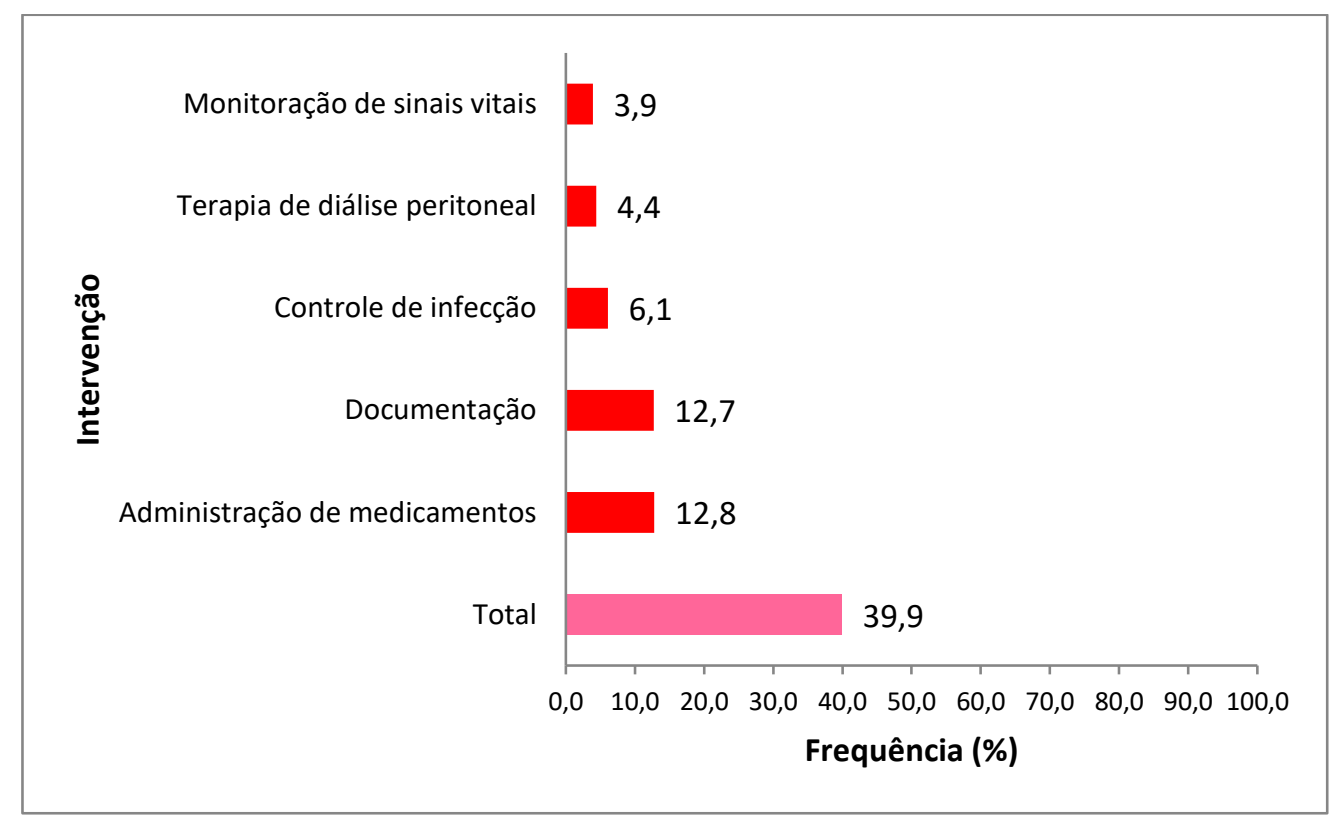

UTIP-NEO - Unidade de Terapia Intensiva Pediátrica e Neonatal.

Fonte: Guimarães (2015). 
Os Gráficos 57 e 58 evidenciaram as cinco intervenções mais frequentes observadas na UTIP-NEO que corresponderam a 43,8\% para os enfermeiros e a 39,9\% para os aux./tec. de enfermagem.

A intervenção Documentação foi a mais frequente $(15,8 \%)$ na categoria enfermeiro e Administração de medicamentos foi a mais frequente (12,8\%) para a categoria téc./aux.de enfermagem.

Com relação ao tipo de cuidado, os enfermeiros não apresentaram intervenções de cuidado direto dentre as cinco intervenções mais frequentes nessa unidade; para os téc./aux. de enfermagem foram: Administração de medicamentos, Controle de infecção, Terapia de diálise peritoneal e Monitoração dos sinais vitais.

As intervenções de cuidado indireto mais frequentes para os enfermeiros foram: Documentação, Troca de informações sobre cuidados de saúde, Preceptor: estudante e Controle de suprimentos; para os téc./aux.de enfermagem foi Documentação.

Gráfico 58 - Distribuição das cinco intervenções mais frequentes observadas, realizadas por enfermeiros na CC. São Paulo, 2017.

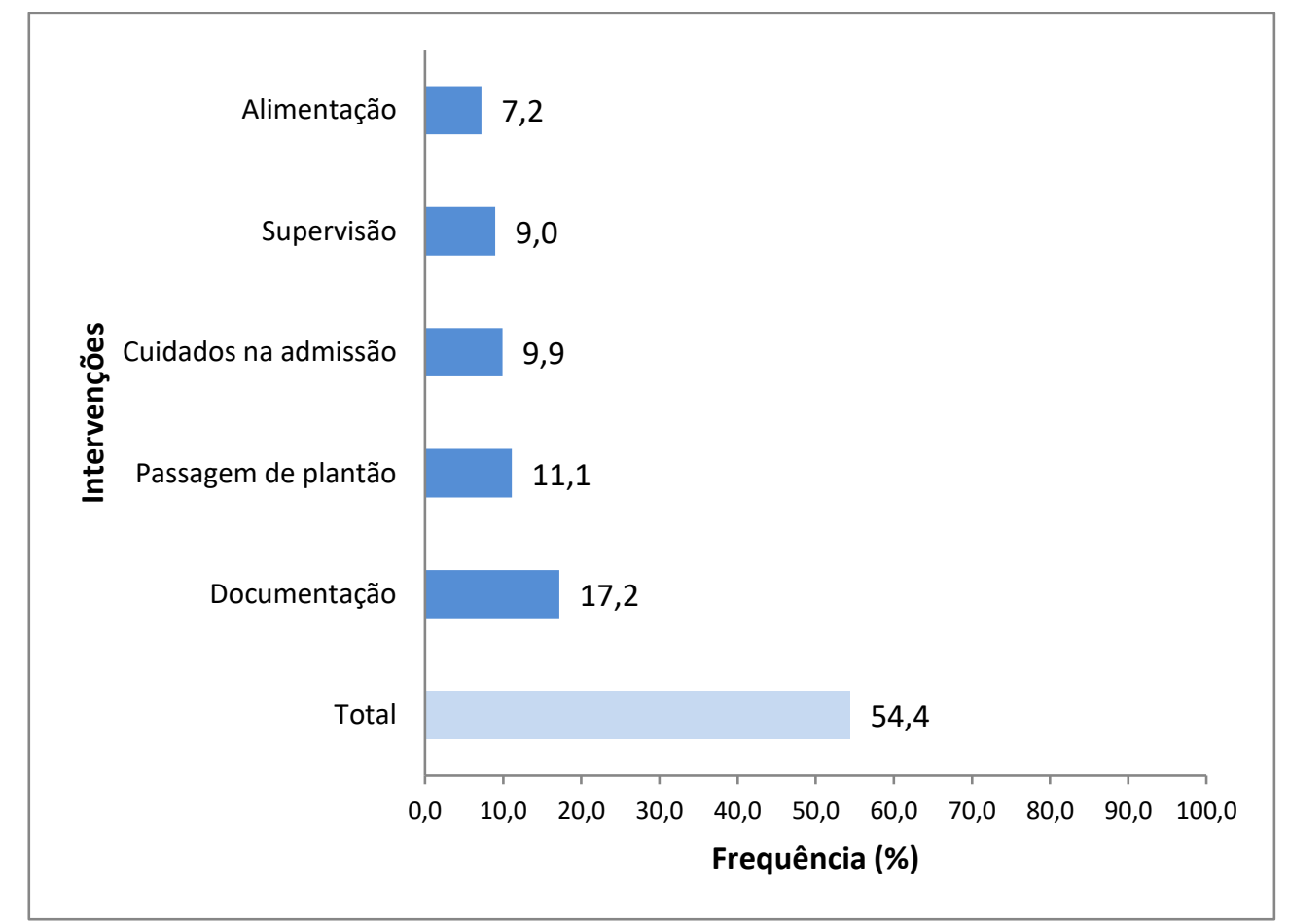

CC - Clínica Cirúrgica.

Fonte: Mello, 2011. 
Gráfico 59 - Distribuição das cinco intervenções mais frequentes observadas, realizadas por téc./aux. de enfermagem na CC. São Paulo, 2017.

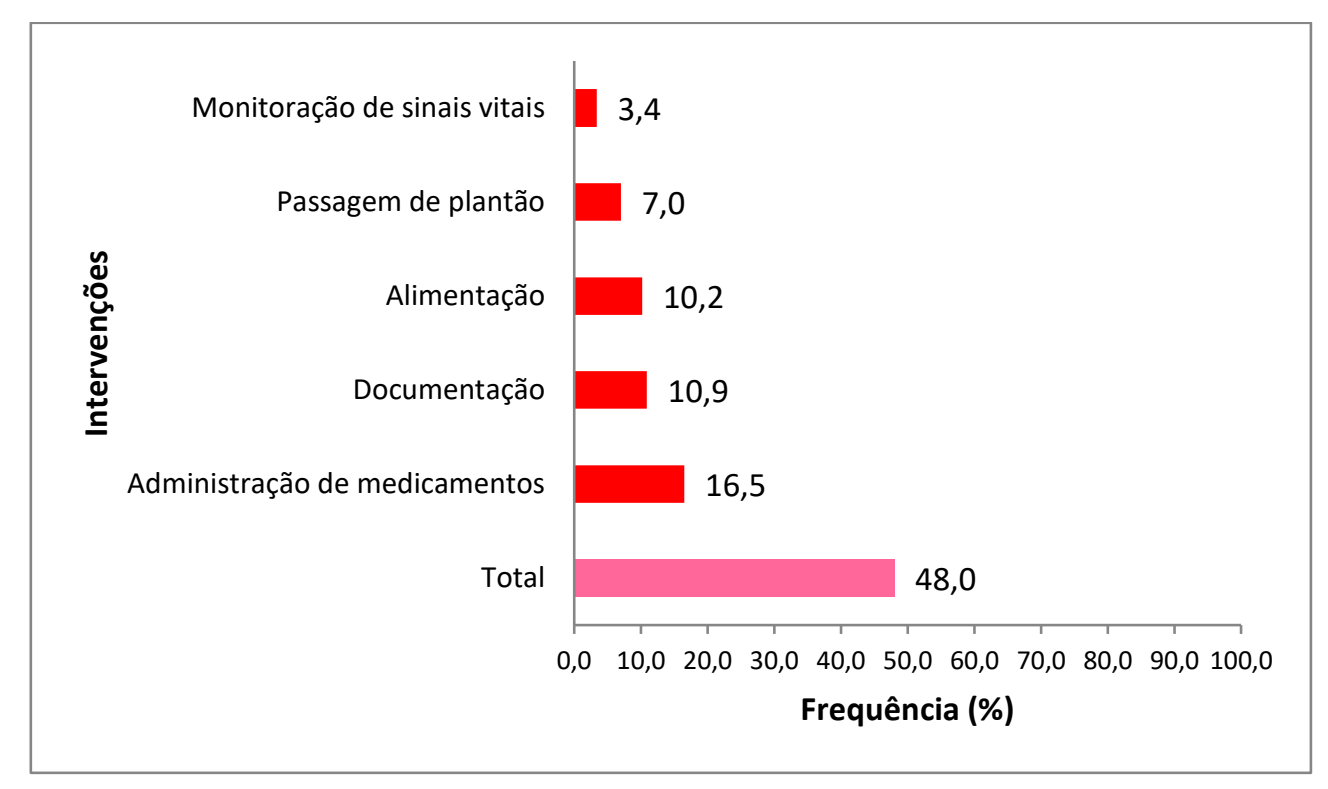

CC - Clínica Cirúrgica.

Fonte: Mello, 2011.

Os Gráficos 58 e 59 evidenciaram as cinco intervenções mais frequentes observadas na CC que corresponderam a $54,5 \%$ das observações dos enfermeiros e a $48 \%$ dos téc./aux. de enfermagem. A intervenção Documentação foi a mais frequente para a categoria de enfermeiros e, para os téc./aux. de enfermagem, foi Administração de medicamentos com frequência de $16,5 \%$.

Com relação ao tipo de cuidado, as intervenções de cuidado direto mais frequentes para os enfermeiros foram: Cuidados na admissão, Supervisão e Alimentação; para os téc./aux. de enfermagem foram: Administração de medicamentos, Alimentação e Monitoração de sinais vitais.

As intervenções de cuidado indireto mais frequentes para os enfermeiros e téc./aux. de enfermagem foram: Documentação e Passagem de plantão. 
Gráfico 60 - Distribuição das cinco intervenções mais frequentes observadas, realizadas por enfermeiros na CM. São Paulo, 2017.

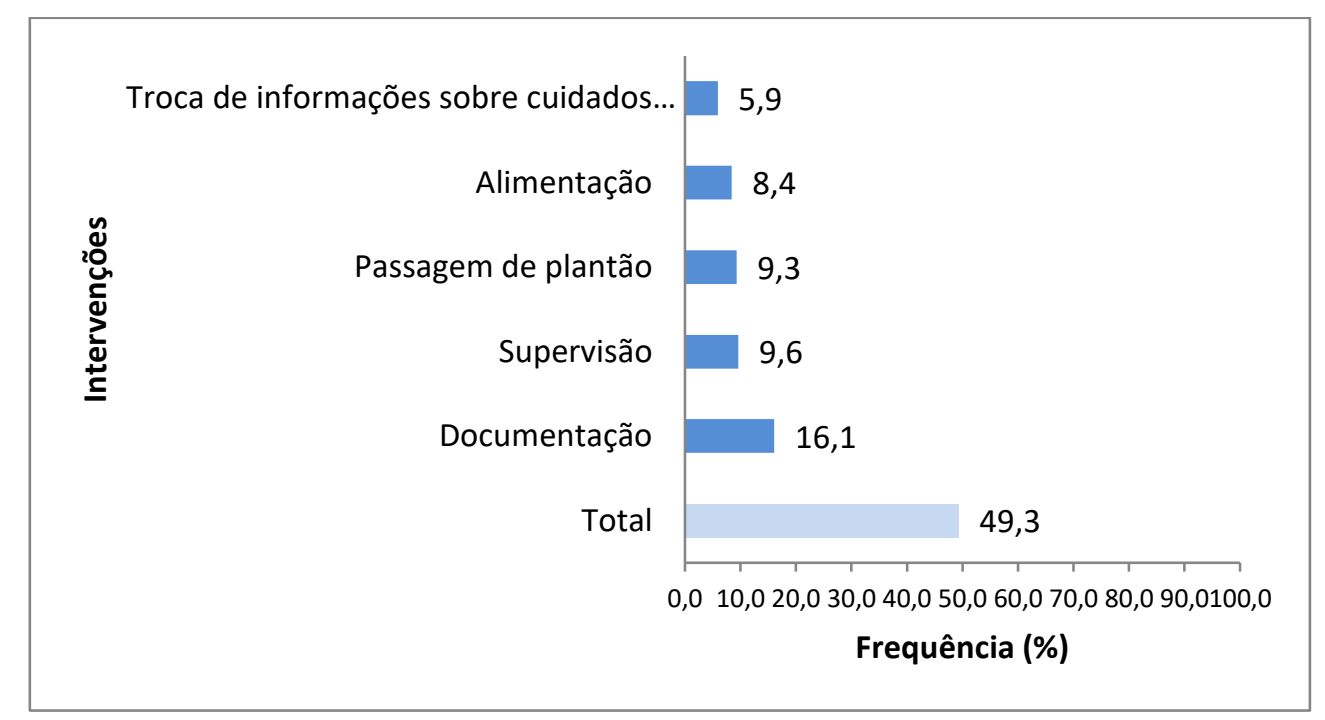

CM - Clínica Médica.

Fonte: Mello (2011).

Gráfico 61 - Distribuição das cinco intervenções mais frequentes observadas, realizadas por técnico/auxiliar de enfermagem na CM. São Paulo, 2017.

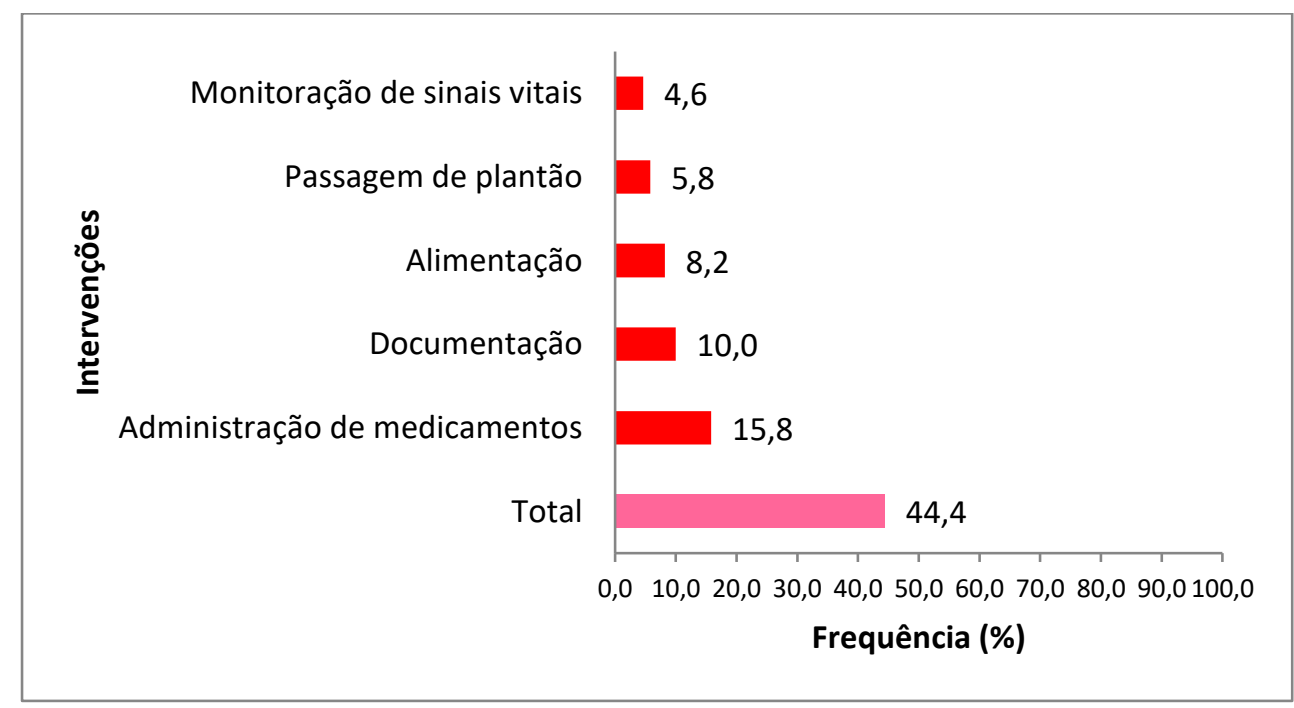

CM - Clínica Médica.

Fonte: Mello (2011).

Os Gráficos 60 e 61 evidenciaram as cinco intervenções mais frequentes observadas na CM que corresponderam a 49,3\% das observações dos enfermeiros e a $44,4 \%$ dos téc./aux. de enfermagem. 
A intervenção Documentação foi a mais frequente $(49,3 \%)$ para as categorias de enfermeiros e para os téc./aux. de enfermagem a intervenção Administração de medicamentos, a mais frequente $(15,8 \%)$.

Com relação ao tipo de cuidado, as intervenções de cuidado direto mais frequentes para os enfermeiros foram: Supervisão e Alimentação; para os téc./aux. de enfermagem foram: Administração de medicamentos, Alimentação, Monitoração de sinais vitais.

As intervenções de cuidado indireto mais frequentes para os enfermeiros foram: Documentação e Passagem de plantão e Troca de informações sobre cuidados de saúde; para os téc./aux. de enfermagem foi Documentação.

Gráfico 62 - Distribuição das cinco intervenções mais frequentes observadas, realizadas por enfermeiros na CM-CC. São Paulo, 2017.

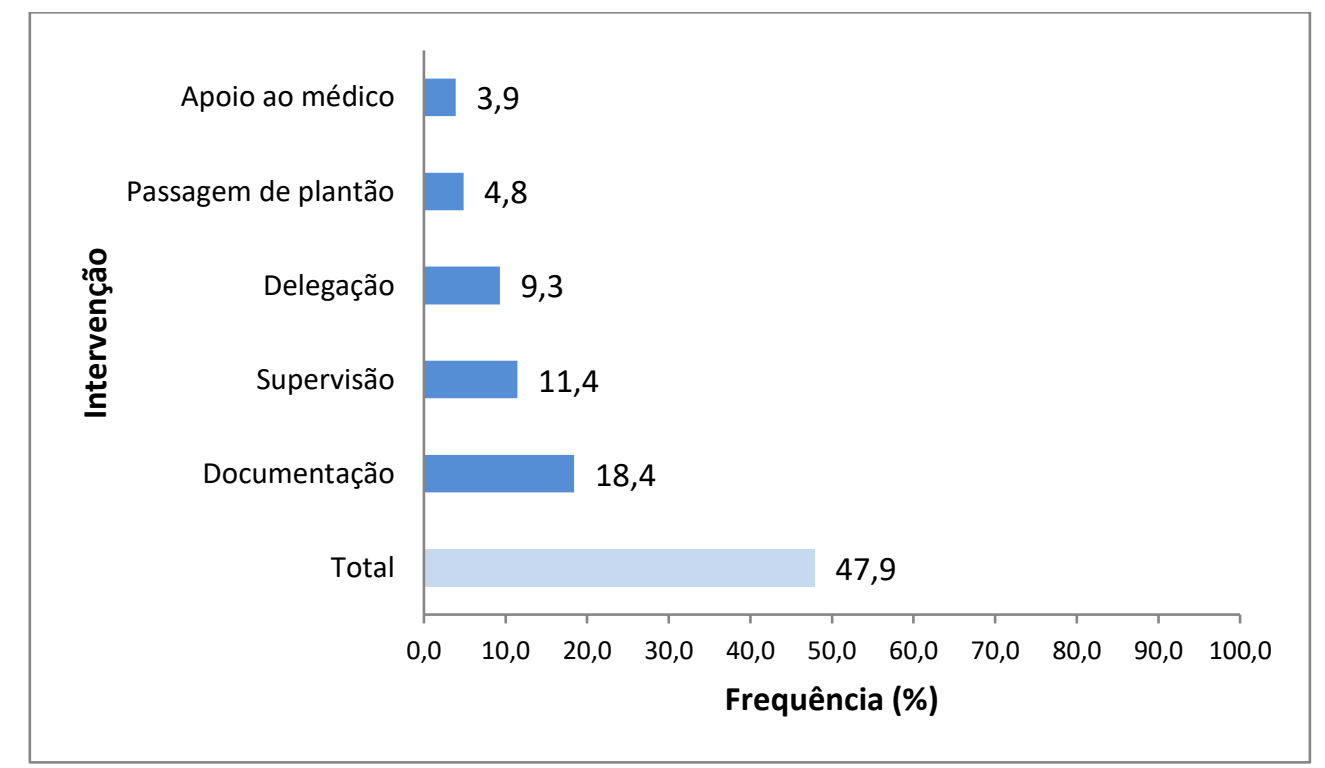

CM-CC - Clínica Médica e Clínica Cirúrgica.

Fonte: Bordin (2008).

O Gráfico 62 apresenta as cinco intervenções mais frequentes observadas na realização do trabalho do enfermeiro na $\mathrm{CM}-\mathrm{CC}$, as quais corresponderam a $47,9 \%$ das observações. A intervenção Documentação foi a mais frequente com $18,4 \%$ das observações. 
Com relação ao tipo de cuidado, a intervenção de cuidado direto mais frequente para os enfermeiros foi: Supervisão; para as intervenções de cuidado indireto: Delegação, Passagem de plantão e Apoio ao médico. A categoria téc./aux. de enfermagem não foi objeto do estudo de Bordin (2008).

Gráfico 63 - Distribuição das cinco intervenções mais frequentes observadas, realizadas por enfermeiros na EMER. São Paulo, 2017.

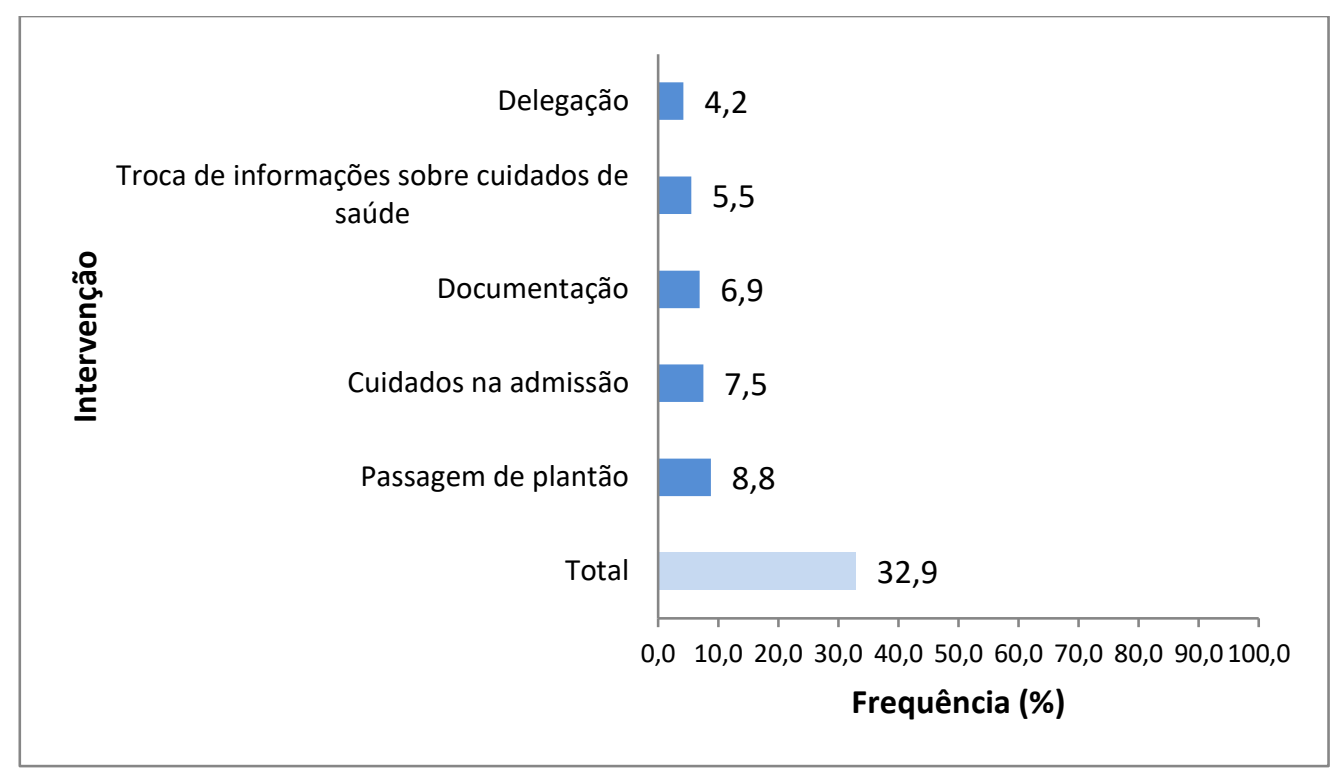

EMER - Emergência.

Fonte: Garcia, 2009.

O Gráfico 63 apresenta as cinco intervenções mais frequentes observadas na realização do trabalho do enfermeiro na EMER, as quais corresponderam a 32,9\% das observações. A intervenção Passagem de plantão foi a mais frequente com $8,8 \%$ delas.

Com relação ao tipo de cuidado, a intervenção de cuidado direto mais frequente para os enfermeiros foi: Cuidados na admissão; para as intervenções de cuidados indiretos: Passagem de plantão, Documentação, Troca de informações sobre cuidados de saúde e Delegação. A categoria téc./aux.de enfermagem não foi objeto do estudo de Garcia (2009). 
Gráfico 64 - Distribuição das cinco intervenções mais frequentes observadas, realizadas por enfermeiros na UTI-A. São Paulo, 2017.

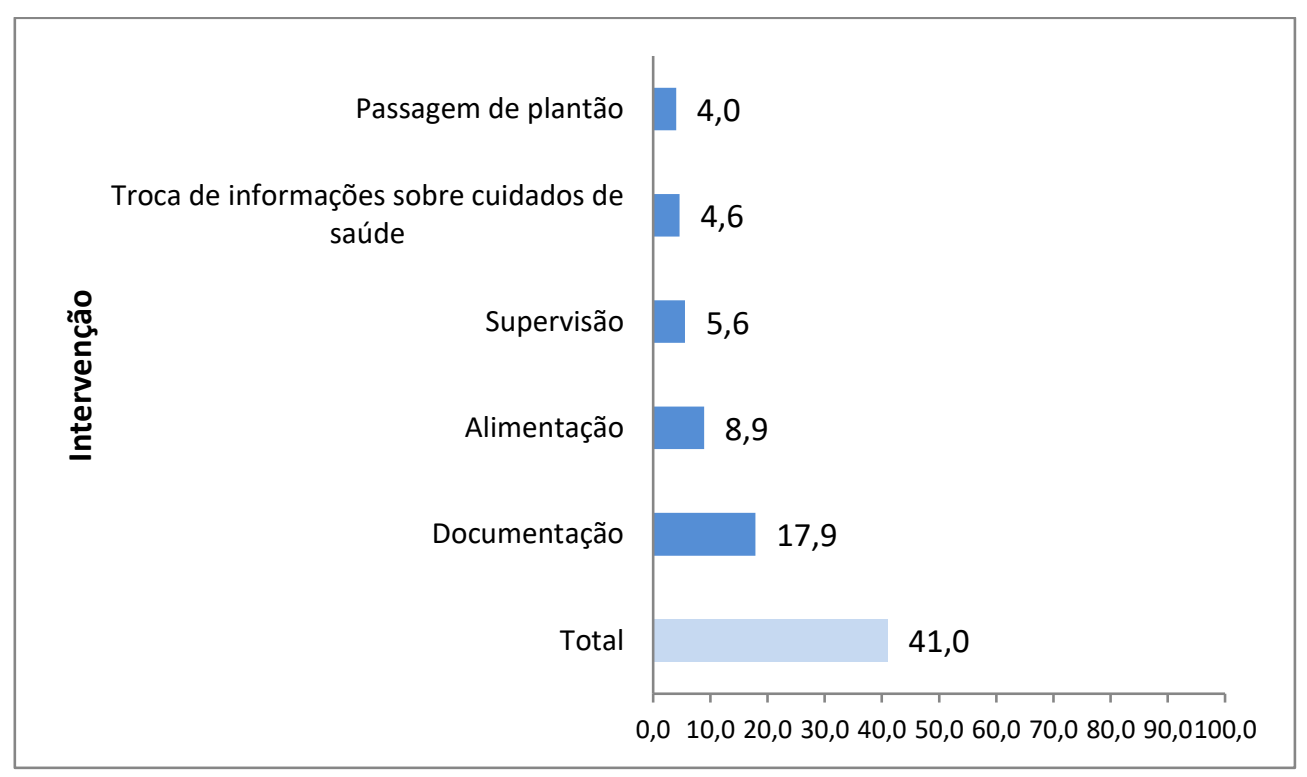

UTI-A - Unidade de Terapia Intensiva Adulto.

Fonte: Mello (2011).

Gráfico 65 - Distribuição das cinco intervenções mais frequentes observadas, realizadas por téc./aux.de enfermagem na UTI-A. São Paulo, 2017.

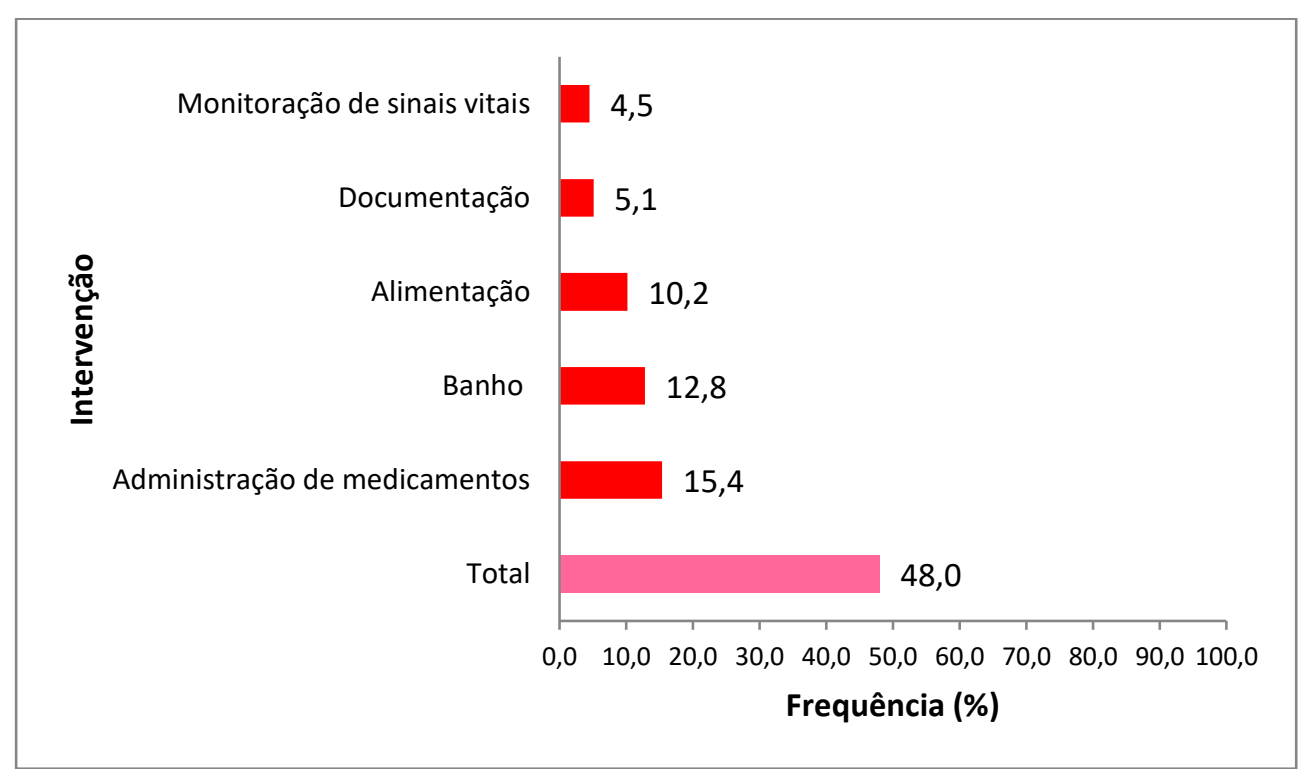

UTI-A - Unidade de Terapia Intensiva Adulto.

Fonte: Mello (2011).

Os Gráficos 64 e 65 evidenciam as cinco intervenções mais frequentes observadas na UTI-A que corresponderam a $41 \%$ das 
observações dos enfermeiros e a $48 \%$ dos téc./aux. de enfermagem. A intervenção Documentação foi a mais frequente $(17,9 \%)$ para a categoria de enfermeiros; e a intervenção Administração de medicamentos foi mais frequente para os téc./aux. de enfermagem com frequência de $15,4 \%$.

Com relação ao tipo de cuidado, as intervenções de cuidado direto mais frequentes para os enfermeiros foram: Alimentação e Supervisão; para os téc./aux.de enfermagem: Administração de medicamentos, Banho, Alimentação, Monitoração de sinais vitais.

As intervenções de cuidado indireto mais frequentes para os enfermeiros foram: Documentação, Troca de informações sobre cuidados de saúde e Passagem de plantão e; para os téc./aux. de enfermagem foi Documentação.

Gráfico 66 - Distribuição das cinco intervenções mais frequentes observadas, realizadas por enfermeiros no CCO. São Paulo, 2017.

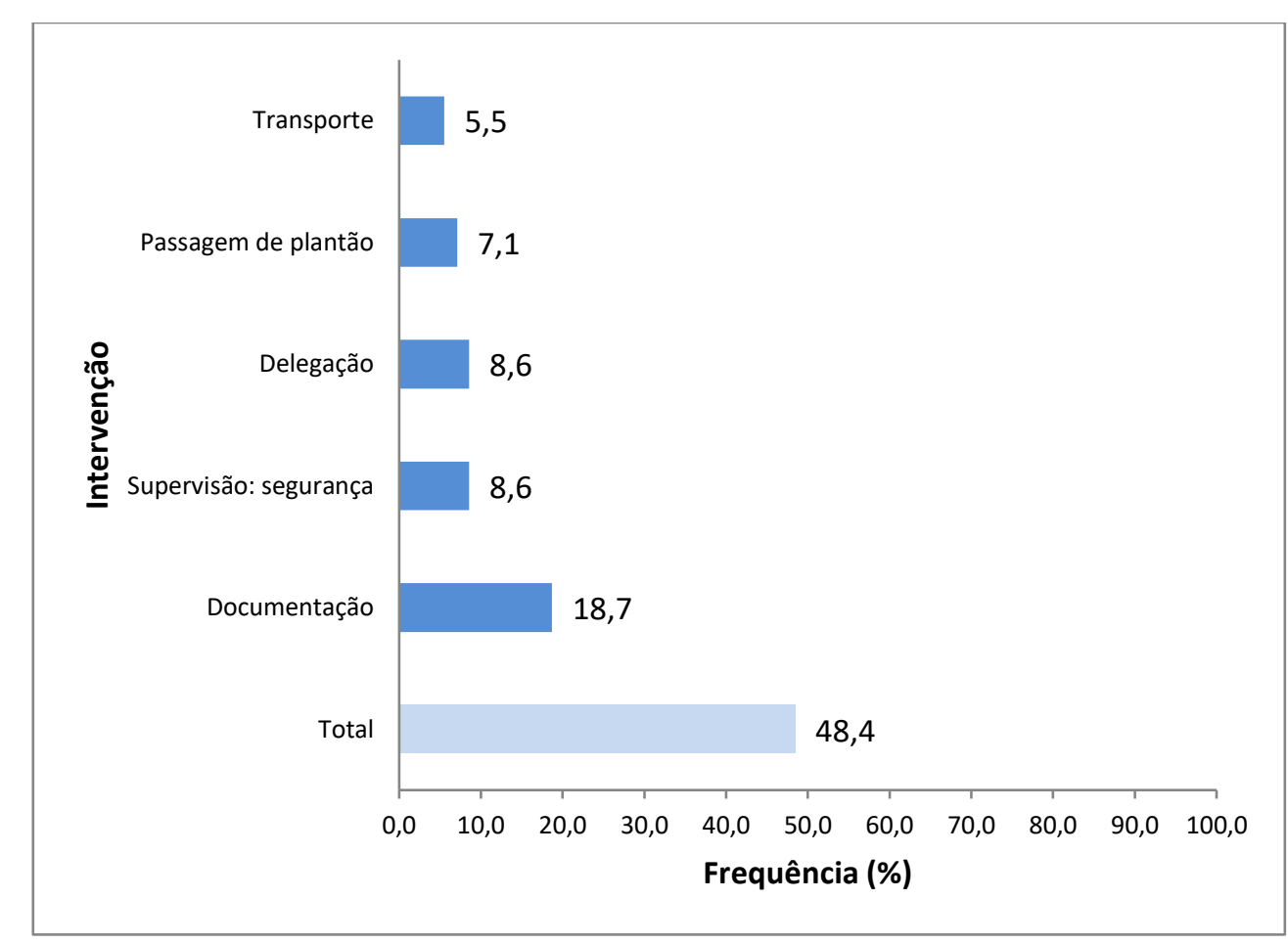

CCO - Centro Cirúrgico de Oncologia.

Fonte: Possari (2011). 
Gráfico 67 - Distribuição das cinco intervenções mais frequentes observadas, realizadas por téc./aux.de enfermagem no CCO. São Paulo, 2017.

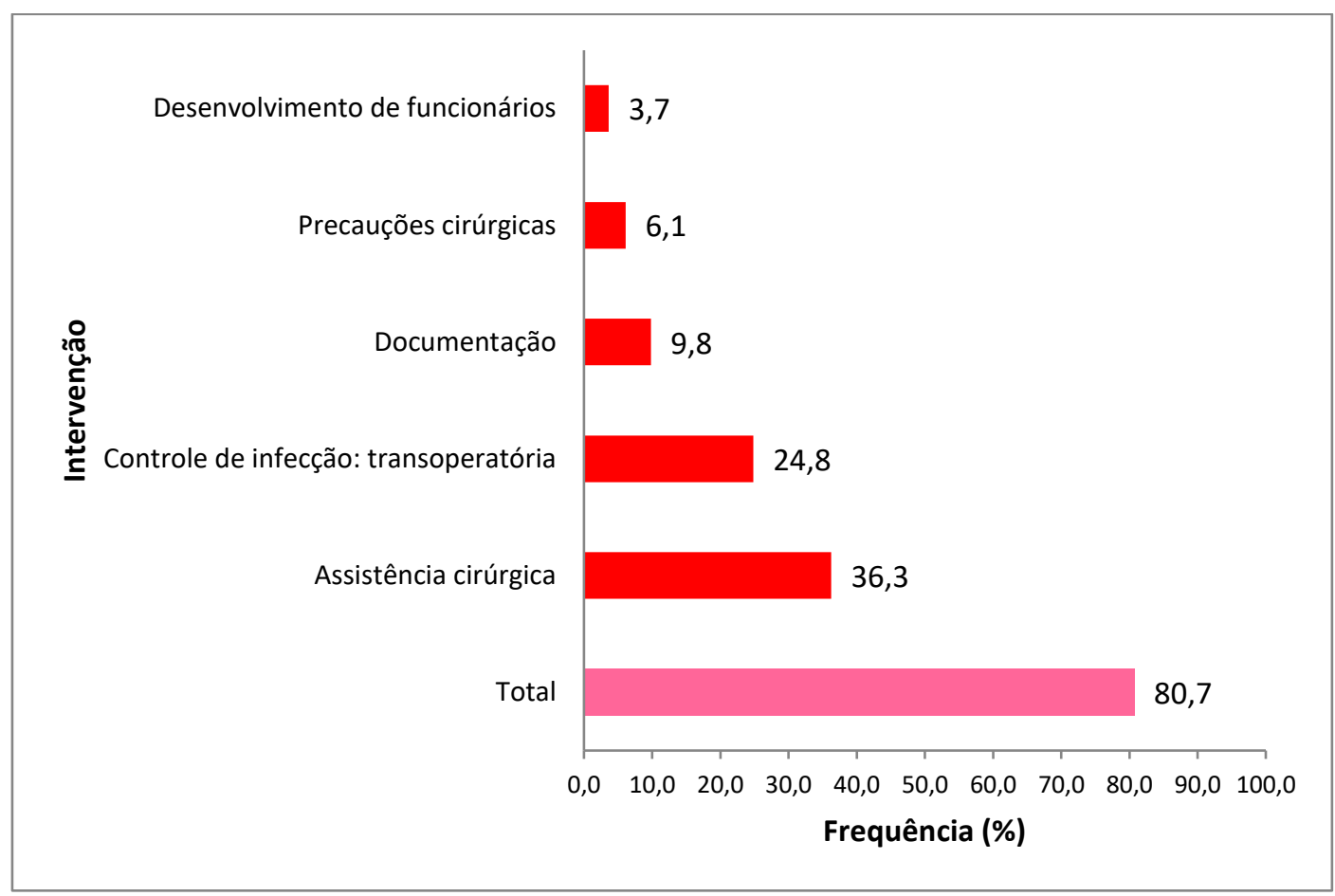

CCO - Centro Cirúrgico de Oncologia.

Fonte: Possari (2011).

Os Gráficos 66 e 67 evidenciaram as cinco intervenções mais frequentes observadas no CCO, que corresponderam a $48,4 \%$ das observações dos enfermeiros e a $80,7 \%$ dos aux./tec. de enfermagem. A intervenção Documentação foi a mais frequente $(18,7 \%)$ para as categorias de enfermeiros e para os téc./aux. de enfermagem a intervenção Assistência cirúrgica foi a mais frequente (36,3\%).

Com relação ao tipo de cuidado, as intervenções de cuidado direto mais frequentes para os enfermeiros foram: Supervisão: segurança e Transporte; para os téc./aux. de enfermagem: Assistência cirúrgica, Controle de infecção: transoperatório e Precauções cirúrgicas.

As intervenções de cuidado indireto mais frequentes para os enfermeiros foram: Documentação, Delegação e Passagem de plantão e; para os téc/aux. de enfermagem foi Documentação e Desenvolvimento de funcionários. 
Gráfico 68 - Distribuição das cinco intervenções mais frequentes observadas, realizadas por enfermeiros na SRPA. São Paulo, 2017.

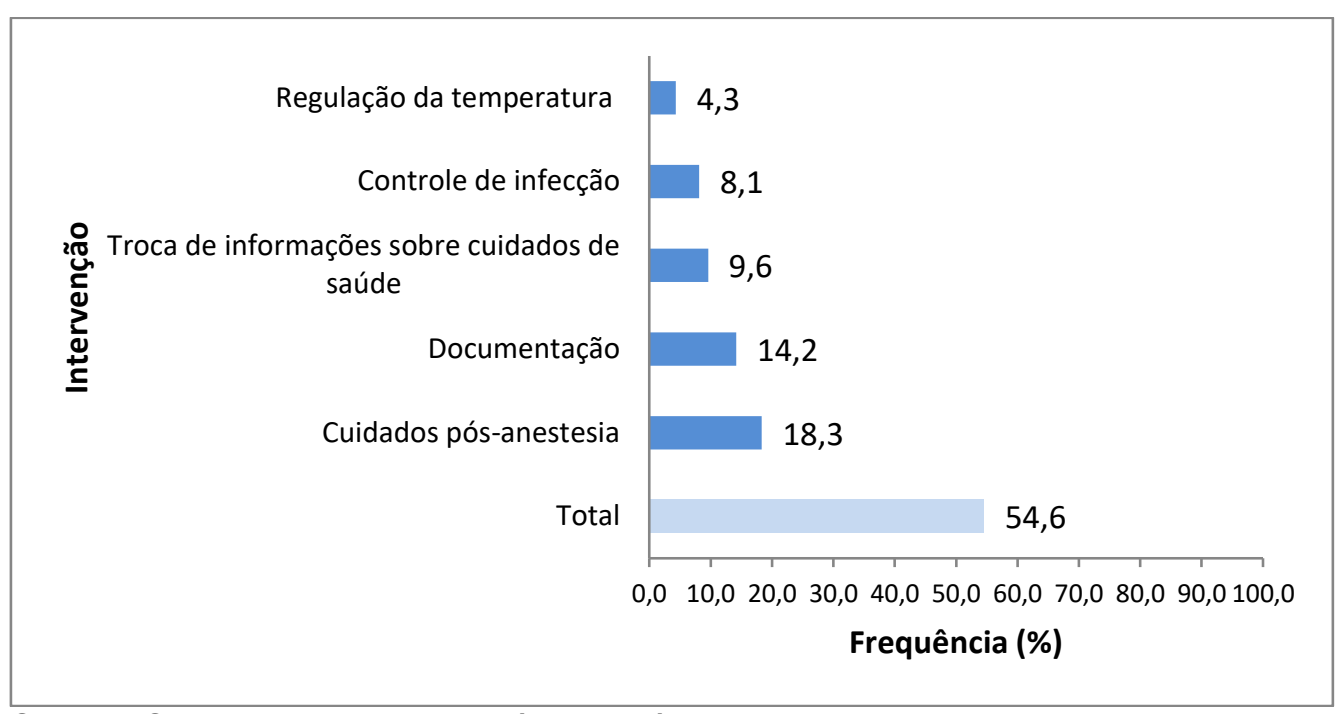

SRPA - Sala de Recuperação Pós-Anestésica.

Fonte: Ricardo (2013).

Gráfico 69 - Distribuição das cinco intervenções mais frequentes observadas, realizadas por téc./aux.de enfermagem na SRPA. São Paulo, 2017.

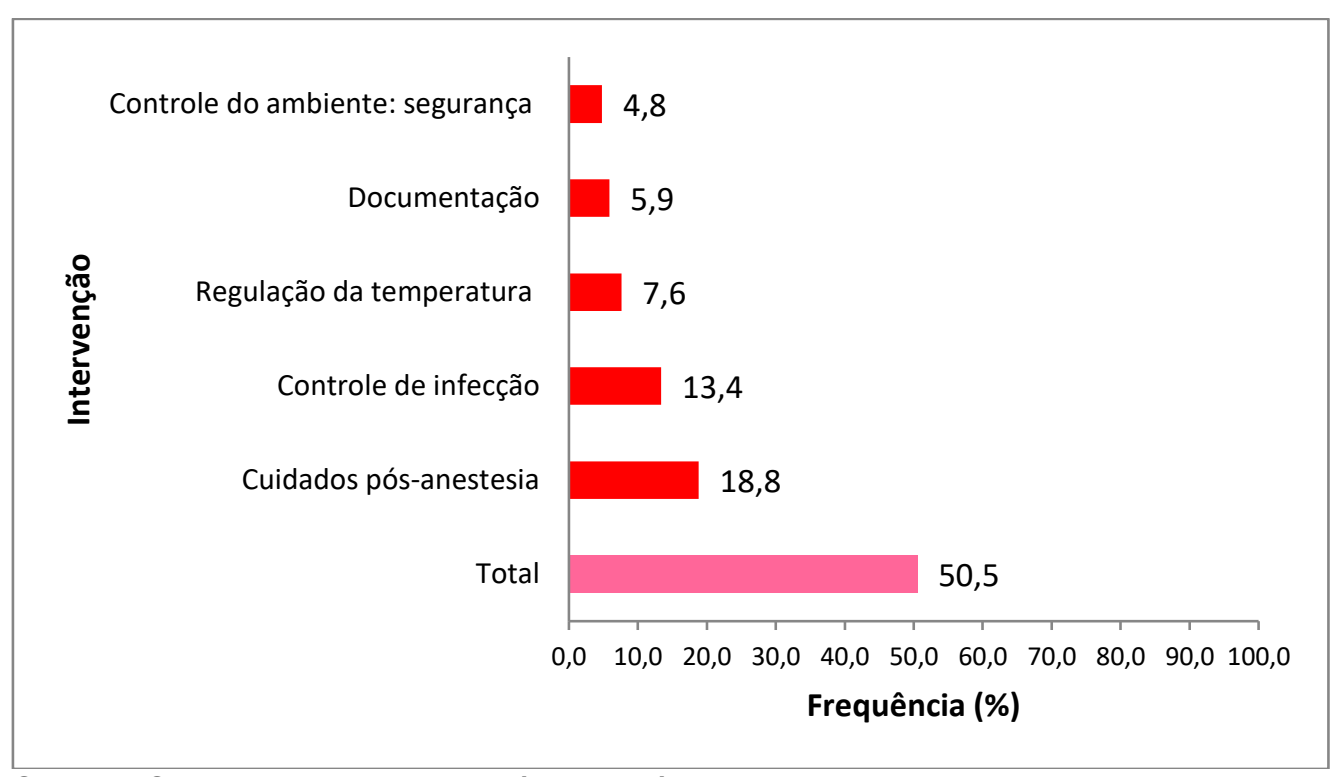

SRPA - Sala de Recuperação Pós-Anestésica.

Fonte: Ricardo (2013).

Os Gráficos 68 e 69 evidenciam as cinco intervenções mais frequentes observadas na SRPA, que corresponderam a 54,6 \%, das observações dos enfermeiros e a 50,5\% dos téc./aux. de enfermagem. 
A intervenção Cuidados pós-anestesia foi a mais frequente para as categorias de enfermeiros e para os téc./aux. de enfermagem e corresponderam, respectivamente, a 18,3\% e 18,8\%.

Com relação ao tipo de cuidado, as intervenções de cuidado direto mais frequentes para os enfermeiros foram: Cuidados pós-anestesia, Controle de infecção e Regulação da temperatura; para os téc./aux.de enfermagem: Cuidados pós-anestesia, Controle de infecção, Regulação da temperatura e Controle do ambiente: segurança.

As intervenções de cuidado indireto mais frequentes para os enfermeiros foram: Documentação e Troca de informações sobre cuidados de saúde; para os téc./aux. de enfermagem foi Documentação.

Gráfico 70 - Distribuição das cinco intervenções mais frequentes observadas, realizadas por enfermeiros no AEOH. São Paulo, 2017.

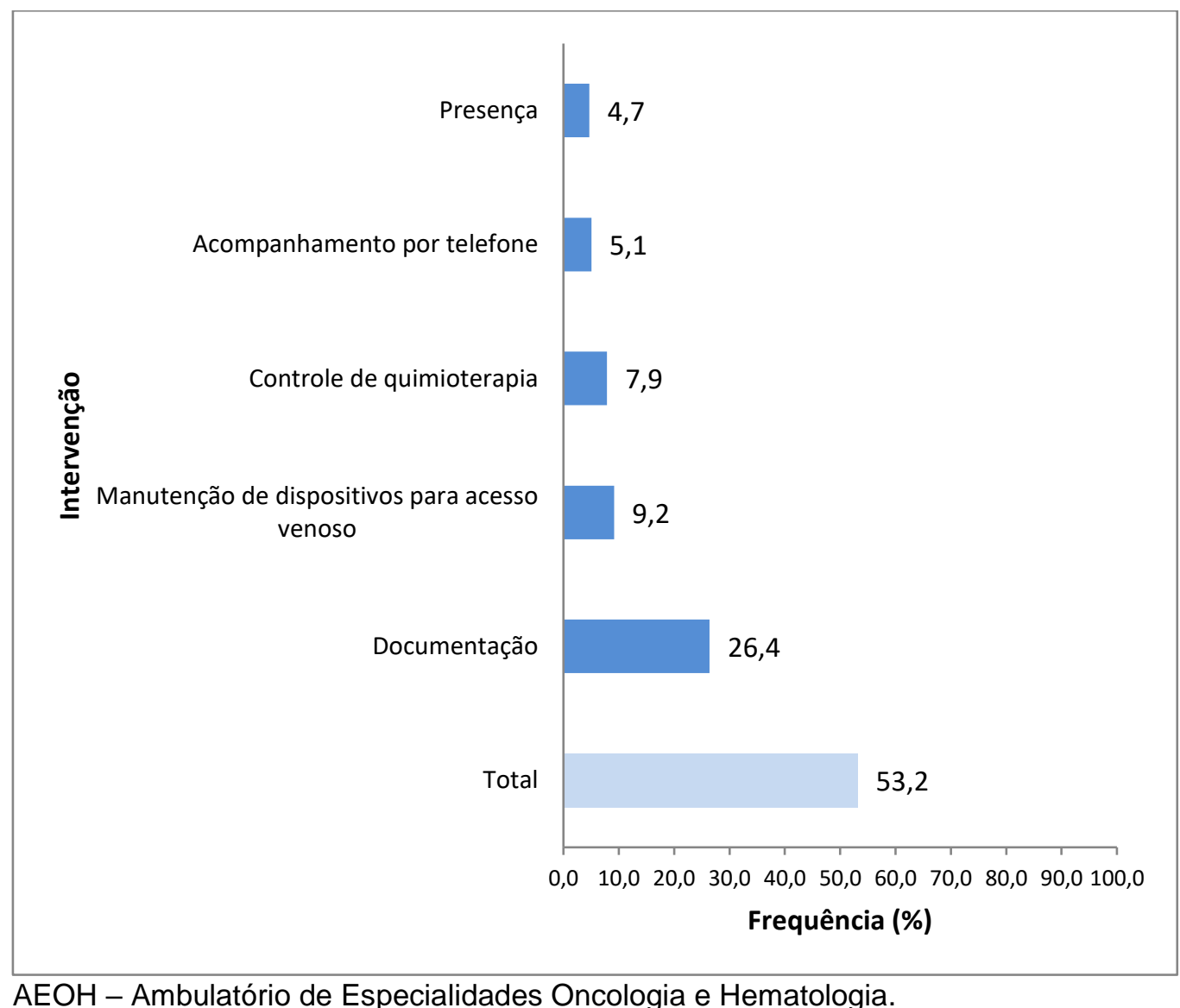

Fonte: Martin (2013). 
Gráfico 71 - Distribuição das cinco intervenções mais frequentes observadas, realizadas por téc./aux. de enfermagem no AEOH. São Paulo, 2017.

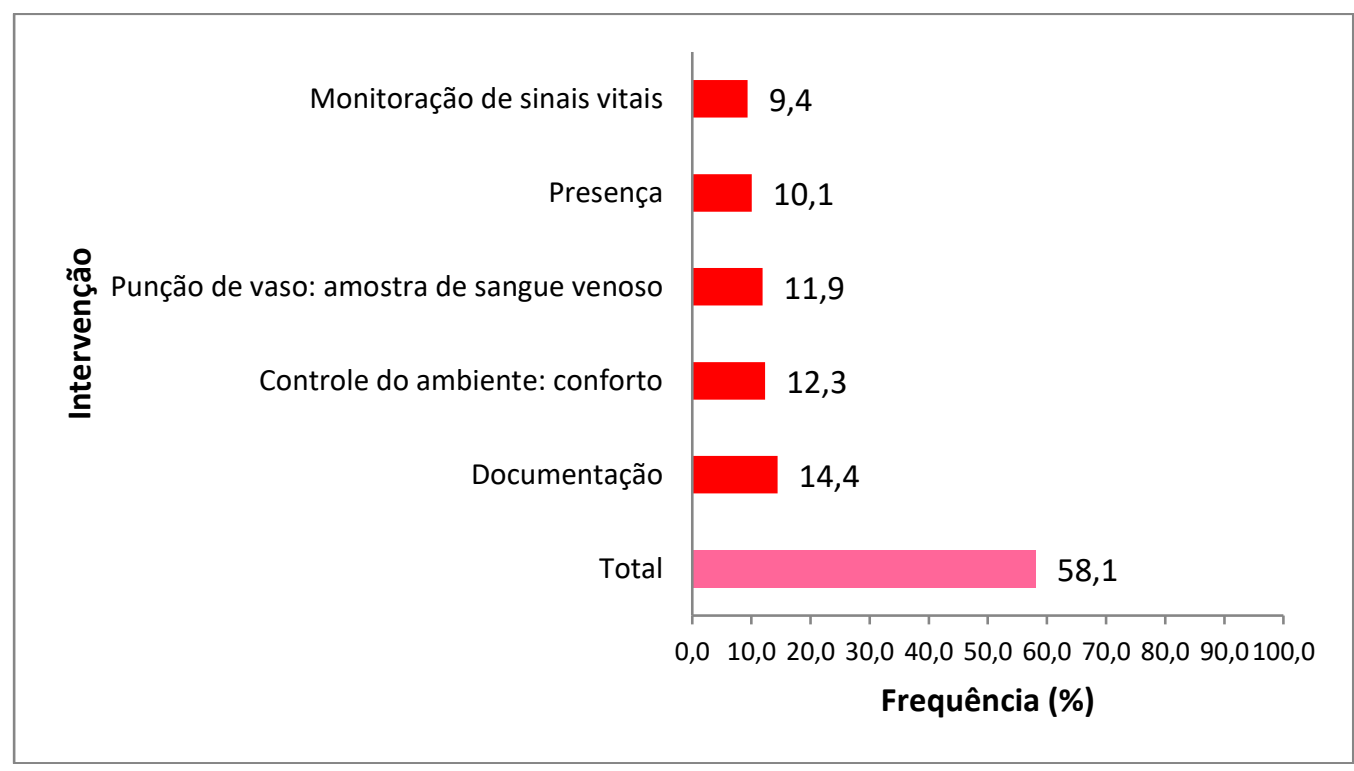

AEOH - Ambulatório de Especialidades Oncologia e Hematologia.

Fonte: Martin (2013).

Os Gráficos 70 e 71 evidenciaram as cinco intervenções mais frequentes observadas no $\mathrm{AEOH}$, que corresponderam a 53,2\% das observações dos enfermeiros e a $58,1 \%$ dos téc./aux. de enfermagem. A intervenção Documentação foi a mais frequente para as categorias de enfermeiros e de téc./aux. de enfermagem e correspondeu, respectivamente, a $26,4 \%$ e $14,4 \%$.

Com relação ao tipo de cuidado, as intervenções de cuidado direto mais frequentes para os enfermeiros foram: Manutenção de dispositivo para acesso venoso, Controle de quimioterapia e Presença; para os téc./aux. de enfermagem: Controle do ambiente: conforto, Punção de amostra de sangue venoso e Monitoração de sinais vitais.

As intervenções de cuidado indireto mais frequentes para os enfermeiros foram: Documentação e Acompanhamento por telefone; para os téc./aux. de enfermagem foi Documentação. 
Gráfico 72 - Distribuição das cinco intervenções mais frequentes observadas, realizadas por enfermeiros no CDI. São Paulo, 2017.

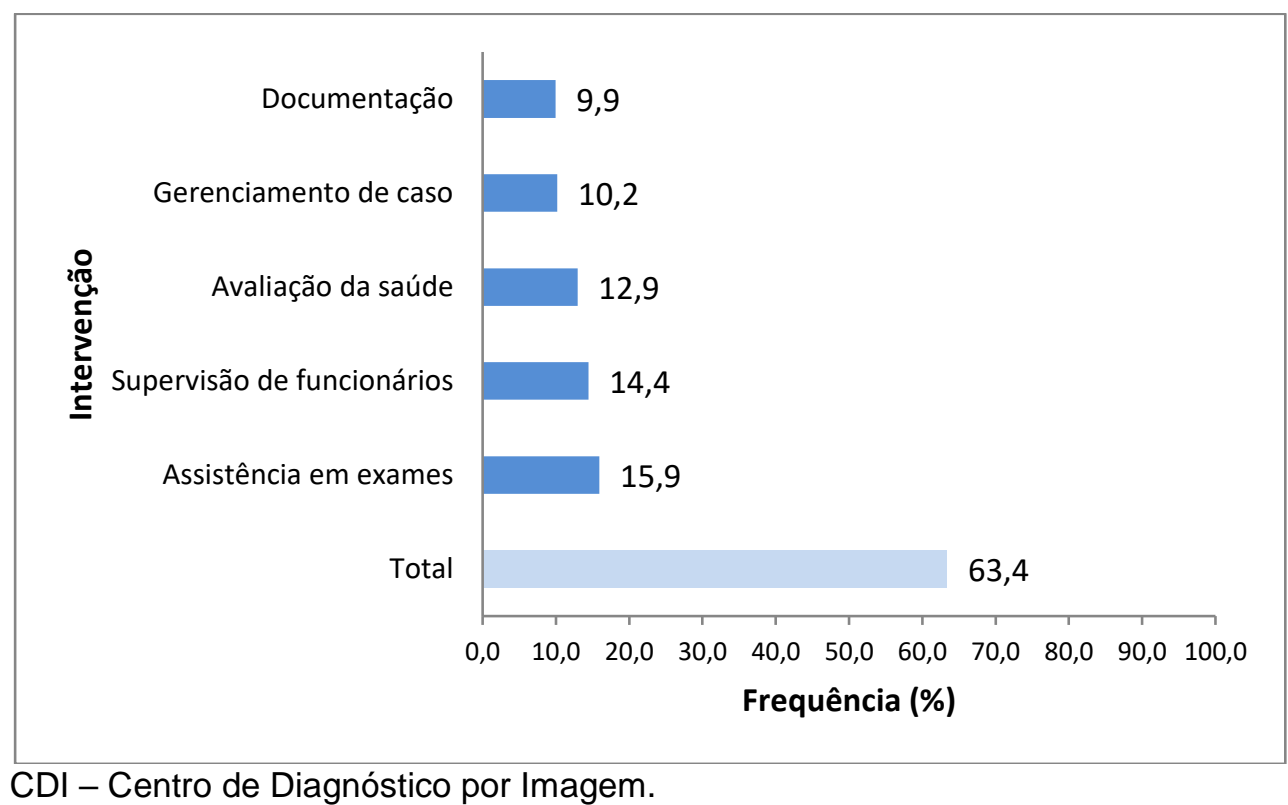

Fonte: Cruz (2015).

Gráfico 73 - Distribuição das cinco intervenções mais frequentes observadas, realizadas por téc./aux. de enfermagem no CDI. São Paulo, 2017.

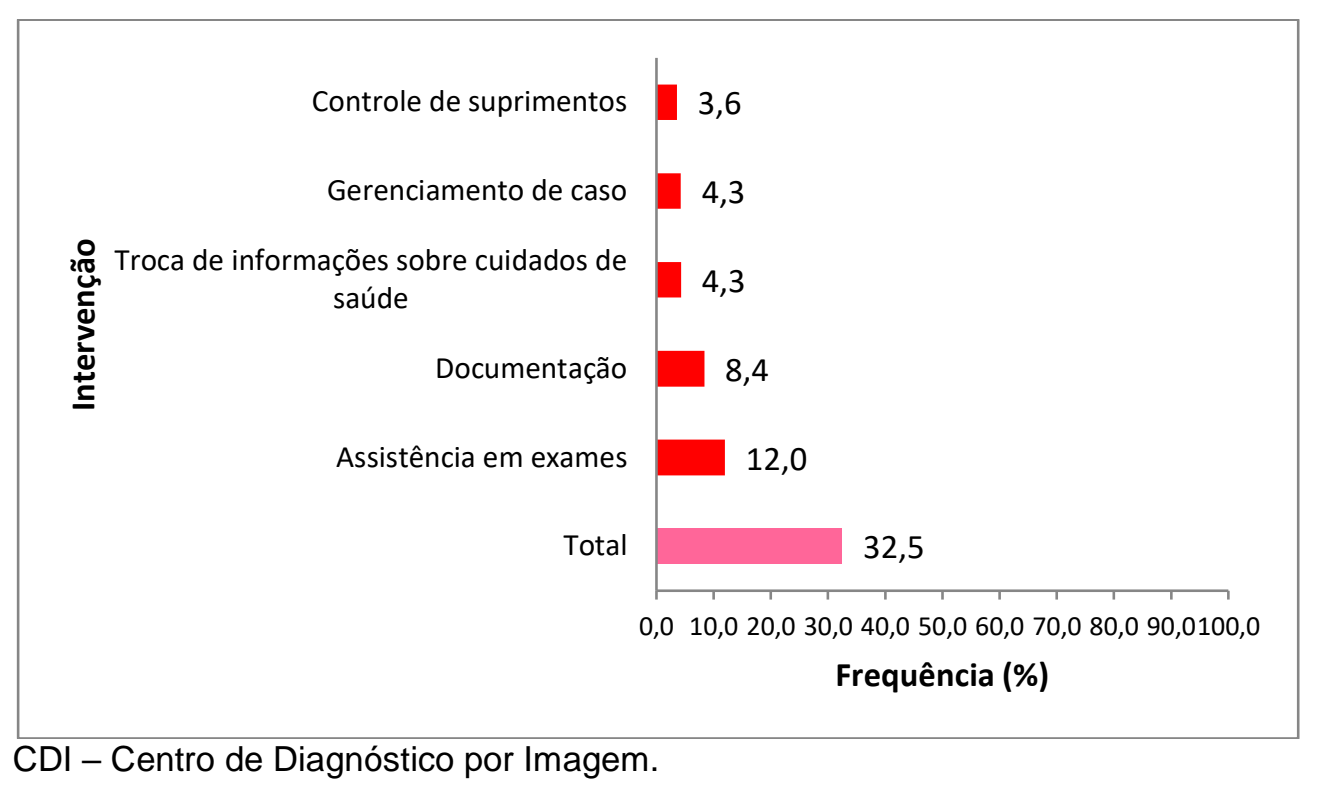

Fonte: Cruz (2015).

Os Gráficos 72 e 73 evidenciaram as cinco intervenções mais frequentes observadas no centro de diagnóstico por imagem, que 
corresponderam a $63,4 \%$ das observações dos enfermeiros e a $32,5 \%$ dos téc./aux. de enfermagem. A intervenção Assistência em exames foi a mais frequente para as categorias de enfermeiros e de téc./aux. de enfermagem correspondeu, respectivamente, a 15,9\% e $12 \%$.

Com relação ao tipo de cuidado, as intervenções de cuidado direto mais frequentes para os enfermeiros foram: Assistência em exames e Avaliação da saúde; para os téc./aux. de enfermagem foi: Assistência em exames.

As intervenções de cuidado indireto mais frequentes para os enfermeiros foram: Supervisão de funcionários, Gerenciamento de caso e Documentação; para os téc./aux. de enfermagem foi Documentação, Troca de informações sobre cuidados de saúde, Gerenciamento de caso e Controle de suprimentos.

Gráfico 74 - Distribuição das cinco intervenções mais frequentes observadas, realizadas por enfermeiros na USF. São Paulo, 2017.

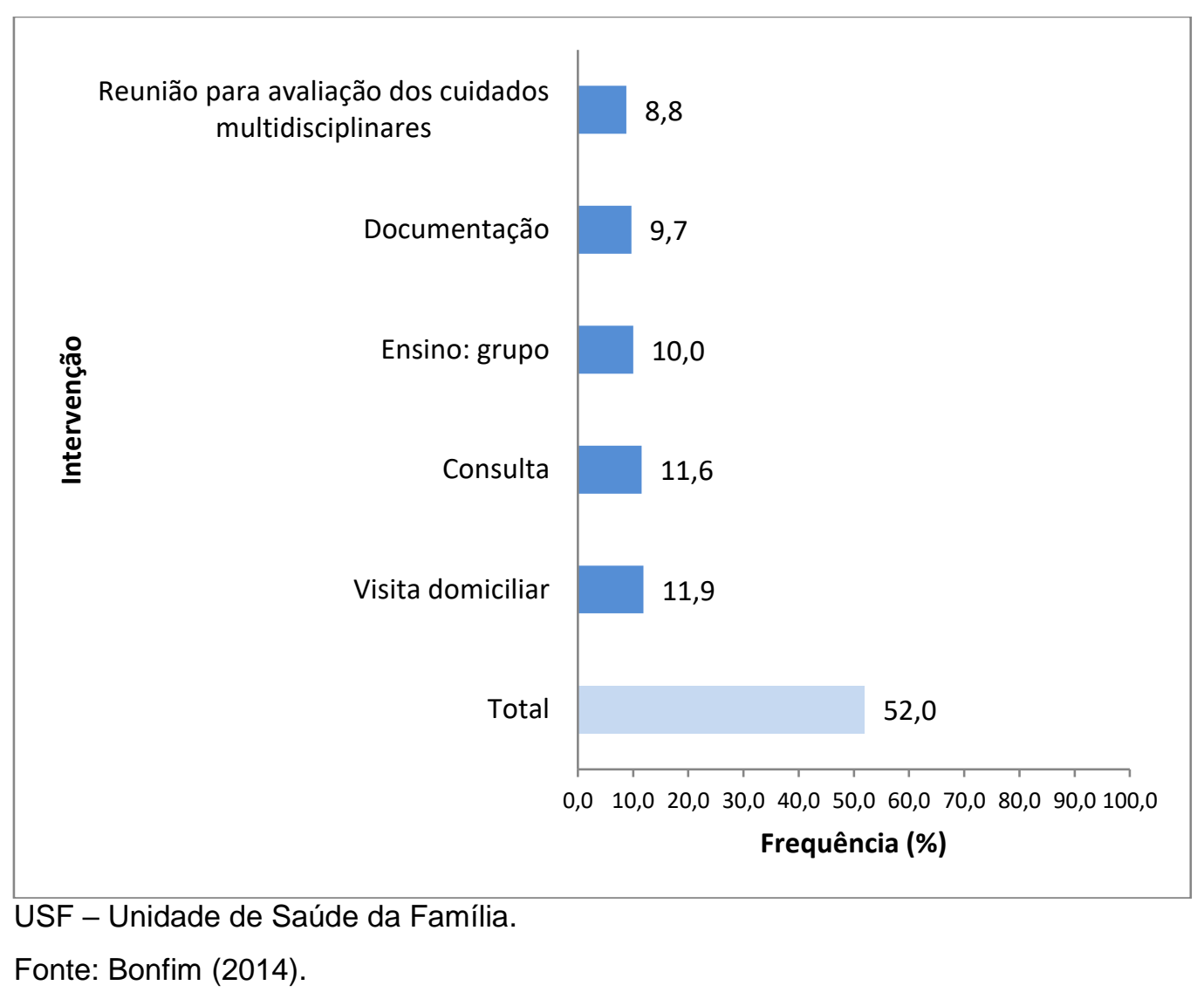


Gráfico 75 - Distribuição das cinco intervenções mais frequentes observadas, realizadas por téc./aux. de enfermagem na USF. São Paulo, 2017.

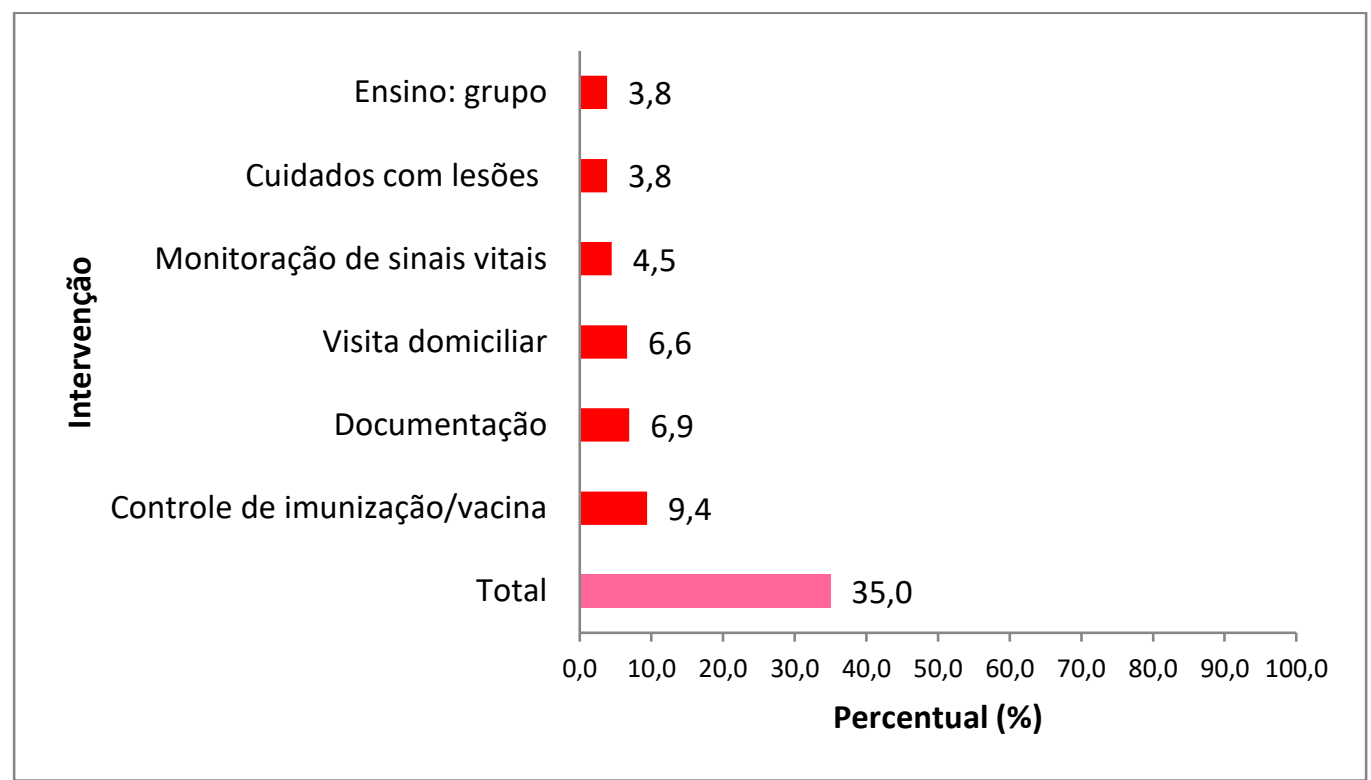

USF - Unidade de Saúde da Família.

Fonte: Bonfim (2014).

Os Gráficos 74 e 75 por se tratarem de duas USF (USF 1 e USF 2), os resultados referentes às cinco intervenções mais frequentes foram semelhantes; dessa forma, nos gráficos apresentados, os resultados foram agrupados. Evidenciam as cinco intervenções mais frequentes observadas que corresponderam a $52 \%$ das observações dos enfermeiros e $35 \%$ das observações dos téc./aux. de enfermagem. A intervenção Visita domiciliar foi a mais frequente (11,9\%) para a categoria de enfermeiros; e a intervenção Controle de imunização/vacina foi mais frequente $(9,4 \%)$ para os téc./aux. de enfermagem.

Com relação ao tipo de cuidado, as intervenções de cuidado direto mais frequentes para os enfermeiros foram: Visita domiciliar e Consulta; para os téc./aux. de enfermagem: Controle de imunização/vacina, Visita domiciliar e Cuidado com lesões.

As intervenções de cuidado indireto mais frequentes para os enfermeiros foram: Documentação e Reunião para avaliação dos cuidados multidisciplinares; para os téc./aux. de enfermagem foi Documentação. 
Gráfico 76 - Distribuição das cinco intervenções mais frequentes observadas, realizadas pelo ATA na USF. São Paulo, 2017.

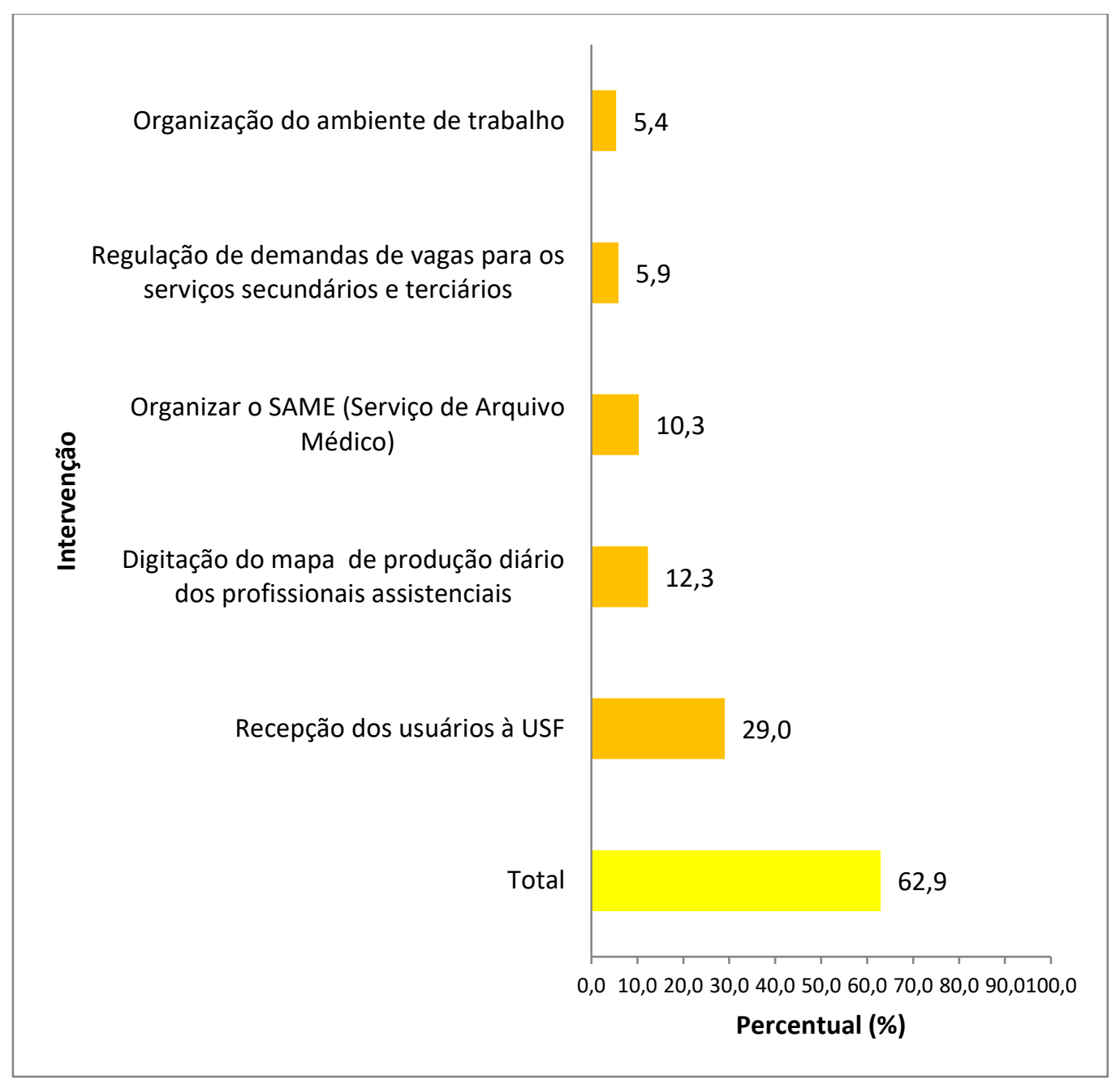

Fonte: Leal (2014).

O Gráfico 76 apresenta as cinco intervenções mais frequentes observadas no trabalho do ATA na realização do seu trabalho na USF, que corresponderam a $62,9 \%$ das observações. A intervenção Recepção dos usuários à USF foi a mais frequente (29\%).

Dentre as intervenções apresentadas, a Recepção dos usuários pode ser classificada como intervenção de cuidado direto. As demais encontradas, com exceção da Organização do ambiente de trabalho, estão relacionadas à Documentação e podem ser classificadas como intervenções de cuidado indireto. 
Gráfico 77 - Distribuição das cinco intervenções mais frequentes observadas, realizadas por nutricionistas clínicos nas unidades hospitalares. São Paulo, 2017.

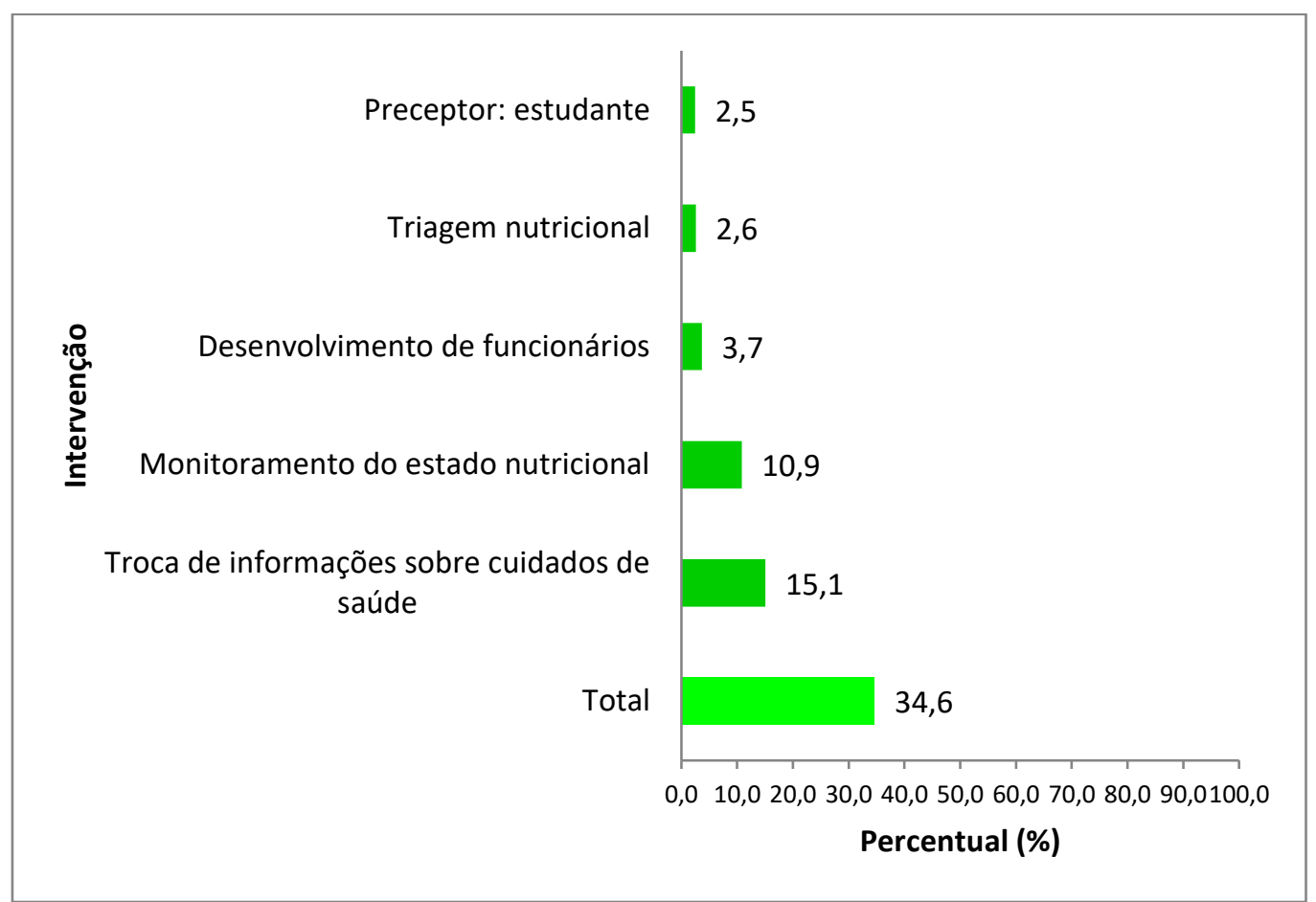

Fonte: Oliveira (2016).

O Gráfico 77 apresenta as cinco intervenções mais frequentes observadas na realização do trabalho dos nutricionistas clínicos na unidade hospitalar, que corresponderam a $34,6 \%$ das observações. A intervenção Troca de informações sobre cuidados de saúde $(15,1 \%)$ foi a mais frequente.

Com relação ao tipo de cuidado, as intervenções classificadas em cuidado direto mais frequentes para os nutricionistas foram: Monitoramento do estado nutricional e Triagem nutricional; e as intervenções classificadas em cuidado indireto mais frequentes foram: Troca de informações sobre cuidados de saúde, Desenvolvimento de funcionários e Preceptor: estudante.

O Quadro 18 apresenta o elenco das cinco intervenções mais frequentes, apresentadas em cada um dos estudos analisados, em que se observa o conjunto de 43 intervenções que contribuíram de forma expressiva para a carga de trabalho dos profissionais de saúde. 
Quadro 18 - Elenco das 43 intervenções mais frequentes no conjunto dos 16 estudos analisados. São Paulo, 2017.

\begin{tabular}{|c|l|c|l|}
\hline 1 & Acompanhamento por telefone & 23 & Desenvolvimento de funcionários \\
\hline 2 & Administração de medicamentos & 24 & Documentação \\
\hline 3 & Alimentação & 25 & Gerenciamento de caso \\
\hline 4 & Apoio ao médico & 26 & $\begin{array}{l}\text { Manutenção de dispositivo para } \\
\text { acesso venoso }\end{array}$ \\
\hline 5 & Assistência cirúrgica & 27 & Monitoração de sinais vitais \\
\hline 6 & Assistência em exames & 28 & $\begin{array}{l}\text { Monitoramento do estado } \\
\text { nutricional }\end{array}$ \\
\hline 7 & Assistência na amamentação & 29 & Passagem de plantão \\
\hline 8 & Avaliação da saúde & 30 & Preceptor: estudante. \\
\hline 9 & Banho & 31 & Presença \\
\hline 10 & Consulta & 32 & $\begin{array}{l}\text { Punção de amostra de sangue } \\
\text { venoso }\end{array}$ \\
\hline 11 & Controle de imunização/vacina & 33 & Recepção dos usuários \\
\hline 12 & Controle de infecção & 34 & Regulação da temperatura \\
\hline 13 & $\begin{array}{l}\text { Controle de infecção: transoperatório } \\
\text { e Precauções cirúrgicas. }\end{array}$ & 35 & $\begin{array}{l}\text { Reunião para avaliação dos } \\
\text { cuidados multidisciplinares }\end{array}$ \\
\hline 14 & Controle de quimioterapia & 36 & Supervisão \\
\hline 15 & Controle de suprimentos & 37 & Supervisão de funcionários \\
\hline 16 & Controle do ambiente & 38 & Supervisão: segurança \\
\hline 17 & Controle do ambiente: conforto & 39 & Terapia de diálise peritoneal \\
\hline 18 & Controle do ambiente: segurança. & 40 & Transporte \\
\hline 19 & Cuidado com lesões & 41 & Triagem nutricional \\
\hline 20 & Cuidados na admissão & $\begin{array}{l}\text { Troca de informações sobre } \\
\text { cuidados de saúde }\end{array}$ \\
\hline 21 & Cuidados pós-anestesia & Visita domiciliar \\
\hline 22 & Delegação & & \\
\hline & & & \\
\hline 1 & & & \\
\hline
\end{tabular}

As intervenções apresentadas no Quadro 18 representam àquelas que mais contribuíram para a carga de trabalho e evidenciaram a especialidade da unidade e da categoria profissional analisada.

Destaca-se que uma das limitações deste estudo foi a dificuldade em analisar o tempo despendido, em horas de cuidado, nas intervenções, pois os métodos para aferir esse tipo de tempo variaram entre os estudos. 
Os mais recentes consideraram que o tempo despendido com as atividades pessoais, atividades associadas e deslocamentos dentro da instituição de saúde deveriam ser rateados nas intervenções de cuidados diretos e indiretos, bem como o tempo de espera nas intervenções em que ocorre.

Os primeiros estudos não contemplaram esse aprimoramento, 0 que, sem dúvida, fez parte do processo de amadurecimento e discussões entre os pesquisadores do GP. 
6 CONCLUSŐES 


\section{CONCLUSÕES}

Foram analisados dezessete estudos que tratavam da construção de instrumentos para a medida da carga de trabalho de profissionais da saúde e foram encontrados dezesseis instrumentos aplicados em unidades de saúde. Dos instrumentos, 11,7\% foram desenvolvidos para medir a carga de trabalho de enfermeiros; para os enfermeiros e téc./aux. de enfermagem, 76,5\%; para nutricionista clínico, 5,9\%, e para assistente técnico administrativo, 5,9\%.

As unidades de saúde corresponderam a: AC; $\mathrm{AEOH}$; CC; CCO; CM; CM-CC; CDI EMER; PED; SN; SRPA; UBS; USF; UTI-A e UTIP-NEO.

Para a construção dos instrumentos, foi utilizado, como referencial teórico, a classificação das intervenções de enfermagem NIC, a qual se mostrou muito eficiente para este fim.

O método para a construção dos instrumentos foi sendo aprimorado ao longo do tempo, porém apresentou etapas comuns a todos eles: identificação das atividades realizadas pelos profissionais de saúde, mapeamento das atividades em intervenções, validação das atividades em intervenções e mensuração do tempo despendido em atividades/intervenções.

O conjunto dos instrumentos apresentou 188 intervenções de cuidado direto; dessas, 70 apresentaram frequência de $\geq 1$ e 80 intervenções de cuidado indireto; dessas, 37 apresentaram frequência de $\geq 1$, cujos resultados podem contribuir para a importante estratégia gerencial a fim de reconhecer $\mathrm{e}$ reorganizar os processos de trabalho das unidades e dos profissionais de saúde que nelas atuam.

A presente pesquisa evidenciou um conjunto de 43 intervenções que ocorreram com mais frequência nas unidades observadas e que impactam na carga de trabalho e no tempo produtivo dos profissionais de saúde, destacando as intervenções comuns para grande parte das unidades e aquelas que especificam a especialidade de atendimento ou da categoria profissional.

Além disso, este estudo permitiu verificar a possiblidade de um instrumento único para medir a carga de trabalho que contemple elenco de 
intervenções comuns e conjunto de intervenções específicas a cada unidade e categoria profissional a ser investigada.

A importância dos estudos analisados, nesta pesquisa, pode ser atribuída ao reconhecimento do rigor científico e do pioneirismo ao serem incorporados os parâmetros de tempos das intervenções estudadas à Resolução Cofen 0543/2017, que estabelece parâmetros para o dimensionamento de profissionais de enfermagem. 
REFERENCIAS 


\section{REFERÊNCIAS}

Adler NJ, Icenhour ML. Analysis throught work sampling of the role os the emergency nurse. J Emerg Nurs. 1993;19(1):28-33.

Aiken LH, Clarke SP, Sloane DM, Sochalski J, Busse R, Clarke H et al. Nurses' reports on hospital care in five countries: the ways in which nurses' work is structured have left nurses among the least satisfied workers, and the problemis getting worse. Health Affairs. 2001;20(3):43-53.

Aiken LH, Clarke SP, Sloane DM, Sochalski J, Silber JH. Hospital nurse staffing and patient mortality, nurse burnout, and job dissatisfaction. JAMA. 2002;288(16):1987-93.

Alcalá MU, Nunes MF, Kato T, Reigada I, Silva RML, Yoshimura DK. Cálculo de pessoal: estudo preliminar para o estabelecimento de quadro de pessoal de enfermagem na superintendência médico hospitalar de urgência. São Paulo: Secretaria de Higiene e Saúde; 1982.

Almeida MCP, Rocha JSY. Considerações sobre a enfermagem enquanto trabalho. In: Almeida MCP, Rocha JSY (org.). O trabalho de enfermagem. São Paulo: Cortez; 1997.

Alves SM, Gomes RMAA, Souza JMC, Azevedo BS, Passos FIP, Vieira NMACE. Enfermagem: contribuição para um cálculo de recursos humanos na área. Rio de Janeiro: Coordenadoria de Comunicação Social do INAMPS; 1988.

Ampt A, Westbrook J, Creswick N, Mallock N. A comparison of self-report and observational work sampling techniques for measuring time end nursing tasks.J Health Serv Res Policy. 2007;12(1):18-24.

Andrade ACR. Distribuição do tempo de trabalho da equipe de enfermagem em unidade de pediatria [dissertação]. São Paulo: Escola de Enfermagem, Universidade de São Paulo; 2014.

Arango HG. Bioestatística: teórica e computacional. $2^{\underline{a}}$ ed. Rio de Janeiro: Guanabara-Koogan; 2005.

Atun R, Andrade L, Almeida G, Cotlear D, Dmytraczenko T, Frenz P et al. Health-system reform and universal health coverage in Latin America. Lancet. 2014;385(9974):1230-47.

Ayoub AC, Alves NRC, Silva YB. Sistema de classificação de paciente. In: Ayoub AC, Fontes ALC, Silva MAA, Alves NRC, Gigliote P, Silva YB. Planejando o cuidar na enfermagem oncológica. São Paulo: Lemar, 2000. p.15-27. 
Baptista PCP. Incapacidade no trabalho: a compreensão de gerentes de enfermagem [tese livre-docência]. São Paulo: Escola de Enfermagem, Universidade de São Paulo; 2014.

Baptista PCP, Pustiglione M, Almeida MCS, Felli VEA, Garzin ACA, Melleiro MM. Saúde dos trabalhadores de enfermagem e a segurança do paciente: 0 olhar de gerentes de enfermagem. Rev Esc Enferm USP. 2015;49(Esp2):122128.

Barham VZ, Sneider WR. Matrix: a unique patient classification system. J Nurs Adm. 1980;10(12):25-31.

Bernardes CL, Vasconcelos LHS, Silva SM, Baptista PCP, Felli VEA, Pustiglione $\mathrm{M}$ et al. Agravos à saúde dos trabalhadores de enfermagem em uma instituição pública de ensino. Rev Esc Enferm USP. 2014;48(4):676-82.

Biblioteca Virtual de Saúde (BVS). Acessado em 10 de outubro de 2016. Disponível em: http://decs.bvs.br/.

Biseng W. Administração financeira em engenharia clínica. São Paulo: Workshop; 1996.

Bochembuzio L. Instrumento para classificação de recém-nascidos de acordo com o grau de dependência [dissertação]. São Paulo: Escola de Enfermagem, Universidade de São Paulo; 2002.

Bochembuzio L. Avaliação do instrumento Nursing Activities Score (NAS) em neonatologia [tese]. São Paulo: Escola de Enfermagem, Universidade de São Paulo; 2007.

Bonfim D. Identificação das intervenções de enfermagem na atenção básica como parâmetro para o dimensionamento de trabalhadores [dissertação]. São Paulo: Escola de Enfermagem, Universidade de São Paulo; 2010.

Bonfim D. Planejamento da força de trabalho de enfermagem na estratégia de saúde da família: indicadores de carga de trabalho [tese]. São Paulo: Escola de Enfermagem, Universidade de São Paulo; 2014.

Bonfim D, Pereira MJB, Pierantoni CR, Haddad AE, Gaidzinski RR. Instrumento de medida de carga de trabalho dos profissionais de saúde na atenção primária: desenvolvimento e validação. Rev Esc Enferm USP. 2015;49(Esp2):25-34. Disponível em: http://www.journals.usp.br/reeusp/article/viewFile/112630/110509.

Bordin LC. Distribuição do tempo de enfermeiras: identificação e análise em unidade médico-cirúrgica [dissertação]. São Paulo: Escola de Enfermagem, Universidade de São Paulo; 2008.

Botelho LLR, Cunha CCA, Macedo M. O método da revisão integrativa nos estudos organizacionais. Gestão e sociedade. 2011;5(11):121-136. 
Brasil. Constituição, 1988. Constituição da República Federativa do Brasil. Brasília: Senado; 1988.

Brasil. Lei Orgânica da Saúde n. 8.080, de 19 de set. 1990.

Brasil. Ministério da Educação. Resolução Conselho Nacional de Educação. Câmara de Educação Superior. CNE/CES n. 3, de 7 de novembro de 2001. Institui as Diretrizes curriculares nacionais para cursos de graduação em enfermagem. Brasília; 2001.

Brasil. Ministério da Saúde. Secretaria Executiva. Sistema Único de Saúde (SUS): instrumentos de gestão em saúde. Brasília; 2002.

Brasil. Conselho Nacional de Secretários de Saúde. SUS: avanços e desafios. Brasília, 2006.

Brasil. Ministério da Saúde. Programa Nacional de Avaliação de Serviços de Saúde: resultado do processo avaliativo 2004-2006. Brasília; 2007.

Brasil. Agênicia Nacional de Vigilância Sanitária. Critérios e diagnósticos de infecções relacionadas à saúde. Brasília; 2017.

Bulechek GM, Butcher HK, Dochterman JM, Wagner CM. Classificação das intervenções de enfermagem (NIC). Trad. de Soraya Imon de Oliveira. 6르 ed. Rio de Janeiro: Elsevier; 2016.

Campana OC. Metodologia da investigação científica aplicada à área biomédica: investigações na área médica. J Pneumol. 1999; 25(2). Disponível em: $\quad$ http://www.scielo.br/scielo.php?script=sci_arttext\&pid=S010235861999000200005

Campedelli MC, Takito C. Sancinetti TR, Benko MA. Cáculo de pessoal de enfermagem: competência da enfermeira. Rev Esc Enferm USP. 1987;21(1):8-15.

Campos GWS, Domitti AC. Apoio matricial e equipe de referência: uma metodologia para a gestão do trabalho interdisciplinar em saúde. Cad. Saúde Pública. 2007;23(2):399-407.

Canabarro ST, Veloso KDS, Eidt OR, Piva JP, Garcia PCR. Nine equivalents of nursing manpower use score (NEMS): um estudo de seu processo hitórico. Rev Gaúcha Enferm. 2010;31(3):584-90.

Canadian Nurses Association (CNA). Measuring nurses workload. Nursing now issues and trends in Canadian Nursing. 2003; 15:1-4.

Carayon P, Gurses AP. A human factors engineering conceptual framework of nursing workload and patient safety in intensive care units. Intensive Crit Care Nurs. 2005;21(5):284-301. 
Carayon P, Alvarado CJ. Workload and patient safety among critical care nuerses. Crit Care Nurs Clin N Am. 2007;19:121-129.

Cardona P, Tappen RM, Terril M, Acosta M, Eusebe MI. Nursing staff time allocation in long-term care: a work sampling study. J Nurs Adm. 1997;27(2):28-36.

Castelhanos BEP, Rodrigues AM, Almeida MCP, Rosa MTL, Mendes SAS. Os desafios da enfermagem para os anos 90. In: Anais $41^{\circ}$ Congresso Brasileiro de Enfermagem; 1989; Florianópolis: Aben, 1989.148-169.

Castro LC, Castilho V. O custo de desperdício de materiais de consumo em um centro cirúrgico. Rev. Latino-Am. Enfermagem. 2013;21(6):1128-34.

Chaboyer W, Wallis M, Duffield C, Courtney M, Seaton P, Holzhauser K et al. A comparison of activities undertaken by enrolled and registered nurses on medical wards in Australia: an observational study. Intern J of Nurs Stud. 2008;45:1274-1284.

Chiesa AM, Westphal MF. A sistematização de oficinas educativas problematizadoras no contexto dos serviços de saúde. Saúde Debate. 1995;(46):19-21.

Cho S, Ketefian S, Barkauskas VH, Smith DG. The effects of nursing staffing on adverse events, morbidity, mortality and medical costs. Nurs Res. 2003;52(2):71-9.

Cianciarullo TI. Instrumentos básicos para o cuidar: um desafio para a qualidade de assistência. São Paulo: Atheneu; 1996:61-74.

Conselho Federal de Enfermagem. Resolução Cofen - 189/1996. Estabelece parâmetros para dimensionamento do quadro de profissionais de enfermagem nas instituições de saúde. In: Conselho Regional de Enfermagem de São Paulo. Documentos básicos de enfermagem: enfermeiros, técnicos e auxiliares. São Paulo; 2001. p. 144-54.

Conselho Federal de Enfermagem. Resolução Cofen - 293/2004. Fixa e estabelece parâmetros para o dimensionamento do quadro de profissionais de enfermagem nas unidades assistenciais das instituições de saúde e assemelhados. In: Conselho Federal de Enfermagem. Brasília; 2004. Disponível em: http://www.cofen.gov.br/resoluo-cofen-2932004_4329.html

Conselho Federal de Enfermagem [homepage na internet]. Pesquisa: perfil da enfermagem no Brasil [acesso em 05 set 2016]. Disponível em: www.cofen.gov.br/perfilenfermagem/

Conselho Federal de Enfermagem. Resolução Cofen - 0527/2016. Atualiza e estabelece parâmetros para o dimensionamento do quadro de profissionais de enfermagem nos serviços/locais em que são realizadas atividades de enfermagem. Conselho Federal de Enfermagem. Brasília; 2016. Disponível em: http://www.cofen.gov.br/resolucao-cofen-no-05272016_46348.html 
Conselho Federal de Enfermagem. Resolução Cofen 0543/2017. Atualiza e estabelece parâmetros para o dimensionamento do quadro de profissionais de enfermagem nos serviços/locais em que são realizadas atividades de enfermagem. Conselho Federal de Enfermagem. Brasília; 2017. Disponível em: http://www.cofen.gov.br/resolucao-cofen-5432017_51440.html

Cruz CWM. Construção de instrumento de medida do tempo de trabalho da enfermagem em centro de diagnóstico por imagem [dissertação]. São Paulo: Escola de Enfermagem, Universidade de São Paulo; 2012.

Cruz CWM, Gaidzinski RR. Tempo de enfermagem em centro de diagnóstico por imagem: desenvolvimento de instrumento. Acta Paul Enferm. 2013;26(1):79-85.

Cruz CWM. Carga de trabalho de profissionais de enfermagem em centro de diagnóstico por imagem [tese]. São Paulo: Escola de Enfermagem, Universidade de São Paulo; 2015.

Cullen DJ, Civetta JM, Briggs BA, Ferrara LC. Therapeutic intervention scoring system: a method for quantitative comparison of patient care. Crit Care Med. 1974;2(2):57-60.

Dal Ben LW. Instrumento para dimensionar horas diárias de assistência de enfermagem residencial [dissertação]. São Paulo: Escola de Enfermagem, Universidade de São Paulo; 2000.

Dias CN, Barbieri LL, Yashimoto LT, Röhsig V. Informática no dimensionamento da equipe de enfermagem. In: Livro programa do $5^{\circ}$ Encontro de Enfermagem e Tecnologia; 1996; São Paulo: ENFTEC; 1996. p. 125-29.

Dini AP. Sistema de classificação de pacientes pediátricos: construção e validação de instrumento [dissertação]. Campinas: Universidade Estadual de Campinas, Faculdade de Ciências Médicas; 2007.

Dini AP, Fugulin FMT, Veríssimo MDLR, Guirardello EB. Sistema de classificação de pacientes pediátricos: construção e validação de categorias de cuidados. Rev Esc Enferm USP. 2011;45(3):575-80.

www.ee.usp.br/reeusp

Duffield C, Wise W. Tell me what we do? Using work sampling to find the answer. Australian Journal of Advanced Nursing. 2003;20(3):24-26.

Duffield C, Roche M, Merrick ET. Methods of measuring nursing workload in Australia. Collegian. 2006;13(1):30-32.

Dutra JS. Competências: conceitos e instrumentos para a gestão de pessoas na empresa moderna. São Paulo: Atlas, 2012.

Egger M, Davey SG, Altman DG. Systematic reviews in health care: metaanalysis in context. London: BMJ books, 2001. 
Felli VEA, Peduzzi M. O trabalho gerencial em enfermagem. In: Kurcgant $P$ (org.). Gerenciamento em Enfermagem. 3‥ ed. São Paulo: Guanabara Koogan; 2016:(21-32).

Fugulin FMT, Silva SHS, Shimizu HE, Campos FPF. Implantação do sistema de classificação de pacientes na unidade de clínica médica do hospital universitário da USP. Rev Med HU-USP. 1994;4(1/2):63-8.

Fugulin FMT. Sistema de classificação de pacientes: análise das horas de assistência de enfermagem [dissertação]. São Paulo: Escola de Enfermagem, Universidade de São Paulo; 1997.

Fugulin FMT. Dimensionamento de pessoal de enfermagem: avaliação do quadro de pessoal das unidades de internação de um hospital de ensino [tese]. São Paulo: Escola de Enfermagem, Universidade de São Paulo; 2002.

Fugulin FMT. Parâmetros oficiais para o dimensionamento de profissionais de enfermagem em instituições hospitalares: análise da Resolução COFEN $n^{\circ}$ 293/04 [tese Livre-docência]. São Paulo: Escola de Enfermagem, Universidade de São Paulo; 2010.

Fugulin FMT, Rossetti AC, Ricardo CM, Possari JF, Mello MC, Gaidzinski RR. Tempo de assistência de enfermagem em unidade de terapia intensiva: avaliação dos parâmetros propostos pela Resolução Cofen n 293/04. Rev. Latino-Am. Enfermagem. 2012;20(2):09. www.eerp.usp.br/rlae

Fugulin FMT, Gaidzinski RR, Lima AFC. Dimensionamento de pessoal de enfermagem em instituições de saúde. In: Kurcgant $P$, coordenadora. Gerenciamento em enfermagem. $3^{\text {a }}$. ed. Rio de Janeiro: Guanabara Koogan; 2016: 115-127.

Gadelha CAG. O complexo industrial da saúde e a necessidade de um enfoque dinâmico na economia da saúde. Ciência e Saúde Coletiva. 2003;8(2):521-535.

Gaidzinski RR. O dimensionamento do pessoal de enfermagem segundo a percepção de enfermeiros que vivenciam esta prática [tese]. São Paulo: Escola de Enfermagem, Universidade de São Paulo; 1994.

Gaidzinski RR. Dimensionamento de pessoal de enfermagem em instituições hospitalares [tese livre-docência]. São Paulo: Escola de Enfermagem, Universidade de São Paulo; 1998.

Gaidzinski RR, Kurcgant P. Dimensionamento do pessoal de enfermagem: vivência de enfermeiros. Nursing. 1998;(1):28-34.

Gaidzinski RR, Fugulin FMT, Peres HHC, Castilho V, Massarollo MCKB, Mira $\mathrm{VL}$ et al. Dimensionamento informatizado de profissionais de enfermagem: inovação tecnológica. Rev Esc Enferm USP. 2009;43(Esp 2):1314-9 
Galvão CM, Sawada NO, Rossi LA. A prática baseada em evidências: considerações teóricas para sua implementação na enfermagem perioperatória. Rev Latino-Am Enfermagem. 2002;10(5):690-5

Galvão CM, Sawada NO, Mendes IAC. A busca das melhores evidências. Rev Esc Enferm USP. 2003;37(4):43-50.

Garcia EA. Distribuição do tempo das enfermeiras em unidades de emergência [dissertação]. São Paulo: Escola de Enfermagem, Universidade de São Paulo; 2009.

Garcia PC. Tempo de assistência de enfermagem em UTI e indicadores de qualidade assistencial: análise correlacional [dissertação]. São Paulo: Escola de Enfermagem, Universidade de São Paulo; 2011.

Gonçalves LA, Garcia PC, Toffoleto MC, Telles SCR, Padilha KG. Necessidades de cuidados de enfermagem em terapia intensiva: evolução diária dos pacientes segundo o Nursing Activities Score (NAS). Rev Bras Enferm. 2006;59(1):56-60.

Gonçalves LA. Segurança do paciente em unidade de terapia intensiva: carga de trabalho de enfermagem e sua relação com a ocorrência de eventos adversos e incidentes [tese]. São Paulo: Escola de Enfermagem, Universidade de São Paulo; 2011.

Gonçalves RBM. Práticas de saúde: processos de trabalho e necessidades. São Paulo: CEFOR; 1992.

Guccione A, Morena A, Piezzi A, Lapichino G. I carichi di lavoro infermieristico. Minerva Anestesiol. 2004;70:411-6.

Guimarães CP. Tempo médio de assistência de enfermagem em unidade de terapia intensiva pediátrica [dissertação]. São Paulo: Escola de Enfermagem, Universidade de São Paulo; 2015.

Gutierrez BAO, Ciampone MHT. O processo de morrer e a morte no enfoque dos profissionais de enfermagem de UTIs. Rev Esc Enferm USP. 2007;41(4):660-7.

Hagerty BK, Chang RS, Spengler CD. Work sampling analysing nursing staff productivy. JONA. 1985;15(9):9-14.

Haynes SN, Richard DS, Kubany ES. Content validity in psychological assessment: a functional approach to concepts and methods. Psychological Assessment. 1995:7(3);238-247.

Hausmann M, Peduzzi M. Articulação entre as dimensões gerencial e assistencial do processo de trabalho do enfermeiro. Texto e Contexto Enfermagem. 2009;18(2):258-65. 
Hoonakker P, Carayon P, Gurses A, Brown R, McGuire K, Khunlerkit A, et al. Measuring workload of ICU nurses with a questionnaire survey: the NASA task load index. Trans Healthc Syst Eng. 2011;1(2):131-143.

Hughes M. Nursing workload: an unquantifiable entity. J Nurs Manag. 1999;7(6):317-22.

Hurst K. Selecting and applying methods for estimating the size and mix of nursing teams: a systematic review of literature commissioned by the Departament of Helath [Internet]. 2002 [cited 2016 nov 28]. Available from: http://www.who.int/hrh/tools/size_mix.pdf

Jennings BM. Work stress and burnout among nurses: role of the work environment and working conditions. In: Hughes RG. Patient safety and quality: an evidence-based handbook for nurses. Rockville (MD): Agency for Healthcare Research and Quality (US). 2008 [cited 2016 nov 28]. Available from: https://www.ncbi.nlm.nih.gov/books/NBK2668/?report=reader

Keene AR, Cullen DJ. Therapeutic intervention scoring system: update. Crit Care Med. 1983;11(1):1-3.

Khan MS, Maitree P, Radhika A. Evaluation and comparison of the three scoring systems at 24 and $48 \mathrm{~h}$ of admission for prediction of mortality in a Indian ICU: a prospective cohort study. Ain-Shams Journal of Anesthesiology. 2015;(08):294-300. [cited 2016 nov 04]. Available from: http://www.asja.eg.net on Friday, November 04, 2016, IP: 143.107.173.82.

Kiekkas P, Poulopoulou M, Papahatzi A, Androutsopoulou C, Maliouki M, Prinou A. Nursing activities and use of time in the postanesthesia care unit. $J$ Perianesth Nurs. 2005;20(5):311-22.

Knaus WA, Draper EA, Wagner DP. APACHE II - Disease scoring system in intensive care. Lancet. 1983:1089.

Knaus WA, Draper EA, Wagner DP. APACHE II - A severity of disease classification system. Crit Care Med. 1985;13:818

Lacerda RTO, Ensslin L, Ensslin SR. Uma análise bibliométrica da literatura sobre estratégia e avaliação de desempenho. Gest. Prod. São Carlos. 2012;19(1):59-78.

Laurell AC, Noriega M. Processo de produção e saúde: trabalho e desgaste operário. São Paulo: Hucitec; 1989.

Leal AERB. Carga de trabalho do profissional administrativo na atenção primária à saúde [dissertação]. São Paulo: Escola de Enfermagem, Universidade de São Paulo; 2014.

Le Gall JR, Lemeshow S, Saulnier F. A new simplified, acute, physiology score (SAPS II): basead on a European/North American multicenter study. JAMA. 1993; 270(24):2957-63 
Leopardi MT. Os instrumentos de trabalho em saúde: razão e subjetividade. In: Leopardi MT, Kirchhof AL, Capella BB, Pires DP, Faria EM, Ramos FRS. Processo de trabalho em saúde: organização e subjetividade. Florianópolis: Papa-Livros; 1999.

Lobiondo-Wood G, Haber J. Pesquisa em enfermagem: métodos, avaliação crítica e utilização. 4ª ed. Rio de Janeiro: Guanabara Koogan; 2001.

Lopetegui M, Po-Yin Yen AL, Jeffries J, Embi P, Payne P. Time motion studies in healthcare: what we are talking about? Journal of Biomedical Informatics. 2014;49:292-9.

Lucena AF, Barros ALB. Mapeamento cruzado: uma alternativa para a análise de dados em enfermagem. Acta Paul Enferm. 2005;18(1):82-8.

Mafra SN, Travassos GH. Estudos primários e secundários apoiando a busca por evidência em engenharia de software. Programa de Engenharia de Sistemas e Computação - Relatório técnico. 2006. Disponível em: http://www.cos.ufrj.br/uploadfile/1149103120.pdf

Mandelli M, Rigoli F. Aplicação de pesquisa de informação para políticas de recursos humanos: as metas regionais para as Américas. Rev Esc Enfermagem USP. 2015:49(Esp2):156-161.

Marcos BB, Ugidos RMC, Méndez EF, Santovenã MV. Proposal of a new assessment scale of workload and nursing times $\left(\mathrm{VACTE}^{\odot}\right)$. Enferm Intensiva 2007;18(3):115-25.

Martin LGR. Dimensionamento de profissionais de enfermagem em ambulatório de oncologia e hematologia [dissertação]. São Paulo: Escola de Enfermagem, Universidade de São Paulo; 2013.

Martins EAP, Haddad MCL. Validação de um instrumento que classifica os pacientes em quatro graus de dependência do cuidado de enfermagem. Rev. Latino-Am. Enfermagem. 2000;8(2):74-82.

Martins GA. Estatística geral e aplicada. São Paulo: Atlas; 2005.

Martins PASF. Sistema de classificação de pacientes na especialidade enfermagem psiquiátrica [dissertação]. São Paulo: Escola de Enfermagem, Universidade de São Paulo; 1997.

Martins PG, Laugeni FP. Administração da produção. São Paulo: Saraiva; 2000. Estudos de tempo; 140-72.

Mattar FN. Pesquisa de marketing: metodologia e planejamento. São Paulo: Atlas, 1996.

Marx K. O capital: crítica da economia política. Rio de Janeiro: Editora Bertrand Brasil; 1994; 202-204. 
Mello MC. Estudo do tempo no trabalho da enfermagem: construção de instrumento de classificação de atividades para implantação do método amostragem do trabalho. [dissertação]. São Paulo (SP): Escola de Enfermagem, Universidade de São Paulo; 2002.

Mello MC. Fugulin FMT, Gaidzinski RR. O tempo no processo de trabalho em saúde: uma abordagem sociológica. Acta Paul Enferm. 2007;20(1):87-90.

Mello MC. Carga de trabalho de enfermagem: indicadores de tempo em unidades de clínica médica, cirúrgica e terapia intensiva adulto [tese]. São Paulo: Escola de Enfermagem, Universidade de São Paulo; 2011. Disponivel em: http://www.teses.usp.br/teses/disponiveis/7/7140/tde-25082011-095746/pt-br.php

Meneses AS. Análise da produção científica dos enfermeiros brasileiros sobre administração em enfermagem no contexto dos programas de pós-graduação stricto sensu: uma abordagem histórica (1963-2011) [dissertação]. São Paulo: Universidade Federal de São Paulo; 2014.

Merhy EE. Em busca do tempo perdido: a micropolítica do trabalho vivo em saúde. In: Merhy EE, Onoko R (org.) Agir em Saúde: um desafio para o público. São Paulo/Buenos Aires: Hucitec/Lugar Editorial; 1997.

Min A, Scott LD. Evoluating nursing hours per patiente day as a nurse staffing measure. Journal of Nursing Management. 2016; 24:439-448.

Miranda DR, Rijk A, Schaufeli W. Simplified therapeutic intervention scoring system: the TISS-28 items - results from a multicenter study. Crit. Care Med. 1996;24(1):64-73.

Miranda DR, Moreno R, Lapichino G. Nine equivalents of nursing manpower use score (NEMS). Intensive Care Med. 1997;23(7):760-765.

Miranda DR. Outcome assessment: TISS as a tool to evaluate cost effectiveness of immunological treatment. Eur J Surg. 1999;584(sup):51-5.

Miranda DR, Raoul N, Rijk A, Schaufeli W, Lapichino G. Nursing activities score. Crit. Care Med. 2003;31(2):374-82.

Moretto Neto L, Silva JJC, Shmitt VGH. As funções básicas da administração. In: Introdução à administração hospitalar. Florianópolis; 2007. [citado em 2017 jan 21] Disponível em: http://www.academia.edu/8669498/Introdu\%C3\%A7\%C3\%A30_\%C3\%A0_A dministra\%C3\%A7\%C3\%A3o_Hospitalar_-_Livro_EAD

Morris R, MacNeela P, Scott A, Treacy P, Hyde A. Reconsidering the conceptualization of nursing workload: literature review. J Adv Nurs. 2007;57(5),463-471.

Munyisia EN, Yu P, Hailey D. How nursing staff spend their time on activities in a nursing home: na observation al study. Journal of Advanced Nursing. 2011;67(9),1908-1917. doi: 10.1111/j.1365-2648.2011.05633.x 
Nogueira RP, Santana JP. Gestão de recursos humanos e reformas do setor público: tendências e pressupostos de uma nova abordagem. Workshop on Global Health Workforce Strategy. França; 2000.

Nogueira RP. Resultado do estudo de avaliação de tendências e prioridades sobre recursos humanos em saúde. In: Brasil. Ministério da Saúde. Política de recursos humanos em saúde. Basília: Ministério da Saúde; 2002:31-44.

O'Brien Pallas L, Thomson D, Linda McGillis Hall, Kerr M, Wang S, Li X et al. Evidence-based standards for mensuring nurse staffing and performance. Ontário: Canadian Helath Service Research Fundation; 2004.

O'Brien Pallas L. Back to future: evidence-informed innovations in health care delivery. In: Berry L, Pierre IS, Price S. Nursing workload and patient care: understanding the value of nurses, the effects of excessive workload, and how nurse-patient ratios and dynamic staffing models can help. Available from:https://nursesunions.ca/sites/default/files/2012.10.04_workload_popular_ english.pdf

Oliveira AC, Garcia PC, Nogueira LS. Nursing workload and occurrence of adverse events in intensive care: a systematic review. Ver Esc Enferm USP. 2016;50(4):679-689. DOI: http://dx.doi.org/10.1590/S0080-623420160000500020

Oliveira, CA. Carga de trabalho do nutricionista clínico: estudo de tempo e movimento contínuo em unidades de internação hospitalar [tese]. São Paulo: Escola de enfermagem, Universidade de São Paulo; 2016. Available from: http://www.teses.usp.br/teses/disponiveis/7/7140/tde-12012017-135719/pt-br.php

Ozcan S, Hornby P. Determining hospital workforce requirements: a case study. Human Resources for Health Development Journal. 1999;3:201-220.

Padilha KG, Sousa RMC, Garcia PC, Bento ST, Finardi EM, Hatarashi RHK. Nursing workload and staff allocation in na intensive care unit: a pilot study according to nursing activities score (NAS). Intensive and Critica Care Nursing. 2010;26(2):108-113.

Pelletier D, Duffield C. Work sampling: valuable methodology to define nursing practice to the study of nursing personnel. Nurs Health Sci. 2003;5(1):31-8.

Pereira IM. Dimensionamento informatizado de profissionais de enfermagem (DIPE): avaliação de um software [dissertação]. São Paulo: Escola de Enfermagem, Universidade de São Paulo; 2011.

Peres HHC, Cruz DALM, Lima AFC, Gaidzinski RR, Ortiz DCF, Trindade MM et al. Desenvolvimento de sistema eletrônico de documentação clínica de enfermagem estruturado em diagnósticos, resultados e intervenções. Rev Esc Enferm USP. 2009;43(Esp 2):1149-55.

Perroca MG. Sistema de classificação de pacientes: construção e validação de um instrumento [dissertação]. São Paulo: Escola de Enfermagem, Universidade de São Paulo; 1996. 
Perroca MG Instrumento para classificação de pacientes de Perroca: validação clínica [tese]. São Paulo: Escola de Enfermagem, Universidade de São Paulo; 2000.

Perroca MG, Gaidzinski RR. Instrumento de classificação de pacientes de Perroca: teste de confiabilidade pela concordância entre avaliadores: correlação. Rev Esc Enferm USP. 2002;36(3):245-52.

Perroca MG Instrumento para classificação de pacientes: opinião de usuários e análise de indicadores de cuidado. Rev Esc Enferm USP. 2008;42(4):65664

Perroca MG. The new version of patient classification instrument: assessment of psychometric properties. J adv Nurs. 2013;69(8):1862-8.

Pfefferkorn B, Rovetta CA. Administrative cost analysis for nursing service and nursing education. Chicago: American Hospital Association/New York, National League of Nursing Education; 1940.

Pierantoni CR, Varella TC, França T. Recursos humanos e gestão do trabalho em saúde: da teoria para a prática. In: Barros AFR et al. (org). Observatório de Recursos Humanos em Saúde no Brasil: estudos e análises. Brasília: Ministério da Saúde, 2004;(2):51-70.

Polit DF, Beck CT. Fundamentos de pesquisa em enfermagem: Avaliação de evidências para a prática de enfermagem. Porto Alegre: Artmed, $7^{\underline{a}}$ ed. 2011.

Possari JF. Dimensionamento de profissionais de enfermagem em centro cirúrgico especializado em oncologia: análise dos indiciadores intervenientes [tese]. São Paulo: Escola de Enfermagem, Universidade de São Paulo; 2011.

Queijo AF. Tradução para o português e validação de um instrumento de medida de carga de trabalho de enfermagem em unidade de terapia intensiva: Nursing Activities Score (NAS) [dissertação]. São Paulo: Escola de Enfermagem, Universidade de São Paulo; 2002.

Queijo AF, Padilha KG. Nursing Activities Score (NAS): adaptação transcultural e validação para a língua portuguesa. Rev Esc Enferm USP, 2009;43(Esp):1018-25.

Queijo AF, Martins RS, Andolhe R, Oliveira EM, Barbosa RL, Padilha KG. Nursing workload in neurological intensive care units: cross-sectional study. Intensive and Critical Care Nursing. 2013;(29):112-116.

Ramos MLT, Bohomol E, Santos M, Barros CG, Ferreira NM, Silva MTA et al. Sistema de classificação de pacientes por grau de dependência do cuidado de enfermagem: ENFSCORE. In: Anais do $4^{\circ}$ Encontro de Enfermagem e Tecnologia; 1996; São Paulo: ENFTEC; 1996. p.128-41. 
Ribeiro CM. Sistema de classificação de pacientes como subsídio para o provimento de pessoal de enfermagem [tese]. São Paulo: Escola de Enfermagem, Universidade de São Paulo; 1972.

Ricardo CM. Tempo das intervenções e atividades de enfermagem na sala de recuperação pós-anestésica: subsídio para determinação da carga de trabalho [dissertação]. São Paulo: Escola de Enfermagem, Universidade de São Paulo; 2013.

Rigoli F, Rocha CF, Foster AA. Desafios críticos dos recursos humanos em saúde: uma visão regional. Rev Latino-Am Enfermagem 2006;14(1):7-16.

Rocco JR, Rocco PRM, Noé RM, David CMN. Escore prognóstico para unidade semi- intensiva pós-operatória. Revista Brasileira Terapia Intensiva. 2003;15(4):153-67.

Rogenski KE. Tempo de assistência de enfermagem: identificação e análise em instituição hospitalar de ensino [dissertação]. São Paulo: Escola de Enfermagem, Universidade de São Paulo; 2006.

Rogenski KE. Carga de trabalho de enfermagem em unidade de pediatria [tese]. São Paulo: Escola de Enfermagem, Universidade de São Paulo; 2014.

Romero EA, Araújo EA, Watanabe MY, Lisboa MAPLP, Abud MH, Santos $\mathrm{NMB}$ et al. Proposta de um instrumento para a classificação dos cuidados de enfermagem quanto ao grau de dependência. In: Anais do $4^{\circ}$ Encontro de Enfermagem e Tecnologia; 1994; São Paulo: ENFTEC; 1994. p.482-88.

Sancinetti TR, Gaidzinski RR, Felli VEA, Fugulin FMT, Baptista PCP, Ciampone MHT, et al. Absenteísmo - doença na equipe de enfermagem: relação com a taxa de ocupação. Rev Esc Enferm USP. 2009;43(Esp2):127783.

Santos NC. Construção de instrumento para identificação da carga de trabalho da equipe de enfermagem em unidades pediátricas [dissertação]. São Paulo: Escola de Enfermagem, Universidade de São Paulo; 2006.

Santos SR. Cálculo de pessoal de enfermagem: estudo de dois métodos. Esc Enferm USP. 1992;26(2):137-54.

Seixas PHDA. Os pressupostos para a elaboração da política de recursos humanos nos sistemas nacionais de saúde. In: Brasil. Ministério da Saúde. Política de recursos humanos em saúde. Brasília; 2002.

Shipp PJ. Guidelines for developing and using workload indicators of staffing need: a manual for implementation. Geneva: World Health Organization; 1998.

Silva LC, Nogueira LS, Settervalli CH, Sousa RMC, Padilha KG. Desempenho de índices de gravidade para estimar risco de morte em unidades de terapia intensiva Rev Esc Enferm USP. 2012;46(4):846-50. 
Soares AVN. Carga de trabalho de enfermagem no sistema de alojamento conjunto [tese]. São Paulo: Escola de Enfermagem, Universidade de São Paulo; 2009.

Soares AVN, Gaidzinski RR, Cirico MOV. Nursing intervention in rooming-in. Rev Esc Enferm USP [online]. 2010;44(2):308-317. ISSN 0080-6234. http://dx.doi.org/10.1590/S0080-62342010000200010.

Souza CA, Jericó MC, Perroca MG. Mapeamento de intervenções/atividades em centro quimioterápico: instrumento para avaliação da carga de trabalho. Rev Latino-Am Enferm. 2013;21(2):[08 telas]. Disponível em: http://www.scielo.br/pdf/rlae/v21n2/pt_0104-1169-rlae-21-02-0492.pdf

Tanos MAA, Massarollo MCKB, Gaidzinski RR. Dimensionamento de pessoal de enfermagem em uma unidade especializada em transplante de fígado: comparação do real com o preconizado. Rev Esc Enferm USP. 2000;34(4):376-82.

Tronchin DMR. Indicadores de enfermagem no âmbito hospitalar: revisão integrativa de literatura [tese livre-docente]. Escola de Enfermagem; Universidade de São Paulo; 2011.

Tsukamoto R. Tempo médio de cuidado ao paciente de alta dependência de enfermagem segundo Nursing Activities Score [dissertação]. São Paulo: Escola de Enfermagem, Universidade de São Paulo; 2010.

Ueti MF, Shiotsu CH, Higuchi CM. César CCF, Iwakura KH, Franco LHRO et al. Metodologia para o cálculo de pessoal de enfermagem: documento preliminar. São Paulo: Secretaria de Estado da Saúde - Centro de Apoio ao Desenvolvimento de Assistência Integral à Saúde - CADAIS/ Grupo de Coordenação para Assuntos de Enfemagem; 1991. Mimeografado.

Upenieks VV. Work sampling: assessing nursing efficiency. Nurs Mange. 1998;29(4):27-9.

Urden LD, Roode JL. Work sampling: a decision-making tool for determining resourses and work redesign. J Nurs Adm. 1997;27(9):34-41.

Vieira M. Recursos humanos em saúde. In: Pereira IB, Lima JCF (org.). Dicionário da educação profissional em saúde. $2^{\underline{a}}$ ed. Rio de Janeiro: EPSJV, 2008. 478p.

Yang KP. Relationship between nurse staffing and patient outcome. J. Nurs. Res. 2003;11(3):149-58.

Yoon JY, King B, Pecanac K, Brown R, Mahoney J, Kuo F. Comparison of timeand-motion observations and self-reports to capture mobility-related nursing care activities for hospitalized older adults. Res Gerontol Nurs. 2015;8(3):1107. 
Westbrook J, Duffield C, Li L, Creswick N. How much time do nurses have for patients? A longitudinal study quantifying hospital nurses patterns of task time distribution and interactions with health professionals. BMC Health Services Reserch. 2011;11:319. Available from:

http://www.biomedcentral.com/1472-6963/11/319.

World Health Organization. Division of human resources development an capacity build. Workload indicators of staffing need (WISN). User's manual. Geneva, Switzerland, 2010 [cited 2016 Dez]. Available from: http://whqlibdoc.who.int/publications/2010/9789241500197_users_eng.pdf. 
APÊNDICES 


\section{APÊNDICES}

\section{APÊNDICE 1 - LINKS DE ACESSO AOS ESTUDOS E AOS RESPETIVOS INSTRUMENTOS DE MEDIDA DA CARGA DE TRABALHO:}

Santos, 2006: http://www.teses.usp.br/teses/disponiveis/7/7131/tde-17102006-122111/ptbr.php

Borin, 2008: http://www.teses.usp.br/teses/disponiveis/7/7131/tde-03092008-120146/ptbr.php

Garcia, 2009: http://www.teses.usp.br/teses/disponiveis/7/7131/tde-22062009-125228/ptbr.php

Soares, 2009: http://www.teses.usp.br/teses/disponiveis/7/7136/tde-14052009-115157/ptbr.php

Bonfim, 2010: http://www.teses.usp.br/teses/disponiveis/7/7140/tde-01072010-130259/ptbr.php

Possari, 2011: http://www.teses.usp.br/teses/disponiveis/7/7140/tde-10052011-122056/ptbr.php

Mello, 2011: http://www.teses.usp.br/teses/disponiveis/7/7140/tde-25082011-095746/ptbr.php

Cruz, 2012: http://www.teses.usp.br/teses/disponiveis/7/7140/tde-21082012-155557/ptbr.php

Ricardo, 2013: http://www.teses.usp.br/teses/disponiveis/7/7140/tde-10092013-144343/ptbr.php

Matin, 2013: http://www.teses.usp.br/teses/disponiveis/7/7140/tde-17072014-140727/ptbr.php

Andrade, 2014: http://www.teses.usp.br/teses/disponiveis/7/7140/tde-09122014-154235/pt$\underline{\text { br.php }}$

Rogesnki, 2014: http://www.teses.usp.br/teses/disponiveis/7/7140/tde-14012015145221/pt-br.php

Bonfim, 2014: http://www.teses.usp.br/teses/disponiveis/7/7140/tde-16092014-105517/ptbr.php

Leal, 2014:

Cruz: 2015: http://www.teses.usp.br/teses/disponiveis/7/7140/tde-09122015-164052/ptbr.php

Guimarães, 2015: http://www.teses.usp.br/teses/disponiveis/7/7140/tde-11052015154213/pt-br.php

Oliveira, 2016: http://www.teses.usp.br/teses/disponiveis/7/7140/tde-12012017-135719/ptbr.php 


\section{APÊNDICE 2 - Instrumento de Coleta de Dados 1}

\begin{tabular}{|c|c|c|c|c|c|c|c|c|c|c|}
\hline & A & B & C & $\mathrm{D}$ & $\mathrm{E}$ & $\mathrm{F}$ & G & $\mathrm{H}$ & I & $\mathrm{J}$ \\
\hline 1 & \multicolumn{10}{|c|}{ Identificação dos estudos } \\
\hline 2 & Orientador & $\begin{array}{c}\text { Autor, } \\
\text { Ano }\end{array}$ & $\begin{array}{c}\text { Nome } \\
\text { completo }\end{array}$ & $\begin{array}{l}\text { Ano da } \\
\text { defesa }\end{array}$ & $\begin{array}{l}\text { Mestrado/ } \\
\text { Doutorado }\end{array}$ & Título & Objetivo & Instrumento & $\begin{array}{l}\text { Usou } \\
\text { NIC }\end{array}$ & $\begin{array}{l}\text { Nome do } \\
\text { instrumento }\end{array}$ \\
\hline 3 & & & & & & & & & & \\
\hline 4 & & & & & & & & & & \\
\hline 5 & & & & & & & & & & \\
\hline 6 & & & & & & & & & & \\
\hline 7 & & & & & & & & & & \\
\hline
\end{tabular}

Fonte: Arquivo da pesquisadora

\begin{tabular}{|c|c|c|c|c|c|c|c|c|c|c|}
\hline & A & $\mathrm{B}$ & C & $\mathrm{D}$ & $\mathrm{E}$ & $\mathrm{F}$ & G & $\mathrm{H}$ & 1 & $\mathrm{~J}$ \\
\hline 1 & \multicolumn{10}{|c|}{ Estudos selecionados/Identificação dos instrumentos } \\
\hline 2 & $\begin{array}{c}\text { Autor, } \\
\text { Ano }\end{array}$ & $\begin{array}{c}\text { Nome do } \\
\text { instrumento }\end{array}$ & $\begin{array}{l}\text { Unidade } \\
\text { estudada }\end{array}$ & $\begin{array}{l}\text { Método/ } \\
\text { Tempo }\end{array}$ & $\begin{array}{c}\text { Intervalo de } \\
\text { tempo em } \\
\text { minutos }\end{array}$ & $\begin{array}{c}\text { Classificação } \\
\text { da } \\
\text { Intervenção }\end{array}$ & Objetivo & Instrumento & Usou NIC & $\begin{array}{l}\text { Nome do } \\
\text { instrumento }\end{array}$ \\
\hline 3 & & & & & & & & & & \\
\hline 4 & & & & & & & & & & \\
\hline 5 & & & & & & & & & & \\
\hline 6 & & & & & & & & & & \\
\hline 7 & & & & & & & & & & \\
\hline
\end{tabular}

Fonte: Arquivo da pesquisadora 
APÊNDICE 2 - Instrumento de Coleta de Dados 2

\begin{tabular}{|c|c|c|c|c|c|c|c|c|}
\hline & A & $\mathrm{B}$ & $\mathrm{C}$ & $\mathrm{D}$ & $E$ & $\mathrm{~F}$ & G & $\mathrm{H}$ \\
\hline 1 & \multicolumn{8}{|c|}{ Identificação dos Instrumentos } \\
\hline 2 & $\begin{array}{c}\text { Autor, } \\
\text { Ano }\end{array}$ & $\begin{array}{c}\text { Nome do } \\
\text { Instrumento }\end{array}$ & $\begin{array}{l}\text { Unidade } \\
\text { estudada }\end{array}$ & $\begin{array}{l}\text { Intervenções } \\
\text { do } \\
\text { Instrumento }\end{array}$ & $\begin{array}{l}\text { Classe da } \\
\text { NIC }\end{array}$ & $\begin{array}{c}\text { Classificação } \\
\text { da } \\
\text { Intervenção }\end{array}$ & $\begin{array}{c}\text { Número da } \\
\text { Intervenção/Atividade }\end{array}$ & $\begin{array}{l}\text { Intervenção/ } \\
\text { atividade }\end{array}$ \\
\hline 3 & & & & & & & & \\
\hline 4 & & & & & & & & \\
\hline 5 & & & & & & & & \\
\hline 6 & & & & & & & & \\
\hline 7 & & & & & & & & \\
\hline
\end{tabular}

Fonte: Arquivo da pesquisadora

\begin{tabular}{|c|c|c|c|c|c|c|c|c|c|c|c|}
\hline & A & B & C & D & $E$ & $\mathrm{~F}$ & G & $\mathrm{H}$ & 1 & $\mathrm{~J}$ & $\mathrm{~K}$ \\
\hline 1 & \multicolumn{11}{|c|}{ Intervenções dos Instrumentos } \\
\hline 2 & \multirow{2}{*}{$\begin{array}{l}\text { Autor, } \\
\text { Ano }\end{array}$} & \multirow{2}{*}{$\begin{array}{l}\text { Nome do } \\
\text { Instrumento }\end{array}$} & \multirow{2}{*}{$\begin{array}{l}\text { Unidade } \\
\text { estudada }\end{array}$} & \multirow{2}{*}{$\begin{array}{c}\text { Número da } \\
\text { Intervenção/Atividade }\end{array}$} & \multirow{2}{*}{$\begin{array}{l}\text { Intervenção/ } \\
\text { atividade }\end{array}$} & \multicolumn{6}{|c|}{ Frequência das Intervenções/ Atividades } \\
\hline 3 & & & & & & Enfermeiro & $\%$ & $\begin{array}{l}\text { Tec./Aux de } \\
\text { enfermagem }\end{array}$ & $\%$ & $\begin{array}{l}\text { Equipe de } \\
\text { enfermagem }\end{array}$ & $\%$ \\
\hline 4 & & & & & & & & & & & \\
\hline 5 & & & & & & & & & & & \\
\hline 6 & & & & & & & & & & & \\
\hline 7 & & & & & & & & & & & \\
\hline
\end{tabular}

Fonte: Arquivo da pesquisadora 
